\title{
BENZ(a)ANTHRACENE IN BENTHIC MARIFE ENVIRONMENTS : BIOAVAILABILITY, METABOLISM, AND PHYSIOLOGICAL EFFECTS \\ ON THE POLYCHAETE Nereis virens
}

\author{
by \\ Anne Blizabeth HcElroy \\ Sc.B., Brown University 1976 \\ SUBMITTED IN PARTIAL FULFILLMENT OF THE \\ REQUIRMENTS FOR THE DEGREE OF \\ DOCTOR OF PHII.OSOPHY \\ at the \\ MASSACHUSETTS INSTITUTE OF TECHNOLOGY \\ and the \\ WOODS HOLE OCEANOGRAPHIC INSTITUTION \\ February 1985 \\ (c) Anne E. McElroy, 1985
}

The author hereby grants to MIT and WHOI permission to reproduce and distribute copies of this thesis document in whole or in part.

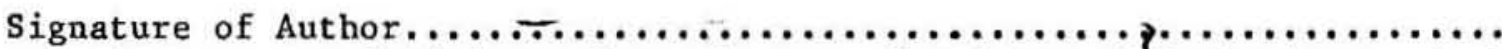
Department of Biology, Massachusetts Institute of echnology and the Joint Program in 0ceanography, Massachusetts Inst itute of

Technology/Woods Hole-Qceanogræaphic Institution, February, 1985.

Certified by.....

John M. Teal

Thesis Speryisor

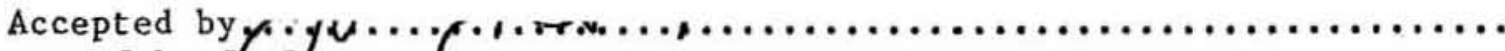
John J. Stegeman

Chairman, Joint Committee for Biologica 1 Oceanography, Massachusetts Institute of Technology/Woods Hole Oceanographic Institution. 


\title{
BENZ(a)AKTHRACENE IN BEFTHIC MARINE BNVIROMMENTS : BIOAVAILABILITY, METABOLISH, AND PHYSIOLOGICAL, EFFECTS ON THE POLYCHAETE Nereis virens
}

\author{
by \\ Anne Blizabeth McElroy \\ Submitted in partial fulfillment \\ of the requirements for the degree of \\ Doctor of Philosophy
}

\begin{abstract}
The fate of $\left[{ }^{14} \mathrm{C}-12\right]$ benz(a)anthracene (BA) was followed in benthic microcosm experiments in the presence and absence of the polychaete Nereis virens. In concert with chemical analysis of BA and its metabolites in all components of the system, physiological and biochemical effects of exposure on Nereis were investigated. BA was introduced in three ways: already sorbed to the entire sediment reservoir; directly into the water column; or incorporated into a gelatin-based diet. Experiments ran from 4 to 25 days. Activity of BA and $\mathrm{BA}$ metabolic products was followed in sediments, worm tissue, and in the water column. ${ }^{14} \mathrm{CO}_{2}$ activity in the water column was also measured. Growth, oxygen consumption, ammonia excretion, adenylate nucleotide pools, and mixed function oxygenase activity of the worms were also monitored.
\end{abstract}

The presence of worms and the mode of introduction had significant effects on the fate of $\mathrm{BA}$ in this system. In experiments. with sediments uniformly labeled with $B A$, worms increased $f l u x$ of $B A$ from the sediment, and after nine days, their presence lead to increased rates of microbial mineralization of $\mathrm{BA}$ to $\mathrm{CO}_{2}$. In experiments where $\mathrm{BA}$ was added directly to the water column, worms mixed $B A$ into the sediment, but had no net effect on removal of $B A$ in the sediment to the water column. BA added to the water column and deposited at the sediment-water interface was more available for uptake by worms, microbial mineralization to $\mathrm{CO}_{2}$, and removal to the water column than $B A$ sorbed to bulk sediments. Regardless of mode of introduction, worms were able to accumulate BA. However, bioavailability of BA previously sorbed to sediments was less than BA added to the water column and allowed to settle at the sediment-water interface. Of the three modes of introduction studied, BA ingested in a geletin-based diet was most available for accumulation by Nereis.

Length of exposure and mode of introduction had significant effects on accumulation and metabolism of BA by Nereis. Of total activity accumulated, the proportion remaining as parent compound decreased with time, and was inversely correlated with relative efficiency for accumulation. The relative amounts of different metabolic products were also affected by time and mode of exposure. In al 1 experiments, most activity recovered from worms was present as metabolic products with on $1 \mathrm{y}$ 
2 to $23 \%$ remaining as parent compound. A significant portion (from 33 to $51 \%$ ) of total activity was not extractable, indicating incorportation into macromo lecular components.

Physiological and biochemical effects of BA exposure on Nereis were minimal. Subtle alterations in adenylate nucleotide pools were observed after 6 days in experiments with either sediment-sorbed BA or BA added directly to the water column. After 25 days of exposure to sedimentsorbed BA, worms showed increased rates of oxygen consumption and ammonia excretion. No significant changes in growth or activity of the mixed function oxygenase systen were observed.

These experiments demonstrated: (1) that the presence of a large burrowing polychaete can have significant effects on the fate of PAH in the benthos; (2) that source can have significant effects on both fate and metabolism of PAH in the benthos; (3) that Nereis virens is capable of accumulating and metabolizing $B A$ from the sediment, water column, or ingested food; and (4) that incorporation into cellular macromolecules is a major fate of accumulated BA.

Thesis supervisor: John M. Teal

Chairman, Biology Department, Woods Hole Oceanographic

Institution, Woods Hole, MA 


\section{Thesis Comaittee}

John M. Teal: Supervisor

Biology Department, W.H.O.I.

Judith M. Capuzzo

Biology Department, W.H.O.I.

John W. Farrington

Chemistry Department, W.H.O.I.

Michael Marletta

Department of Nutrition and Food Sciences, M.I.T.

Jerry M. Neff

Battelle New England

John J. Stegeman

Biology Department, W.H.O.I. 


\section{ACXNOHLEDGKHEFTS}

Many people deserve to be acknowledged for helping me complete my degree, I will mention only a few.

My entire committee were very supportive during this ordeal. They a 11 istened to me, and freely gave advise and help. In addition, the Woods Hole contingent of my committee gave their friendship, and basicly adopted me into their laboratory groups. I would also like to thank all the people in John, John, and Judy's labs would also treated me as one of their own. Special thanks go to Dan Repeta, Bruce Tripp, and Bruce Woodin, for instruction and he $1 p$ with the idiosyncrasies of HPLC, organic chemistry, and enzymatic analysis; Brian Howes, who came out on a Sunday morning to measure redox potentials in my chambers; Richard Van Etten who provided much appreciated technical assistance during the latter phases of this research, and Dale Leavitt, who in addition to my committee, critically read my thesis. Brian Binder, BB-Plot, Ken Foreman, and John Teal helped make most of my graphics possible. Finally I would like to thank Chery 1 Ann Butman, Anne Giblin, Steve Lohrenz, and especially Dale Leavitt for advice, comradery, inspiration, and mora1 support.

This research was supported by the DOE/BLM contract DE-AC0277EV04256 A007 and interagency agreement AA550-IA7-20 to J.W. Farrington and J.M. Tea 1; NOAA contract 83-ABD-00012 to J.M. Teal; OIP support to J.M. Teal and the author; and support to the author from the Andrew W. Mellon Foundation through the CRL; the NWF/API Environmental Conservation Fellowship Program, Sigma $X i$, and the WHOI/MIT Joint Program in Oceanography. 
$-6-$

To my family

John, Marian, and Mary McElroy, and Josie 


\section{ABBREviatrous}

ACN : acetonitrile

ADP: adenosine triphosphate

AHH : ary 1 hydrocarbon hydroxylase

AMP: adenosine monophosphate

ANOVA: analysis of variance

ATP: adenosine triphosphate

$B A$ : benz(a)anthracene

$B P$ : benzo(a)pyrene

BSA : bovine serum albumin

$\mathrm{C}_{18}$ : octadecylsilane

$\mathrm{CHCl}_{3}$ : chloroform

CPM: counts per minute

DEE: diethyl ether

DPM: disintegrations per minute

EC: energy charge

EDTA: ethylene diamine tetracetic acid

EtOH: ethano1

GDW: gram dry weight

GWW : gram wet weight

HPLC: high pressure liquid chromatography (chromatograph)

$\mathrm{Hx}$ : hexane

LDH: lactate dehydrogenase

LSC: liquid scintillation counting (counter)

$\mathrm{MeOH}$ : methano1

MFO: mixed function oxygenase

MR: myokinase

NADH: nicotine adenine dinucleotide reduced form

NADPH: Nicotine adenine dinucleotide phosphate reduced form

0.D.: optical density

PAH: polycyclic aromatic hydrocarbons

PEP: phosphoeno1 pyrophosphate

PK: pyruvate kinase

SNK : Student-Neuman-Keuls test

Tris : $\operatorname{tr}$ is (hydroxymethy 1 ) aminomethane

UV: ultraviolet 


\begin{tabular}{lr}
\multicolumn{1}{c}{ TABIB OF CONTEKTS } & Page \\
ABSTRACT & 2 \\
THESIS COMMITTEE & 4 \\
ACKNOWLEDGEMENTS & 5 \\
ABBREVIATIONS & 7 \\
LIST OF FIGURES & 10 \\
LIST OF TABLES & 13 \\
CHAPTER 1. INTRODUCTION & 15 \\
PAH in the environment & 16 \\
Factors affecting the distribution of PAH in the benthos & 19 \\
PAH metabolism & 26 \\
Biological and chemical availability of PAH & 32 \\
Metabolic fate of PAH in the benthos & 39 \\
Effects of PAH exposure on marine organisms & 35 \\
Problems of experimental design & 38 \\
Scope of thesis research & 39
\end{tabular}

CHAPTER 2. EXPERIMENTAL APPROACH

$\begin{array}{ll}\text { Exposure system } & 42\end{array}$

Analytical methods $\quad 48$

$\begin{array}{ll}\text { Dosing } & 49\end{array}$

Physiological measurements $\quad 53$

Analysis of BA and BA metabolites 61

CHAPTER 3. THE FATE OF BENZ(a)ANTHRACENE IN BENTHIC MICROCOSMS: INFLUENCE OF Nereis virens AND MODE OF EXPOSURE

Results 
Experiment with BA added to the water column

Experiment with BA labeled food 116

Discussion

Summary

CHAPTER 4. IN VIVO METABOLISM OF BENZ(a)ANTHRACENE BY Nereis virens

Results

Distribution of accumulated activity into metabolite 130 classes

138

Separation of polar metabolites in organic extract by

Enzymatic analysis of glucuronide and sulfate conjugates

Discussion

156

Summary

169

CHAPTER 5. PHYSIOLOGICAL EFFECTS OF BENZ(a)ANTHRACENE EXPOSURE ON Nereis virens

Results

Biochemical indices

Whole Animal physiological indices

174

Discussion

Summary

CHAPTER 6. SUMMARY

APPENDIX 1. BIOGEOCHEMISTRY OF BENZ(a)ANTHRACENE IN RECIRCULATING BENTHIC MICROCOSMS 


\section{LIST OR PIGURES}

1.1 BA metabolic pathways

2.1 Schematic diagram of experimental system

2.2 Isotope purification using Waters Sep-Paks

2.3 Extraction of BA labeled food

$2.4{ }^{14} \mathrm{C}$ HPLC chromatogram of BA labeled food

2.5 Wet weight/dry weight linear regression for Nereis virens

2.6 Diurnal oxygen consumption and ammonia production

2.7 ATP assay protocol

2.8 ADP and AMP assay protocol

2.9 Benzo(a)pyrene hydroxylase assay protocol

$2.10 \mathrm{UV}$ chromatogram of HPLC separation of representative BA standards

2.11 Sediment extraction protocol

2.12 Worm extraction protocol

2.13 Enzymatic analysis of conjugates protocol

2.14 Concentration curve for B-glucuronidase and ary 1 sulfatase assay using worm aqueous extracts

2.15 Analytical determination of metabolite classes

$3.1{ }^{14} \mathrm{C}$ HPLC chromatogram of organic extracts of sediment cores taken at the beginning and end of experiments $1 \& 2$

$3.2{ }^{14} \mathrm{C}$ HPLC chromatogram of organic extracts of sediment cores taken at the beginning, middle, and end of experiment 3

3.3 BA flux to water column in experiment 1

3.4 BA flux to water column in experiment 2

3.5 BA flux to water column in experiment 3

3.6 BA mineralization to carbon dioxide in experiment 3

$3.7{ }^{14} \mathrm{C}$ HPLC chromatogram of organic extracts of sediment cores taken at the beginning and end of experiment 4 
3.8 Initial removal rate of $B A$ from the water column during recycling in experiment 4

3.9 BA flux to water column after initiation of flow-through conditions in experiment 4

$3.10^{14} \mathrm{C}$ HPLC chromatogram of organic extract of water sample from experiment 4

3.11 BA mineralization to carbon dioxide after initiation of flow-through conditions in experiment 4

$3.12 \mathrm{BA}$ flux to the water column after addition of labeled food in experiment 5

4.1 Distribution of recovered radiolabe 1 for each type of experiment comparing different metabolite classes

4.2 Distribution of recovered radiolabe 1 in different metabolite classes compared between experiment

4.3 Total incorporation into different metabolite classes in experiments with sediment-sorbed BA

4.4 UV HPLC chromatogram of a representative worm organic extract

$4.5{ }^{14} \mathrm{C}$ HPLC chromatograms of worm organic extracts from experiment 1

4.6 ${ }^{14} \mathrm{C}$ HPLC chromatograns of worm organic extracts from experiment 2

4.7 ${ }^{14} \mathrm{C}$ HPLC chromatograms of worm organic extracts from experiment 3

$4.8{ }^{14} \mathrm{C}$ HPLC chromatograms of worm organic extracts from experiment 4

$4.9{ }^{14} \mathrm{C}$ HPLC chromatograms of worm organic extracts from experiment 5

$4.10^{14} \mathrm{C}$ HPLC chromatograms of organic extracts after enzymatic cleavage of glucuronid and sulfate conjugates in experiment 3

$4.11^{14} \mathrm{C}$ HPLC chromatograms of organic extracts after enzymatic cleavage of glucuronid and sulfate conjugates in experiment 4

$4.12{ }^{14} \mathrm{C}$ HPLC chromatograms of organic extracts after enzymatic cleavage of glucuronid and sulfate conjugates in experiment 5

5.1 Oxygen consumption, ammonia production, and the $0 / N$ ratio in 
experiment 1

5.2 0xygen consumption, ammonia production, and the $0 / \mathrm{N}$ ratio in experiment 2

5.3 Oxygen consumption, ammonia production, and the $0 / \mathrm{N}$ ratio in experiment 3

5.4 0xygen consumption, ammonia production, and the $0 / \mathrm{N}$ ratio in experiment 4

5.5 0xygen consumption, ammonia production, and the $0 / \mathrm{N}$ ratio in experiment 5

A.1 Radioactivity recovered on suspended particulates

A.2 Concentration of ${ }^{14} \mathrm{CO}_{2}$ in the water column

A.3 UV chromatogram of metabolite standards

A.4 HPLC chromatogram of organic extract of sediment collected on day 9

A.5 HPLC chromatogram of organic extract of sediment collected on day 15

A.6 HPLC chromatogran of organic extract of sediment collected on day 42

A.7 HPLC chromatogram of organic extract of Nephtys incisa from chamber 1

A.8 HPLC chromatogram of organic extract of Nephtys incisa from chamber 2 


\section{InIST OP TABLES}

2.1 Comparison of different methods for quantifying ${ }^{14} \mathrm{C}-\mathrm{BA}$ activity in water samples

3.1 Total BA concentration in sediment samples from experiments 1,2 , and 3

3.2 Percent of total radioactivity recovered in aqueous extracts of sediments samples from experiments 1,2 , and 3

3.3 Size fractionation of radioactivity in sediment cores taken at the end of experiment 3

3.4 BA accumulation in worm tissue in experiments 1,2 , and 3

3.5 Who le chamber mass balance in experiments 1,2 , and 3

3.6 Total BA concentration in sediment samples from experiment 4

3.7 Depth fractionation of radioactivity in sediment cores taken at the end of experiment 4

3.8 Size fractionation of radioactivity in sediment cores taken at the end of experiment 4

3.9 BA accumulation in worm tissue in experiment 4

3.10 Whole chamber mass balance in experiment 4

3.11 BA recovered from individual sediment cores in experiment 5

3.12 Whole chamber mass balance in experiment 5

4.1 Percentage of total radioactivity recovered from worm tissue . in major metabolite classes

4.2 Concentrations of major metabolite classes in worm tissue

4.3 Separation of polar metabolites in organic extracts of worms tissue by reverse phase HPLC

4.4 Glucuronide and sulfate conjugates in aqueous extracts of worm tissue

5.1 Benzo(a)pyrene hydroxylase activity in microsomes prepared from whole worm homogenates

5.2 Adenylate nucleotide pools and ratios

5.3 Summary of statistical analyses of adenylate nucleotide poo $1 \mathrm{~s}$ from control worms used in different experiments 
5.4 Summary of analysis of variance on the effects of BA exposure and length of exposure on oxygen consumption

5.5 Summary of analysis of variance on the effects of BA expsoure and length of exposure on ammonia production

5.6 Worm weight changes

A.1 Distribution of ${ }^{14} \mathrm{C}$ at end of 42 day experiment

A.2 Distribution of ${ }^{14} \mathrm{C}$ from surface sediments and worm $t$ issues using reverse phase HPLC 
CHAPTBR 1:

IXTRODUCTIOA

\section{PAI in the enviroment:}

The annual discharge of petroleum hydrocarbons into the wor $1 d^{\prime} s$ oceans has been estimated at 1.9 to 11.1 million tons (Connel and Miller, 1980,1981). The single largest component of petroleum hydrocarbon input Is chronic land-based discharges, such as precipitation run-off and sewage, associated with the routine use of fossil fuels in industrialized areas (NAS, 1975; Hoffman et a1., 1984). Once introduced into the aquatic system, non-volatile hydrocarbons, due to their characteristically low water solubility, do not remain dissolved for long. They are removed from solution either by direct mixing to the sediment surface, by adsorption onto particles, or by uptake into aquatic organisms. The importance of sediments as reservoirs for hydrocarbons has been we 11 documented in natural (Hites et a1., 1980; Royal Society,, 1980; Wakeham and Farrington, 1980; Farrington and Tripp, 1977; NAS, 1975), as we 11 as experimenta 1 (Gearing et a 1., 1979, 1980).

Although less abundant on a per weight basis than aliphatic hydrocarbons, polycyclic aromatic hydrocarbons (PAH) constitute a significant, long-lived, and biologica11y active portion of the total hydrocarbons in the benthic environment. The primary source of PAH to sediments global1y is thought to be the combustion of fossil fuels (LaFlamme and Hites, 1979; Wakeham and Farrington, 1980). In the coastal zone land-based runoff (Hoffman et a 1., 1984; Prahl et a 1. 1984) and input from unburned coal (Tripp et a1., 1981) can a 1 so be major sources of PAH to the benthos. Blumer and Sass (1972) demonstrated that biochemical degradation selectively removes alkanes prior to removing the complex mixture of 
cyclic and aromatic hydrocarbons. Long-term studies of an oil spill in a New England salt marsh showed that aromatic hydrocarbons were retained in sediments at least 6.5 years after the spil1. The aromatic hydrocarbons remaining were relatively enriched in the heavier molecular weight fractions (Teal et al., 1978). Prudhoe Bay crude oil experimentally weathered under a variety of simulated intertidal weather conditions also became enriched in the heavier tri- and tetra-aromatic hydrocarbon fractions (Riley et a1., 1980-81).

Complex PAH mixtures in marine sediments are ubiquitous, and have been detected in remote pristine areas including the Nares abyssal plain, Walvis Bay, the Cariaco Trench, and the Gulf of Maine (Giger and Blumer, 1974; Farrington, et a 1. 1977; La Flamme and Hites, 1978). Coasta1 sediments have elevated PAH levels due to their proximity to industrial. regions. Analysis of sediment profiles in various parts of the world indicates that PAH input has increased dramatically since 1900 (Hites, et a 1., 1977: Grimmer and Bohnke, 1975). The deposition and retention of substantial concentrations of PAH in surface sediments emphasizes the need for understanding the fate and effects of these compounds in benthic ecosystems. Organisms living in the sediment will be continually exposed to $\mathrm{PAH}$ present in pore waters, on particles, in detritus (both within and upon the sediment), and in other organisms.

Factors affecting the distribution of PAH in the benthos:

A multitude of factors can affect the distribution of PAH in the benthos. In nearshore areas physical processes such as tidal pumping, wind-driven and tidal currents, and storm events can influence deposition, resuspension, and advection of PAH. The distribution of PAH can 
also be affected by biological activity. PAH can be transformed either chemically or biologically to more reactive products. Photooxidation of PAH leads to a wide range of products of including quinones (Zafiriou, 1977). Lee and Takahashi (1977) reported photolysis to be a major factor in removal of benzo(a)pyrene in the watercolumn of CEPEX enclosures. Sorption of PAH onto sediment particles, even under full illumination, reduces their susceptibility to photolysis (Zepp and Schlotzhauer, 1979), and in most benthic environments, ambient light levels are low. Although photooxidation and large scale physical processes can affect $P A H$ in the benthos, particularly in intertidal and nearshore environnents, the following discussion will focus on interactions between biological processes and PAH in the benthos.

Infaunal organisms can alter the chemical composition of sediment, pore water, and overlying water (Aller, 1978; Aller \& Yingst, 1978; Fisher et a1., 1980). Burrowing organisms also have an impact on microcirculation near the sediment surface (Eckman, 1978). These effects result from: (1) irrigation of subsurface burrows for feeding and respiration; (2) deposition of mucous both within burrows and at the sediment surface; and (3) movement of sediment for burrow and tube construction, and feeding. Few reports exist on how these activites affect the distribution of hydrophobic compounds residing in sediments. Gordon et a 1. (1978) estimated that observed densities of the polychaete Arenicola marina could remove all sediment-bound oil resulting from an oil spill in Chedabucto Bay, Nova Scotia in a period of 2-4 years. Lee et a1., (1978) found the presence of the polychaete Capite11a sp. increased the removal rate of several PAH from sediments. More recent 1 y Karickhoff and Morris 
(1985) found bioturbation by oligochaetes increased flux of sedimentsorbed chlorinated hydrocarbons to the water column by a factor of 4 to 6.

The presence of infaunal organisms can also affect both removal and microbial mineralization of PAH. Gardner et a1. (1979) compared rates of removal and mineralization of sediment spiked with anthracene, flouranthene, benz(a)anthracene (BA), and benzo(a)pyrene (BP) in the presence and absence of Capite 11 a sp. Capite 11 a increased the removal rate of a 11 PAH from the sediment. The effect of the worms was most pronounced with the larger ( $>3$ ring) PAH. Furthermore, mineralization rates of $\mathrm{BA}$ added to sediments taken from depth in chambers with worms were higher than in sediments taken from depth in chambers without worms.

The tendency for organic molecules to sorb onto particles is largely determined by the organic content (Means et al., 1979) and size (Steen et a1., 1978) of the particulate matter available. Karickhoff (1979) calculated the relationship between empirically determined partition coefficients, normalized to organic content of the sorbant ( $\left.\mathrm{K}_{\mathrm{oc}}\right)$, to octano1water partition coefficients $\left(\mathrm{K}_{\mathrm{ow}}\right)$ of the organic compounds. Bioconcentration of organic pollutants in marine organisms has also been found to correlate with $K_{o w}$ (Neely et a 1., 1974; Vieth et a1., 1979). In addition to particulate matter, organic colloids have been shown to be important sorbants for organic compounds (Means and Witjayaratne, 1982). Boehm and Quinn (1973) found that dissolved organic matter (DOM) increased the solubility of hydrocarbons in seawater, and that removal of DOM increased accumulation of hydrocarbons by filter feeding bivalves (Boehm and Quinn, 1976). Leversee et a1. (1982) reported that accumulation of several PAH 
by Daphnia were affected by the presence of synthetic (Aldrich humic acids) or natural DOM, or natural particulate matter. Particulate size and organic content are also known to influence feeding behavior of benthic organisms. Particulate protein content has been shown to affect both selection (Taghon, 1982) and feeding rate (Taghon and Jumars, 1984) of deposit feeding polychaetes. Several species of deposit feeders have demonstrated the ability to selectively feed on small sediment particles (Taghon, 1982). These studies clearly illustrate that the physica1/chemical properties of organic compounds and available sorbant material can affect the chemical- and bio-availability of organic pollutants.

\section{PAH Yetabolism}

Metabolic transformation of PAH greatly alters their chemical and biological reactivity. Therefore this process can have profound effects on both the fate of PAH in the environment, and their effects on organisms.

Bacteria are the only organisms able to completely mineralize PAH to $\mathrm{CO}_{2}$ (See review by At las, 1981). Although both bacteria and fungi are capable of metabolizing PAH, mineralization rates of the larger PAH (greater than three rings) in natural systems have been found to be slow, and no known microbes are capable of using these larger PAH as a sole carbon source (At las, 1981). Lee and Takahashi (1977) attempted to measure BP and fluorene mineralization in water taken from CEPEX enclosures that had been spiked with PAH and petroleum hydrocarbons. They detected no mineralization of fluorene and could detect only very low $(1 \pm 0.7 \mathrm{ug} / 1-\mathrm{day})$ rates for $B P$, which gave a turnover time of 1,400 days for BP in the enclosure. Lu et al. (1977) were also unable to detect 
mineralization of $B P$ in an aquatic microcosm where BP was added to the water column. Saltzman (1982) measured microbial mineralization of PAH spiked to sediments taken from North Sea oil fields and only occasionally found significant rates of BP degradation, whereas naphthalene was always mineralized.

Lee and Ryan (1983) compared microbial mineralization of several FAH spiked into either seawater or sediment-seawater $s$ lurries taken from both clean and oil-contaminated environments. PAH containing fewer than four rings (naphthalene, methy lnaphtha lene, and phenanthrene) were mineralized in water samples while other larger PAH (BA, chrysene, fluorene, and anthracene) were not, unless illuminated with sunlight. However, in sediment-seawater slurries al1 PAH studied were degraded. Since microbial activity on sediment particles exceeds that in the water column the increased degradation of PAK associated with sediment particles is not surprising. Hinga et a 1. (1980) found $29 \%$ of a water column spike of BA, in the MERL mesocosms at the University of Rhode Is land, was mineralized to $\mathrm{CO}_{2}$ in 230 days. In this experiment it was not possible to distinguish between either BA mineralized in the water column and that mineralized at the sediment-water interface or between microbial degradation and photooxidation.

Herbes and Schwal1 (1978) looked at mineralization of PAH spiked into undiluted sediment taken from clean and oil-polluted environments. They found turnover times for added PAH to be faster in sediments from contaminated areas and faster for the lower molecular weight PAH (naphthalene and anthracene) than for the higher molecular weight PAH (BA and BP). In sediment from oil contaminated areas, naphthalene was degraded 
within hours, whereas the turnover time for $B A$ was approximately 400 days, and that for BP was greater than 3.3 years. Gardner et a 1 . (1979) using sediment from benthic microcosms containing $P A H$ and petroleum hydrocarbons, found mineralization rates of BA spiked to sedimentseawater slurries taken from surface sediments to be higher than in sediments taken from depth. Since microbial mineralization requires oxygen (Gibson, 1976), populations of PAH mineralizers should be localized at the sediment water interface where oxygen would not be 1 imiting.

In concert, these studies indicate that although microbial mineralization of two and three ring PAl may be an important process, the significance of this pathway for larger PAH in the water column is negligible. It is more likely that photooxidation and sorbtion onto sinking particles are the primary processes responsible for removing laxger PAH from the water column. Once on the bottom, mineralization of the larger PAH, particularly at the sediment-water interface, may take on greater importance.

In mamma $1 \mathrm{~s}$, PAH metabolism is initiated by a NADPH-dependent enzyme system where cytochrome $\mathrm{P}-450$ is the terminal oxidase. This enzyme system is commonly referred to as a mixed function oxygenase (MFO) system because it splits molecular oxygen, adding one atom of oxygen to the substrate, while the second atom forms a water molecule. This system is responsible for the metabolism of a wide variety of foreign compounds in addition to $\mathrm{PAH}$, and is also responsible for metabolizing endogenous substrates such as steroid hormones. Fish and invertebrates possessa MFO systems that are similar to those found in mamals (see reviews by Stegeman, 1981 and Lee, 1981), and some evidence for MFo activity has 
been observed in most aquatic eukaryotic organisms (Neff, 1979).

A schematic of MFO metabolism of $B A$ is shown in Figure 1.1 The MFO system inserts oxygen onto the ring forming a very reactive epoxide intermediate. The epoxide can rearrange to a phenol, can be converted to a diol either by spontaneous rearrangement or via the enzyme epoxide hydrolase (EH), can be conjugated to form a water soluble metabolite through the action of enzymes such as glutathione-s-transferase or UDP glucuronosyl transferase, or, because it is a strong electrophile, can covalently bind to nucleophiles such as cellular macromolecules. Polar metabolites can be further metabolized by the MFo system at other ring positions, which can lead to the formation of a very reactive diolepoxide intermediate. The diol-epoxide can also bind to cellular macromoleucles or can be hydrolyzed to triol or tetrol metabolites.

This figure illustrates the dichotomous nature of PAH netabolism in eukaryotic organisms. It leads to the production of water soluble conjugated metabolites that can be excreted, and to the production of highly reative electrophiles that can spontaneous1y bind to DNA, RNA, and proteins. PAH induced carcinogenesis requires that the PAH be activated (metabolized) before binding to DNA (Sims and Grover, 1974; Jerina and Da ley, 1974). Wood et a 1., (1977) have demonstrated that the 3,4-diol metabolite of $\mathrm{BA}$ is 10 to 20 time more tumorogenic than the parent compound when applied topica11y to mouse skin.

One important aspect of the MFO system is that it can be induced by exposure to a wide variety of compounds including PAH and PCBs. Induction involves the de novo synthesis of new cytochromes $\mathrm{p}-450$ with increased ability to metabolize specific substrates. Experimental evidence 
Figure 1.1: Possible metabolic fate of benz(a)anthracene in eukaryotic organisms. $M F O=$ mixed function oxygenase. $G-S-T=g$ lutathione $S-$ transferase. GSH= reduced glutathione. UDPGA $=$ uridine diphosphate glucuronic acid. UDPG-S-T= UDP glucuronosyl S-transferase. Glu= glutamate. $G 1 y=$ glycine. 


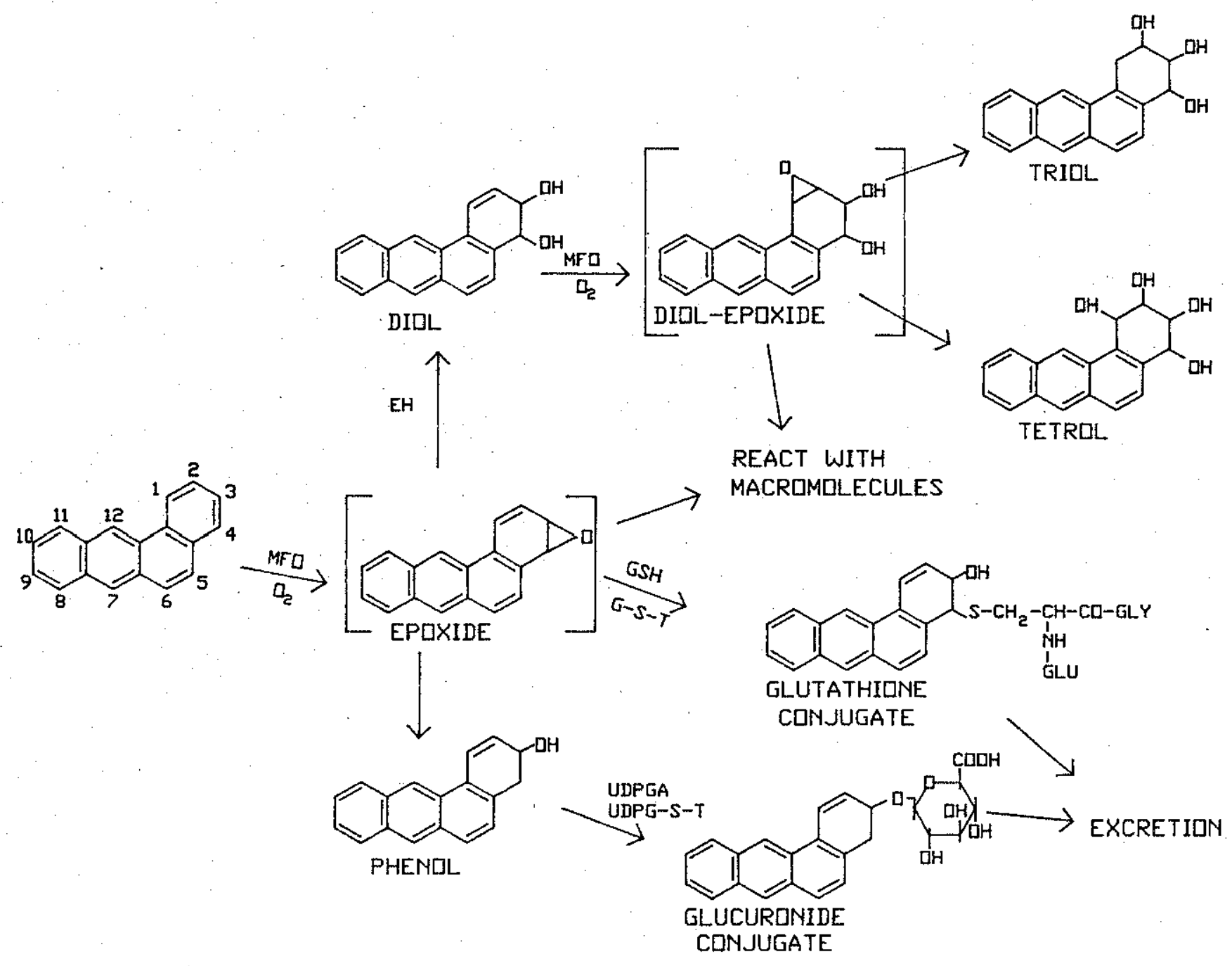


indicative of induction include enhanced hydroxylation activity of MFo substrates, elevated concentrations of cyctochrome $\mathrm{P}-450$, and by stylized reponses to selective inhibitors (Stegeman, 1981). However, compounds that stimulate the MFO system do not necessarily initiate commensurate increases in the activity of conjugating enzymes (Statham et al., 1.978; Balk et al., 1980). Therefore previous exposure to compounds which can induce the MFO system might increase the production and residence time of reactive PAH metabolites binding to cellular macromolecules.

Most characterization of the MFO system has been done in vitro using purified proteins in reconstituted systems or microsomal membrane preparations. This type of investigation has produced much useful information on what factors can affect MFO activity and substrate specificity, and or the kinetics of metabolite formation. However, in the intact system in a functional organism there are many additional processes that may affect MFO activity such as availability of substrates and cofactors, the inhibition by reaction products or other compounds, the presence of enzymes and substrates for conjugation, and the scavenging of reactive intermediates by cellular nucleophiles. Investigation of in vive metabolism is required to actually determine the fate of accumulated PAH in organisms.

In vivo metabolism of PAH has been observed in virtual1y al1 species of $\mathrm{fish}$ investigated, including teleosts (Lee et a1., 1972; Ahokas et a 1., 1975; Lu et a 1., 1976; Roubal et a1., 1977; Statham et a 1., 1978; Varanasi et a 1., 1979; Solbakken, 1980; Lech and Bend, 1980; Richert et a 1., 1982; Varanasi and Gmur, 1981) and elasmobranchs (Solbakken and Palmork, 1980). In vivo PAH metabolism has also been observed in many species of crustacea (Corner et a 1., 1973, 1976; Lee et a 1., 1976; Lu et 
a1., 1977: Sanborn and Malins, 1977; Herbes and Rissi, 1978; Palmork and Solbakken, 1980; and Leversee et a1., 1981); in echinoderms (Malins and Roubal, 1982) and in a few polychaetes as described below. Attempts to measure in vivo metabolism have produced negative results in two coelenterates (Lee, 1975) and the bivalve mollusc Mytilus edulis (Lee et al, 1972a), although evidence of in vivo PAH metabolism has been observed in the gastropod mollusc Physa (Lu et al., 1976).

Lee and coworkers have demonstrated that Nereis virens has a functional MFo system (Singer et a1., 1979). They have reported increases in AHH activity and cytochrome $\mathrm{P}-450$ concentrations in Nereis collected from polluted environments in Maine and have also shown an occasional increase in these parameters after feeding Nereis food contaminated with PAH or PCBs in the laboratory (Lee et al., 1981b). They have also shown in vitro metabolism of BP to primarily phenolic and diol metabolites (Fries and Lee, 1984). In vivo metabolism of chlorinated hydrocarbons such as lindane (Goerke and Ernst, 1980) and a pentachlorobipheny 1 (Goerke, 1984) has been reported in Nereis virens, but in vivo PAH metabol ism has not been investigated. Lee et a 1. (1979) have reported increased AHH activity in another polychaete Capitel 1 a sp. after long-term exposure to petroleum hydrocarbons. Rossi and Anderson (1977) reported that another polychaete, Neanthes arenaceodentata, could metabolize naphthalene. However, Augenfeld et a 1. (1983) did not find direct evidence for in vivo metabolism of sediment-sorbed phenanthrene, chrysene, or BP by the lugworm Abarenicola pacifica.

\section{Biologica 1 and cheaical availability of PAH:}

Tissue concentrations of individual PAH such as BP observed in 
aquatic organisms varies from undetectable to several ppm (Neff, 1979). A consistent trend for the selective retention of the larger, more hydrophobic components of oil has been observed in both field and laboratory studies. Polychaetes collected from the New York Bight and from Buzzards Bay showed preferential retention of PAH with three or more rings (Farrington et a 1., 1985). Similar findings were reported for benthic invertebrates in an extensive study of chemical contamination in central and southern Puget Sound (Malins et al., 1980). Preferential accumulation of aromatic hydrocarbons over lighter molecular weight other components in fuel oil has been observed in the laboratory for oysters, clams, polychaetes, 1impets, shrimp, and fish (Stegeman and Tea1, 1973; Neff et a 1., 1976; Clement et a1., 1980; Farrington et a 1., 1982). Laboratory studies of accumulation of one to 5 ring aromatic hydrocarbons have demonstrated a correlation between number of rings and accumulation and retention in Coho salmon (Roubal et a1., 1977) and a deposit feeding clam Macoma inquinata (Roseijadi et a1., 1978).

Analysis of benthic organisms and the sediment they inhabit supports the premise that PAH from different sources are not equally available for accumulation by benthic organisms. Shaw and Wiggs (1980) found petroleum derived hydrocarbons in the filter feeding bivalve Mytilus edulis whereas coal-derived hydrocarbons were found in a deposit feeding bivalve Macoma baltica from the same area. Work in the MERI mesocosms, looking at the addition of $\$ 2$ fue 1 oil to the water column, showed different patterns of PAH accumulation in sediment, limpets living on the walls near the sediment-water interface, and polychaete worms living in the sediments (Farrington et al., 1982). Similar patterns were observed between PAH in 
the polychaete Nephtys incisa and sediments collected in the New York Bight (Farrington et a1., 1985).

Accumulation of dissolved PAH in organisms has been we 11 documented, with bioaccumulation factors ranging up to many orders of magnitude (Neff, 1979). Uptake of $\mathrm{PAH}$ is a function of water solubility, with the smaller and more soluble PAH being taken up more rapidly than the larger and less soluble PAH. PAH retention is a function of the rate of excretion via metabolic processes, and the rate of passive processes such as desorption of accumulated PAH out of the organism. Therefore, smaller PAH will be both taken up and lost more rapidly than larger PAH. Similarly, accumulation of PAH in organisms such as fish that are capable of rapid PAH metabolism, is frequent ly much lower than that seen in organisms without active PAH degrading systems such as molluscs, due to the rapid turnover of these compounds (Stegeman, 1981).

Accumulation of PAH via trophic transfer has frequent $1 \mathrm{y}$ been observed, although this mode of uptake seems to be more variable. Rossi (1977) was unable to detect accumulation of naphthalene from labeled detritus eaten by the deposit feeding worm Neanthes arenaceodentata. However, Elder et a1. (1979) found Nereis virens was capable of dietary accumulation of PCB mixtures in labeled clam tissue. Dietary accumulation of a variety of PAH has been documented in larval bivalves (Drobosky and Epifanio, 1980), in crustacea (Conner et a1., 1976; Lee et a 1., 1978); and in fish (Dixit \& Anderson, 1977; Palmork \& Solbakken, 1980). Lee et a 1. (1976) found uptake of BP in 1 arva 1 blue crab to be more efficient from food than from water, and Corner et a1. (1976) found similar results for uptake of naphthalene in Calanus. Dobrosky and Epifanio (1980) 
however, found the opposite trend for BP accumulation in larval bivalves. Recent1y Rubinstein et a1. (1984) reported dietary transfer of PCBs from Nereis virens to the demersal fish Leiostomus xanthurus to be more efficient than direct uptake from contaminated sediments.

The bioavailability of PAH sorbed to sediments is not we 11 understood. Since there will always be a dissolved phase whenever particulates or even colloidal material such as DOC are present, discriminating between uptake from particulate versus uptake from solution is extremely difficult. To adequately assess the importance of uptake from dissolved v8. sorbed $\mathrm{PAH}$, exacting comparisons between concentration factors, total accumulation, and especially rates of uptake via the two sources would have to be made.

Factors which affect sorptive capacity of sediments also affect flux of PAll from sediments and, potential1y, bioaccumulation. Gardner et al. (1979) found that 2 to 5 ring $P A H$ were 108 t most rapidy from sediments with the lowest sorptive capacity. Flux was highest from medium sands with large particle sizes and low organic carbon content, intermediate from fine sands with smaller particle sizes, and lowest from marsh peat with the highest organic carbon content and smallest average particle sizes.

Roesijadi et a1. (1978) exposed a filter feeding clam, Protothaca stamina, a deposit feeding clam Macoma inquinata, and a deposit feeding worm, Phascolosoma agassizii, to sediment containing Prudhoe Bay crude oil. The deposit feeders accumulated hydrocarbons to a greater extent than the suspension-feeder. However, Rossi (1977) was unable to detect accumulation of naphthalene from sediment or food in the deposit feeding 
worm Neanthes arenaceodentata, whereas Lyes (1979) observed naphthalene accumulation from sediments by the worm Arenicola marina and Courtney and Langston (1978) observed PCB accumulation from sediments by two other polychaetes. Other investigators have detected accumulation of PAH from sediments by fish (Varanasi and Gmur, 1981). Even though it seems that most organisms can accumulate $\mathrm{PAH}$ from sediment reservoirs, concentrations in organisms great $1 y$ exceeding that in the sediment reservoir are rarely observed in marine organisms.

Several investigators have found similar total amounts of accumulated PAH in organisms exposed to either sediment or water sources, although concentration factors for water uptake were much higher, as would be expected based on partitioning. Roesijadi et al. (1978) looked at accumulation of phenanthrene, chrysene, and $B P$ from labeled sediments by Macoma inguinata either suspended above, or in direct contact with the sediment. In a 7 day exposure, net uptake was of the same order of magnitude for a 11 PAH regardless of whether or not the clams were in direct contact with the sediment. Courtney and Langston (1978) compared uptake of the PCB mixture Arochlor 1254 from sediment and seawater by two deposit feeding polychaetes. Again, similar absolute amounts of PCBs were accumulated from both sources. However, in this case the concentration in sediment was $1 \mathrm{ppm}$ whereas that in the water column was $1 \mathrm{ppb}$.

The time course for biological uptake and loss of PAH from sediment seems to be much longer than for that from the water column for compounds with very low water solubility. After exposure of the deposit feeding clam Macoma baltica to sediment-sorbed PAH for 45 days, tissue concentrations of BP were still increasing at an exponential rate whereas 
concentration of chrysene had already peaked and was beginning to decline, and concentration of phenanthrene was declining exponential1y (Roesijadi et a1.1978). Fowler et a1.(1978) compared accumulation of the PCB mixture Penoclor DP-5 from sediment and from water by the polychaete Nereis diversicolor. Accumulation from the water column attained equilibrium after on $1 y$ two weeks, while accumulation from sediment attained equilibrium after two months. Both uptake and depuration was dose dependent with worms in contact with higher concentrations of PCBs taking longer to reach equilibrium. Calculations based on concentration factors from the sediment ( 3 to 4), from the water column (800) and from ambient PCB levels in sediment and water indicated that the water column could only contribute one percent of the observed PCBs accumulated at equilibrium.

Since most PAH in the marine environment are deposited in sediment reservoirs, it is unfortunate that the chemical and biological availability of these pools are not better understood. Based on current literature, it seems that sediment $\mathrm{PAH}$ reserves, particularly those near the sediment water interface and within the bioturbated zone are more available for bioaccumulation and degradation. Although the efficiency of uptake from particulates appears to be much less than that from the dissolved form, the sheer mass of PAH located in the sediment dictates that sediments are a major source of PAH to benthic organisms. PAH a lready accumulated in marine organisms are available for uptake by predators with efficiencies similar to that seen for uptake from the dissolved form. The potential importance of dietary transport of PAH by mobile predators such as fish into pristine environments or into the 
human food chain warrents further investigation. Recent field evidence by Malins et a1. (1985) suggests that this vector may be important in Puget Sound.

Metabolic fate of PAH in the benthos:

Although numerous studies have investigated different factors affecting the fate of PAH in the benthos as described above, there have been on 1 y a few attempts to construct a complete mass balance of what actual1y happens to $\mathrm{PAH}$ in relatively undisturbed benthic systems. Using the 13,000 1 MERL mesocosms at the University of Rhode Island, Hinga et a 1. (1980) followed BA added to the water colurn in all components of the system for 230 days. Degradation of BA proceeded rapidly in the water column. The activity of the parent compound accounted for $70 \%$ of the total activity in the water column on day one, but by day 9 this had been reduced to $20 \%$. The actua 1 extent of BA degradation was probably even higher since only the lipid portion of the extract was analyzed for metabolic products and 30 to $40 \%$ of total activity in the water column was not 1 ipid extractable. By day 60 , the on 1 y activity left in the water column was as $\mathrm{CO}_{2}$ from mineralized $\mathrm{BA}$. Concentration of ${ }^{14} \mathrm{CO}_{2}$ in the water column peaked on day 12 and slowly decreased throughout the rest of the experiment. A cumulative total of $29 \%$ of BA added to the microcosm was mineralized to $\mathrm{CO}_{2}$ by the end of the experiment.

BA was rapidly deposited at the sediment-water interface, with maximum concentrations in the top centimeter found in the first sediment samples taken on day 10. Polar metabolites of BA were found in a 11 cores analyzed, although this was not done until day 86. As time increased, BA was mixed into the sediment. Significant levels of polar metabolites (up 
to $95 \%$ ) were found to depths of $6 \mathrm{~cm}$ in some cores. Due to the rapid disappearance of BA from the water column and the presence of BA polar metabolites in the sediment, it is likely that a major portion of BA mineralization to $\mathrm{CO}_{2}$ and metabolism to polar intermediates occurred near the sediment-water interface, and that net production of $\mathrm{CO}_{2}$ resulted from removal of $B A$ from the sediment.

A similar experiment was conducted by McElroy et a1., (1982; Appendix 1) where ${ }^{14} \mathrm{C}-\mathrm{BA}$ was added to the water column in two 2301 recirculating microcosms each containing a $0.25 \mathrm{~m}^{2}$ sediment box. As was seen in the MERL experiment, BA disappeared from the water column in a matter of days. The production of ${ }^{14} \mathrm{CO}_{2}$ followed kinetics similar to those reported by Hinga et al. (1981). The concentration of BA in surface sediments increased rapidly and after 42 days over $97 \%$ of recovered activity was found in the top $2 \mathrm{~cm}$ of the sediment reservoir. In this experiment most of the BA present in sediment cores appeared as polar metabolites as early as nine days after introduction of isotope to the chambers. A population of the deposit feeding worm Nephtys incisa recovered from the chambers after 42 days of exposure also contained very 1 ittle unmetabolized BA. Since this experiment was run in the dark, it is believed that al1 degradation occurred via metabolism.

Herbes and Schwa11 (1978), as part of a comparative study of microbial transformation of $\mathrm{PAH}$ in pristine and petroleum-contaminated sediments, constructed a mass balance of PAH added directly to undiluted sediments. The percent of parent PAH remaining in the sediment after 24 hours was $7 \%$ for naphthalene, $78 \%$ for anthracene, $82 \%$ for $B A$, and $78 \%$ for BP. Incubations for BA and BP were continued for 26 days, during which a 
significant decrease in the amount of BA occurred whereas no significant change in the amount of $B P$ remaining was observed. For naphthalene, a significant portion of degraded PAH was mineralized to $\mathrm{CO}_{2}$ (approx. $50 \%$ in 48 hours), or bound to microbial biomass (approx. $28 \%$ in 48 hours) with only a few percent recovered as polar metabolites in the sediment. For anthracene, a much greater percentage (approx. $10 \%$ after 128 hours) was found in the polar fraction as compared to $4 \%$ as $\mathrm{CO}_{2}$ and $23 \%$ bound. For both BA and BP after 14 days about $2 \%$ of activity was bound to microbes, 3 and $5 \%$ respectively found as polar compounds and 2.1 and $0.1 \%$ recovered as $\mathrm{CO}_{2}$. This study supports work described earlier indicating that microbial mineralization of the larger sediment-sorbed PAH is not a rapid process.

Varanas $i$ and Gmur (1981) and Augenfeld et a 1. (1982) followed the fate of PAH from labeled sediments into fish, and deposit feeding worms and clams. Varanasi and Gmur reported rapid uptake and metabolism of naphthalene and BP in English sole. Bu $1 \mathrm{k}$ concentration of BP in the sediment over ten days did not change although bulk concentrations of naphthalene decreased. Chromatographic analysis of sediment and pore water extracts showed that BP remained unmetabolized whereas approximate1y 7 and $14 \%$ of naphthalene activity in the sediment and pore water extracts was found as polar metabolic products. Augenfe1d at a1. (1982) reported that after 60 day exposures to sediment sorbed phenanthrene, chrysene, or BP both Macoma and Abarenicola accumulated PAH; but polar metabolic products were not detected in either organisms or sediments.

These experiments indicate that the bioavailability of PAH for uptake and metabolism is high $1 \mathrm{y}$ dependent on their individual chemical 
properties and rough $1 \mathrm{y}$ decreases with decreasing solubility. However, in some cases even the larger PAH such as BA and BP are available for accumulation and metabolism by benthic organisms. A comparison between the two microcosm experiments where BA was added to the water column (Hinga et a1., 1981; and McE1roy et a1., 1982, Appendix 1) and the experiments with labeled sediments (Herbes and Schwa11, 1978) also indicate that PAH may be differentially available, depending on the degree to which they are associated with particles.

Bffects of PAH exposure on arine organiss:

The effects of PAH on aquatic organisms have been the object of numerous investigations. The responses are highly species specific and are also dependent on factors such as life history stage, salinity, temperature, and reproductive status. The range of accute toxicities of specific $\mathrm{PAH}$ as indicated by $\mathrm{LC}_{50}$ vary from 1 ess than 10 parts per billion to greater than 1 parts per thousand (Neff, 1979). Although toxicity testing generates an easily defined endpoint, this type of investigation yields 1 ittle information on mechanisms of toxicity, or environmental ly disruptive levels.

Organisms maintain homeostasis through a variety of systems operating at all levels of biological organization from biochemical to community levels of structure. The ability of any one or combination of systems to mitigate disruption may ameliorate effects before they become evident at higher leve1s. Adverse effects of petroleum hydrocarbons have been observed at al1 levels of organization in many marine organisms (Capuzzo, 1985). Effects at one level of organization leading to demonstrable effects in a higher level of organization have been documented 
(Capuzzo et a1., 1984). Others have demonstrated saturation of an adaptive response in one system leading to disruption in other systems (Brown et a1., 1982). The time required to observe measurable effects is highly dependent on the magnitude of disruption, the sensitivity of the component under investigation and the level of biological organization studied. In general the lag time for response increases with each leve1 of organization, with effects at the biochemical and cel lular level occurring on a time course of seconds to days, while those at the population or community level occuring on a $t$ ime course of months to decades (NAS, 1971). From a predictive standpoint, investigation at the initial levels of response, such as physiological and biochemical levels, has the advantage of speed, simplicity, and the potential of indicating specific mechanisms of toxicity.

Physiological measurements of stress are confounded by the extreme variability of these indices to both intrinsic and extrinsic factors. Responses are often not dose dependent, particularly if the contaminant can be metabolized or sequestered. The effects of experimental manipulation and natural variables such as season, light, or nutritional status can often produce effects of greater magnitude than the treatment under investigation. A combination of measurements designed to evaluate the status of individuals, either integrated into a single index at one level of organization such as scope for growth (Bayne et a1., 1975), or by following energetic parameters at adjacent levels of organization (Capuzzo, 1985) might provide a less variable and better appraisal of the general response of an organism. With any of these approaches it is essential to either have very detailed information on variability of 
these indices in natural populations, or to compare responses between closed $1 y$ matched experimental and control organisms under identical conditions.

Aromatic hydrocarbons have been found to produce a variety of physiological and biochemical effects on marine organisms. (See reviews by Neff, 1979 and Capuzzo, 1985). Effects observed at the ce1lular and biochemical level include chromosomal aberrations and increased rates of sister chromatid exchange (Hooftman and Vink, 1981); induction of mixed function oxygenase activities (Stegeman, 1981, Lee, 1981); alterations in free amino acid ratios (Augenfeld et al., 1980-81); increases in 1ysosomal fragility (Moore et a1. 1978); disruption of glucose metabolism (Riley et al., 1981); changes in respiratory pigment concentrations (Crider et a 1., 1982); and reduced affinity of respiratory pigments for oxygen as we 11 as alterations in cardiac output, heart rate, and hemolymph pH (Sabourin, 1982); alterations in neurotransmitter levels (Fingerman and Short, 1983), disruptions in RNA polymerase and RNAase activities (Viarengo and Moore, 1982); changes in glycogen content (Augenfeld et a1., 1983); alterations in adenylate nucleotide pools (Ivanovici, 1980); disruption of 1ipid metabolism (Stegeman \& Sabo, 1976; Capuzzo et a1., 1984); and 1 iver hypertrophy (Fletcher et a1., 1982). Effects of petroleum hydrocarbons observed on whole animals include alterations in oxygen consumption rates (Anderson et a1, 1974; Gilfillin and Vandermeulen, 1978; Edwards, 1978; Laughlin and Neff, 1980), ammonia excretion rates (Vargo, 1981; Capuzzo and Lancaster, 1981), feeding rate (Gordon et a 1., 1978), time to metamorphosis in larval invertebrates (Capuzzo et al., 1984), growth (Hauschildt-Li11ge, 1982), and reproduc- 
tive success (Hose et al., 1982).

The sensitivity of marine worms, particularly polychaetes, to petroleum hydrocarbons appears to be quite variable. George (1971) found variations in population abundance in two species of cirratulid worms to be no different after an oil spil1, and although oil was found to depress feeding rates of Arenicola marina, populations of this worm were found existing in sediments severely impacted by an oil spil1 (Gordon et al., 1978). Nevertheless, effects of petroleum hydrocarbons on marine worms have been documented at community and population levels affecting species composition and abundance (E1mgren et a 1., 1980; Mclusky et a 1., 1980); at the whole animal levels causing increased mortality (Mohamed, 1974), reduced growth and feeding rates, and fertility (Lee et a1., 1981, Hauschildt-Li11ge, 1982; Augenfe1d,1980; Fries and Lee, 1984); and at the biochemica 1 level inhibiting activities of glycolytic enzymes such as phosphofructokinase (B 1ackstock, 1980), increasing mixed function oxygenase activity (Lee et $a 1,, 1979,1981$ ), and decreasing tissue glycogen (Augenfeld et a1., 1983) and alanine concentrations while increasing tissue lipid concentrations (Carr and Neff, 1984). Toxicities of water soluble fractions of several test oils to different species of worms is highly species specific ranging by over one order of magnitude (Carr and Reish, 1977), with refined oils being generally more toxic than crude oils (Rossi et a 1., 1976).

\section{Problems of experimental design}

Many of the studies mentioned above either documented effects on endemic populations in environments contaminated with hydrocarbons or have measured responses of individual organisms to water soluble oil 
fractions. In either case the mixture of chemicals present is large and complex. Detailed chemical analysis of the mixtures to show how they may change over the duration of the experiment is often not conducted, so actual exposure concentrations and accumulated concentrations are not precisely known. In addition to adequate chemical characterization in laboratory studies, it is also important to maintain and test organisms in an environment that simulates as closely as possible natural physical and chemical conditions. For instance, when investigating the response of burrowing organisms to a sediment associated compound it is important to study the organism in a system containing sediment. DeWild (1973), Vernberg (1977), and Pamatmat (1982) have all reported differences in metabolic rates of burrowing organisms depending on whether or not sediment was available. Accumulation of and responses to chemical contaminants by burrowing organisms has also been shown to be affected by the presence or absence of sediment (Pesch \& Morgan, 1978; Fowler et al., 1978). The maintenance of water quality is another important variable requiring consideration. Depletion of oxygen and build up of excretory products in static bioassay systems can affect physiological parameters. (Prosser, 1973). Higher basal metabolic rates have been reported for a mysid shrimp depending on whether a static or flow through experimental system was used (Smith and Hargrave, 1984).

\section{Scope of thesis research:}

Previous investigations have clearly demonstrated that PAH in the benthic environment are influenced by an interactive collage of physical, chemical, and biological process. Of the many processes involved, metabolic transformation of $\mathrm{PAH}$ is one that has only begun to be investigated 
on an environmental scale. The numerous investigations on the effects of PAH on benthic organisms have documented a myriad of effects, although the results are so varied, it is difficult to make meaningful generalizations. In reading the 1 iterature, the lack of investigations of realistic exposures to a chemical1y we 11 -characterized contaminant is apparent. The goal of the thesis research described here was to investigate both the fates and effects of $\mathrm{PAH}$ in the benthos. An interdisciplinary approach was used, focusing on interactions between benthic organisms and PAH in the benthic environment. Emphasis was placed on the role of metabolic transformations, bioavailability from different sources, and subletha1 effects on infaunal organisms. Due to the interactive nature of these processes, it was decided that from an environmental perspective they could not be studied in isolation. Attempting to investigate so many different processes in one system limited the resolution possible for analysis of any one process. Nevertheless, the results from this investigation of BA, a model hydrophobic pollutant compound, in an intact benthic system, support the validity of this approach, and contribute to the understanding of the fate of $\mathrm{PAH}$ in the marine environment, and anima $1 /$ sediment/chemical interactions.

The presentation of this thesis was organized to minimize repetition, while logically separating the results into managible units for easy reading. The introduction provides a brief backround to the relevant literature. The second chapter describes the experimental approach and analytical methods. This investigation involved five major experiments. Portions of the results from all experiments are divided between the next three chapters: (3) the fate of BA in the system; (4) in vivo 
metabolism of BA by the polychaete Nereis virens; and (5) the physiological effects of BA exposure on Nereis. Chapter 6 summarizes the entire investigation. The results of a previous investigation on the fate of $\mathrm{BA}$ in a large recirculating benthic microcosm conducted by our laboratory are presented in Appendix 1. 
CHAPTER 2:

EXPER IMBRTTAI. APPROACH

\section{Experimenta 1 system:}

The experimental design of this study was directed to simultaneously measure both the fates and effects of a higher molecular weight (>3 rings; Neff, 1979) PAH in a model benthic system. In order to carry out a multidisciplinary study of a system as complex as the benthos, investigation was centered on a single $\mathrm{PAH}$, benz(a)anthracene (BA), and a single benthic organism, the polychaete Nereis virens. BA was chosen as a representative $\mathrm{PAH}$ because, due to its low water solubility it is thought to be primarily associated with particles. Although BA is classified as a known mutagen (Ames, 1972), not much is known of its in vivo metabolism or sublethal effects in marine organisms. Radioisotopes were used to allow construction of a complete budget for tota 1 BA and BA metabolites. Nereis virens was chosen as a representative infaunal organism because it is omnivorous, relatively large and hardy, its life history and physiology are relatively we 11 known, and it has been shown to possess the MFo system necessary for PAH metabolism (Lee et a l., 1979).

An attempt was made to design an experimental system that would provide a realistic benthic environment from the standpoint of both the biology of Nereis and the geochemistry of BA. A flow-through system was used to mimic the real flow regime in the near-shore benthos by providing a constant supply of oxygenated water to the worms and removing worm metabolic products. Natural sediments were used since attempting to duplicate the physical and chemical characteristics of sediment, such as grain size, organic carbon content, and surface properties that affect both biological and geochemical processes, would have been very diffi- 
cult.

The benthos receives contaminant inputs from a variety of sources including the bulk sediment reservoir, the water column, and large objects such as detritus and animal carcasses that may be deposited. In an attempt to study how bioavailability is affected by source, BA was introduced in three ways: (1) already bound to sediment, simulateing input from dumping activity; (2) directly into the water column, sinulating input from urban run-off or spilled oil; and (3) as labeled food, simulating input from organisms or detritus contaminated with PAH acquired elsewhere. A11 of these exposure senarios were directed toward understanding the fate of $\mathrm{BA}$ in the subtidal benthos. Factors which might be important to the fate of $\mathrm{BA}$ in intertidal or sha1 low benthic environments such as photoxidation, turbulence, or tidal pumping were not considered. PAH are not known to be acutely toxic at concentrations present in most environments. Because this study was aimed at sublethal effects of PAH exposure and at PAH metabolism, a multilevel bioenergetic approach was used to monitor the physiological effects of BA exposure. Animal bioenergetics are known to be affected by exposure to oil (Capuzzo, 1985). Energy is a common currency used at all levels of organization in an organism, thus it is reasonable to consider that disruption in the bioenergetics at one level may precede disruption at the next level.

A schematic of the exposure chamber developed for these experiments is shown in Figure 2.1. This chamber was designed with two purposes in mind: (1) measurement of whole chamber metabolic rate and (2) measurement of the concentration of $B A$ and $B A$ metabolites in the sediment, worms, and water column. Each chamber enclosed a total volume of two liters. In 


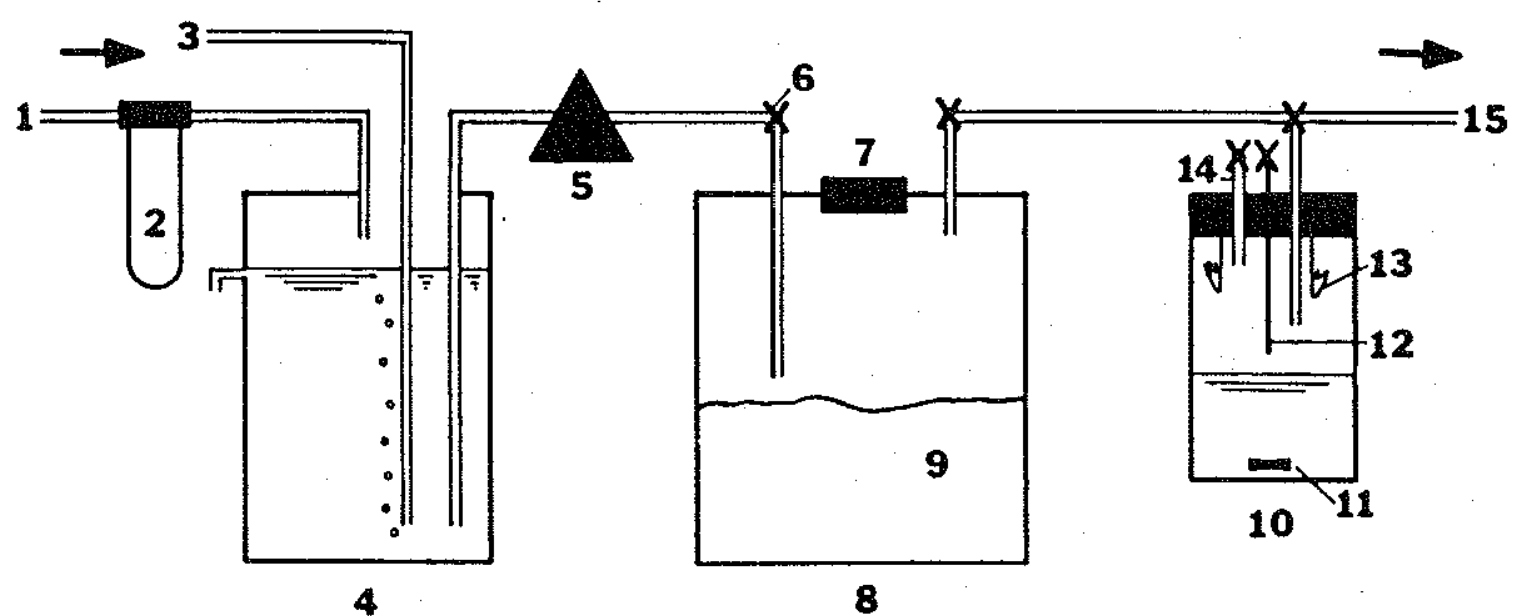

Figure 2.1: Schematic diagran of experimental system. 1. seawater inlet; 2. 1 um honeycomb filter; 3. air 1 ine; 4. seawater reservoir; 5. peristaltic pump; 6. 3-way stopcock; 7. silicon stopper; 8. exposure chamber; 9. sediment; $10 . \mathrm{CO}_{2}$ trapping chamber; 11 . magnetic stirring bar; 12. acid injection port; 13. wicks to collect $\mathrm{Co}_{2} ; 13$. vent; 15 . waste out let.I 
most experiments the chambers contained 450 grams dry weight ( $g d w)$ of sediment with a water column of 1.4 liters (1) of seawater. The system was composed almost entirely of glass to minimize sorption of organic compounds and was designed to be both gas and water tight. Silicon rubber was used for tubing connections and the central stopper, and plastic 3-way stopcocks were used to take samples from the in let and out let ports. Chambers were held together by two plexiglass rings connected by 4 threaded rods which sandwiched the chamber top to the bottom, a small silicon rubber gasket forming the seal.

A11 chambers received water from a common head tank of filtered seawater maintained at saturated oxygen tensions with vigorous air bubbling. A constant flow of water was driven by peristaltic pumps (Harvard, Mode 1203 in experiment 1 and 2 and Cole Palmer Masterflex Model 7508 in experiments 3-5). Water entered the chambers near the sediment surface and exited near the top to provide good mixing. Chamber effluent could either be collected for sampling, diverted into a $\mathrm{CO}_{2}$ trapping chamber, or discarded. The entire experimental system was enclosed in a temperature controlled room maintained at $14^{\circ} \mathrm{C}$ and $\mathrm{i} 11 \mathrm{umin-}$ ated continuously by red 1 ight.

Standard experimental design included nine chambers run simultaneous $1 \mathrm{y}$, allowing for three different treatment regimes with three replicate chambers for each treatment. One set of chambers contained worms not exposed to $B A$, the second contained worms exposed to $B A$, and the third received $B A$ but did not contain any worms. This design al lowed comparisons to be made between the effects of $B A$ on the worms and the effects of the presence of worms on the distribution of $B A$ in the system. 
The only exception to this general plan was in the experiment with BA labeled food (exp. 5). Since this was a feeding experiment, chambers without worms were not run in favor of having additional chambers for replication of control and exposed groups.

Natural sediments were collected with a $0.1 \mathrm{~m}$ Van Veen grab sampler from a depth of 10 meters in Buzzards Bay, MA $\left(41^{\circ} 32^{\circ} 2^{\prime \prime} \mathrm{N}, 70^{\circ} 45^{\circ} 05^{\prime \prime} \mathrm{W}\right)$ and stored frozen until use. These sediments contained $2 \%$ organic carbon (Perkin-Elmer CHN Elemental Analyzer Mode 1240 ) and were composed of $8.5 \%$ sand and $91.5 \%$ silt and clay sized particles (determined by wet sieving). Before each experiment sediments were thawed and rinsed with seawater filtered to 1 um. The sediment-seawater slurry was homogeneous in appearance without any visible impurities. After thawing sediments were kept cold until introduction into experimental chambers.

Nereis virens were obtained from the Back River Estuary in Boothbay, ME. This is a relatively unpolluted area with $30 \%$ salinity water and sediment of a grain size similar to that of the sediment used in these experiments. Worms were maintained at the Environmental Systems Laboratory (ESL) in a flow-through seawater system containing natural sediment. In addition to sediment, the worms were fed either minced Mytilus edulis tissue (exp. 1-3) or a formulated diet (Leavitt, 1985) which was supplemented with $20 \%$ Mytilus edulis tissue. Prior to use in an experiment, worms were acclimated at the experimental temperature of $14^{\circ} \mathrm{C}$ for at least one week.

In experiments with sediment-sorbed BA, labeled or control sediments were added to the chambers and allowed to settle before initiation of flow. Approximately 8 hours later, initial cores were taken and the 
worms added. During al 1 experiments water samples were collected at regular intervals for determination of oxygen and ammonia concentrations, and for extraction of total $\mathrm{BA}$, and ${ }^{14} \mathrm{CO}_{2}$. At the end of the experiment (and also near the middle in the month-long sediment exposure experiment) cores were taken, and then worms were gently teased out of the sediment. The experimental plan was modified slightly for experiment 4 where BA was introduced direct $1 y$ into the water column, and in experiment 5 where BA was introduced as 1 abeled food. In experiment 4, after the BA spike was introduced, output from the chambers was diverted back into the chambers to conserve isotope. After isotope addition, water was pumped over the sediment surface for 2 day during which radioactivity in the water column was monitored. At this point, the worms were added and 8 hours later the chambers were switched back to the normal flow-through mode to avoid hypoxia and/or high ammonia concentrations. In the feeding experiment (exp. 5) worms were added and oxygen consumption and ammonia production rates were measured for two days prior to food introduction.

The exposures used in this study were of relatively short duration covering periods of days to weeks. The experiments were set up in this way to focus on metabolism of $B A$ and the initial effects of subletha 1 exposure on worm bioenergetics. Previous work by Malins and his coworkers on in vivo $\mathrm{PAH}$ metabolism in $\mathrm{fish}$ and invertebrates indicated that the process is rapid, occurring on a time course of hours to days (Varanasi and Malins, 1977). Previous work in our laboratory, looking at the fate of BA introduced into the water column of a large benthic recirculating chamber, showed substantial metabolism of $\mathrm{BA}$ in a period of days to weeks (McElroy et al., 1982; Appendix 1). 


\section{Ana 1ytica 1 methods:}

\section{Chericals :}

BA was purchased from Aldrich Chemical Co., Milwaukee, WI, and ${ }^{14} \mathrm{C}-$ $\mathrm{BA}$ and ${ }^{3} \mathrm{H}-\mathrm{BP}$ from Amersham-Searle, Skokie, II. Authentic standards for BA and BP metabolites were provided by Dr. David Longfellow at the Nationa 1 Cancer Institute. Aquaso 1, Protoso1, phenethylamine, and Countoff were obtained from New England Nuclear, Boston, MA and Scintiverse II from Fisher Scientific. A11 other chemicals and enzymes were obtained from Sigma Chemical Co. All solvents were obtained from Burdick and Jackson.

\section{Glassware:}

A1 1 glassware and equipment used in these experiments was washed using standard laboratory procedures. In addition, all glassware used for $B A$ analysis was solvent rinsed with two rinses with methanol followed by two rinses with chloroform. Glassware used for biochemical analyses was soaked in $10 \%$ hydrochloric acid after washing and rinsed again in distilled water. After use with radioisotopes all glassware was soaked overnight in a $2 \%$ solution of Count-off, rinsed and cleaned as described above.

\section{Light:}

In order to focus only on the biochemical transformations of BA in these experiments it was necessary to avoid photooxidation. Consequently, the experiments, and all analyses involving samples used for metabo1 ite determination were carried out under red 1 ight.

\section{Quantification:}

Total BA concentration was calculated using the specific activity of 
isotope used in each experiment and the extraction efficiencies determined empirically for each type of analysis. Extraction efficiencies were based on recovery of knwon amounts of isotope added to unlabeled samples. $\left[{ }^{14} \mathrm{C}\right]$ activity was quantified in all samples by liquid scintillation counting (LSC) using a Beckman LS100-C counter and either Aquasol or Scintiverse II as scintillants. Counting efficiencies were determined using either ${ }^{3} \mathrm{H}$ - or ${ }^{14} \mathrm{C}$-toluene as internal standards. Unless indicated otherwise, all data are presented as the mean \pm the standard error. Statistical analyses employed ( $\mathrm{Zar}, 1984$ ) are described in either in the text or in figure legends. When necessary, data were transformed to either reduce the variance or approximate a normal distribution prior to using parametric statistics. The significance level required to demonstrate a statistical difference between means was 0.05 .

Dosing :

$\left[12-{ }^{14} \mathrm{C}\right]$ Benz(a) anthracene of specific activity $49 \mathrm{mCi} / \mathrm{mMo} 1$ was obtained in sealed $100 \mathrm{uCi}$ ampules. A fresh ampule was used for each experiment. The isotope spiking solution was made up in a carrier of acetonitrile and unlabeled BA. Specific activities of the spiking solutions used in each experiment were $4.60 \times 10^{-3}, 4.67 \times 10^{-3}, 4.76 \times 10^{-3}$, $3.61 \times 10^{-2}$, and $2.15 \times 10^{-1} \mathrm{uCi} / \mathrm{ug} \mathrm{BA}$ in experiments $1-5$ respective $1 \mathrm{y}$. Prior to dosing, each spike mixture was chromatographed on HPLC (See section 3.10 for analys is conditions.) to assure purity of $\geq 98 \%$. If the spike mixture did not meet these specifications it was purified using Sep-Pak (Waters Assoc.) cartridges following the procedure out lined in Figure 2.2. Once purity was assured the spiking mixture was used to dose the chambers as described below. 
Figure 2.2

ISOTOPE PURIFICATION USING WATERS SEP-PAK GARTRIDGES

\author{
Dry isotope under $\mathrm{N}_{2}$ \\ Rinse $\mathrm{C}_{18}$ Sep-Pak with $10 \mathrm{~m} 1 \mathrm{Hx}$ \\ Transfer isotope to Sep-Pak in $\leq 2 \mathrm{~m} 1 \mathrm{Hx}$

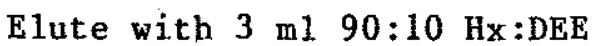 \\ Dry under $\mathrm{N}_{2}$
}

Check purity on BPLC if $\leq 98 \%$ continue

Rinse silica Sep-Pak with $10 \mathrm{~m} 1 \mathrm{Hx}$

Activate with $2.0 \mathrm{~m}^{1} \mathrm{H}_{2} \mathrm{O}$

Deactivate with $1: 1 \mathrm{MeOH}: \mathrm{H}_{2} \mathrm{O}$

Transfer isotope to Sep-Pak in 53:27:20 MeOH:EtOH : $\mathrm{H}_{2} \mathrm{O}$

Elute with $3 \mathrm{ml} \mathrm{Hx}$

Dry with $\mathrm{Na}_{2} \mathrm{SO}_{4}$

Check purity on HPLC 


\section{Sediwent spiking:}

The sediment labeling method was adapted from methods of Karickhoff (1980), and was designed to minimize microbial oxidation and maximize binding of BA to sediment particles. Three equal portions of washed sediments were placed into gallon glass jars and diluted with filtered seawater to form a slurry which was approximately $50 \%$ seawater and $50 \%$ sediment. Two jars each received a solution containing BA in acetonitrile. A third jar received an equal volume of uncontaminated acetonitrile. The jars were sealed, shaken vigorously by hand then strapped onto a rotary shaking table. Jars of sediment were continuously mixed on the shaking table for at least 24 hours at $4^{\circ} \mathrm{C}$, interupted periodica $11 \mathrm{y}$ by vigorous hand shaking to resuspend all sediment. After the equilibration period the labeling solution was removed from the sediment by centrifugation $\left(500 \mathrm{~g}, 5 \mathrm{~min}, 4^{\circ} \mathrm{C}\right)$ and the sediment resuspended in clean filtered seawater. Direct counts of the labeling solution after sediment removal indicated that less than $1 \%$ of the isotope added remained in solution. The contents of' each galion jar were then split equally between three replicate chambers. After the sediment settled, flow was initiated and the experiment started 10 to 20 hours 1 ater. In three separate sediment dosing experiments $(1,2, * 3)$ this sediment 1 abeling procedure resulted in $B A$ concentrations in the sediment at the beginning of each experiment of $7.93 \pm .51,8.61 \pm 1.46$, and $6.23 \pm .24 \mathrm{ug} / \mathrm{gdw} \mathrm{respec}-$ tively.

\section{Water column spiking:}

Just prior to spike introduction, chambers containing washed sediment were switched from flow-through to a recycling mode, where chamber 
effluent was pumped directly back into the chamber. Each chamber received either $2.0 \mathrm{ml}$ of a spiking solution containing BA in acetonitrile or $2.0 \mathrm{ml}$ of acetonitrile alone. Water samples were taken at regular intervals to follow the course of $B A$ removal from the water column for the next two days. After 47 hours sma11 sediment samples were taken with a Pasteur pipette and counted to ensure that isotope from the water column had settled out on the sediment surface. Worms were then added to each chamber, and flow switched from recycle mode to flow-through mode eight hours later, purging BA remaining in the water column.

Preparation of MA labeled food:

$\left[{ }^{14} \mathrm{C}\right]$ Benz(a)anthracene was incorporated into a formulated diet containing lyophilized Mytilus edulis soft tissue. Two batches of the diet, each sufficient to yield 20 individual portions were prepared using the following ingredients:

$1.69 \mathrm{ml}$ water

$0.66 \mathrm{~g}$ gelatin

$0.19 \mathrm{~g}$ freeze dried Mytilus powder $0.094 \mathrm{~g}$ cod 1 iver oil

90 u1 hexane (with or without ${ }^{14} \mathrm{C}-\mathrm{BA}$ ).

Cod liver oil was placed in a sma 11 aluminum weighing pan and either hexane (for the control diet) or the BA spike in hexane (for the labeled diet) was mixed in. Next the dried Mytilus and the gelatin were mixed together and mixed into the cod liver oil. The water (heated to steaming) was then quickly stirred into the mixture and the pan heated to $100^{\circ} \mathrm{C}$ for a few seconds until the gelatin dissolved. The pan was immediately placed on ice as soon as the gelatin melted.

This procedure produced a circular slab of food approximately $6 \mathrm{~cm}$ in diameter and $1 \mathrm{~mm}$ thick with an elastic consistency. The slab was cut 
into pieces which weighed $102.3 \pm 4.2 \mathrm{mg}$ each. Three extra pieces of labeled food not used in the experiment were extracted according to the methods out 1 ined in Figure 2.3. The concentration of BA in the extracted food was $17.8 \pm 0.9 \mathrm{ug} / \mathrm{gdw}$, representing $84.0 \%$ of the 1 abe 1 added; $98.5 \%$ of activity was recovered in the organic extract, $0.2 \%$ in the aqueous extract, and $1.3 \%$ in the aqueous precipitate (See section 3.12 for explanation of extraction protoco 1). HPLC analysis of the organic extract of the 1 abeled food showed that $>98 \%$ of labe 1 was present as unaltered BA (Figure 2.4).

\section{Worm veights:}

Wet weight of individual worms was taken just prior to placing them in exposure chambers at the beginning of each experiment and just after removal at the end of each experiment. Worms were removed from sediment by gently stirring the sediment until they swam to the surface where they could be retrieved without damage and placed in a beaker of seawater. After being blotted quickly, worms were weighed to the nearest $\mathrm{mg}$ on a Cahn Mode 1 TA4100 balance.

In calculations involving worm weights, the starting weight of worms was used in the week-long experiments where worm weight did not change, (exp. 1,2,4,5). For the month-1ong experiment (exp. 2), where worms lost weight, daily weights were calculated from the total weight loss assuming a linear decline. When necessary, dry weights were calculated from wet weights using a linear regression of wet and dry weights taken for a group of control worms shown in Figure 2.5.

Oxygen consumption and ammonia production:

Oxygen consumption and ammonia production were calculated by differ- 
Figure 2.3

\section{EXTRACTION OF BENZ(a)ARTHRACENE IAABLED TOOD}

Add $0.8 \mathrm{ml}$ of steaming $\mathrm{H}_{2} \mathrm{O}$ to sample maintained at $50^{\circ} \mathrm{C}$

$$
\text { Stir to dissolve }
$$

Rinse spatula with $2 \times 1 \mathrm{~m} 1$ hot $\mathrm{MeOH}$

\section{Vortex}

Add $1 \mathrm{~m} 1 \mathrm{CHCl}_{3}$

Shake we 11 , sonicate $10 \mathrm{~min}$

Add $1 \mathrm{ml} \mathrm{H}_{2} \mathrm{O}$ and $1 \mathrm{~m} 1 \mathrm{CHCl}_{3}$

Shake we11, sonicate $10 \mathrm{~min}$

Centrifuge $5 \mathrm{~min}$ low speed

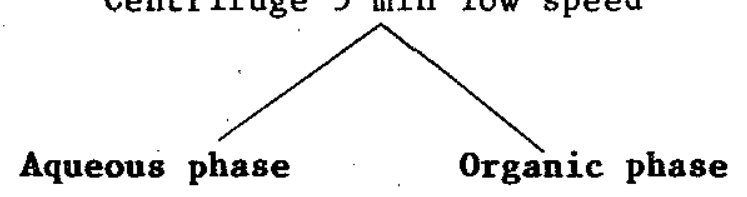

Add $2 \mathrm{ml} \mathrm{CHCl}_{3}$

Stir $5 \mathrm{~min}$ at $50^{\circ} \mathrm{C}$

Sonicate $5 \mathrm{~min}$

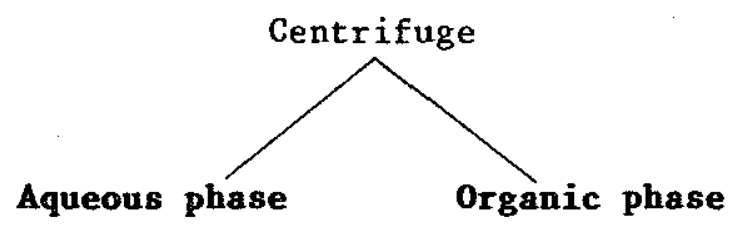

LSC

Combine organic phases

Dry with $\mathrm{NaSO}_{4}$

HPLC and LSC 


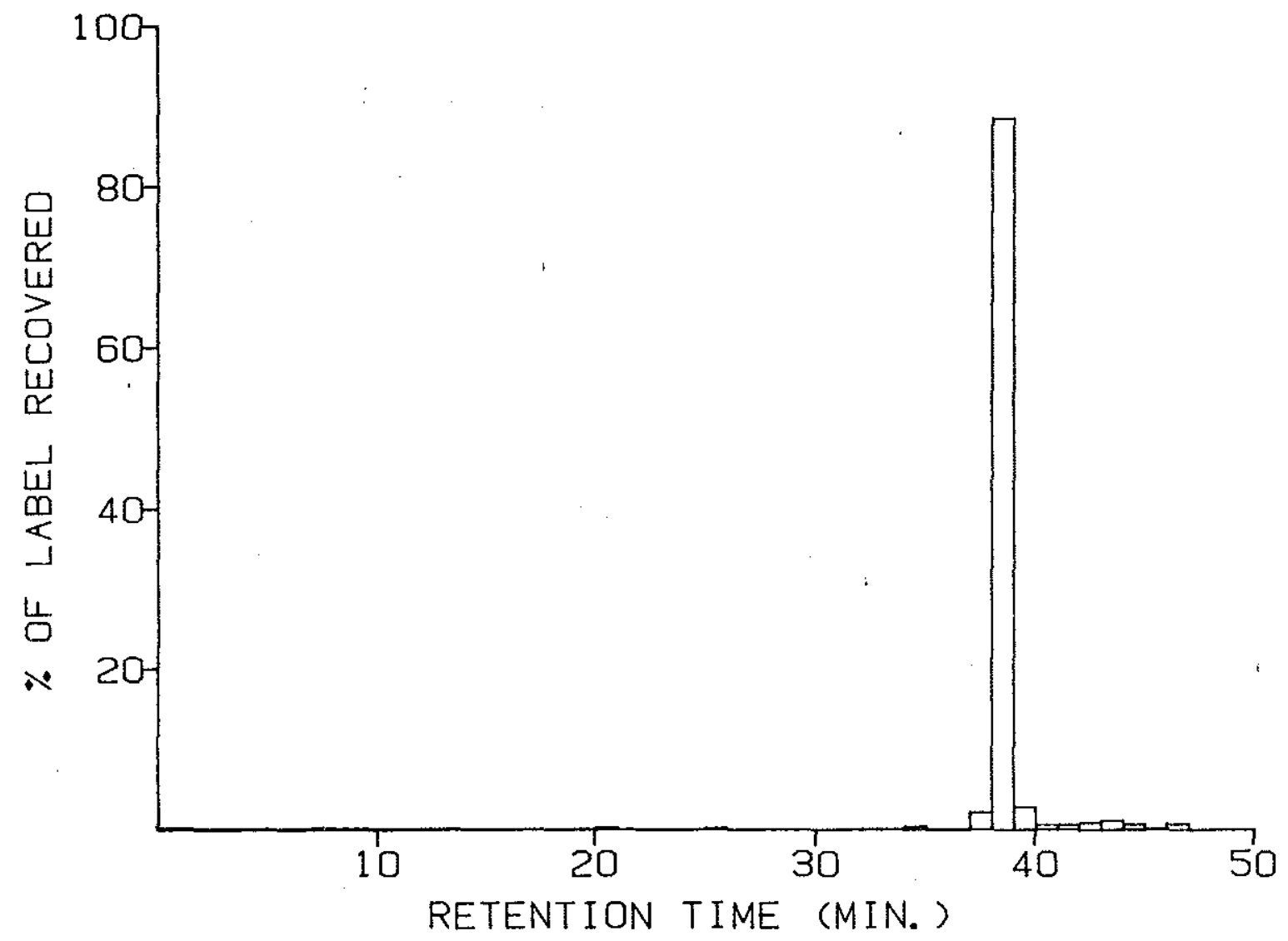

Figure 2.4: ${ }^{14} \mathrm{C}$ HPIC chromatogram of BA labeled food. 


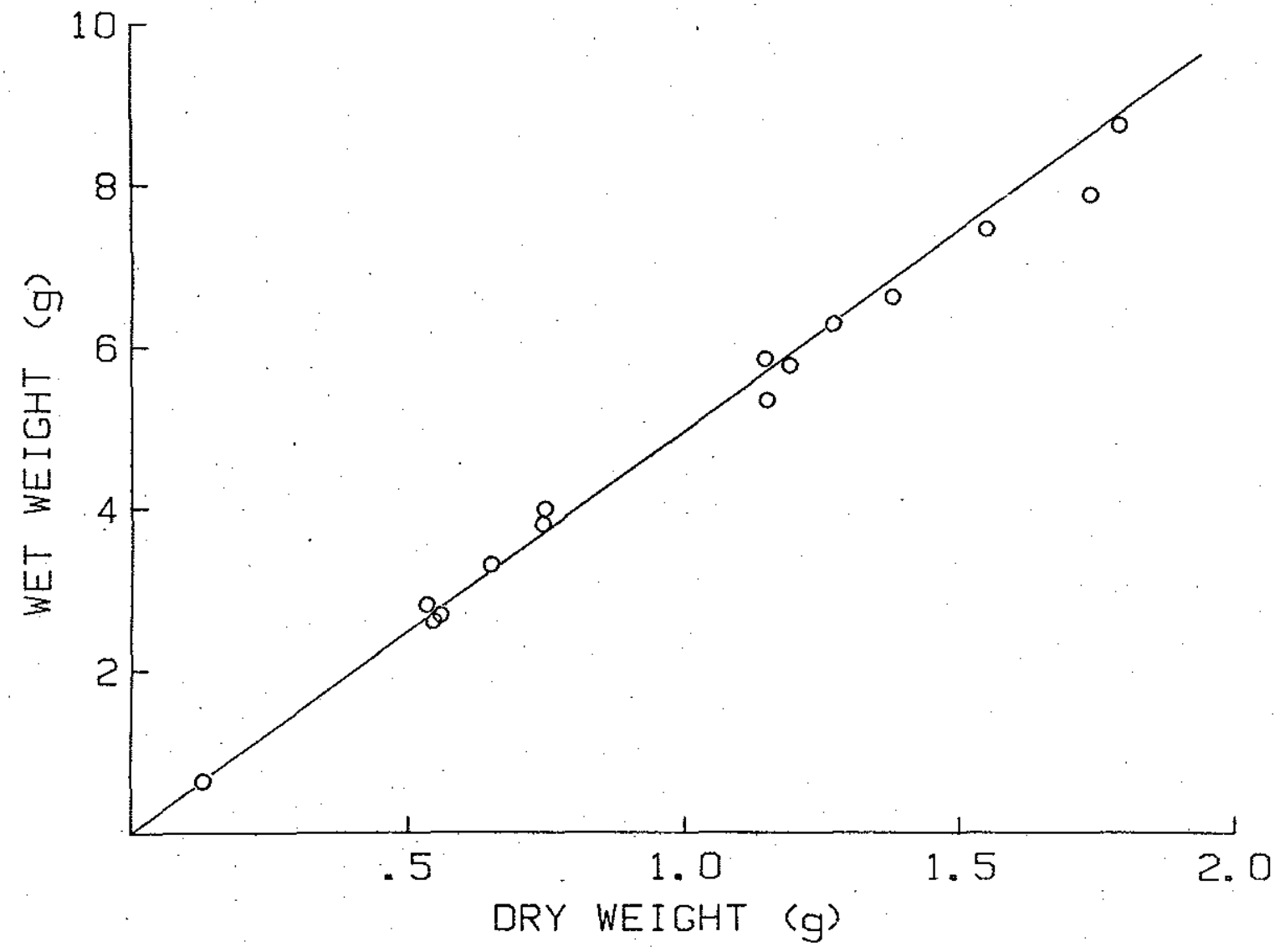

Figure 2.5: Wet weight/dry weight linear regression for Nereis virens 
ence from concentrations in water entering and leaving the chambers. Residence time of water in the chambers was maintained at 2 to 2.3 hours. Each chamber contained 4 worms. No attempt was made to correct for nonworm metabolic activity in the chambers. Although metabolic measurements were made on chambers without worms, due to the absence of irrigated burrows these were not considered to be valid controls for non-worm metabolism. Comparisons between rates in control chambers and chambers receiving $B A$ are made assuming that $B A$ had no measurable effect on nicrobial metabolism. Although it would have been best to test this assumption directly, several factors suggest that the assumption is reasonable. Bacteria cannot use larger PAH such as BA as a sole carbon source, (Gibson, 1976), therefore extensive metabolism of the molecule is needed before easily metabolizable fragments are produced. Especially considering the relatively abundant source of carbon already in these sediments, it is unlikely that cometabolism of BA would support increased microbial activity (Perry, 1979). In addition, low and consistent rates of microbial mineralization of BA observed in the 25 day experiment with sediment-sorbed BA (See Chpater 3) suggest that the presence of BA alone was not responsible for stimulation of microbial activity sufficent to make a measureable impact on whole chamber respiration.

Samples were taken at the same time each day to minimize any diel periodicity in activity. This was probably unnecessary, because in one experiment, measurements of oxygen consumption and ammonia production taken every two hours for 28 hours showed no pronounced die 1 patterns (Figure 2.6). This observation is supported by previous work, by Scott (1976) who found no periodic diel fluctuations in Nereis virens respira- 
Figure 2.6: Diurnal cycle of whole chamber oxygen consumption and ammonia production. Values represent single measurements on one chamber over time. Circles represent control chambers. Triangles represent chambers with BA. Multiple values at one time point show range for all replicate chambers at that time. 

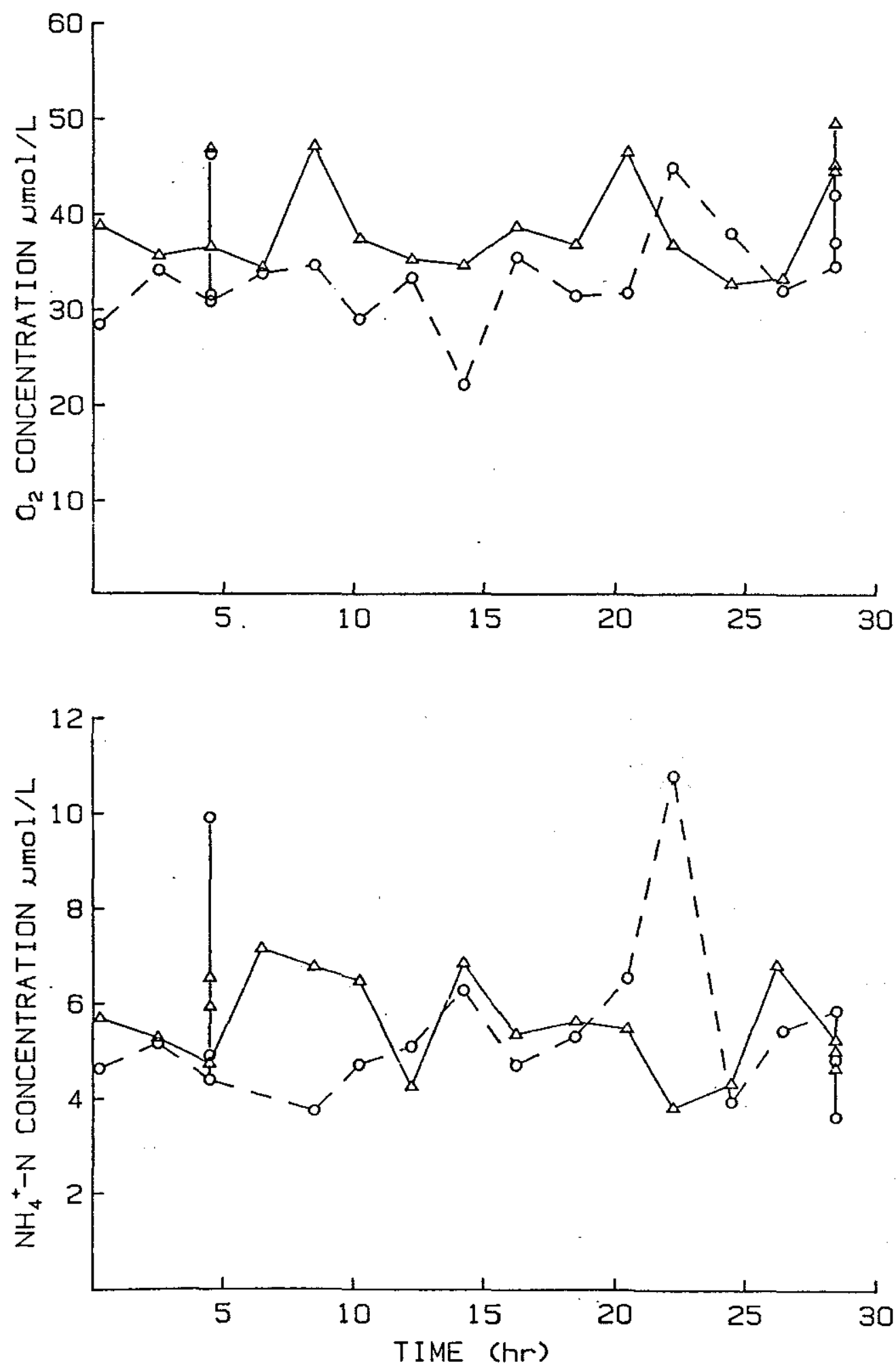
tion when worms were kept under constant illumination or darkness.

$0: N$ ratios (the atomic ratio of oxygen consumed to nitrogen produced) were calculated from measured oxygen consumption and ammonia excretion rates. Ammonia has been shown to be the primary excretory product of marine polychaetes (Hult, 1969; $0^{\circ}$ Malley and Terwilliger, 1975). In addition to ammonia analysis, total nitrogen was analyzed in one set of samples using persulfate oxidation at $110^{\circ} \mathrm{C}$ (Grassholff, 1976) followed by standard analysis on a Technicon autoanalyzer. The variation between duplicate samples was large; however, the results indicated that $73 \pm 14 \%$ of total nitrogen in the chamber effluent was in the form of ammonia.

Water samples were drawn from the inlet and outlet ports of the chambers into glass syringes that were immediately capped and placed on ice until analysed. Dissolved oxygen was measured using a polarographic oxygen electrode (Radiometer Copenhangen E5046 $\mathrm{pO}_{2}$ electrode with either a Radiometer PHA930 $\mathrm{O}_{2}$ analyzer or a Strathkelvin $781 \mathrm{~b} \mathrm{O}_{2}$ meter) housed in a temperature controlled water jacket maintained at the same temperature as the exposure system. The electrode was calibrated between zero and $100 \%$ saturation using a zeroing solution (Radiometer) and $14^{\circ} \mathrm{C}$ seawater made saturated by sparging with air for 30 minutes. Measurements were made on each sample until readings stabilized at \pm .05 ppm. Although measurements for each chamber were usually made on single samples, duplicate samples taken periodically had an average coefficient of variation of $1.26 \%$ Since al1 chambers received water from a common source, oxygen concentration was measured on $1 y$ in three randomly picked in 1 et ports and the average of these measurements was used to calculate the 
oxygen consumption measured in samples taken at the out let ports of each chamber.

Ammonia was measured as $\mathrm{NH}_{4}{ }^{+}-\mathrm{N}$ using the methods of solorzano (1969). Water samples were collected at the same time as those for dissolved oxygen. Because of its low ammonia content, water in the head tank feeding the chamber was used for analytical blanks and to dilute ammonium chloride standards for calibration. Therefore, ammonia concentration in the water entering the chambers was taken to be zero. Ammonia concentration was routinely deternined from a single analysis of a single sample from each chamber. However, duplicate analyses of single samples, and duplicate samples taken from individual chambers periodically indicated that the average coefficient of variation between duplicate ana1yses and duplicate samples was $2.65 \%$ and $3.30 \%$, respectively.

Oxygen consumption and ammonia production rates were calculated from the difference in concentration between water entering and leaving the chambers multiplied by the volume of the water column in the chambers divided by the residence time of water in the chambers. Calculated rates were then normalized to the wet weight of worms in each chamber.

\section{BA mineralization to carbon dioxide:}

Dissolved $\mathrm{CO}_{2}$ was stripped from $250 \mathrm{~m} 1$ water samples collected directly into traps as pictured in Figure 2.1. The traps contained 0.5 ml of saturated potassium hydroxide which kept the pH of the sample above 10 to prevent $\mathrm{CO}_{2}$ loss during collection; two trapping wicks each containing $0.3 \mathrm{~m} 1$ of a quaternary amine as a trapping agent; and a stirring bar. Protosol was used as a trapping agent in experiments 1-2, and phenethylamine was used in experiments 3-5. After water collection the 
traps were sealed, acidified with sulfuric acid to a pH less than 2, and stirred for 14 to 24 hours. The only exception to this was in experiment 1 where the traps were stirred for only 12 hours. Carbon 14 activity in carbonate collected on the wicks was then quantified by LSC after neutralization with Tris buffer and the addition of a small amount of water.

Extraction efficiency of the $\mathrm{CO}_{2}$ stripping procedure determined using ${ }^{14} \mathrm{C}$ labeled bicarbonate was $54.0 \%$ using Protosol and $86.6 \%$ using phenethylamine as trapping agents. Chemica1- or photo-oxidation of dissolved BA in water samples during the stripping procedure would lead to overestimation of BA mineralization. This possibility was assessed by running the extraction on seawater spiked with ${ }^{14} \mathrm{C}-\mathrm{BA}$. $8.33 \%$ of the total $\mathrm{BA}$ concentration in seawater could be liberated to $\mathrm{CO}_{2}$ using the procedure out lined above. To avoid overestimation of BA nineralization due to this analytical problem, in cases where measurable amounts of BA were found in the water colum, the concentration of ${ }^{14} \mathrm{CO}_{2}$ measured was reduced by a factor of 0.0833 times the concentration of BA observed in at that time in water samples.

Total ${ }^{14} \mathrm{C}$ activity in the water column:

Total concentration of BA (parent plus metabolic products) was determined by several different methods. The standard procedure involved concentrating a 50 to $600 \mathrm{ml}$ water sample on a $\mathrm{C}_{18}$ Sep-Pak (Waters Assoc.) cartridge, eluting the sample with $10 \mathrm{ml}$ of acetonitrile, reducing the volume by evaporation, and quantification by LSC. In the first experiment, water samples were extracted twice with $25 \mathrm{ml}$ of ethyl acetate, the volume of the extract reduced by evaporation, and activity quantified by LSc. In the third and fourth experiments, in addition to 
the Sep-Pak method, $750 \mathrm{ml}$ samples were extracted two times each with 20 $\mathrm{m} 1$ of chloroform and a 1:1 mixture of methanol/chloroform. BA metabolites present in some of these extracts were analyzed using HPLC as described below. In the fourth experiment, activity was initially high enough to allow direct quantification of unextracted samples by LSC. A comparison of the various methods used is shown in Table 2.1. Solvent extraction of large volume samples gave the best estimate of total activity and was comparable to results obtained with direct counting of unextracted samples. The Sep-Pak method underestimated total activity by a factor of $1.81 \pm .22$. Unfortunate $1 y$, due to the low activity of most water samples and the limitations on doing many replicate large volume extractions, it was necessary to use the Sep-Pak method for routine analysis, and correct flux measurements for the low efficiency of extraction.

Adenylate nucleotide poo1s in individual worms:

Methods for adenylate nucleotide extraction were adapted from those of Karl and Holm-Hansen (1978) and Walsh and Somero (1981). After the worms were weighed at the end of the experiment, a cross-sectional piece of worm tissue containing approximately 3 segments and having an average weight of $0.5 \mathrm{~g}$ was quickly removed from just behind the pharynx and freeze-clamped clamped in liquid nitrogen cooled tongs. Time elapsed between tissue removal and clamping was less than 5 seconds. The frozen tissue was homogenized in liquid nitrogen cooled mortars with 3.0 m1 of ice-cold $0.6 \mathrm{~N}$ sulfuric acid. After thawing at $0^{\circ} \mathrm{C}$ the precipitate was removed by centrifugation for 30 minutes at $3000 \mathrm{~g}$ at $4^{\circ} \mathrm{C}$, and duplicate $1.0 \mathrm{ml}$ a liquots of the extract neutralized with $0.5 \mathrm{ml}$ of $1.2 \mathrm{~N}$ sodium hydroxide and buffered with $1.5 \mathrm{ml}$ of a solution containing 12 mM EDTA 
Table 2.J.

\section{COMPARISON OF DIFYEREMT METHODS FOR QUANTIFYIRG TOTAL \\ 14 C ACTIVITY IF WATER SAMPLES}

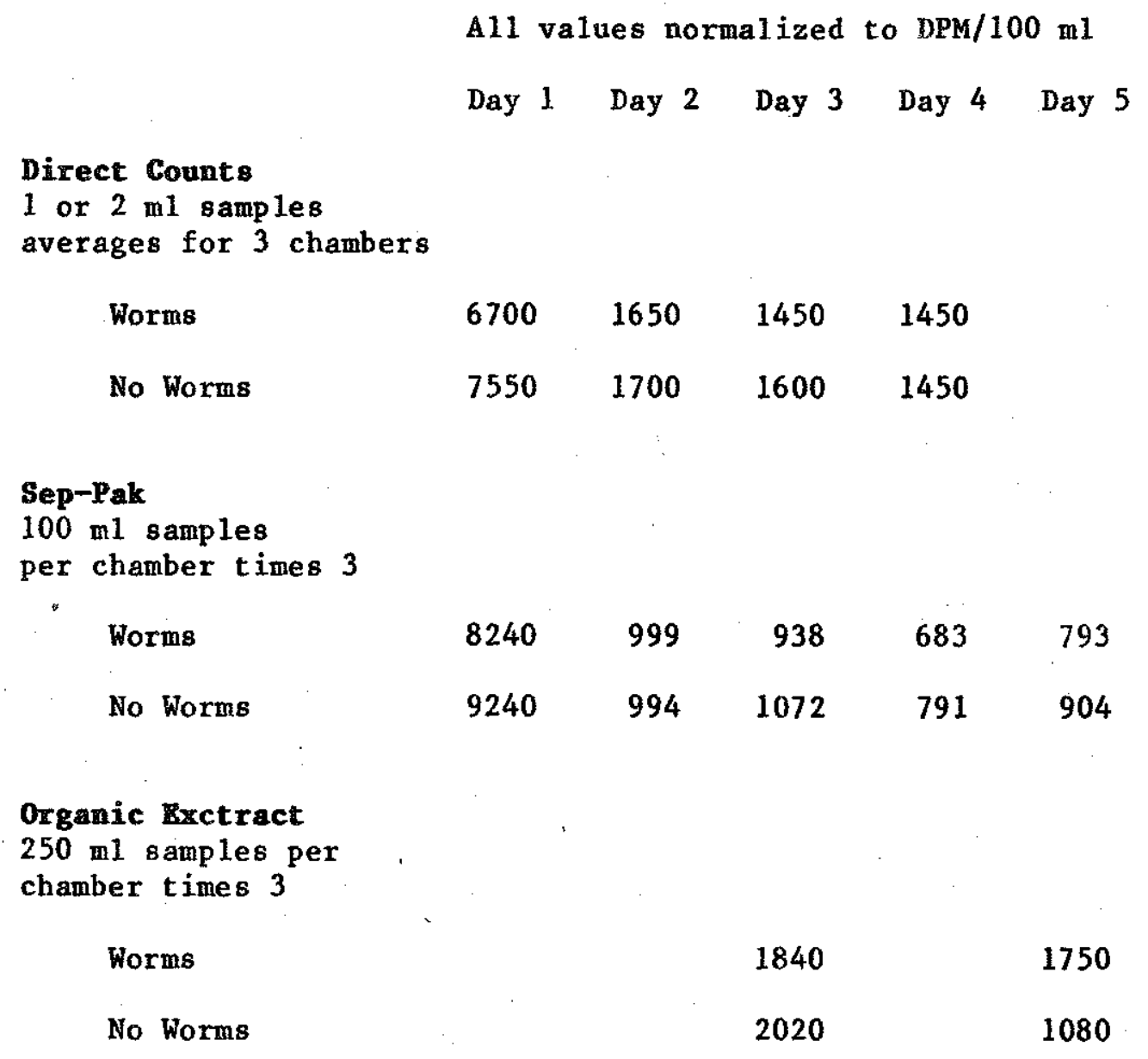


and $100 \mathrm{mM}$ Tris $\mathrm{pH}$ 7.0. Buffered extracts were frozen and stored at $70^{\circ} \mathrm{C}$ for less than two weeks until ans lysis.

Concentrations of ATP, ADP, and AMP in these extracts were measured spectrophotometrically using NADH coupled enzymatic reactions employing methods (Figures 2.7 and 2.8) modified from those described in Bergmeyer (1974). Concentrations were calculated from standards for each nucleotide measured each day of analysis. Samples were run in duplicate. The average coefficients of variation were $10.8,8.7$, and $7.5 \%$ for ATP, ADP, and AMP respective1y.

Mixed function oxygenase activity in whole worm homogenates:

Mixed function oxygenase activity was measured radiometrica11y using microsomes prepared from whole worm homogenates and $\left[{ }^{3} \mathrm{H}-\mathrm{U}\right]$ benzo(a)pyrene as a substrate. After removal of the head and the first few sections for adenylate nucleotide analysis, the remainder of the worms from each chamber were pooled and homogenized in a solution containing $150 \mathrm{mM}$

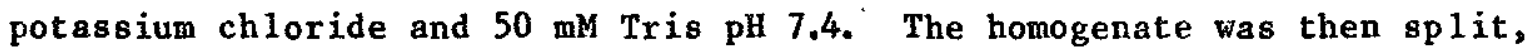
one fraction frozen for $B A$ analysis as described below, and the other used for microsome preparation. Microsomes were sedimented by centrifugation at $4^{\circ} \mathrm{C}$ using sequential spins of $800 \mathrm{~g}$ for 10 minutes, $12,000 \mathrm{~g}$ for 10 minutes, and $39,000 \mathrm{~g}$ for 90 minutes following the methods of Lee et a1. (1979). In the last three experiments two modifications were made. Sedimented microsomes were washed by resuspension in fresh homogenation buffer and resedimentation. Additionally, the protease inhibitor PMSO (phenylmethy 1-sulfonylflouride) was added to the homogenate and the supernatant before each 90 minute spin. After isolation microsomes were resuspended in a buffer containing 1 mM EDTA, 1 mM dithiothreitol, 


\section{ADENOS INE TRIPHOSPHATE ASSAY}

\section{Reaction Protocol:}

Mix $\begin{aligned} & .833 \mathrm{ml} \text { Buffer } \\ & .020 \mathrm{ml} \text { NADH } \\ & .127 \mathrm{~m} 1 \text { Sample }\end{aligned}$

Incubate 10 min room temperature

Read at $340 \mathrm{~nm} \quad \mathbf{B}_{\mathbf{I}}$

Add $.020 \mathrm{ml}$ Enzyme mixture

Incubate $30 \min 30^{\circ} \mathrm{C}$

Read at $340 \mathrm{~nm} \mathbf{B}_{2}$

$\mathbf{A T P}=\mathbf{E}_{2}-\mathbf{B}_{\mathbf{1}}$

\section{Solutions :}

Buffer Triethanolamine hydrochloride $18.6 \mathrm{mg} / \mathrm{m} 1$

$$
\begin{array}{ll}
\mathrm{K}_{2} \mathrm{CO}_{3} & 3.39 \mathrm{mg} / \mathrm{ml} \\
\mathrm{MgSO}_{4} \cdot 7 \mathrm{H}_{2} \mathrm{O} & 1.0 \mathrm{mg} / \mathrm{ml} \\
\text { EDTA } \cdot \mathrm{Na}_{2} \mathrm{H}_{2} \cdot \mathrm{H}_{2} \mathrm{O} & 0.4 \mathrm{mg} / \mathrm{ml} \\
\text { Glycerate } 3 \text {-phosphate } & 3.30 \mathrm{mg} / \mathrm{ml}
\end{array}
$$

NADH : $\quad 6.81 \mathrm{mg} / \mathrm{ml}$ in $5 \% \mathrm{NaHCO}_{3}$

Enzyme Mixture:

Glyeraldehyde-3-phosphodehydrogenase

$$
\text { EC No. 1.2.1.12 } 209 \mathrm{U} / \mathrm{ml}
$$

3-Phosphoglycerate phophokinase EC No. 2.3.2.3

Enzymes in $3.2 \mathrm{M}\left(\mathrm{NH}_{4}\right)_{2} \mathrm{SO}_{4}$

Standards in $20 \mathrm{mM}$ Tris $\mathrm{pH} 7.7$ 
Figure 2.8

\section{ADENOSINE DIPHOSPHATE AND MONOPHOSPHATB ASSAY}

\section{Reaction Protocol:}

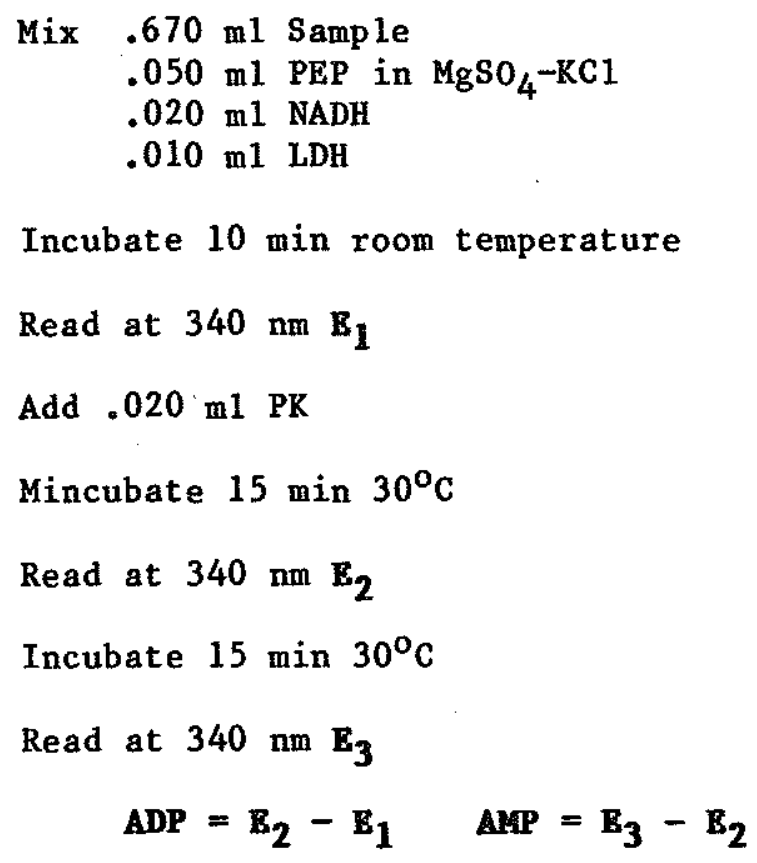

\section{Solutions:}

PEP : $6.0 \mathrm{mg} / \mathrm{ml}$ in $\mathrm{MgSO}_{4} \cdot 7 \mathrm{H}_{2} 0123 \mathrm{mg} \cdot \mathrm{ml}$ $\mathrm{KC} 1400 \mathrm{mg} / \mathrm{ml}$

$\mathrm{NADH}: 8.52 \mathrm{mg} / \mathrm{ml}$ in $5 \% \mathrm{NaHCO}_{3}$

LDH : $1900 \mathrm{U} / \mathrm{ml}$ in $3.2 \mathrm{M}\left(\mathrm{NH}_{4}\right)_{2} \mathrm{SO}_{4} \mathrm{EC}$ No. 1.1 .1 .27

$\mathrm{PK}: 710 \mathrm{U} / \mathrm{ml}$ in $3.2 \mathrm{M}\left(\mathrm{NH}_{4}\right)_{2} \mathrm{SO}_{2} \mathrm{EC} \mathrm{No} 2.7 .1 .40$

MK: $630 \mathrm{U} / \mathrm{m} 1$ in $3.2 \mathrm{M}\left(\mathrm{NH}_{4}\right)_{2} \mathrm{SO}_{4} \mathrm{EC}$ No. 2.7 .4 .3

Standards in $20 \mathrm{mM}$ Tris $\mathrm{pH} 7.7$

AMP standards a 1so contained ATP 
$20 \%$ glycerol, and $50 \mathrm{mM}$ Tris $\mathrm{pH} 7.4$.

The radiometric BP hydroxylase activity assay (Figure 2.9) was adapted from methods originally described by Van Cantfort et al. (1977) and modified by stegeman and Binder (1980). The assay was run at $30^{\circ} \mathrm{C}$ for 30 minutes using assay mixtures killed at time zero for blanks. The assay and blanks were run in triplicate for each sample. Following these procedures, the rate of $\mathrm{BP}$ oxidation was linearly related to time (up to 30 minutes) and microsoma 1 protein concentration (up to $1 \mathrm{mg}$ ). Microsoma 1 protein concentration was determined using the methods of Lowry et a 1. (1951) using bovine serum albumin as a standard.

\section{High pressure liquid chromatography (HPLC):}

Reverse phase HPLC was used to separate metabolic products from parent BA in concentrated organic extracts of sediment, water, and worm homogenates. Separations were carried out using either a Dupont Model 840 or Perkin-E 1 mer Mode 1 Series 41 iquid chromatograph equipped with fixed wavelength detection at $254 \mathrm{~nm}$ and reverse phase $5 \mathrm{um} 25 \mathrm{~cm}$ analytical columns (either slurry packed Dupont Zorbax, or Altech 605-RP, or Rainin Microsorb) equipped with an Upchurch guard column dry packed with Polyosil (Rainin Inst.) 25-40 um irregularly shaped $\mathrm{C}_{18}$ packing. HPLC analyses were run at $35^{\circ} \mathrm{C}$ with gradient elution from solvent A (water) to solvent B (methanol/ethanol 2:1) using a three step linear program on: (1) the Dupont chromatograph, changing from 45 to $35 \% \mathrm{~A}$ in $15 \mathrm{~min}, 35 \%$ to $20 \% \mathrm{~A}$ in 30 minutes, and jumping to and holding at $0 \% \mathrm{~A}$ for 15 minutes at a flow rate of $1.5 \mathrm{~m} 1 / \mathrm{min}$; and (2) on the Perkin-E lmer chromatograph changing from 50 to $35 \% \mathrm{~A}$ in $15 \mathrm{~min}, 35$ to $0 \% \mathrm{~A}$ in $25 \mathrm{~min}$, and ho $1 \mathrm{ding}$ at $0 \%$ A for 10 minutes at a 1 low rate of $1.0 \mathrm{~m} 1 / \mathrm{min}$. 
Figure 2.9

\section{BENZO(a) PYREIE HYDROXYLASE ASSAY}

\section{Reaction Mixture:}

Mix $.070 \mathrm{ml}$ buffered microsomes

$$
.010 \mathrm{ml}^{3} \mathrm{H}-\mathrm{BP}
$$

Equilibrate at $30^{\circ} \mathrm{C}$

Start reaction with $.020 \mathrm{~m} 1 \mathrm{NADPH}$

Shake $30 \mathrm{~min}$ at $30^{\circ} \mathrm{C}$

Stop reaction with $.300 \mathrm{~m} 1150 \mathrm{mM}$ KOH $85 \%$ DMSO

Remove unmetabolized BP by $3 \mathrm{Hx}$ extractions $1.0 \mathrm{ml} \mathrm{Hx}$ Vortex 10 seconds

Centrifuge $5 \mathrm{~min} 2.5 \mathrm{~K}$ RPM $4^{\circ} \mathrm{C}$

Remove Hx by aspiration

Neutralize portion of aqueous extract for LSC

\section{Solutions :}

Buffer: $1.4 \mathrm{mg} / \mathrm{ml}$ BSA in $50 \mathrm{mM}$ Tris $\mathrm{pH} 7.4$

NADPH : $2.5 \mathrm{mg} / \mathrm{ml}$ in buffer

$\mathrm{BP}: .078 \mathrm{mg} / \mathrm{m} 1$ in Buffer 
Aliquots from the entire run were collected for quantification of BA and BA metabolites. Identity of BA and BA metabolites was based on retention times of authentic standards provided by the National Cancer Institute. A chromatograph showing representative metabolite class standards using the Perkin-Elmer chromatograph is shown in Figure 2.10. Background corrected DPM in each fraction collected were summed for the entire run and activity assigned to a particular metabolite or class of metabolites presented as a percentage of tota 1 activity recovered.

\section{Sediment sampling and analysis:}

Sediment cores were taken in duplicate from each chamber at the beginning and end of each experiment. The only exceptions being the month-long sediment exposure experiment where cores were also taken in the middle of the experiment, and the feeding experiment where cores were taken on $1 \mathrm{y}$ at the end. Twelve miameter cores, approximate $1 \mathrm{y} 5 \mathrm{~cm}$ deep were taken with butyrate plastic core tubes and immediately frozen until analysis. In most experiments whole cores were analyzed. However, in the water column exposure experiment one set of duplicate cores from the end of the experiments were cut into three sections comprising the top centimeter, the second centimeter, and the remainder of the core, before extraction.

In the month-long sediment exposure experiment and the water column exposure experiment, an extra set of cores was taken at the end of the experiment from each chamber. Cores from chambers with worms and from chambers without worms were pooled and size fractionated by wet sieving prior to freezing. Fractions analyzed included a known volume of filtrate passing through a glass fiber filter (Whatman type GF/F), the size 


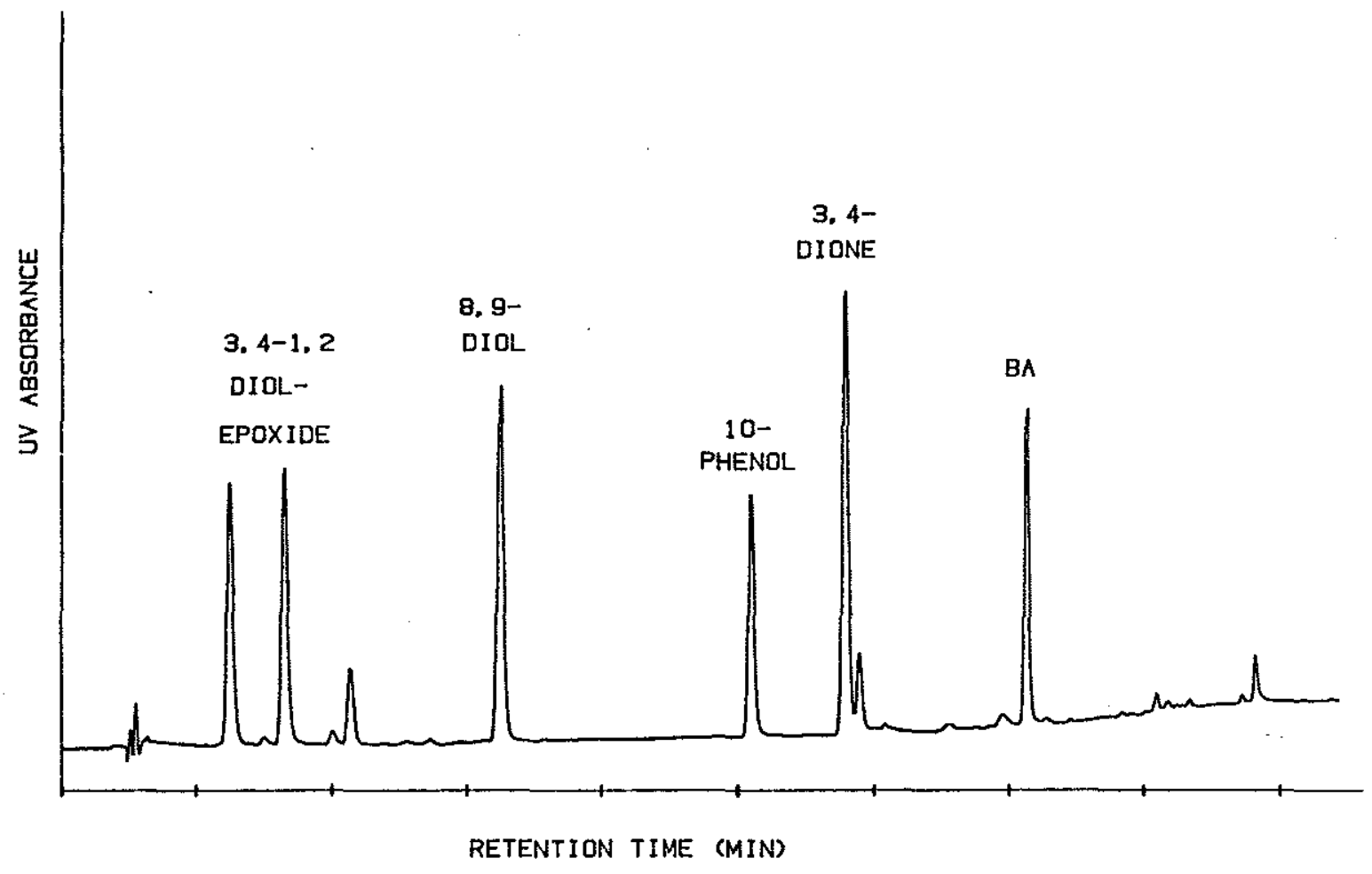

Figure 2.10: UV chromatogram of HPLC separation of representative BA st andards 
fraction passing a 35 um screen but collected on the glass fiber filter, the fraction passing a 125 um screen but collected on the 35 um screen, the fraction passing a 250 um screen but collected on the 125 um screen, and the fraction collected on the 250 um screen. Nothing was collected on a 500 um screen. Although sieving was done as gently as possible, fecal pellets were disaggregated during this process. With the exception of the filtrate sample all fractions were collected on preweighed glass fiber filters.

Sediment samples were extracted for BA and BA metabolites as described schematical1y in Figure 2.11, using a general 1ipid extraction scheme modified from that of Bligh and Dyer (1959). In this method BA and metabolites are recovered in the organic extract, and conjugated metabolites are recovered in the aqueous extract. Subsamples of the organic extract were analyzed for total 1ipid, determined gravimetrica 11y, and tota 1 BA concentration determined by LSC. Total BA concentration was normalized to the dry weight of the sediment measured after extraction. The organic extract was further analyzed fon the presence of metabolic products by HPLC as described above. Total BA concentration in the aqueous extract was determined after drying in an oven at $70^{\circ} \mathrm{C}$ and rehydration before LSc. Extraction efficiency was determined by spiking unlabeled sediment samples with ${ }^{14} \mathrm{C}-\mathrm{BA}$ prior to extraction. Efficiency of BA extraction was found to be $90.7 \%$.

\section{Wor homogenates, BA extraction and analysis:}

Frozen whole worm homogenates pooled from the worms in each chamber were freeze-dried before extraction. The extraction scheme for worm tissue is described schematical1y in Figure 2.12, and was modified from 


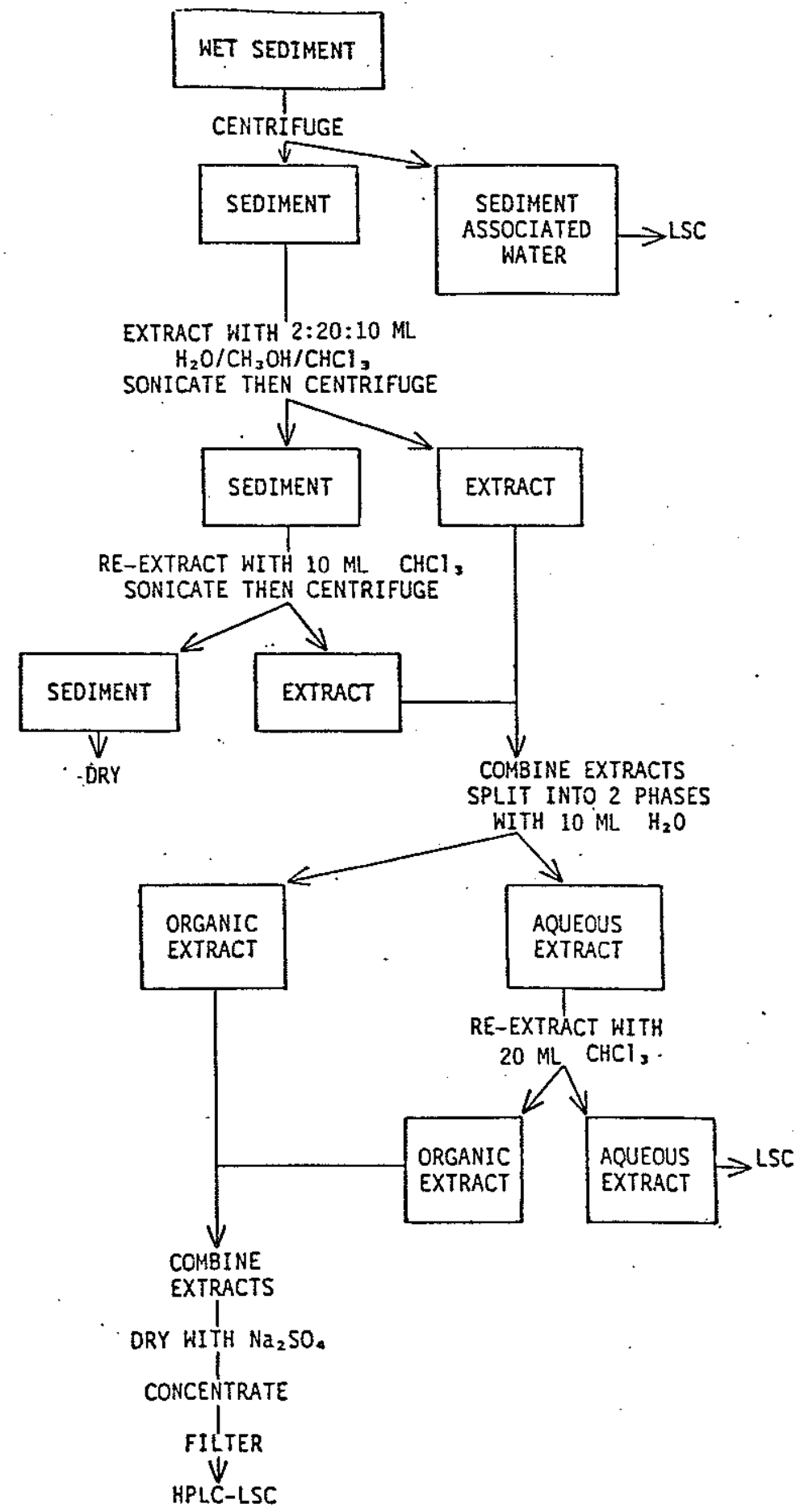

Figure 2.11: Sediment extraction protoco1 


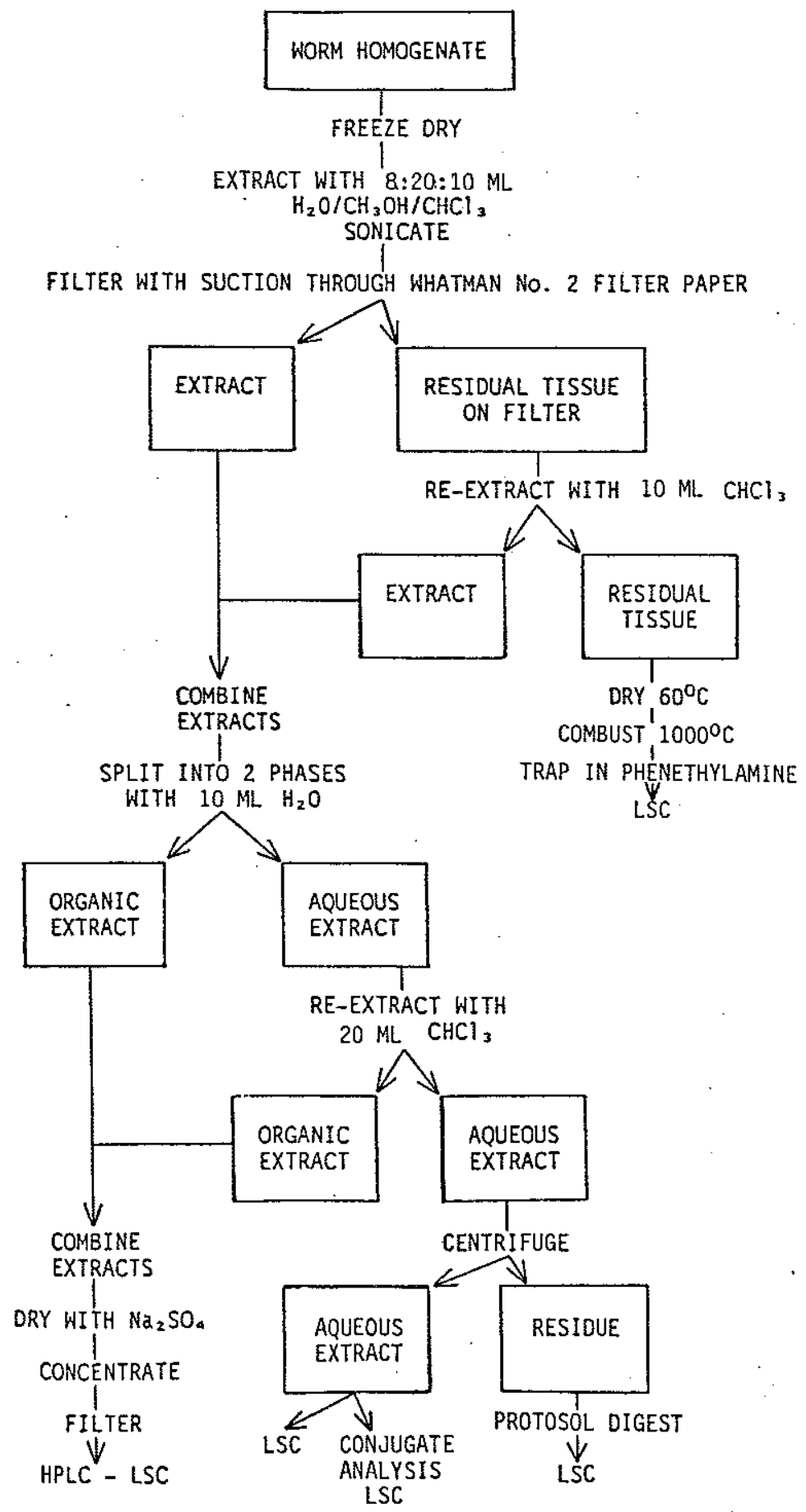

Figure 2.12: Worm extraction protocol 
that of B1igh and Dyer (1959), Baird et a1.(1977), and Varanasi and Ginur (1981). As in the sediment extraction scheme, BA and oxygenated metabolites were recovered in the organic extract, and conjugated metabolites in the aqueous extract. In the worm extraction sequence a fluffy precipitate was present in the aqueous extract. After separation by centrifugation the aqueous precipitate was digested with Protosol at $35^{\circ} \mathrm{C}$ overnight, bleached with hydrogen peroxide, neutralized, and the radioactivity remaining quantified by LSc. Unextractable activity remaining in worm tissue after extraction was analyzed by combusting the worm residue at $1000^{\circ} \mathrm{C}$ and bubbling the effluent through phenethylamine in a vigreux column. Radioactivity trapped in the phenethylamine was quantified by LSc. Efficiency of the worm extraction procedure was estimated by spiking unexposed hydrated worm homogenates witb ${ }^{14} \mathrm{C}-\mathrm{BA}$ prior to extraction. Extraction efficiency for BA was found to be $95.6 \%$. Subsamples of organic extracts of worm tissue were analyzed for tota 1 lipid, total BA activity, and the presence of BA metabolites on HPLC as described above.

The aqueous extract of worm homogenates was found to contain a significant fraction of tota 1 radiolabel incorporated, so an attempt was made to quantify what type of conjugated metabolites had been formed. Methods used for conjugate analysis were modified from those of Varanasi and Gmur (1981) and from methods supplied by Sigma Chemical Co. These are described schematical1y in Figure 2.13. After concentration and removal of residual solvent by rotary evaporation at $40^{\circ} \mathrm{C}$, aqueous extracts were treated with the enzymes B-glucuronidase and arylsulfatase to convert sulfate and glucuronide conjugates back to organic extractable, polar metabolites. The aqueous extracts treated with the conjugate 
Figure 2.13

\section{CONJUGATE ANALYSIS}

\section{Reation Mixutre:}

$2.0 \mathrm{~m} 1$ Concentrated Worm Aqueous Extract

$2.0 \mathrm{ml}$ Sample Buffer

$0.1 \mathrm{~m} 1$ Enzyme Mixture

Incubate at $35^{\circ} \mathrm{C}$ for 20 hours

\section{Extraction Protoco 1:}

Add $5 \mathrm{ml} \mathrm{CHCl}_{3} 10 \mathrm{ml} \mathrm{MeOH}$

Vortex, sonicate $10 \mathrm{~min}$

Add $5 \mathrm{ml} \mathrm{CHCL}_{3}$ and $5 \mathrm{ml} \mathrm{MEOH}$

Vortex, centrifuge low speed $10 \mathrm{~min}$

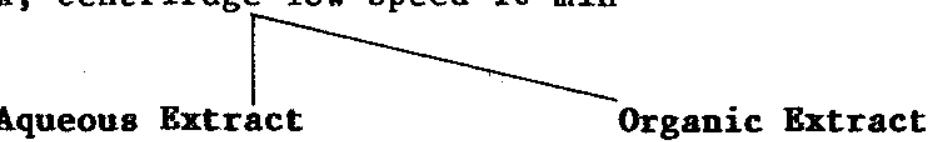

Reextract with $10 \mathrm{ml} \mathrm{CHCl}_{3}$

Vortex, sonicate $10 \mathrm{~min}$

Centrifuge low speed $10 \mathrm{~min}$

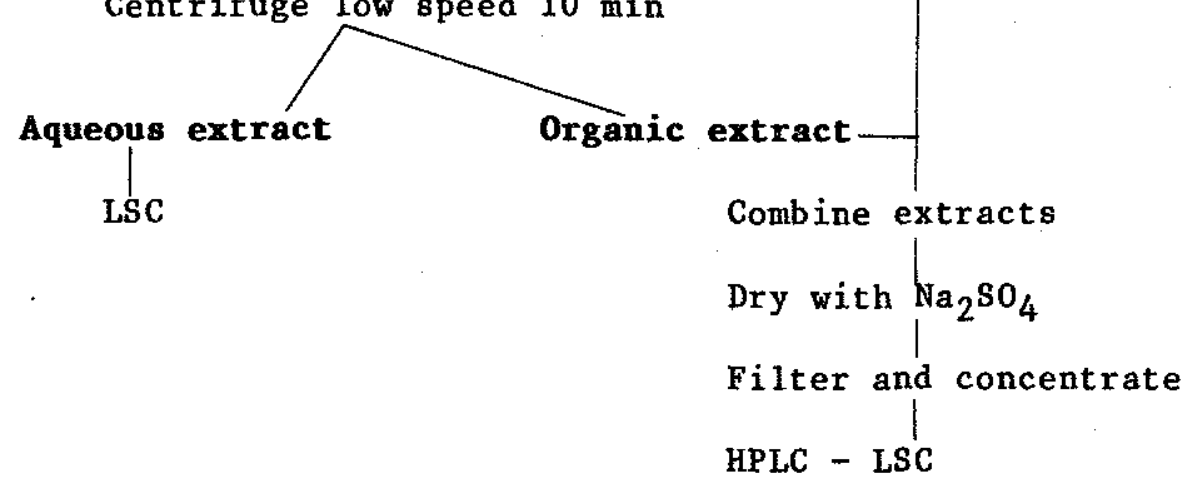

\section{Solutions:}

Sample Buffer: $200 \mathrm{mM}$ Acetate $\mathrm{pH} 5.0$

Enzyme Mixtures: Ary1 sulfatase $500 \mathrm{U} / \mathrm{ml}$ EC No. 3.1.6.1 B-glucuronidase $10,000 \mathrm{U} / \mathrm{ml}$ EC No. 3.2.1.31 in $75 \mathrm{mM}$ potassium phosphate $\mathrm{pH} 6.8$ 
cleaving enzymes were then re-extracted using the procedures out lined in Figure 2.12. The increase in activity found in the organic extract (in excess of that extracted from aqueous extracts incubated without enzymes) was then compared to the original activity contained in the aqueous extract before conjugate cleavage to determine the amounts of sulfate and glucuronide conjugates originally present. Possible inhibition of the enzymes by the worm aqueous extract was tested using extracts spiked with known concentrations of para-nitrophenyl sulfate and phenophthalein glucuronide under conditions where conjugate cleavage can be monitored spectrophotometrically. Under these assay conditions, unconjugated product formation showed a linear dependance on substrate concentration (Figure 2.14).

The assignment of radioactivity into specific metabolite classes was based on the operational1y defined extraction and seperation techniques described above. A schematic describing these designations is shown in Figure 2.15. Values for tota 1 BA recovered from the worms were calculated from the sum of radioactivity in the organic and aqueous extracts and unextractable radioactivity in the aqueous precipitate and the worm residue.

The data are expressed as radioactivity in the form of $B A$ or $B A$ metabolic products recovered from the worms. However, no attempt was made to inhibit bacteria associated with the worms by antibiotics. Consequently there was no way to distinguish between metabolites formed by Nereis itself, and metabolites produced by attached or enteric bacteria.

Whole worm homogenates were used for analysis of worm BA and BA metabolic products. Worms were not allowed to depurate their gut con- 


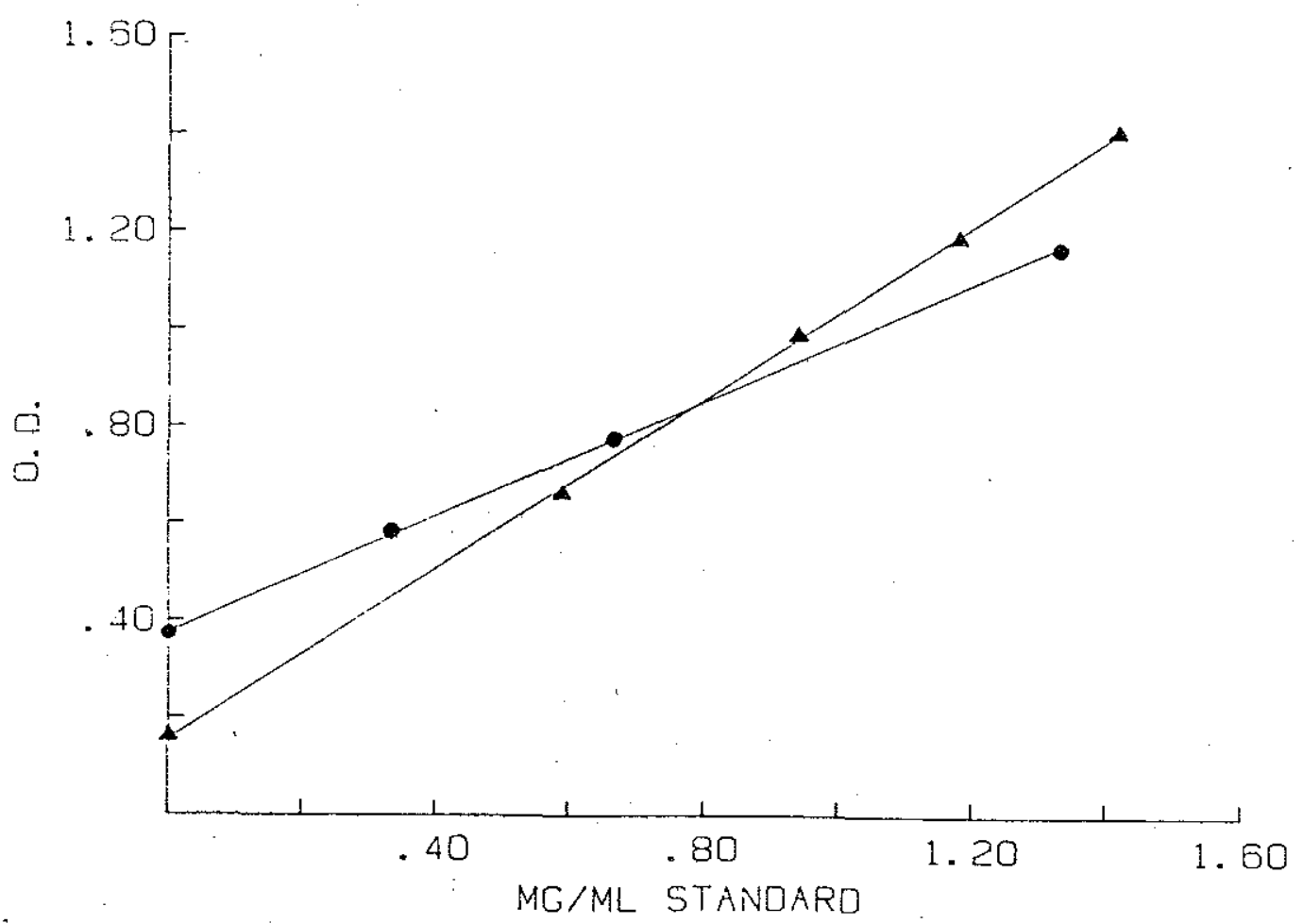

Figure 2.14: Concentration curve for B-glucuronidase and ary 1 sulfatase assay using indicator substrates added to worm aquesous extracts. Circles show arylsulfatase assay. Triangles show B-glucuronidase assay. Concentrations of products read at $410 \mathrm{~nm}$ for the arylsulfatase assy and $540 \mathrm{~nm}$ for the B-glucuronidase assay. 
Figure 2.15

\section{AMALYTICAL DETERMINATION OF METABOLITE CLASSES}

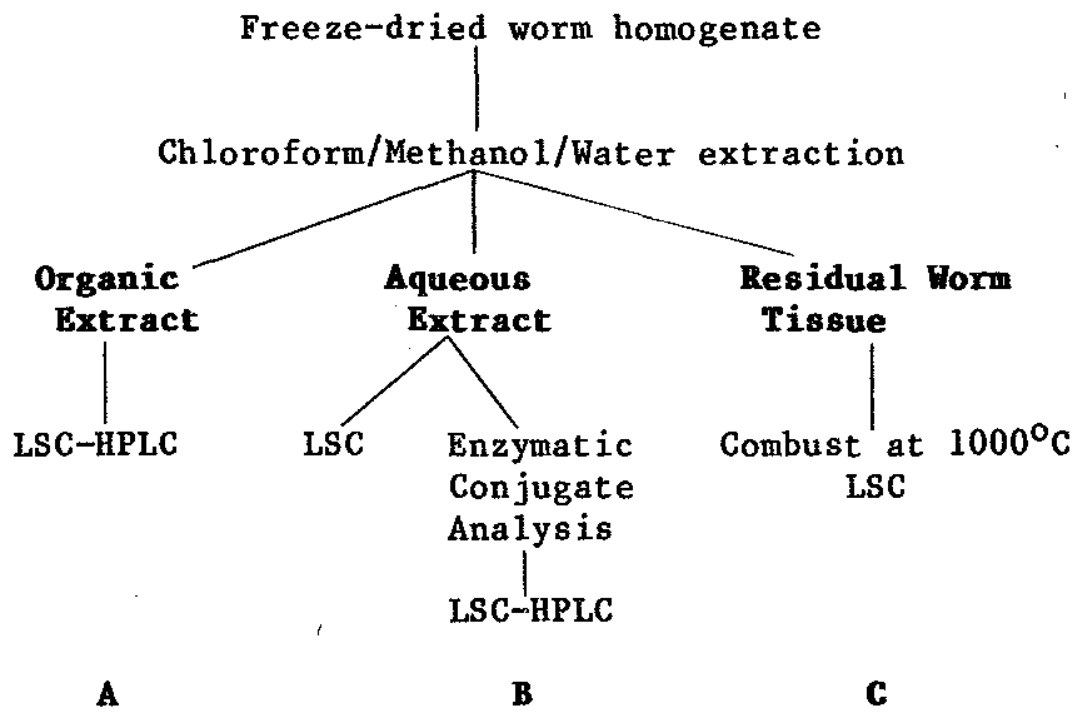

A: Contains BA and Polar Metabolites

B: Contains Conjugates Metabolites

C: Contains Unextractable Radioactivity 
tents, nor were their intestines removed prior to homogenation. Therefore, it is likely that most worms contained some sediment in their guts, which in experiments 1-4 would have contained measurable quantities of isotope. Depuration studies on control worms indicated that intestinal contents on $1 y$ accounted for $3 \%$ of the total wet weight of the worms. 


\section{CTAPTBR 3:}

THR FATE OF BEHZ(a)ANTHRACEME IF BENTHIC MICROCOSHS: IMILUEMCE OR Mereis virens AND RODE OF BXPOSURB

\section{Results :}

Results from experiments with BA labeled sediment, with BA added to the water column; and with BA introduced as labeled food will be presented separately. For each type of experiment detailed information on the fate of BA in sediment, worms, and water column will be presented, then these values will be used to calculate an overall mass balance of BA recovered from the system.

\section{Experiments with sediment-sorbed BA:}

Three experiments were conducted where sediment was labeled with BA prior to placement in the exposure chambers. The dose to the sediment was approximately the same in a 11 experiments. In the first two experiments measurements were taken for 6 days, and in the third experiment measurements were taken for 25 days.

Concentration of BA in sediment cores for both the 6 day and the 25 day experiments with sediment-sorbed BA are presented in Table 3.1. Although the sediments used in these experiments were labeled in bulk with continuous mixing, the variability in BA concentration in the sediment was considerable. Analysis of replicate cores taken at the same time in the same chamber gave coefficients of variation ranging from 5.6 to 14.3 averaging $10.2 \pm 2.5 \%$ In a 11 three experiments concentration of $B A$ in the bulk sediments did not change between initial and final cores, nor did the presence of worms have a measurable effect. Total BA concentration from all cores taken in the two 6 day experiments were indistinguishable $(8.53 \pm .33$ and $8.86 \pm .73 \mathrm{ug} / \mathrm{gdw})$. However, mean sediment tota 1 
Table 3.1

\title{
BERZ(a)ANTHRACENR CONGERTRATION IN SEDMANT SAMPLES FROY EXPERTIBNTS UTTH SEDMNETI-SORBED BEWZ(\&)ANTHRACERE
}

\author{
Initial ug/gdw $\quad$ Mid $\quad$ Final
}

Experiment 1

6 days

\begin{tabular}{cc} 
With worms & $8.94 \pm .25$ \\
Without worms & $8.42 \pm .39$ \\
\hline$(2)$
\end{tabular}

$7.65 \pm .86$

(4)

$9.04+.40$

(3)

Experiment 2

6 days

$\begin{array}{rcc}\text { With worms } & 10.96 \pm 1.43 & 8.96 \pm .45 \\ \text { Without worms } & 6.35 \pm 1.83 & (3) \\ & (2) & 8.10 \pm .65 \\ & & (2)\end{array}$

Experiment 3

25 days

With worms

$6.14 \pm .42$

(3)

$6.46 \pm .55$

(2)

$6.93 \pm .25$

Without worms

$6.29 \pm .31$

(5)

$6.89+.19$

(3)

Values presented as mean $\pm \mathrm{SE}(\mathrm{n})$.

Within each experiment $B A$ concentrations in initial and final cores, and from cores taken from chambers with and without worms were compared using the Student's t-test. No significant differences between means were observed. 
BA concentration from all cores taken from the 25 day experiment with sediment-sorbed BA was 1 ess, $6.60 \pm 0.15 \mathrm{ug} / \mathrm{gdw}$.

The sediment extraction scheme used in these experiments yields two fractions, an organic fraction containing BA and polar metabolites, and an aqueous fraction containing very polar conjugated metabolites. In al1 sediment samples analyzed, an average of on 1 y $0.04 \%$ of total radioactivity recovered was in the aqueous extract (Table 3.2). Even though activity in the aqueous fraction represented a sma11 fraction of total activi$t y$, in the 25 day experiment the presence of worms caused a significant increase in activity in the aqueous sediment extract. The same trend was seen in the two short-term experiments, although in this case differences between chambers with and without worms were not statistically significant.

HPLC analysis of the organic fraction indicated very little evidence of polar BA metabolites in any of the sediment exposure experiments. Representative chromatograms of organic extracts from sediment samples from each of the sediment exposure experiments are shown in Figures 3.1 and 3.2. Unmetabolized $B A$ in all sediment samples amounted to an average of $98.0 \pm .2 \%$ of total radioactivity recovered from the chromatogram. No peaks, other than $\mathrm{BA}$, containing greater than $1 \%$ of total radioactivity were observed.

BA concentration in sediment cores taken at the end of the 25 day experiment and fractionated according to particle size is presented in Table 3.3. In order to have enough material, cores from the three replicate chambers were pooled before fractionation, thus there is no estimate of variability in these data. No large differences were apparent between 
Table 3.2

\% OF TOTAL RADIOACTIVITY RECOVERED IN AQUEOUS RXTRACTS OF SEDIFENT II BXPRR IWEKTS WITH SEDTMRKT-SORBED BEKZ(a)AKTHRACENE (EXPERIMENTS $1,2, \& 3$ )

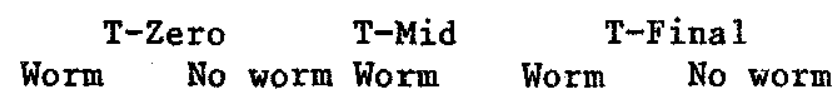

Experiment \#1

$$
\begin{array}{cc}
.0563 \\
\pm .0132 & .0504 \\
(3) & \pm .0110
\end{array}
$$

$$
\begin{array}{rr}
.0558 & .0438 \\
+.0402 & \pm .0013 \\
(3) & (3)
\end{array}
$$

Experiment \#2

$$
\begin{array}{rr}
.0196 & .0108 \\
+.0080 & +.0042 \\
(3) & (2)
\end{array}
$$

$$
\begin{array}{rr}
.0620 \\
\pm .0402 \\
\begin{array}{l}
(3) \\
(2)
\end{array}
\end{array}
$$

Experiment \#3

$$
\begin{array}{rcccc}
.0254 & .0273 & .0449 & .0958 & .0217 \\
\pm .0040 & \pm .0032 & \pm .0241 & \pm .0258 & \pm .0050 \\
(3) & (2) & (3) & (3)
\end{array}
$$

Values expressed as mean $\pm \mathrm{SE}(\mathrm{n})$.

Means within each experiment compared using arcsin transformed data by ANOVA and SNK.

T-F worm $\neq$ any other mean in exp.3 except T-Mid $p<.025$. 
Figure $3.1:{ }^{14} \mathrm{C}$ HPLC chromatogram of organic extracts of sediment cores taken at the beginning $(a)$ and end (b) of experiment 2. Overlay on $x$ axis refers to retention time windows corresponding to different classes of authenticBA metabolite standards. Abreviations: $S F=$ solvent front; $D-E=$ diol-epoxide. Non-polar refers to all activity eluting after BA. 

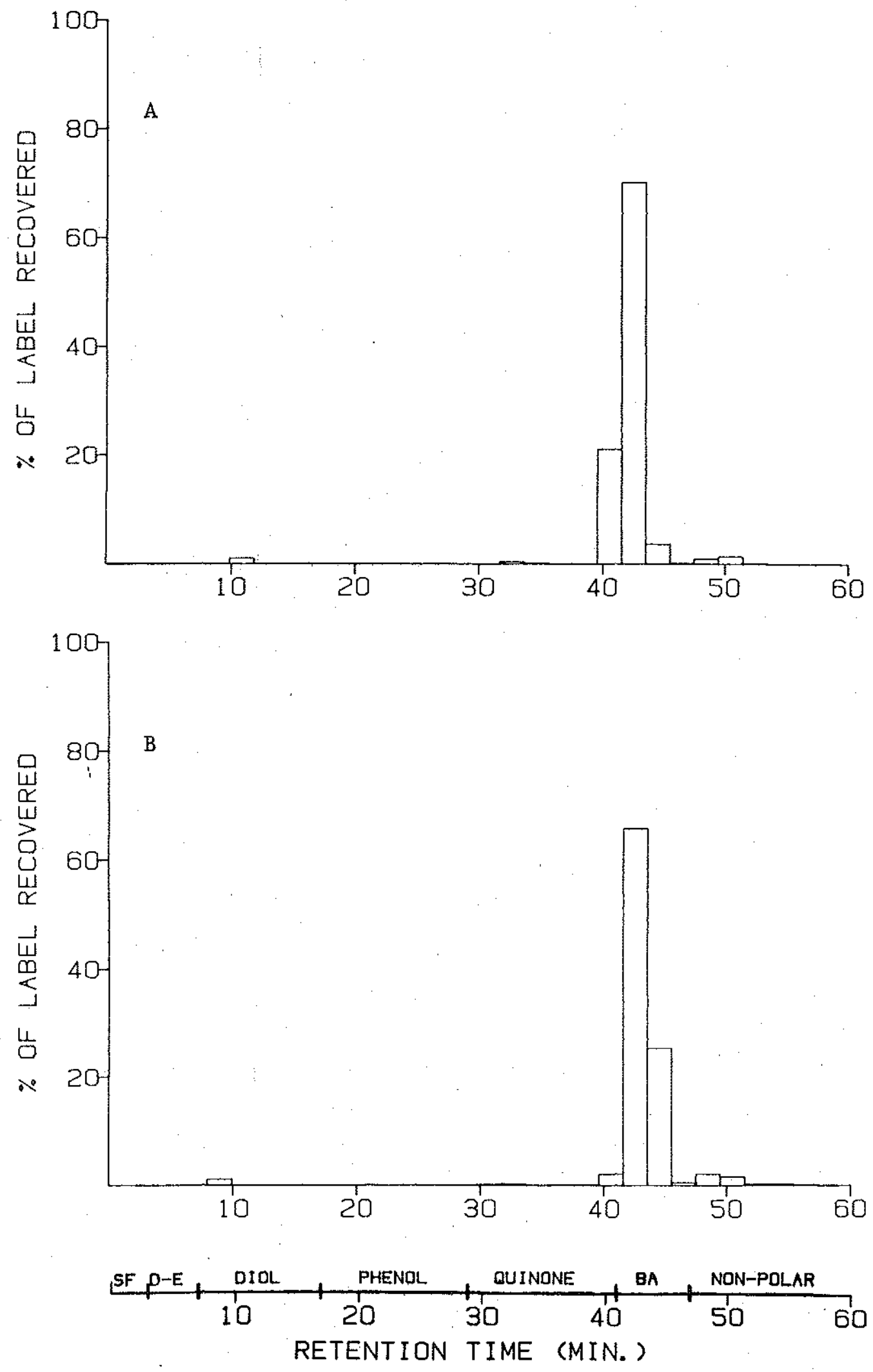
Figure 3.2: ${ }^{14} \mathrm{C}$ HPLC chromatogram of organic extracts of sediment cores taken at the beginning (a), middle (b), and end (c) of experiment 3 . overlay on $x$ axis refers to retention time windows corresponding to different classes of authentic BA metabolite standards. Abreviations: $\mathrm{SF}=$ solvent front; $\mathrm{D}-\mathrm{E}=$ diol-epoxide. Non-polar refers to all activity eluting after BA. 
$-88-$
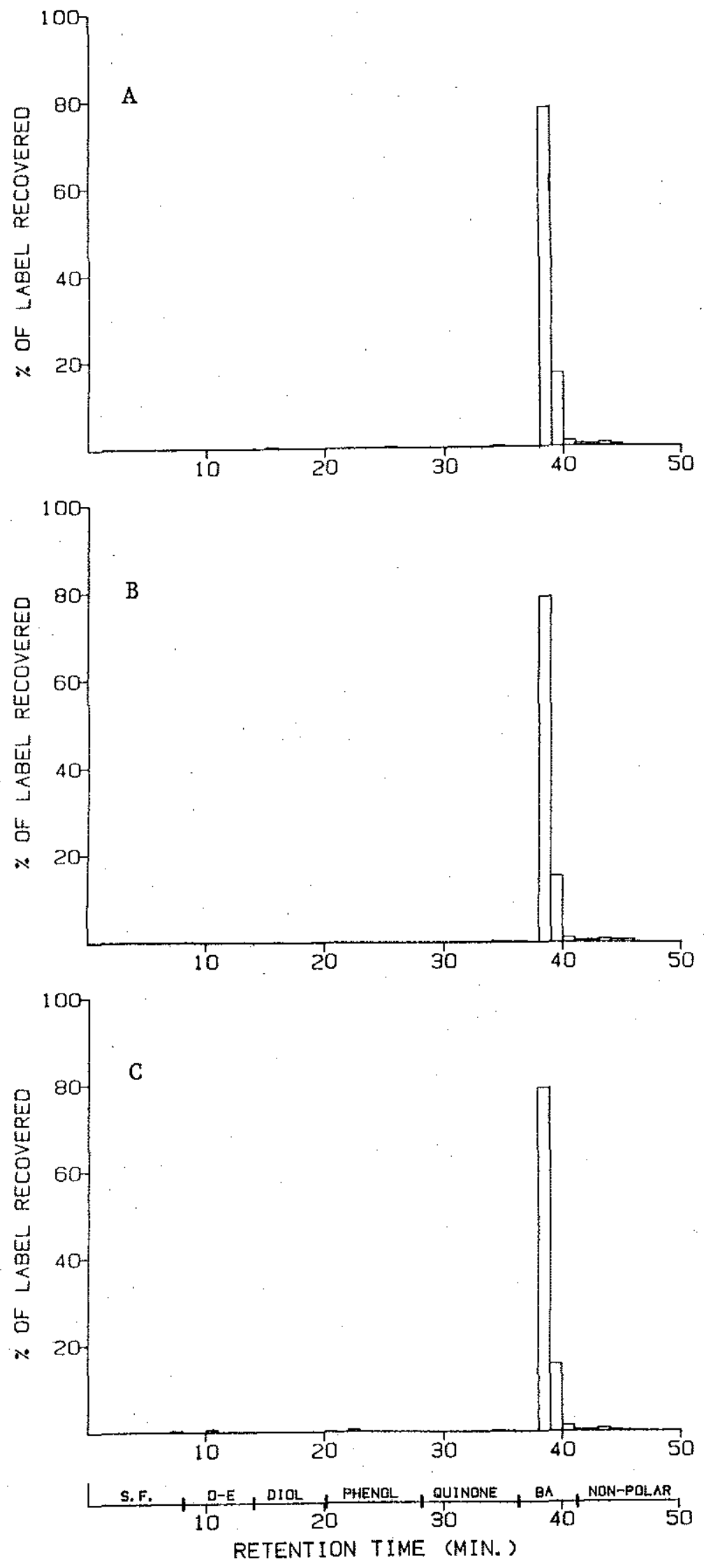
Table 3.3

SIZE FRACTIONATION OF RADIOACTIVITY IN SEDIMENT CORES TAKEN

IH THE 25 DAY EXPERTMRHT VITH SEDIRERT-SORBED BENZ(a)ANTHRACENB (BXPERIMENT 3)

$\%$ of Total Activity Recovered Normalized to gdw

With worms

Without Worms

Filtrate

1.4

1.0

Gff-37 um

76.7

70.8

$37-125$ um

19.8

24.8

125-250 um

1.8

2.4

$>250$ um

.50

1.0 
chambers with and without worms. Most of the BA is associated with 1-37 um sized particles, and approximate 1 y $97 \%$ is present on particles less than 125 um.

The sediments remined oxidized throughout each experiment. At no point was any darkening due to a redox discontinuity observable. To verify the apparent oxidized state of the sediment, $E_{h}$ was measured at the end of the 25 day experiment using platinum electrodes. $E_{h}$ averaged $+221 \mathrm{mV}\left(14^{\circ} \mathrm{C}, \mathrm{pH} 6.9\right)$ at depths of 1 to $5 \mathrm{~cm}$ in all three experimental treatments.

Concentrations of total BA (parent and metabolites) recovered from worms harvested at the end of 6 and 25 day exposures to sediment-sorbed BA are given in Table 3.4. Significant 1 y more BA accumulated in worms exposed for 25 days than in worms exposed for only 6 days, with worm concentrations exceeding those in the sediment after 25 days. Total BA accumulated was $5.02 \pm .27$ and $5.28 \pm .44$ for the two 6 day experiments and $13.08 \pm .44 \mathrm{ug} / \mathrm{gdw}$ for the 25 day experiment. Compared to tota1 BA concentration in the sediments, this corresponds to bioconcentration factors (ppm worm/ppm sediment) of $0.656,0.589$, and 1.89 .

Activity in individual water samples was not high enough to allow HPLC analysis for the presence of metabolic products. Therefore, activity in seawater samples must be considered a sum total of parent BA and whatever metabolic products may have been present. In all experiments with sediment-sorbed BA, flux to seawater was greater in chambers with worms than in chambers without worms although variability between replicate chambers was high (See Figures 3.3-3.5). The somewhat lower rates seen in the first experiment may be due to the seawater extraction tech- 
Table 3.4

BENZ(a)ANTHRACENB ACCUMUTATION INTO WORM TISSUE IR EXPERTMBRTS WITI SEDIAEHT-SORBED BEAZ(a)ARTHRACENR (EXPERIMFATS $1,2, \& 3$ )

$$
\text { ug/gdw } \quad \text { CF }
$$

Experiment 1

6 day exposure

Experiment 2

6 day exposure

Experiment 3

25 day exposure
$5.02 \pm .27$

(3)

$$
5.28 \pm \frac{.44}{(3)} \quad .589 \pm .050
$$

$13.08 \pm .44$

(2)

$1.89 \pm .09$

Values expresed as mean $\underline{+S E}(\mathrm{n})$.

$\mathrm{CF}=\mathrm{ug} / \mathrm{gdw}$ in worms $/ \mathrm{ug} / \mathrm{gdw}$ sediment.

Means for concentrations in worms compared between experiments by ANOVA and SNK. Exp. $3 \neq$ Exp. 1 or Exp. 2 p $<.005$. 


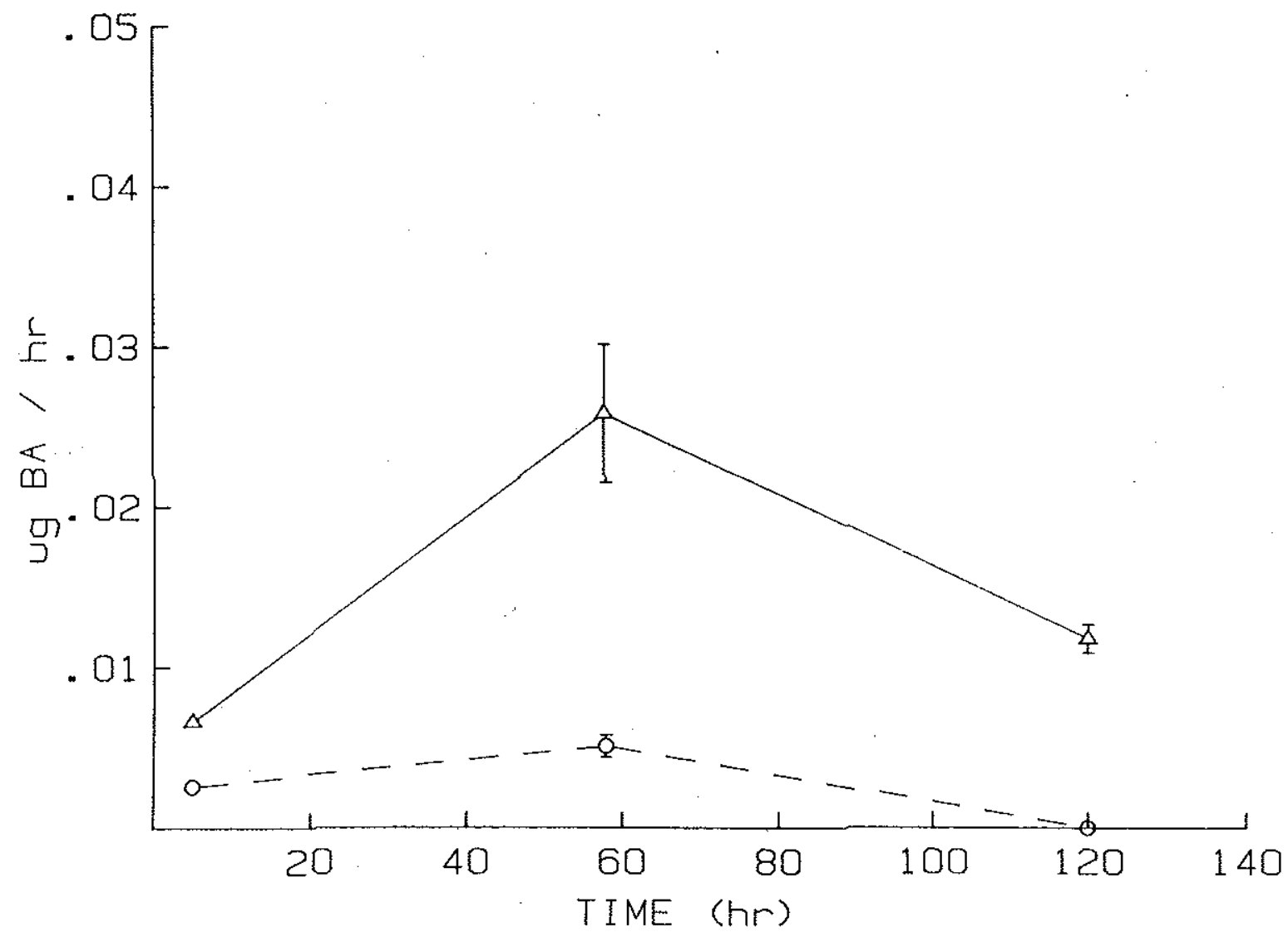

Figure 3.3: BA flux to water column in experiment 1. Circles represent chambers without worms. Triangles represent chambers with worms. Values expressed as mean $\pm S E n=3$. 


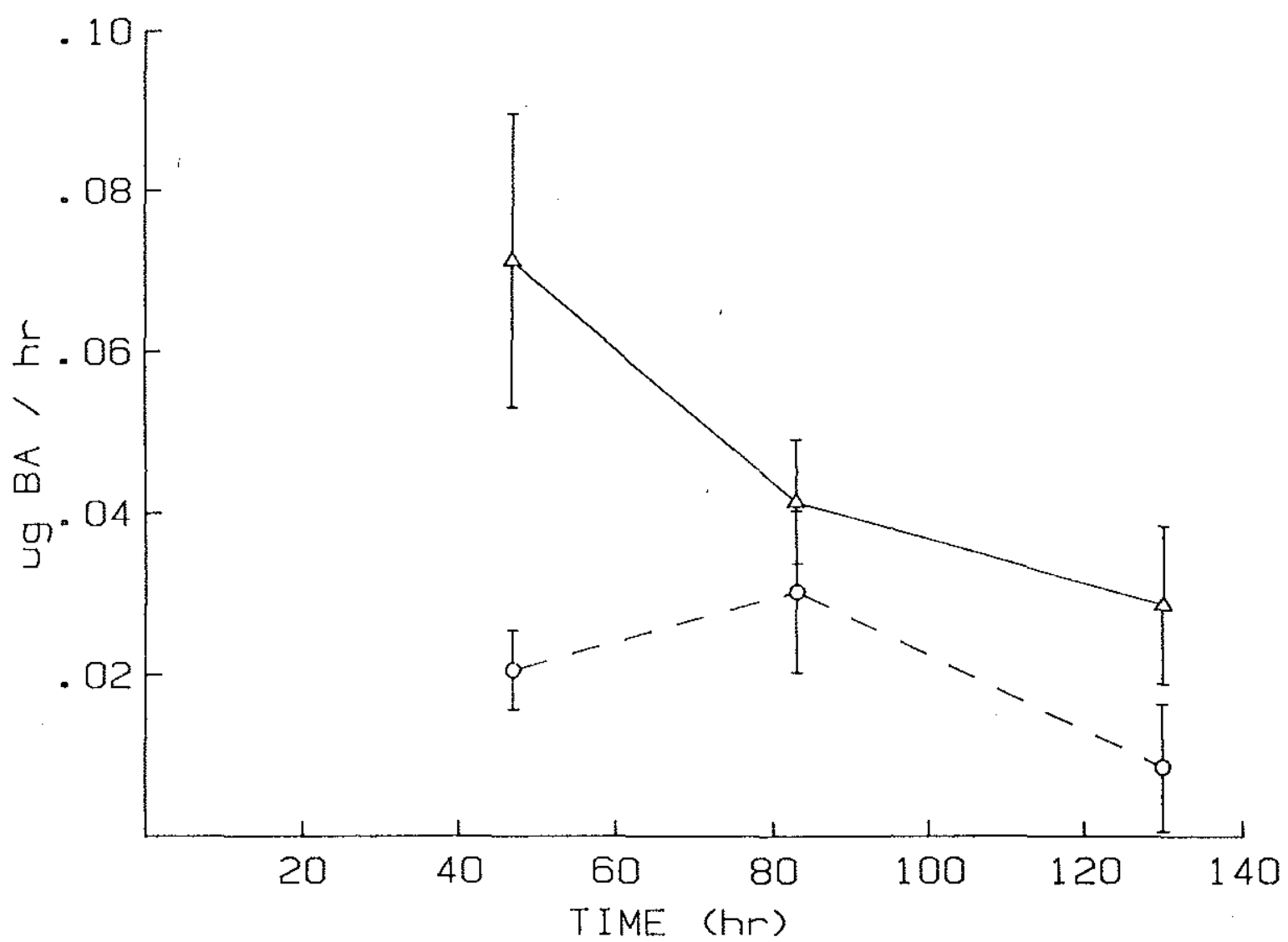

Figure 3.4: BA flux to water column in experiment 2. Circles represent chambers without worms. Triangles represent chambers with worms. Values expressed as mean $\pm S E n=4$. 


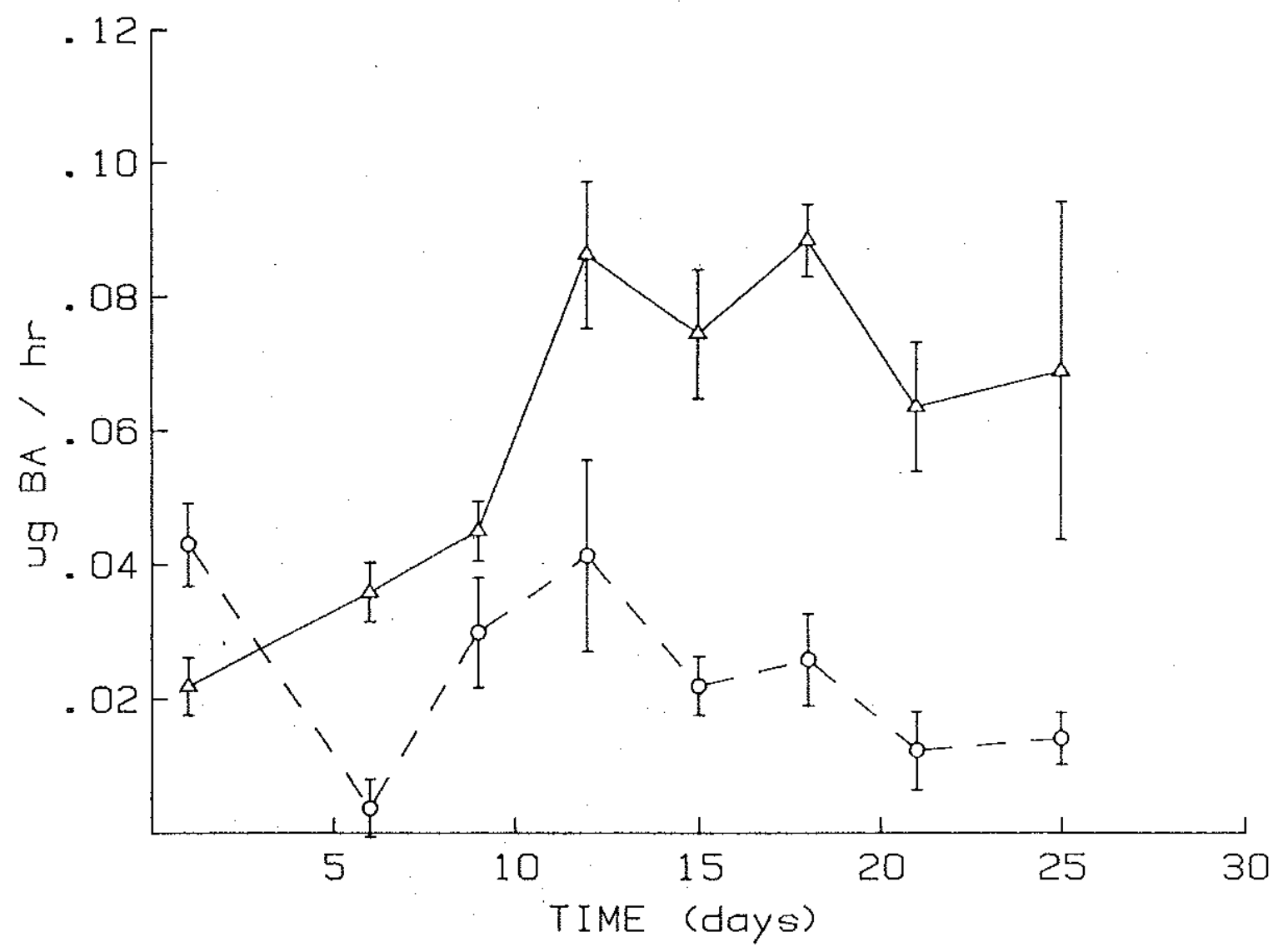

Figure 3.5: BA flux to water column in experiment 3. circles represent chambers without worms. Triangles represent chambers with worms. Values expressed as mean $\pm S E n=3$. 
nique which was not used subsequently (See Chapter 2). The effect of BA treatment and time on $f$ lux of $B A$ into the water column in experiments 2 and 3 were compared using two-way ANOVA with replication. Experiment 1 was not tested due to lack of equal numbers of replicates. In both experiments most of the variation could be accounted for by treatment, although both time and the time/treatment interaction accounted for significant $(p<.05)$ portions of the variability.

Linear regressions of $B A$ flux to the water column as a function of time for each treatment were run to see if there were any consistent trends with time, by testing for significant differences from zero in the slope of the regression. In the two short term experiments there were no consistent significant effects of time on flux. However, in the 25 day experiment $f 1 u x$ in chambers with worms increased significant $1 y(p<.05)$ with time whereas $f l u x$ in chambers without worms remained constant. The increase in $f l u x$ in chambers with worms was most noticable after 9 days (Figure 3.5).

The total amount of $B A$ removed from the sediment $v i a$ the water column was estimated by integrating flux over the entire experiment assuming 1 inear rates of change between sampling points. In chambers with worms in the short-term experiments 2.04 and 5.34 ug BA were removed via the water column, whereas in chambers without worms on 1 y 0.367 and $2.31 \mathrm{ug} B A$ were removed by this route in experiments 1 and 2 , respective1y. In the 25 day experiment the effect of worms was more pronounced, where $34.8 \mathrm{vs} .1 .37 \mathrm{ug} B A$ were removed via the water column in chambers with and without worms. This amounts to an average increase in the removal of BA from sediments to the water column by factor of about 4 
in the 6 day experiments and 25 in the 25 day experiment due to the presence of worms.

$\mathrm{BA}$ mineralization to $\mathrm{CO}_{2}$ was only detectable in the 25 day experiment with sediment-sorbed BA (Figure 3.6). The presence of worms led to significant increases in the rate of $\mathrm{BA}$ mineralized to $\mathrm{CO}_{2}$. Analysis by 2-way ANOVA showed that the presence of worms accounted for most of the observed variability although time and time/treatment interactions were also significant. Rate of BA mineralization in chambers with worms increased significantly with time $(p<.005)$, particularly in the latter half of the experiment, whereas rates in chambers without worms remained the same.

The total amount of mineralized BA was estimated as described above for the total amount of BA lost to seawater. At the end of the experiment 13.8 and $7.25 \mathrm{ug}$ of $\mathrm{BA}$ had been completely mineralized to $\mathrm{CO}_{2}$ in chambers with and without worms, respectively, over the course of the experiment. The presence of worms resulting in almost a doubling in the total amount of BA mineralized.

A mass balance of the percent of total BA recovered from each compartment in chambers from the short and long term sediment exposure experiments is presented in Table 3.5. Data represent averages of radioactivity recovered from the sediment, worms, and water column (as total radioactivity extracted from seawater and as $\mathrm{CO}_{2}$ extracted from seawater) expressed on a whole chamber basis. The results have been presented in this way to assess the importance of the presence of worms on the overal1 fate of sediment-sorbed BA in this system, and to allow comparison to the fate of $\mathrm{BA}$ in the other experiments discussed below. 


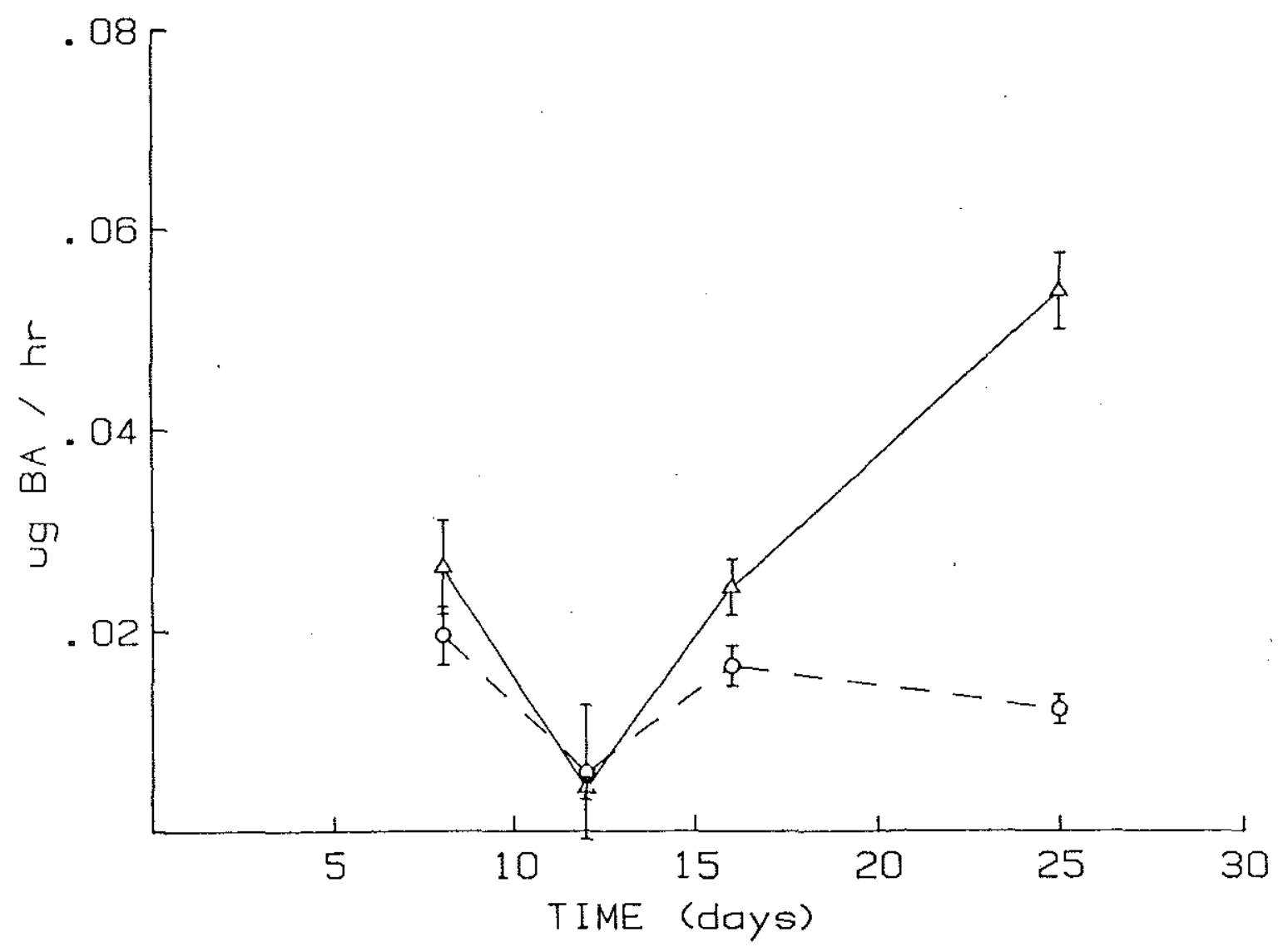

Figure 3.6: BA mineralization to carbon dioxide in experiment 3 . Circles represent chambers without worms. Triangles represent chambers with worms. Values expressed as mean $\pm S E n=3$. 
Table 3.5

UHOLE CHAMIBER MASS BALANCE: \% OF TOTAL ACTIVITY RECOVRRED AT ERD OF EXPERIMENTS VITH SEDIFIBKT-SORBED BEHZ(a)AMTHRACENE (EXPERIMERTS $1,2, \& 3$ )

Sediment Worms $\begin{array}{r}\text { Water Column } \\ \text { Tot ext. } \mathrm{CO}_{2}\end{array}$

Experiment 1

6 day exposure With worms Without worms

99.4

100 .

0.57

-

0.06

0.01

N.D.

N.D.

Experiment 2

6 day exposure

With worms

Without worms

Experiment 3

25 day exposure

With worms

Without worms
97.3

99.3
1.15

0.46

0.46

0.25 
In the two 6-day experiments (exp.1\&2), greater than $99 \%$ of the activity recovered was found in the sediment reservoir. Although the presence of worms had significant effects on the percent of activity in aqueous extracts of sediment and $f$ lux of $B A$ to the water column, due to the large mass of sediment in these experiments, on a total chamber basis, the presence of worms was not significant. The difference between the percent of recovered labe 1 in the sediment averaged only $0.62 \%$ between chambers with and without worms, and $0.52 \%$ was due to activity recovered from the worms themselves. In the first two experiments, total BA recovered from worms averaged 6.1 times that removed via the seawater.

In the 25 day experiment, in chambers with worms, isotope renaining in the sediment dropped to $97.3 \%$ of total recovered, and the percentage recovered from worms was about equal to that removed via the seawater, and 2.5 times that mineralized to $\mathrm{CO}_{2}$. In contrast, greater than $99 \%$ of activity was recovered from the sediment in chambers without worms even though a greater percentage of isotope was recovered as $\mathrm{CO}_{2}$ and as total $B A$ in seawater in this experiment than was in the first two experiments. Experiment with $\mathrm{BA}$ added to the water column:

Mean total BA concentrations on a whole core basis are shown in Table 3.6. No significant differences were observed either between initial and final cores or between cores from chambers with or without worms. Variability observed in the BA concentration in sediment samples taken in this experiment was higher than seen in experiments with sediment-sorbed BA. The mean coefficient of variation for duplicate cores was 0.541 . This increased variability probably resulted from patchy deposition of BA from the water column which was further enhanced 
Table 3.6

BEHZ(a)ANTHRACEHR CONCENTRATIONS IN SEDIMENT SAMPLES FROM EXPERIKEET UITH BEHZ(a)AKTHRACERE ADDED DIRECTLY TO THE WATER COLUMN (EXPERTMEMT 4)

$$
\text { T-Zero T-Final }
$$

Total [BA]

ug/gdw

$$
\begin{array}{lll}
\text { With Worms } & .173 \pm .019(3) & .194 \pm .036(6) \\
\text { Without Worms } & .150 \pm .038(3) & .149 \pm .037(5)
\end{array}
$$

$\%$ in Aqueous

Extract

$$
\begin{array}{lll}
\text { With Worms } & .0476 \pm .0245(3) & .539 \pm .241 \text { (3) } \\
\text { Without Worms } & .0572 \pm .0266(3) & .0094 \pm .0010
\end{array}
$$

Means of total concentrations compared between $T-0$ and $T-F$ for chambers with and without worms using Student's t-test.

Arcsin transformations of means of $\%$ of total activity in aqueous extract were compared between all groups by ANOVA and SNR. $\mathrm{T}-\mathrm{F}$ Worm $\neq$ a 11 other $\mathrm{p}<.05$. 
in chambers with worms by bioturbation.

The percent of total extractable activity in the aqueous extract is also shown in Table 3.6. A significant increase in the percent of label in the aqueous extract was found in the chambers with worms at the end of the experiment. This small but detectable presence of polar BA metabolites was also evident from HPLC analysis of the sediment organic extract (Figure 3.7), although no discernible peaks were visible. Most radioactivity still chromatographed as unmetabolized BA, with $96.9 \pm .9 \%$ of recovered label present as nonpolar compounds. This represents a significant increase in the presence of metabolized BA when compared to experiments 1,2, and 3 ( $p<.001$ Mann Whitney U-test).

Since most of the BA remaining after wash-out should have been at the surface of the sediment, one set of cores from the end of the experiment was fractionated with depth prior to extraction. The ratio of BA per depth section to BA per core on both a ug/gdw and total ug basis in chambers with and without worms is shown in Table 3.7. These values were normalized to total activity recovered from each core to correct for the patchy distribution of $\mathrm{BA}$ in different parts of the sediment reservoir. For any given section there were significant differences in the concentration of BA present between chambers with and without worms. The presence of worms resulted in mixing BA down into the sediment. On a ug/gdw basis, only $82 \%$ of $B A$ remained in the top $\mathrm{cm}$ in chambers with worms compared to $98 \%$ in chambers without worms. The effect of worms was observed at a 11 depthes, with 11 vs. $1.2 \%$ and 7 vs. $1.3 \%$ of tota 1 abe 1 recovered from the second and bottom $3 \mathrm{~cm}$ of the sediment column in chambers with and without worms respectively. 
Figure $3.7{ }^{14} \mathrm{C}$ HPLC chromatogram of organic extracts of sediment cores taken at the beginning (a) and end (b) of experiment 4. 0ver lay on $x$ axis refers to retention time windows corresponding to different classes of authentic BA metabolite standards. Abreviations: $S F=$ solvent front; $D-E=$ diol-epoxide. Non-polar refers to all activity eluting after BA. 


$$
-103-
$$
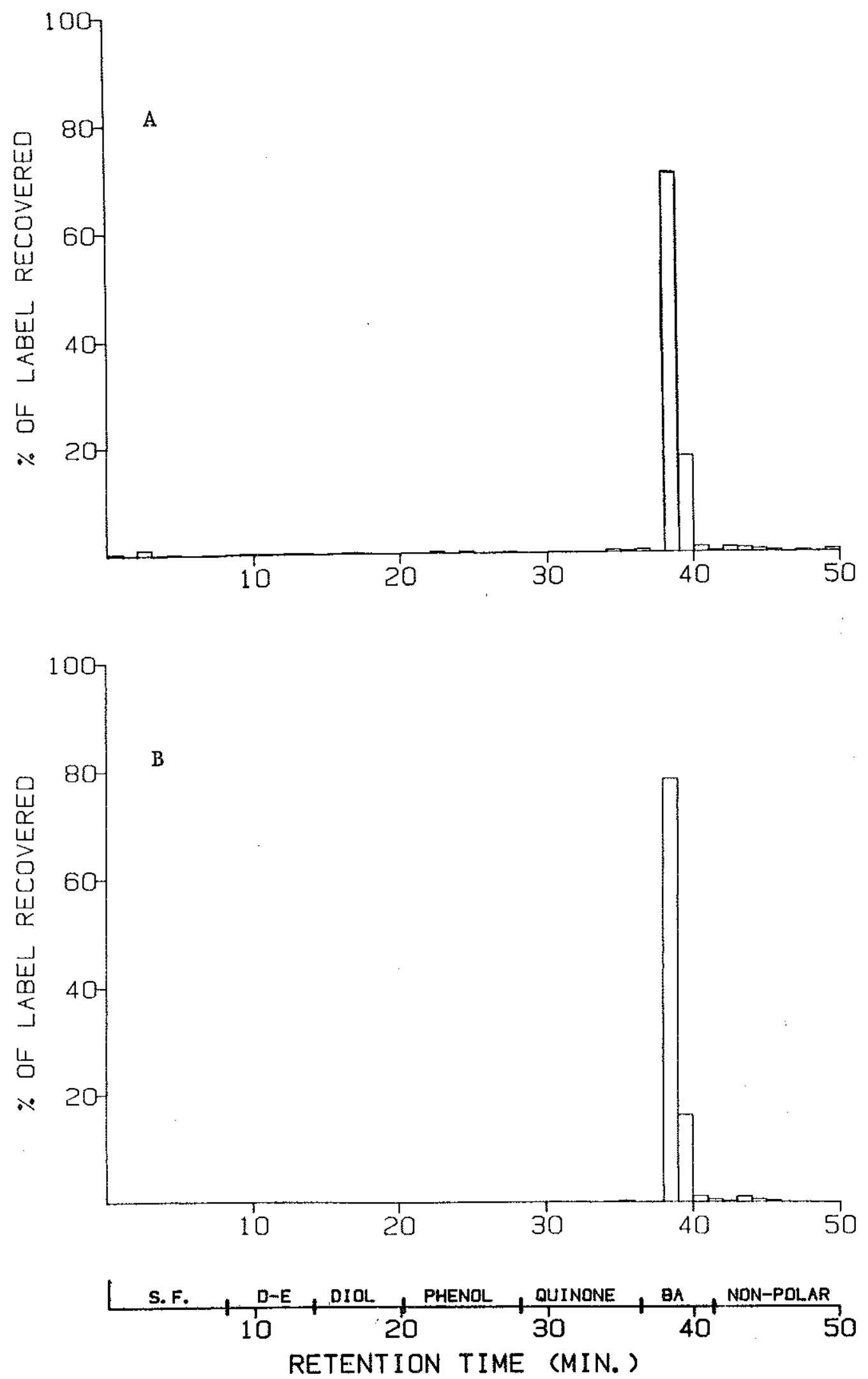
Table 3.7

DEPTH FRACTIONATION OF RADIOACTIVITY IN SEDIMENT CORES

TAKEN AT THB EWD OF THE EXPERIMEMI WITI BERZ(a)ATTHRAGERE ADDED

DIRRCTIY TO THE WATER COLUMII

(EXERIMTSTT 4)

Without Worms

1-2 cm

With Worms

Without Worms

$3 \mathrm{~cm}$-Bottom

With Worms

Without Worms
[BA]

$$
93.12 \pm 3.12
$$

$99.15 \pm .16$

$\begin{array}{ll}6.95 \pm 2.86 & 7.65 \pm 3.01 \\ 0.65 \pm .21 & 1.08 \pm .11\end{array}$

$\%$ of total

Radioactivity

Recovered

$86.52 \pm 4.83$

$97.38 \pm .51$

$\pm .11$

$0.78 \pm .27 \quad 5.83 \pm 1.86$

$0.20 \pm .05 \quad 1.54 \pm .60$

Values presented as mean $\pm S E n=3$, normalized to percent of activity recovered from each column.

Means between chambers with and without worms were comared using Student's t-test on arcsin transformed data. In all cases differences were significant $p<.05$. 
One set of unfrozen cores were fractionated according to particle size prior to extraction (Table 3.8). As in experiment 3 most of the radiolabel was present on particles between 1 and 37 um in size with $92 \%$ found on particles between 1 and $125 \mathrm{um}$. No obvious differences were seen between chambers with and without worms in this experiment, or between the size distribution of $\mathrm{BA}$ in this experiment and that found in the experiments with sediment-sorbed BA.

Concentration of $B A$ recovered from worms exposed to BA introduced via the water column for 6 days is presented in Table 3.9. Total BA accumulated was $3.81 \pm .36 \mathrm{ug} / \mathrm{gdw}$, similar to that occurring after 6 days in experiments with sediment-sorbed BA (See Table 3.4). However, the mass of $B A$ in the sediment reservoir in experiments 1 and 2 , where sediments were uniformly labeled, was much larger than in this experiment, where most of the BA was in the top $\mathrm{cm}$ of the sediment $(3540 \mathrm{vs}$. $39.7 \mathrm{ug}$ ). Consequent ly even though the concentration of BA accumulated was similar, the percentage of total BA present accumulated into worms was much higher. Table 3.9 shows the BA concentration factor in worms (ppm worm/ppm sediment) partitioned according to depth. Normalizing to concentrations in the top one cm worms accumulated $2.06 \pm .67$ times the concentration in the sediment. This represents a concentration factor 3 times higher than observed in short-term experiments with sediment-sorbed BA (See Table 3.4). The concentration factor calculated without taking into account the depth distribution was $19.6 \pm 5.5$. These data suggests that worms were accumulating BA from the surface where they feed even though most of the surface area of the worm's integument was exposed to sediments containing negligible amounts of BA. 
Table 3.8

\section{SIZE FRACTIONATION OF RADIOACTIVITY IN SEDIMENT CORES TAKBE TROY THE EXPERIMRAT UITH BEHZ(a)ALTHRACERE ADDED DIRECTLY TO THE WATER COLUNA (BXPER IRERET 4)}

$\%$ of Total Activity Recovered

Normalized to $\mathrm{gdw}$

With Worms

1.5

73.3

19.9

3.8

1.4
Without Worms

$$
2.5
$$

75.8

15.5

3.3

2.8 
Table 3.9

BENZ(a)ANTHRACBNE ACCUUULATION INTO WORY TISSUE IN BXPERIMEAT WITH BBNZ(a)ARTHIRACERE ADDED DIRBCTLY TO THE VATER COLUNA (BXPBRIMBNT 4)

\begin{tabular}{|c|c|}
\hline $3.81 \pm .36 \mathrm{ug} / \mathrm{gdw}$ & \\
\hline $\begin{array}{l}\text { Concentration Factors } \\
\text { (ug/gdw worm)/(ug/dgw }\end{array}$ & sediment) \\
\hline Total Core & $19.6 \pm .6$ \\
\hline $0-1 \mathrm{~cm}$ & $2.06 \pm .67$ \\
\hline $1-2 \mathrm{~cm}$ & $42.8 \pm 12.8$ \\
\hline $\begin{array}{l}3 \mathrm{~cm} \text { to bottom } \\
\text { of core }\end{array}$ & $175 \pm 76$ \\
\hline
\end{tabular}


BA concentration in the water column during the period when chambers were in the recirculating mode after spike addition is shown in Figure 3.8. After the chambers were switched to flow through, the remainder of the spike still retained in the water column was washed out of the chambers. The washout was $98 \%$ complete within 16.5 hours, with BA flux leveling off 39 hours after the chambers were re-opened. BA flux to the water column after switching to flow-through is shown in Figure 3.9. No difference in flux rate was observed between chambers with worms and those without worms.

On the third day after the chambers were re-opened, extracts of large $250 \mathrm{ml}$ water samples were pooled and analyzed for the presence of polar metabolites by HPLC. Activity in fractions collected from the HPLC are shown in Figure 3.10 for a combined extract from the chambers containing worms. Smal1 peaks averaging a few percent of the total activity recovered were present in the region of tetrol and diol-epoxide, diol, phenol, and quinone metabolite standards. Although most of the activity (>85\%) was still present as nonpolar BA, it was substantially less than that seen in sediment extracts from experiments 1,2, and 3. Unfortunate1y the sample from the chambers without worms was lost, so there is no way to assess the possible impact of worms on the presence of BA metabolites in the water column.

Flux of BA mineralized to $\mathrm{CO}_{2}$ into the water column is shown in Figure 3.11. No differences were seen between rates in chambers with worms and those without worms. Rates were undetectable 15 hours after the start of flow through conditions and increased throughout the rest of the experiment, although they were always much lower than rates observed 


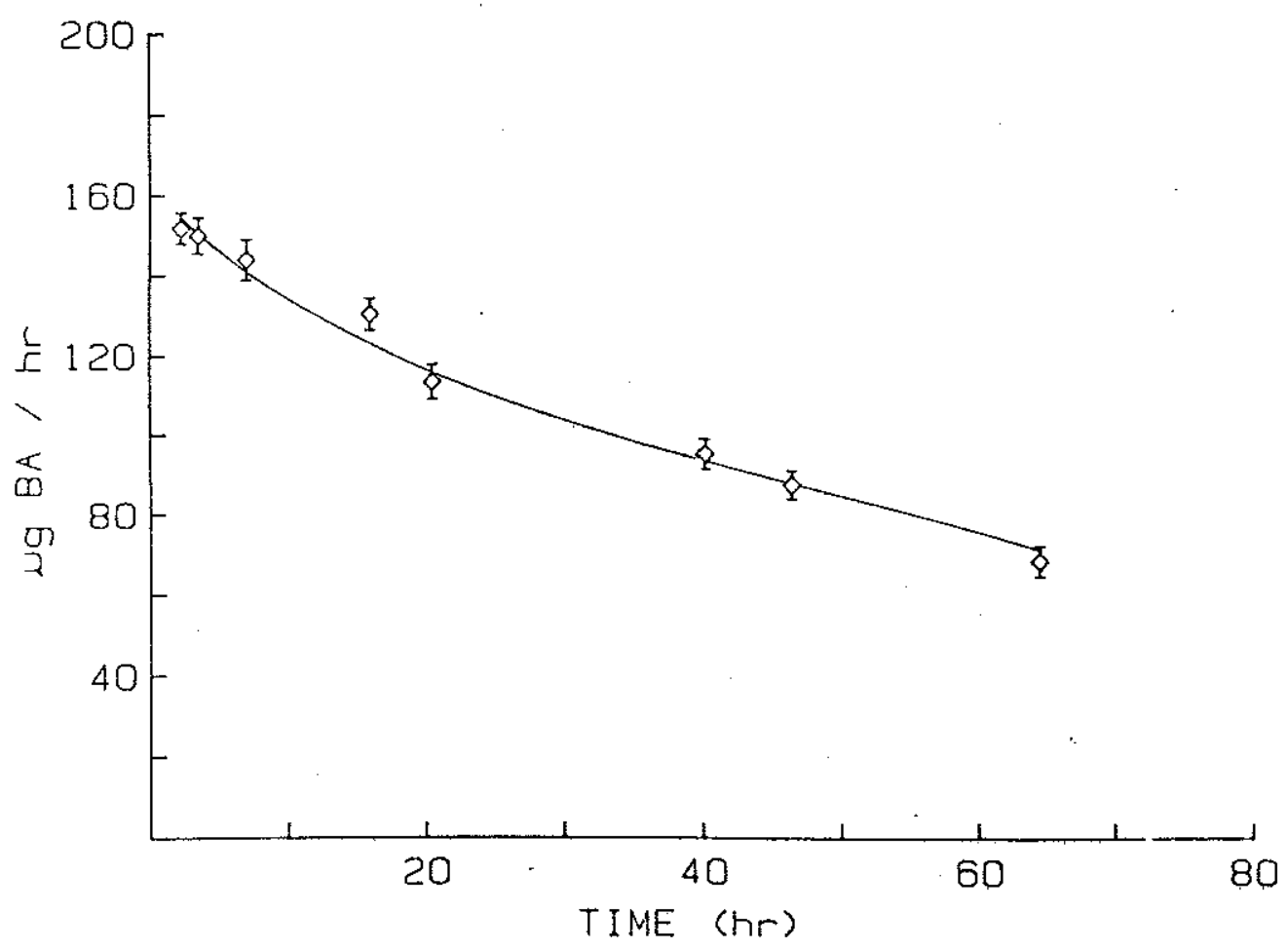

Figure 3.8 Initial removal rate of $\mathrm{BA}$ from the water column during the recycle mode in experiment 4. Values expressed as mean $\pm S E$ for all chambers $n=6$. 


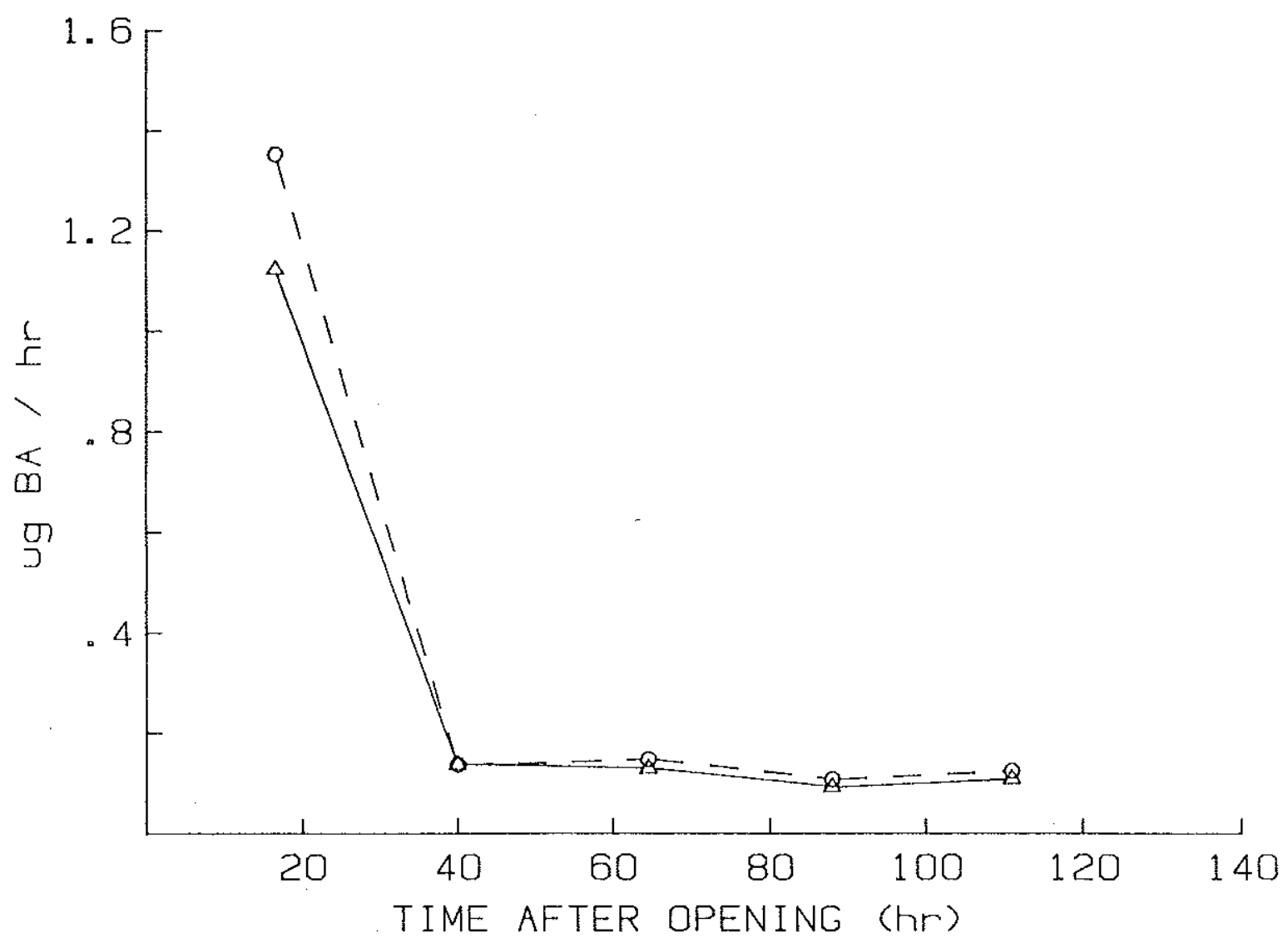

Figure 3.9: BA $f l u x$ to water column in experiment 4 after reinitiation of flow-through circulation. Circles represent chambers without worms. Triangles represent chambers with worms. Values represent radioactivity in samples pooled from 3 replicate chambers. 


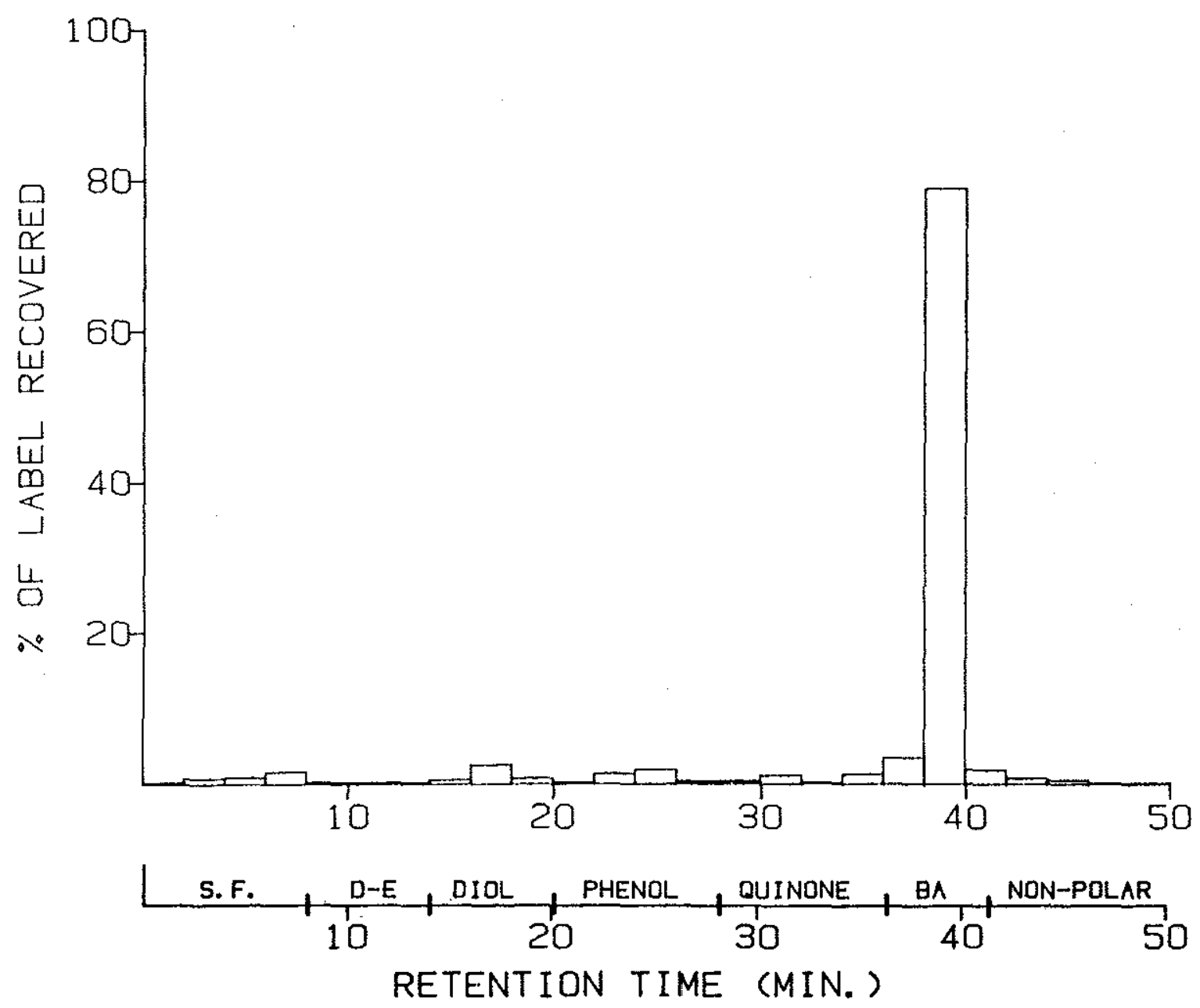

Figure $3.10:{ }^{14} \mathrm{C}$ HPLC chromatogram of organic extract of water sample from experiment 4 . Over 1 ay on $x$ axis refers to retention time windows corresponding to different classes of authentic BA metabolite standards. Abreviations: $S F=$ solvent front; $D-E=$ diol-epoxide. Non-polar refers to all activity eluting after BA. 


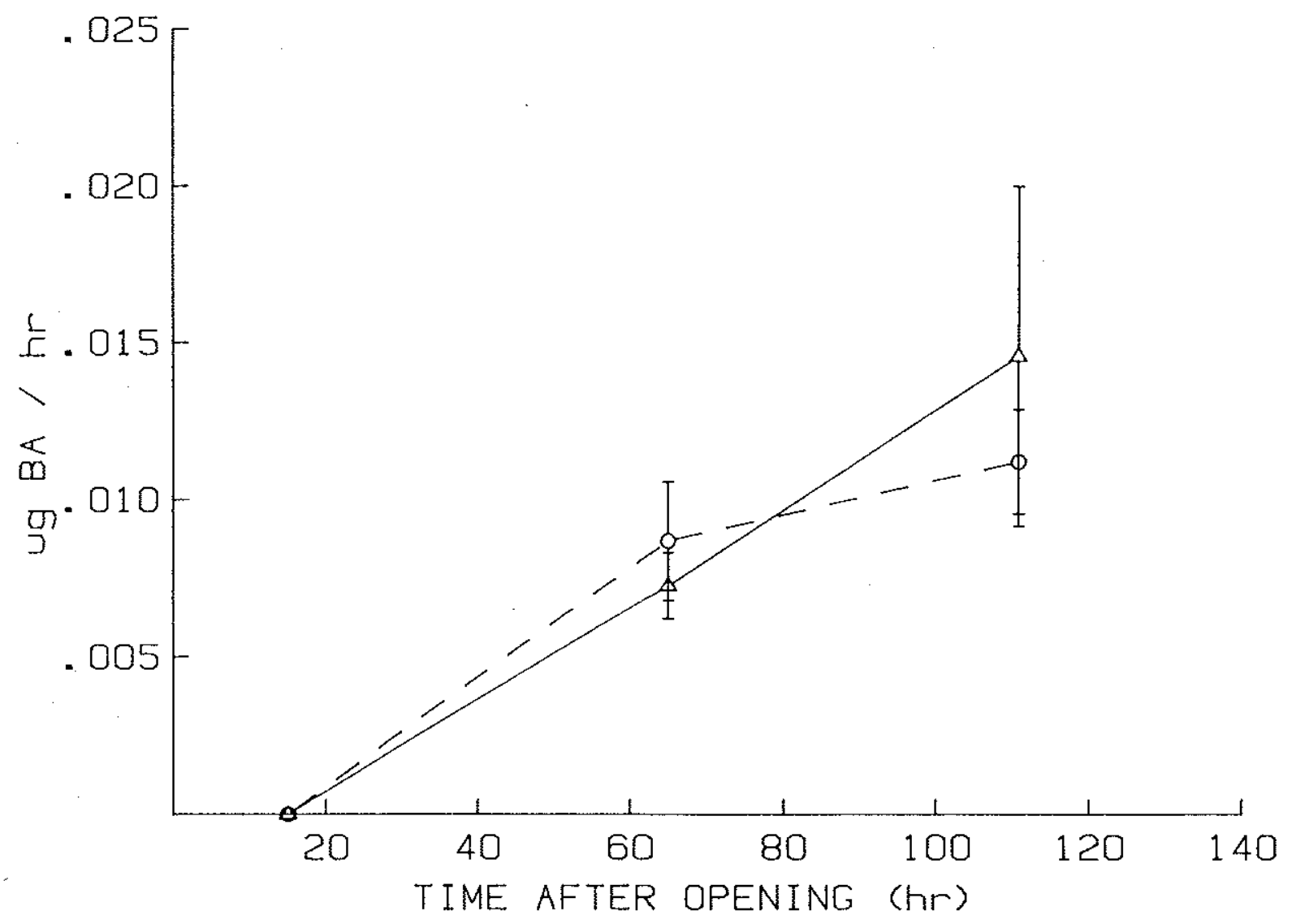

Figure 3.11: BA mineralization to carbon dioxide after initiation of flow-through conditions in experiment 4. Circles represent chambers without worms. Triangles represent chambers with worms. Values expressed as mean $\pm S E n=3$. 
in the 25 day experiment with sediment-sorbed BA (See Figure 3.6). Variability in mineralization rates was large, coefficients of variation ranging from 62 to $97 \%$. However, even with such large variability the change in $f 1 u x$ rate with time was statistically different than zero $(p<.01)$ both for chambers with and chambers without worms.

Calculating a mass balance of BA in this experiment was more complicated than in experiments with sediment-sorbed BA. Since BA activity was not uniformly distributed throughout the sediment column, the total mass of $B A$ recovered from the sediment was calculated by taking the average total recovered per core and multiplying by the number of cores it would take to completely sample the sediment surface. Because BA flux to the seawater did not change with time after washout was complete, total removal of $\mathrm{BA}$ to the water column was calculated by taking the average rate over the last 4 days and multiplying by the length of exposure. No attempt was made to include BA left over from the initial spike that was washed out of the chambers after resumption of flow-though conditions in mass balance calculations.

The mass balance of BA for this experiment, calculated as described above, is presented in Table 3.10 . In the chambers with worms on 1 y $72 \%$ of BA recovered was in the sediment. Approximately $13 \%$ was recovered from the worms or removed via total extractable label in the water co 1umn, and on 1 y $0.75 \%$ was lost to the water column mineralized to $\mathrm{CO}_{2}$. In chambers without worms sinilar proportions of total radioactivity recovered were found in the sediment and as mineralized to $\mathrm{Co}_{2}$, although $24 \%$ of total activity was removed via the water column. The actual amounts of $B A$ removed $v i a$ the water column were very similar for chambers with 


\section{Table 3.10 \\ WROLB CHAMBER MASS BALANCE: TOTAL RADIOACTIVITY AND $z$ OF TOTAL RECOVERED AT EHD OF BXPERIMENT UITH BENZ(a)ARTHRACEWB ADDED DIRECTIY TO THE WATER COLUMR (BXPBRIMENT 4)}

$\begin{array}{ll}\text { Sediment Worms } & \text { Water Column } \\ & \text { Tot ext. } \mathrm{CO}_{2}\end{array}$

ug Total Benz(a)anthracene

Recovered

(BA plus metabolites)

Worms

Without worms

$\%$ of Total Radioactivity Recovered

Worms

Without worms
71.7

12.7

13.0 .738

47.4<smiles>C[Hg]</smiles>

14.3

.740

73.1

12.9

13.2

.750

75.9

$\cdots$

22.9

1.18 
and without worms (13.0 vs $14.3 \mathrm{ug})$. However, the presence of the worms as a BA reservoir in the chambers with worms, and a s1ight 1 , but not significantly, lower amount of BA recovered from sediment in chambers without worms, resulted in a higher percentage of total recovered attributed to flux into the water column. After washout, the average BA flux to the water column was $0.2 \mathrm{ug} / \mathrm{hr}$, as compared to $0.005 \mathrm{ug} / \mathrm{hr}$ as an average for the same length of time in the experiments with sediment sorbed $B A$, even though concentration of $B A$ at the surface was lower in this experiment. This elevated flux indicates that BA loosely associated with the surface $f l o c$ is more available for desorption than BA previously bound to sediment particles.

Bxperiment with BA labeled food:

Al1 chambers contained worms in this experiment. Each chamber received a single dose of 4 pieces of 1 abeled food which was placed at the sediment surface in different parts of the chamber. In all chambers, within four hours, a 11 but one piece of food had been eaten. The last piece was consumed sometime between 6 and 14 hours after addition.

A11 chambers received control sediments, so no initial cores were taken in this experiment. Concentrations of BA extracted from individual sediment cores taken 96 hours after the addition of labeled food are given in Table 3.11. Concentrations were very low, averaging on 1 y 0.780 $\mathrm{ng} / \mathrm{gdw}$, and were highly variable ranging over one order of magnitude In contrast to the other experiments, $9.1 \%$ of the total activity recovered from the sediment was found in the aqueous extract. Activity in the aqueous extract was also highly variable ranging from 0.52 to $21.2 \%$ of the total recovered per core. Replicate cores from each chamber had an 
Table 3.11

BEHZ(a)AYTHRACENE RECOVERED FROY IRDIVIDUAL SEDTMEWT CORES IH BXPERIMRHT UITH BEHZ(a)AMTHRACENE IABELED FOOD

(EXPRR IKEMT 5)

TOTAL COACBMrRation AND $z$ OF TOTAl, IN AQUEOUS EXTRACT

$\begin{array}{cc}\text { ng BA/gdw } & \% \text { in Aqueous Extract } \\ .329 & 11.75 \\ .282 & 16.10 \\ .508 & 10.29 \\ .767 & 0.52 \\ .730 & 3.05 \\ 2.457 & 21.16 \\ .410 & 1.04 \\ \text { Mean }=.780 & \\ \mathrm{SE}=.285 & \text { Mean }=9.13 \\ & \mathrm{SE}=3.00\end{array}$


average coefficient of variation of $45 \%$ for total activity and $114 \%$ for the percent of total in the aqueous extract. Unfortunately total activity of the sediment extracts was insufficient to allow analysis for polar metabolites on HPLC.

The concentration of $\mathrm{BA}$ recovered from worms taken from each chamber 96 hours after feeding was $0.517 \pm .033 \mathrm{ug} / \mathrm{gdw}$. Based on relative concentrations, the worm/food concentration factor was on 1 y 0.028 , but the total amount of BA in worm $t$ issue accounted for $83 \%$ of the 1 abeled BA added to the chamber. The ratio between the BA concentration in worms and sedinents was 663 .

BA flux to the water column is shown in Figure 3.12. The first water sample represents the first hour after addition of labeled food to the chambers. The relatively low flux observed at this point indicated that little leakage of BA from the food occurred before it was consumed. Flux was highest the day after ingestion, $2.3 \mathrm{ng} / \mathrm{hr}$. Considering the fact that these measurements were made on $1 y$ once each day, the actual maximum rate may have been higher. On the second, third, and fourth day rates remained fair $1 y$ constant, averaging around 2.5 times that seen right after feeding. Flux of BA to the water column were approximately an order of magnitude less than those observed in experiments with sediment-sorbed $B A$ and two orders of magnitude lower than those observed when BA was introduced via the water column. There was no detectable flux to the water colum of $\mathrm{BA}$ mineralized to $\mathrm{CO}_{2}$.

The mass balance of BA in this experintent was calculated as the total amount recovered, as a percentage of total activity recovered and as a percentage of the spike added to each chamber (Table 3.12). After 


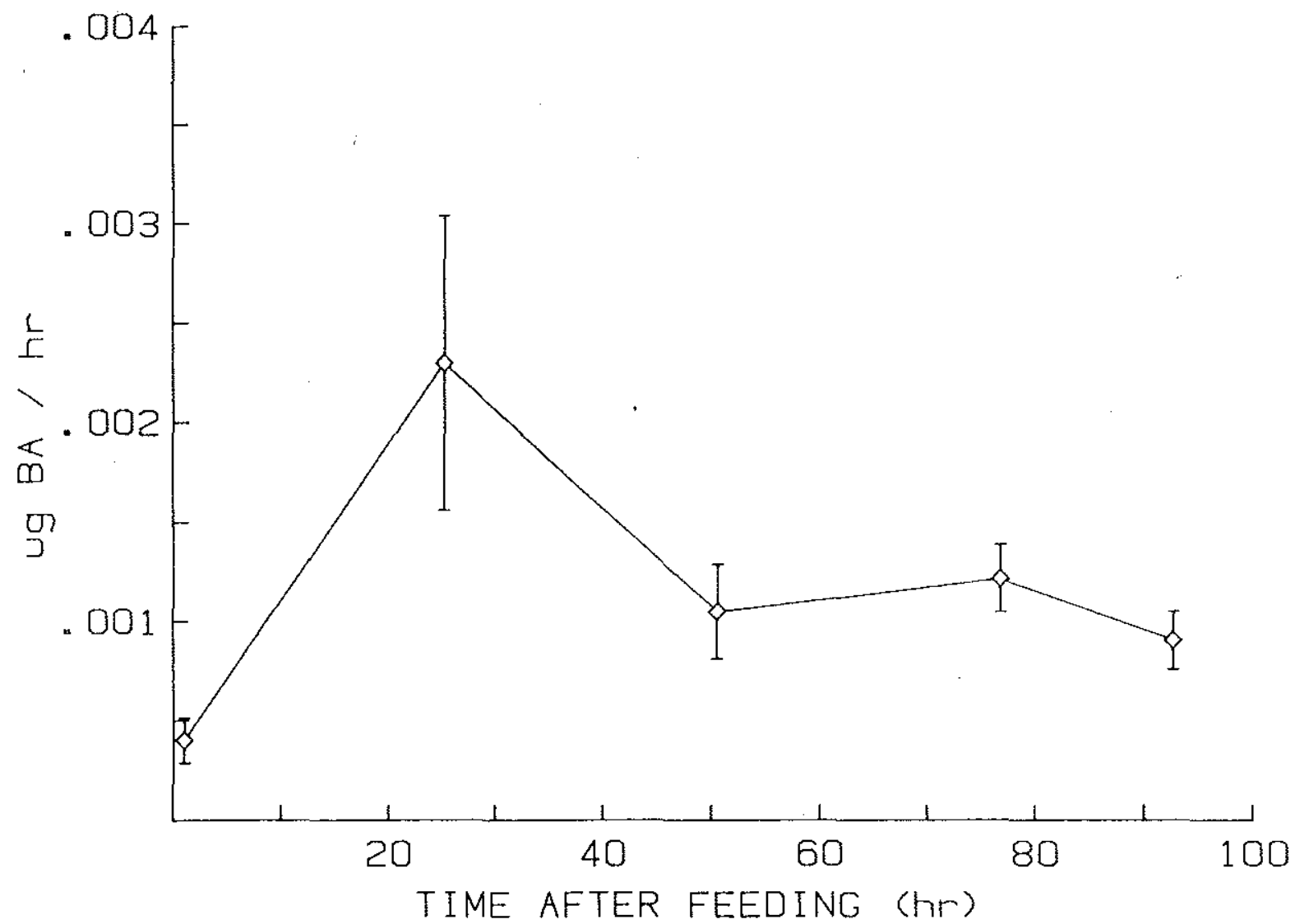

Figure 3.12: BA flux to water column in experiment 5 after introduction of labeled food. Values expressed as mean $\pm S E n=4$. 
Table 3.12

WHOLE CHAMBER MASS BAIANCE: TOTAL ACTIVITY RECOVERED AT THB END OF EXPERIMRMT HITH BEHZ(a)AMTHRACERE ADDED IN LABELED FOOD (BXPERIMENT 5)

$\begin{array}{ll}\text { Sediment Worms } & \text { Water Column } \\ & \text { Tot ext. } \mathrm{CO}_{2}\end{array}$

ug Total

BA Recovered

.301

2.14

.122

N.D.

(BA plux metabolites)

$\%$ of Total Recovered

11.8

83.5

4.76

0

$\%$ of Total Added

11.6

82.3

4.69

0

2.60 ug Benz(a)anthracene added $98.5 \%$ recovered 
96 hours, $82.3 \%$ of the spike added was recovered from the worms, with $4.7 \%$ removed via the water column, and $11.6 \%$ recovered from the sediment. over $98 \%$ of BA added to the chambers was recovered indicating that the worms did indeed consume all food offered and that the chambers were sampled effective1y.

\section{Discussion:}

The presence of worms had significant effects on the fate of $B A$ in the benthic microcosms investigated in these experiments. In experiments with sediment-sorbed $B A$, flux from the sediment to the water column was always higher in chambers with worms than in chambers without worms, and this effect intensified with time. Increased flux of BA out of sediments due to the presence of worms could have been caused by several processes. Worm burrows increase the surface area of the sediment exposed to the water column and thereby provide more area for diffusion. Irrigation activities of the worms for respiration flush the burrows and maintain a concentration gradient favoring BA flux out of the sediment. Subsurface worm activity also increases oxygen and nutrient supplies to sediment at depth which could also increase microbial mineralization of BA. In addition, excretion of water soluble metabolites by the worns would also augment the flux of BA from the sediments.

In the short-term experiments there was no evidence of microbial BA mineralization, so it is unlikely that microbes were responsible for the increased flux in these experiments. More likely, the increased flux was mediated by a combination of worm burrow activity and excretion of BA metabolites. Assuming that as a minimum, subsurface burrows must have been large enough to contain the worms present in each chamber, worm 
burrows increased the surface area of the sediment water interface by a factor of approximately 2 to 3 in the chambers used in this study. Additiona11y, using a conservative estimate of burrow irrigation rates for benthic organisms ventilating just for respiratory purposes of 2.5 ml/g-hr (calculated from Davis, 1979), the water in burrows would be replaced twice an hour. Based on these calculations, it is surprising that worms did not increase BA flux even more than was observed.

The increase in BA flux from the sediment reported here is similar to that reported by Karichkoff and Morris (1985) who looked at the effect of tubifex worms on release of chlorinated hydrocarbons from sediment. They found that worms increased the net upward mobility by a factor of 20 by completely mixing the $10 \mathrm{~cm}$ bioturbated zone. However, they also found that packaging sediment into fecal pel lets retarded desorption. The net effect of worm reworking was to increase net flux out of the sediment by factor of 6 over that seen by diffusion alone. The enhanced $f 1 u x$ of hydrocarbons from the sediment reported by Karichkoff and Morris were due to the complete mixing of the bioturbated zone by a small oligochaete. In contrast, the enhanced release of $B A$ from the sediment mitigated by Nereis was due to construction and irrigation of discrete burrows.

In the longer-termed experinent with sediment-sorbed BA in addition to flux mediated by burrow construction and irrigation, enhancement of flux may have been mediated in part by microbial activity. Both BA mineralization rate and flux to the water column increased in chambers with worms after 12 days. $\mathrm{BA}$ mineralized to $\mathrm{CO}_{2}$ would not be detected by solvent extraction of BA from the water column. The co-occurrence of 
increased rates of ${ }^{14} \mathrm{CO}_{2}$ production and total extractable ${ }^{14} \mathrm{C}$ observed in the water column could have been fortuitous, or could have been due to incomplete mineralization of BA leading to an increase in water soluble metabolites.

Supplementation of diffusive flux of BA out of the sediment by the excretion of water soluble BA conjugates produced by worms is supported by two lines of evidence. Worms from both the short- and long-term sediment exposure experiments contained significant amounts of water soluble BA metabolites (See Chapter 4). The formation of conjugated metabolites is thought to be the primary pathway for PAH excretion in organisms with competent MFO systems. The increase in the percentage of activity seen in the aqueous extracts of sediments taken from chambers with worms supports the premise that worms were excreting some water soluble metabolites. No increase in water soluble activity in sediment cores taken from chambers without worms was observed. In addition the percentage of activity in aqueous sediment extracts was more pronounced in the longer-termed sediment exposure experiments, as was the percentage of activity recovered from the worms.

Although the presence of worms significantly increased the rate of removal of BA from sediments in experiments with sediment-sorbed BA, due to the large excess of sediment in the chambers as compared to worms $(\sim 200 \mathrm{x})$, on a whole chamber basis worms did not have a large effect on bulk removal of $\mathrm{BA}$. Using the rates of $\mathrm{CO}_{2}$ mineralization and $\mathrm{f} 1 \mathrm{ux}$ to seawater observed in the 25 day experiment and assuming they remained constant, the residence time of BA in chambers with worms would be approximately 4 years as opposed to 9.5 years for chambers without worms. 
Gardner et a1. (1979) looked at the impact of a sma11 polychaete Capite1 la sp. on the removal of anthracene, fluoranthene, $B A$, and $B P$ mixed into sediments. In 60 days they found increased removal of PAH from sediments in the presence of worms, and that the effects were more pronounced with larger PAH. Capite 11a increased the rate of BA removal by a factor of 1.3 to 1.8 times depending on sediment type. They hypothesized that the increased removal was due to either worm or microbial metabolism of $\mathrm{BA}$, but, they did not measure either process direct $1 \mathrm{y}$. In contrast Augenfeld et al. (1982) did not find the presence of the deposit-feeding polychaete Abarenicola to have significant effects on decreasing sediment concentrations of $\mathrm{BP}$, chrysene, and phenanthrene, in 60 day benthic chamber experiments. The mass of sediment was approximate 1 y 1000 times greater than that of the worms in their study, so the effect of worms may have been more difficult to detect.

In the experiments where $B A$ was added directly to the water column, the presence of worms had a different effect. Neither the flux of BA out of sediment nor microbial mineralization of $\mathrm{BA}$ to $\mathrm{CO}_{2}$ were affected by the presence of worms. Since almost al1 of the activity was present at the sediment-water interface, flux of BA through worm burrows should not have the same importance as when bulk sediments were labeled. However, worms did produce a net downward mixing of $B A$ into the sediment. The reduction in $f$ lux out of the sediment due to burial may have been compensated by increased $f l u x$ of $B A$ due to burrow irrigation or excretion of water soluble metabolites.

Regardless of mode of introduction $B A$ was available for accumulation by Nereis virens. The bioavailability of sediment-sorbed and ingested BA 
contrasts with an earlier report by Rossi (1977) who found PAH in these forms unavailable for uptake by the worm Neanthes arenaceodentata. Other investigations with worms have reported $\mathrm{PAH}$ and $\mathrm{PCB}$ accumulation from sediment and dietary sources (Augenfe1d et a1., 1982; Lyes et al., 1979; Courtney and Langston, 1978; Goerke, 1979; Roesijadi et a 1., 1978; Fowler et a1., 1978); as have investigations with other organisms such as fish (Varanasi and Gmur, 1981, Varanasi et a1., 1979; Palmork and Solbakken, 1981), midge larvae (Leversee et al., 1982), blue crab larvae (Lee et a 1., 1976), and the accumulation of PCBs in larval bivalves (Dobroski and Epifanio, 1980).

Quantifying the efficiency of different modes of uptake is difficult. An accurate determination requires either comparison of accumulation when al1 components of the systems are at equilibrium, or detailed analysis of the kinetics of uptake, metabolism, and depuration. Since it can take months for benthic organisms such as deposit feeders to reach equilibrium concentrations with hydrophobic compounds such as the larger PAH and PCBs (Roesijadi et a1., 1978; Fowler et a 1., 1978), and determination of detailed uptake and depuration kinetics was beyond the capabilities of the experimental system available, a compromise approach was used. Bioaccumulation from different sources was compared after similar exposure periods.

On the basis of percent of total BA accumulated into worms, dietary BA incorporated into digestible food was more available than BA added to the water column, which was more available than BA sorbed to bulk sediments. The percentage of total activity in the chambers recovered from worms was $83 \%$ when worms were fed BA 1 abeled food, $13 \%$ when BA had been 
added to the water column, and less than $1 \%$ when worms were exposed to a sediment reservoir uniformly labeled with BA. However, due to the large differential in the total amount of BA available to worms in experiments using these different methods of introduction, this comparison is not entirely valid. The concentration factors between water, sediment, and worms observed here are not directly comparable to those reported by other studies because no attempt was made in this study to ascertain if equilibrium conditions had been reached. However, worm/sediment concentration factors for worms exposed to BA in the short-term experiments $(1,2, \& 4)$ can be compared. In short-term exposures to sediment-sorbed BA (exp.1\&2), worms on $1 y$ accumulated BA to 0.6 times the concentration seen in bu 1k sediments. In comparison, in the short-term water column exposure experiment (exp.3), worms accumulated BA to a greater extent. Even when normalized to the highest sediment concentrations found in the top centimeter of the sediment, the worm/sediment concentration of BA was greater than 2. On a whole core basis the accumulation factor increased to 17. These ratios indicate that BA introduced direct $1 \mathrm{y}$ to the water column, most of which was transfered to the sediment-water interface via mixing and adsorption during the recycle mode, was more available for worm accumulation than BA already sorbed to sediment particles.

Making comparisons based on concentration factors between experiments with sediment-sorbed BA or BA added to the water column and the experiment with BA labeled food are problematic. In the first two cases, the worms were exposed to a large pool of BA, but they probably only came in direct contact with a snall portion of that present. In the feeding experiment, once worms ate the food, the entire dose was within the worm. 
Nevertheless the extremely high efficiency with which Nereis accumulated BA from food ( $>83 \%$ ) suggests that of the different modes of introduction investigated in this study, BA in ingested food was most available for accumulation.

This finding is particularly interesting when compared to a recent field study by Malins et a1.(1985). Bile samples from English sole collected from different parts of Puget Sound showed flourescence spectra indicating the presence of PAH metabolites. Although PAH concentrations in the sediment where some of these fish were collected were low, PAH concentrations in the stomach contents (predominantly polychaete worms) of the fish were high. Due to the mobility of these fish, it is impossible to say where they accumulated the PAH. Nevertheless, these results strongly indicate that diet may be an important source for FAH accumulation in the field, and support the conclusions of this study that dietary transfer of PAH may be an important process.

On a whole chamber basis, the mode of introduction had dramatic effects on what happened to BA. Over the time course of a month, most of the sediment-sorbed BA remained in the sediment. Removal by accumulation into worms, flux to seawater, or microbial mineralization was sma 11 compared with the total mass of BA present. As discussed above, the presence of worms enhanced removal, but in the short time scale of these experiments, the overa11 effect was sma11.

When BA became associated with the sediment-water interface after being spiked to a recirculating water column, in addition to being more available for accumulation by worms, it was much more available for removal via diffusive flux to seawater and microbial mineralization to 
$\mathrm{CO}_{2}$ regardless of whether or not worms were present. In this experiment approximately $1 \%$ of total $\mathrm{BA}$ recovered was mineralized to $\mathrm{CO}_{2}$, and 13 to $23 \%$ was lost to the water column. In comparison, rates of BA mineralization were undectable and on $1 y 0.1 \%$ of total radioactivity was lost to the water column in week-long experiments with sediment-sorbed BA. A substantial portion of these effects may be due to the deposition of BA at the sediment-water interface, an area of enhanced microbial activity and diffusive flux. Nevertheless, the increased concentration factors exhibited by worms in this experiment suggest that BA may not be as tight 1 y bound to sediments when introduced in this way. These findings are in agreement with studies indicating negligible microbial mineralization of sediment-sorbed PAH with more than 3 rings (Herbes and Schwal1, 1979, and Gardner et a1., 1979). The results presented here are also in agreement with two previous investigations of BA added to the water column in large benthic microcosms (Hinga et a1., 1981; and McElroy et a1., 1982, Appendix 1), reporting microbial mineralization of $B A$.

\section{Sury:}

The results of this investigation emphasize the interactive effects of biologica1, chemical, and physical processes on the fate of chemicals in the benthos. The presence of the burrowing polychaete Nereis virens and the mode of BA introduction had significant effects on the fate of BA in benthic microcosms. BA loosely associated with particles at the sediment-water interface was relatively labile, and was more available for accumulation and metabolism by Nereis, mineralization by microbes, and diffusive flux to the water column than BA sorbed to bulk sediments. The presence of worms also had a positive effect on microbial mineraliza- 

tion of BA. BA in a protein-based food was most efficient ly accumulated by Nereis, whereas sediment-sorbed BA was least available for accumulation. 



\section{CHAPTER 4: \\ IN VIVO METABOLISH OF BENZ( 8 )ANTHRACERE BY Nereis virens}

\section{Results:}

\section{Distribution of accumalated activity into metabolite classes:}

Concentrations and the percent of total activity accumulated into different metabolite classes are shown in Table 4.1. Nereis was able to extensively metabolize accumulated $\mathrm{BA}$ regardless of the mode of introduction. On 1 y 2 to $23 \%$ of radioactivity recovered from worms was unmetabolized BA. Due to the presence of unmetabolized BA in sediment in the intestines of these worms when they were collected, in experiments 1-4 the percent of total activity in worms reported as BA is probably an overestimate by up to a few percent.

High pressure liquid chromatography of worm organic extracts revealed a small percentage of radiolabel eluting after BA. Although the identity of this fraction is unknown, chromatographic conditions suggest that it is nonpolar and probably larger than BA. This fraction accounted for only a small percentage of recovered isotope in each experiment, so it will not be discused further. However, previous work on in vivo metabolism of BA by the worm Nephty incisa indicated that incorporation of radiolabe 1 into this unknown fraction can be significant (See Appendix 1).

The distributions of parent $\mathrm{BA}$ and metabolite classes in each experiment are given in Tables 4.1 and 4.2, and displayed in Figures 4.1 and 4.2. Arcsin transformations of the percentages were compared by ANOVA and SNK. Brackets at the bottom of each histogram join classes that are not significant ly different from each other $(p>05)$.

The size of each metabolite pool as a proportion of total is plotted 
Table 4.1

\section{DISTRIBOTION OF RADIOACTIVITY RECOVERED FROM WORHS PERCERTAGE OF RECOVERBD RADIOACTIVITY IH MAJOR METABOLITE CLASSES}

\begin{tabular}{|c|c|c|c|c|c|}
\hline & $\mathrm{BA}$ & $\begin{array}{l}\text { Polar } \\
\text { Met. }\end{array}$ & $\begin{array}{l}\text { Conj. } \\
\text { Met. }\end{array}$ & Unext. & $\begin{array}{l}\text { Non-pol. } \\
\text { Lipid }\end{array}$ \\
\hline \multicolumn{6}{|l|}{$\begin{array}{l}\text { Experiments with } \\
\text { sediment-sorbed BA }\end{array}$} \\
\hline 6 day exposures & $\begin{array}{r}23.0 \\
+4.2\end{array}$ & $\begin{array}{r}11.0 \\
+2.4\end{array}$ & $\begin{array}{r}31.7 \\
\pm \quad 2.1\end{array}$ & $\begin{array}{r}32.9 \\
\pm \quad 2.1\end{array}$ & $\begin{array}{c}1.36 \\
+0.63\end{array}$ \\
\hline 25 day exposure & $\begin{array}{r}4.47 \\
\pm 0.94\end{array}$ & $\begin{array}{r}6.48 \\
+2.98\end{array}$ & $\begin{array}{r}35.1 \\
\pm \quad 1.4\end{array}$ & $\begin{array}{r}52.6 \\
+\quad 2.4\end{array}$ & $\begin{array}{r}1.25 \\
\pm 0.50\end{array}$ \\
\hline
\end{tabular}

Experiment with $B A$ added to the water column

\begin{tabular}{|c|c|c|c|c|}
\hline 6 day exposure & $\begin{array}{r}8.80 \\
+0.67\end{array}$ & $\begin{array}{r}5.52 \\
+0.04\end{array}$ & $\begin{array}{r}45.9 \\
\pm \quad 1.6\end{array}$ & $\begin{array}{r}38.1 \\
\pm \quad 0.8\end{array}$ \\
\hline
\end{tabular}

Experiement with

BA labeled food

\begin{tabular}{|c|c|c|c|c|}
\hline 4 day exposure & $\begin{array}{r}2.11 \\
+0.43\end{array}$ & $\begin{array}{r}7.68 \\
+0.52\end{array}$ & $\begin{array}{r}48.1 \\
\pm \quad 1.2\end{array}$ & $\begin{array}{r}40.8 \\
+\quad 0.9\end{array}$ \\
\hline
\end{tabular}

$\mathrm{BA}=$ benz ( $\mathrm{a})$ anthracene

Polar Met. = polar metabolites

Conj. Met. = conjugated metabolites

Unext. = unextractable label

Non-po1. Lipid = lipid extractable, nonpolar labe1

Values expressed as mean $\pm \mathrm{SE}$

Values for BA in experiment $1-4$ may be slight overestimates due to unmetabolized BA on sediment in gut of worm. Gut contents can account for $3 \%$ of body weight.

Results of statistical analysis presented with data in Figures 4.1-4.3. 
Table 4.2

\section{DISTRIBUTION OF RADIOACTIVITY RECOVERED FROY HORHS \\ CONCEHTRATIONS IN MAJOR METABOLITB CLASSES}

\begin{tabular}{|c|c|c|c|c|c|}
\hline & \multicolumn{5}{|c|}{$u g / g d w$} \\
\hline & BA. & $\begin{array}{l}\text { Polar } \\
\text { Met. }\end{array}$ & $\begin{array}{l}\text { Conj. } \\
\text { Met. }\end{array}$ & Unext. & $\begin{array}{l}\text { Non-pol. } \\
\text { Lipid }\end{array}$ \\
\hline \multicolumn{6}{|l|}{$\begin{array}{l}\text { Experiments with } \\
\text { sediment-sorbed BA }\end{array}$} \\
\hline 6 day exposures & $\begin{array}{r}1.22 \\
\pm 0.26\end{array}$ & $\begin{array}{r}.585 \\
\pm .137\end{array}$ & $\begin{array}{c}1.65 \\
\pm 0.07\end{array}$ & $\begin{array}{c}1.61 \\
\pm 0.03\end{array}$ & $\begin{array}{r}.073 \\
\pm .036\end{array}$ \\
\hline 25 day exposure & $\begin{array}{r}.590 \\
+.134\end{array}$ & $\begin{array}{r}.836 \\
+.369\end{array}$ & $\begin{array}{r}4.59 \\
\pm 0.15\end{array}$ & $\begin{array}{r}6.89 \\
\pm 0.55\end{array}$ & $\begin{array}{r}.166 \\
\pm .066\end{array}$ \\
\hline \multicolumn{6}{|l|}{$\begin{array}{l}\text { Experiment with } \\
\text { BA added to the } \\
\text { water column }\end{array}$} \\
\hline 6 day exposure & $\begin{array}{r}.333 \\
\pm .031\end{array}$ & $\begin{array}{r}.210 \\
+.018\end{array}$ & $\begin{array}{r}1.75 \\
+0.18\end{array}$ & $\begin{array}{r}1.45 \\
+0.15\end{array}$ & $\begin{array}{r}.062 \\
\pm .009\end{array}$ \\
\hline \multicolumn{6}{|l|}{$\begin{array}{l}\text { Experiement with } \\
\text { BA labeled food }\end{array}$} \\
\hline 4 day exposure & $\begin{array}{r}.0107 \\
\pm .0016\end{array}$ & $\begin{array}{r}.0399 \\
\pm .0044\end{array}$ & $\begin{array}{r}.249 \\
\pm .021\end{array}$ & $\begin{array}{r}.210 \\
\pm .011\end{array}$ & $\begin{array}{r}.007 \\
\pm .001\end{array}$ \\
\hline \multicolumn{6}{|c|}{$\begin{array}{l}\mathrm{BA}=\text { benz(a) anthracene } \\
\text { Polar Met. = polar metabolites } \\
\text { Conj. Met. = conjugated metabolites } \\
\text { Unext. = unextractable label } \\
\text { Non-pol. Lipid = lipid extractable, nonpolar label } \\
\text { Values expressed as mean } \pm \mathrm{SE}\end{array}$} \\
\hline \multicolumn{6}{|c|}{$\begin{array}{l}\text { Values for } B A \text { in experiment } 1-4 \text { may be slight overestimates due to } \\
\text { unmetabolized BA on sediment in gut of worm. Gut contents can } \\
\text { account for } 3 \% \text { of body weight. }\end{array}$} \\
\hline
\end{tabular}


for each experiment in Figure 4.1. The majority of total radioactivity recovered was found in the conjugated metabolite and unextractble fractions in a 11 experiments. The relative distribution of metabolite classes was the same in the last 3 experiments. Only in the short-term experiments with sediment-sorbed BA (exp. 1\&2) was a distinct 1 y different pattern seen, where the percentage left in the worms as parent compound was approximately equal to that present as conjugated metabolites and as unextractable activity.

Figure 4.2 shows the same data grouped according to metabolite class, illustrating the patterns in percent of total activity accumulated in each class between experiments. In short-term exposure to BA, the percent of parent compound remaining is highest in experiments with sediment-sorbed $B A$ and lowest in the experiment with BA labeled food, with an intermediate value observed when BA was added directly to the water column. The percent of total remaining as BA after long-term exposure to sediment-sorbed BA was similar to that seen in the short-term experiments with labeled food and BA added to the water column. The percent of total activity recovered in the polar metabolite fraction was not significantly different in any experiment.

The percent of activity recovered as conjugated metabolites was similar after both short- and long-term exposure to sediment-sorbed BA. Conjugates in the short-term experiments, where BA was added to the water column or when BA was added in 1 abeled food, represented a much higher percentage of total activity. The percent of total activity in the unextractable fraction was highest after long-term exposure to sedimentsorbed BA, lowest after short-term exposure to BA., and approximately 
Figure 4.1: Distribution of recovered radiolabel for each type of experiment, comparing different metabolite classes. Values expressed as mean $\pm S E$ of the percent of total radioactivity recovered in each metabolite class. Bars connecting different groups indicate no significant difference $(p>0.05)$. Means of arcsin transformed data compared by ANOVA and SNK. 


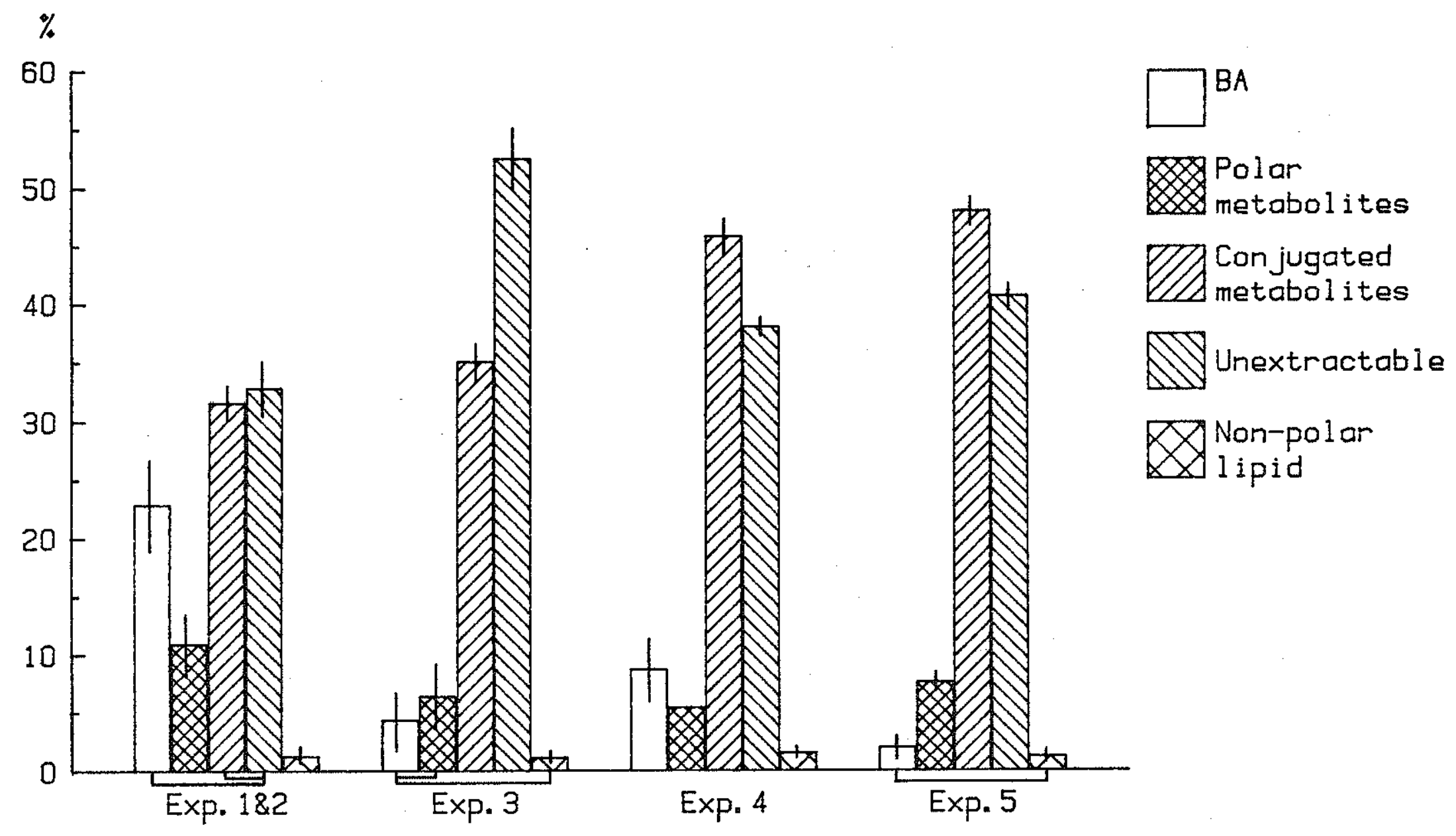


Figure 4.2: Distribution of recovered radiolabe 1 in different metabolite classes compared between experiment. Values expressed as mean $\pm \mathrm{SE}$ of the percent of total radioactivity recovered in each metabolite class. Bars connecting different groups indicate no significant difference $(p>0.05)$. Means of arcsin transformed data compared by ANOVA and SNK. 


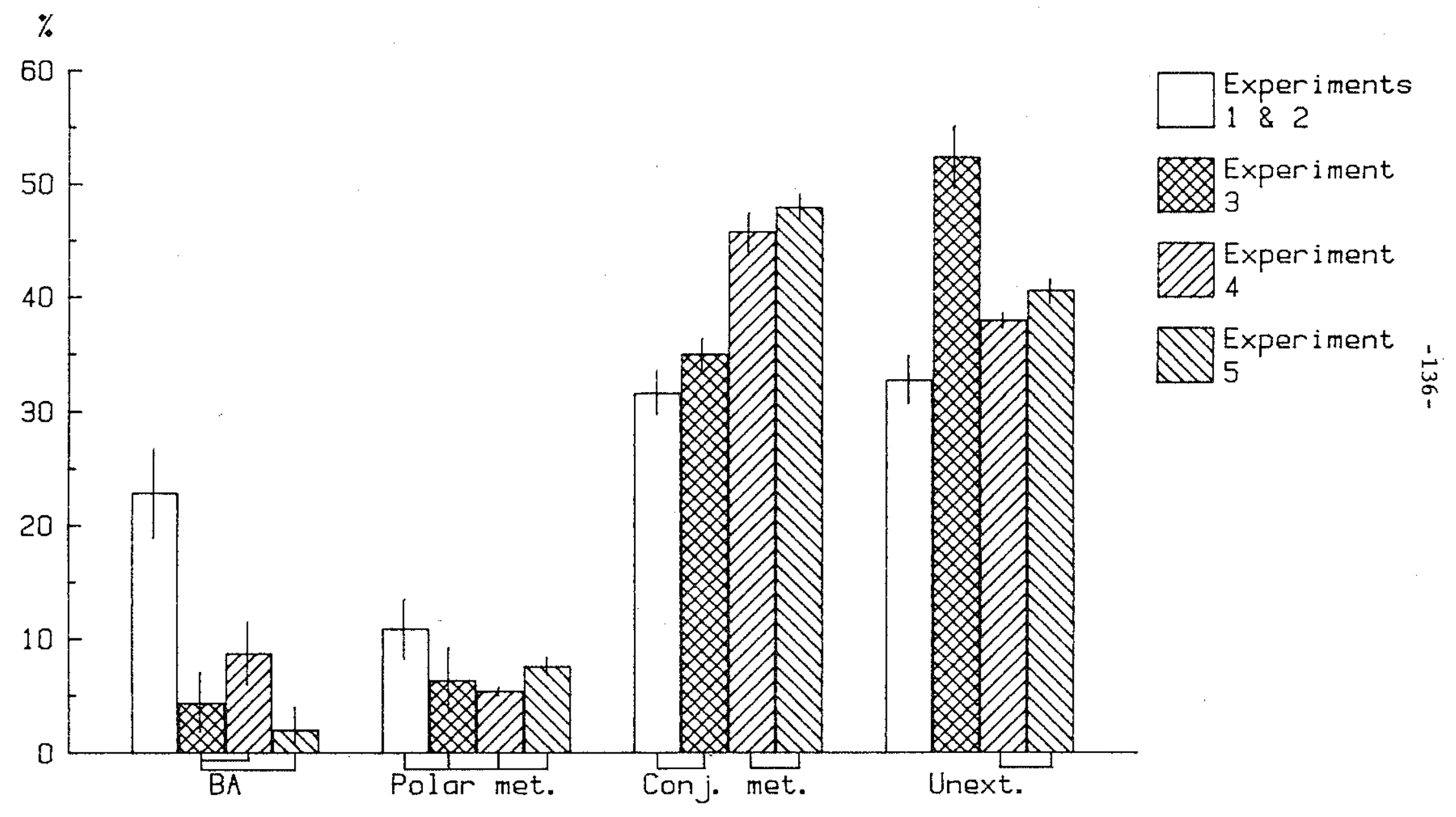


equal in experiments where BA was added either to the water column or in the food.

In the short- and long-term experiments witb sediment-sorbed $B A$, worns were continuous $1 \mathrm{y}$ exposed to similar concentrations of BA. Therefore comparisons between the absolute amounts accumulated into each of the metabolite classes can be considered. Figure 4.3 shows total accumulation into each metabolite class in ug/gdw for the 6 and 25 days experiments. Although the percentage recovered as BA decreased with length of exposure (see Figure 4.2), the absolute amount remained the same. Both the percentage of total and the absolute amounts of polar metabolites were not affected by length of exposure. In contrast, concentration of conjugated metabolites and of activity in the unextractable fraction increased dramatically with time. The concentration of conjugates increased by a factor of 2.8 , while concentration in the unextractable fraction increased by a factor of 4.3. Although the percentage of total activity in these two pools were equal in the short-term experiments (See Figure 4.1), the concentration in the unextractable fraction was significant ly higher than that in the conjugate pool after 25 days.

Separation of polar etabolites in organic eztract by reverse phase HPLC:

Organic extracts of worm tissue were analyzed by reverse phase HPLC to separate BA from polar metabolic products. Due to the complex mixture of compounds in addition to BA and BA metabolic products present in the organic extract, UV absorbance was of 1 itt le use in identifying polar metabolites (Figure 4.4). Attempts to clean-up wormorganic extracts using Waters Assoc. $C_{18}$ or silica Sep-Pak cartridges were unsuccessful. 
Figure 4.3: Total incorporation into different metabolite classes in experiments with sediment-sorbed $\mathrm{BA}$. Values expressed as mean $\pm \mathrm{SE}$. Means for each metabolite class compared between 6 and 25 day experiments using Student's T-test. * indicates significant difference $(p<0.05)$. 

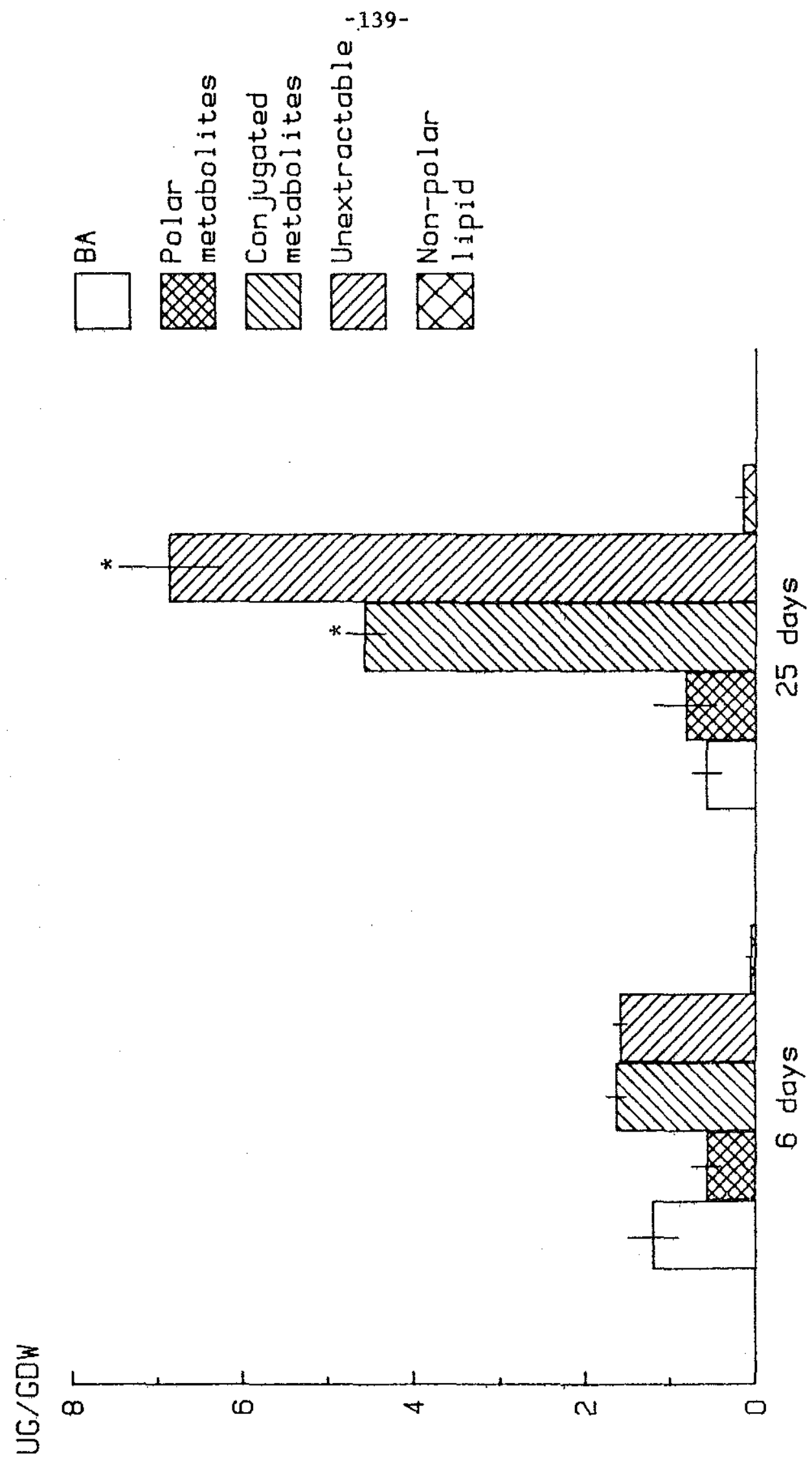


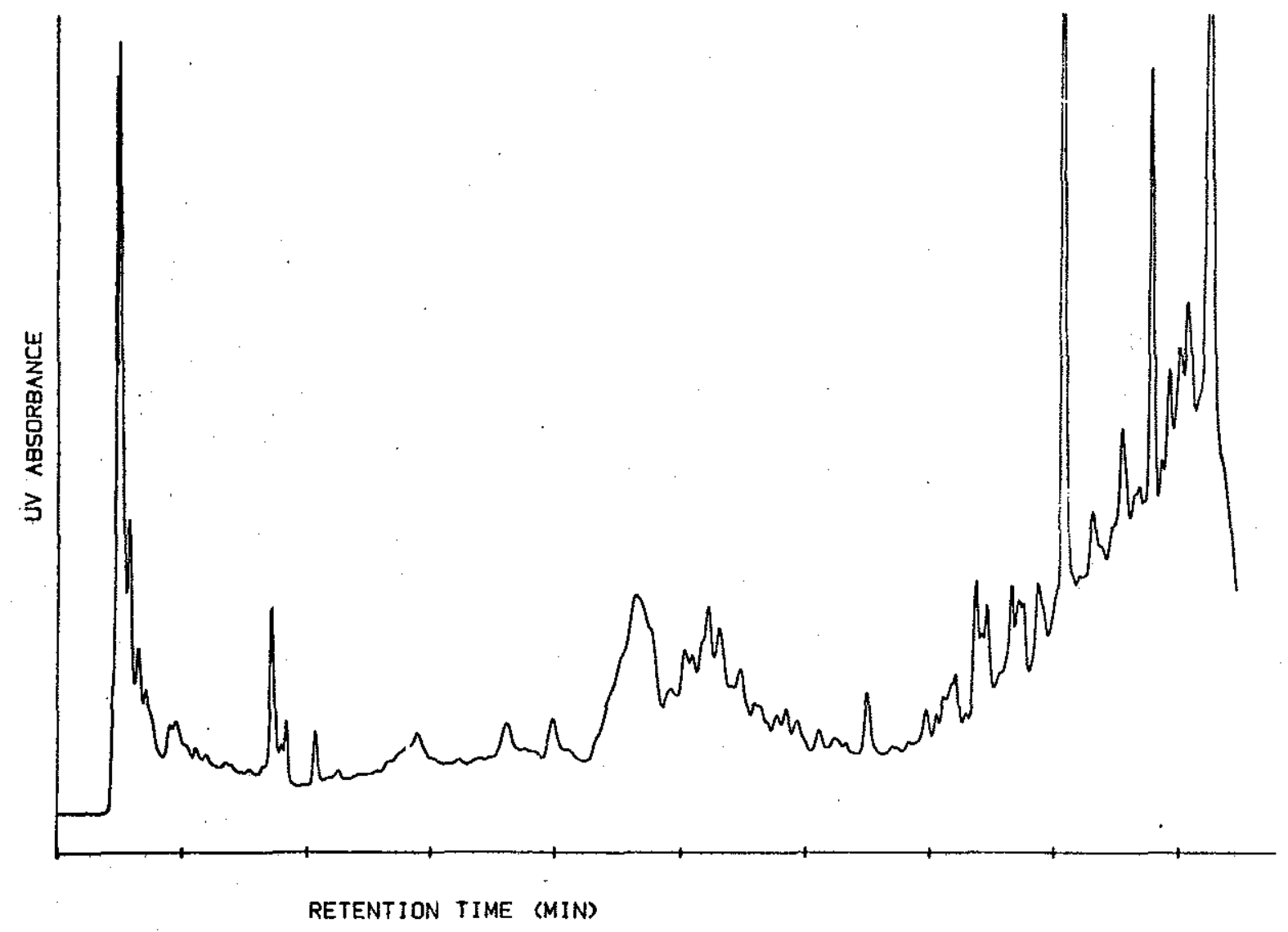

Figure 4.4: UV HPLC chromatogram of worm organic extract 
The to the wide range in polarity of polar metabolites and parent BA, it was not possible to significantly reduce either the polar or non-polar UV absorbing contaminants without also removing radiolabeled compounds of interest. To avoid missing unknown peaks, fractions of the HPLC eluant were collected for the entire run and ${ }^{14}$ cactivity analyzed by LSC. Authentic standards were available from the NCI for some polar BA metabo1ites. A chromatogram of representative classes of metabolite standards is shown in Figure 2.10. Co-injection of standards and worm extract indicated that the presence of extract did not alter retention time of standards, thus identification of polar metabolites was based on retention time.

The chromatograms generated from the ${ }^{14} \mathrm{C}$ activity collected in fractions seperated by HPLC (Figures $4.5-4.9$ ) are a 1 so complex. Due to the high lipid content of the worm organic extracts, not much material could be injected on the HPLC. Frequent ly there was a smearing of activity with broad humps in various portions of the chromatogram rather than in discrete peaks. Part of this smearing may have been due to overloading the column, and some was probably due to the fact that relatively long ( 1 or 2 minute) fractions were collected that most likely split some peaks and joined others. Identification of specific metabolites was further hampered by the availability of only some of the possible polar metabolites, and co-elution of others. Therefore radioactivity separated using HPLC was only identified to the level of metabolite class. Intervals of the chromatogram were assigned to several classes of metabolites based on the retention times of a 11 available standards. These retention time windows have been overlayed on the $x$ axis of each chromatogram. 
Figure 4.5: ${ }^{14} \mathrm{C}$ HPLC chromatograms of worm organic extracts from two chambers in experiment 1 . Overlay on $x$ axis refers to retention time windows corresponding to different classes of authentic BA metabolite standards. Abreviations: $S F=$ solvent front; $D-E=$ diol-epoxide. Non-polar refers to all activity eluting after $B A$. 


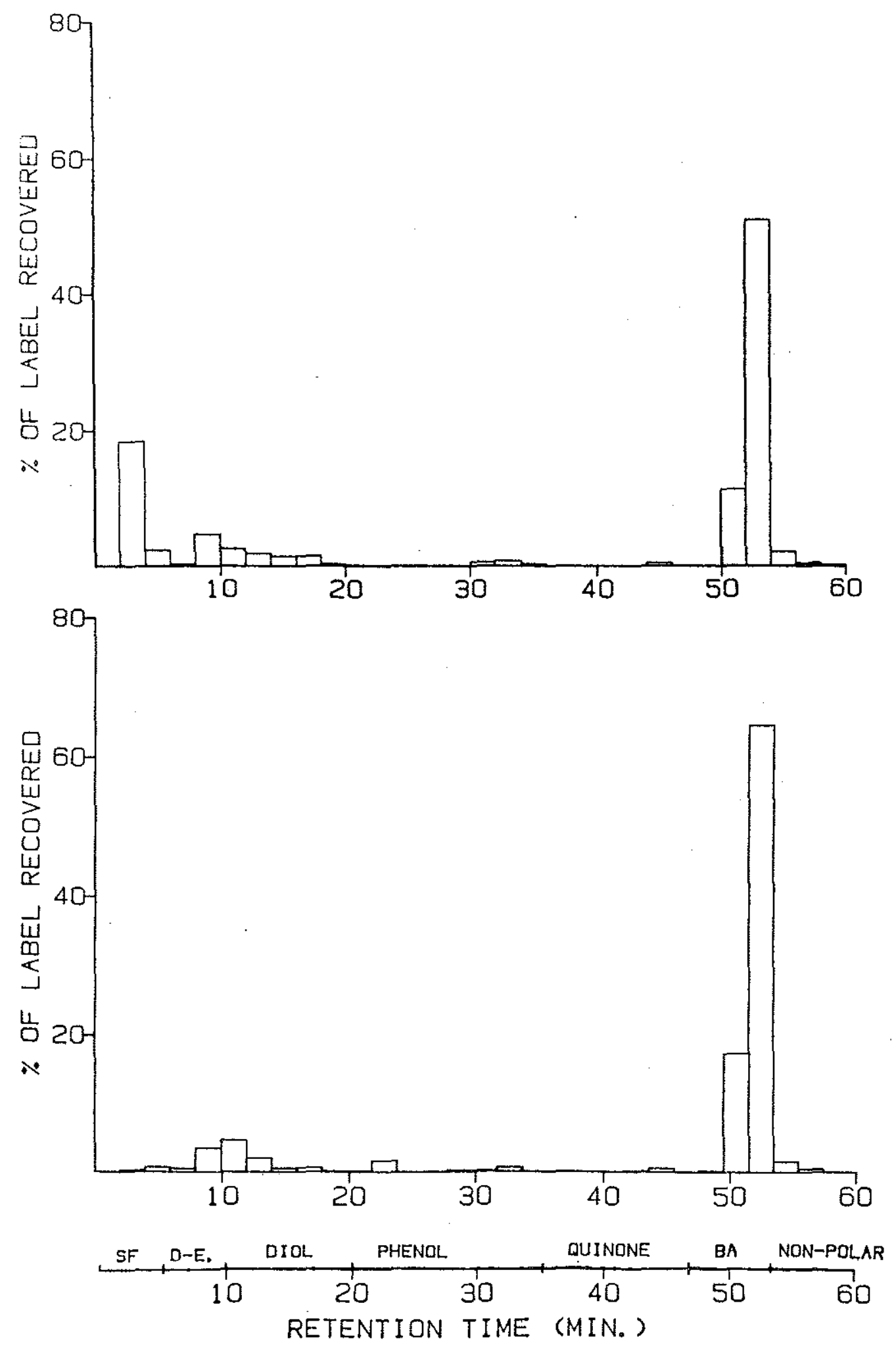


Figure $4.6:{ }^{14} \mathrm{C}$ HPLC chromatograms of worm organic extracts from two chambers in experiment 2. Overlay on $x$ axis refers to retention time windows corresponding to different classes of authentic BA metabolite standards. Abreviations: $S F=$ solvent front; $D-E=$ diol-epoxide. Non-polar refers to all activity eluting after BA. 

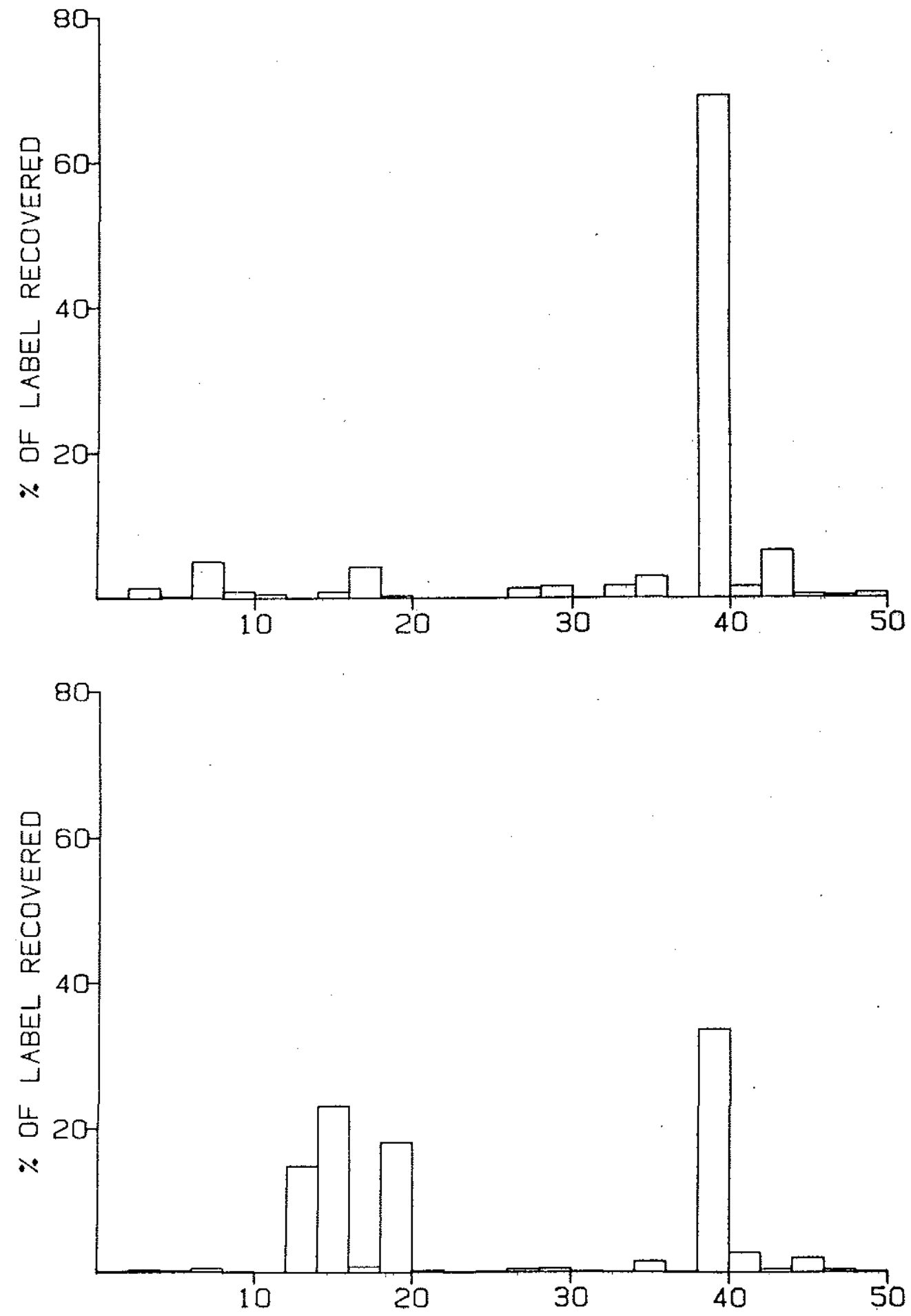

S.F. $=\underset{10}{\frac{D-E}{10}}, \frac{D I O L}{20}, \frac{\text { PHENOL }}{30}, \frac{\text { DUINONE }}{30}, \frac{B A}{40}+\frac{N D N-P O L A R}{50}$ RETENTION TIME (MIN.) 
Figure 4.7: ${ }^{14} \mathrm{C}$ HPLC chromatograms of worm organic extracts from all chambers experiment 3 . Over lay on $x$ axis refers to retention $t$ ime windows corresponding to different classes of authentic BA metabolite standards. Abreviations: $S F=$ solvent front; $D-E=$ diol-epoxide. Non-polar refers to all activity eluting after $\mathrm{BA}$. 

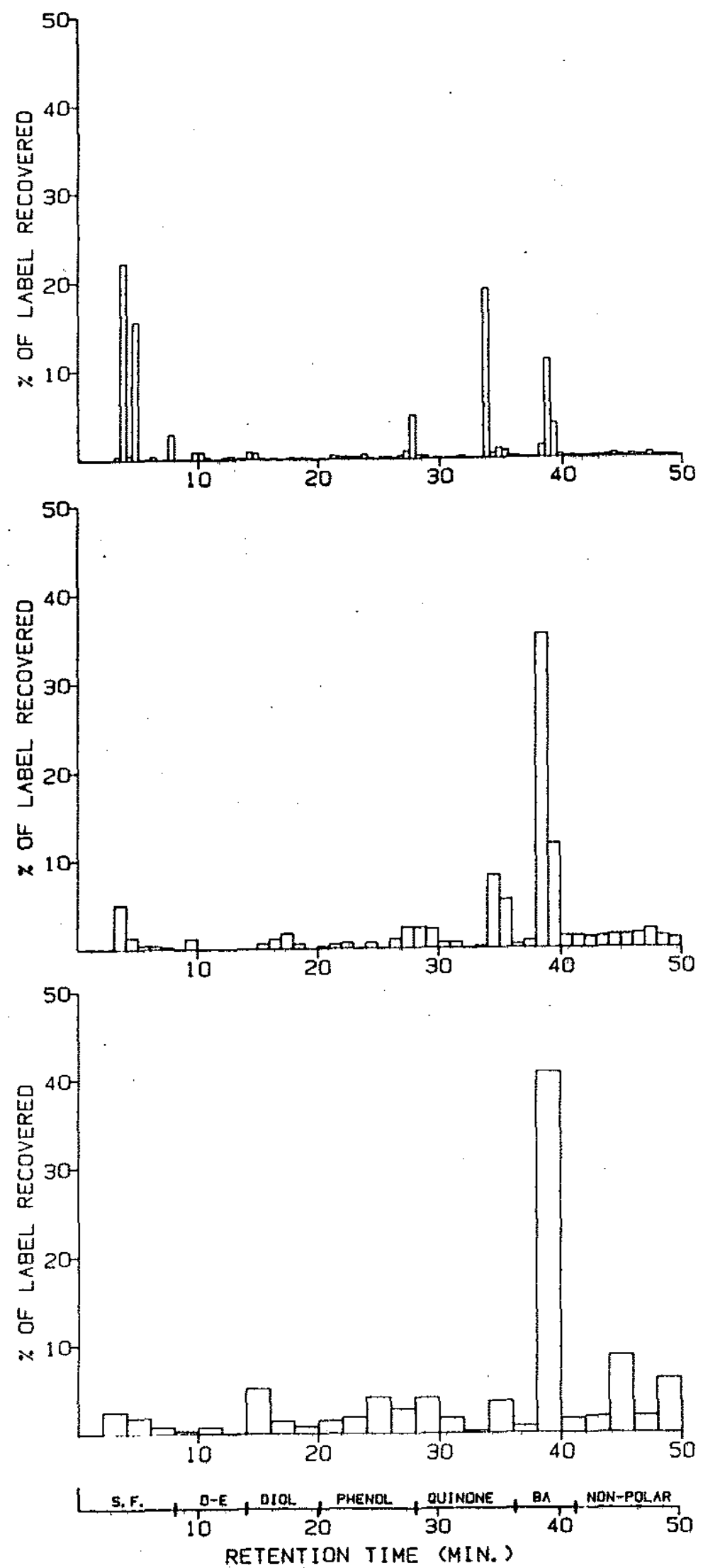
Figure 4.8: ${ }^{14} \mathrm{C}$ HPLC chromatograms of worm organic extracts from a 11 chambers in experiment 4. Overlay on $x$ axis refers to retention time windows corresponding to different $c 1$ asses of authentic BA metabolite standards. Abreviations: $S F=$ solvent front; $D-E=$ diol-epoxide. Non-polar refers to a 11 activity eluting after BA. 

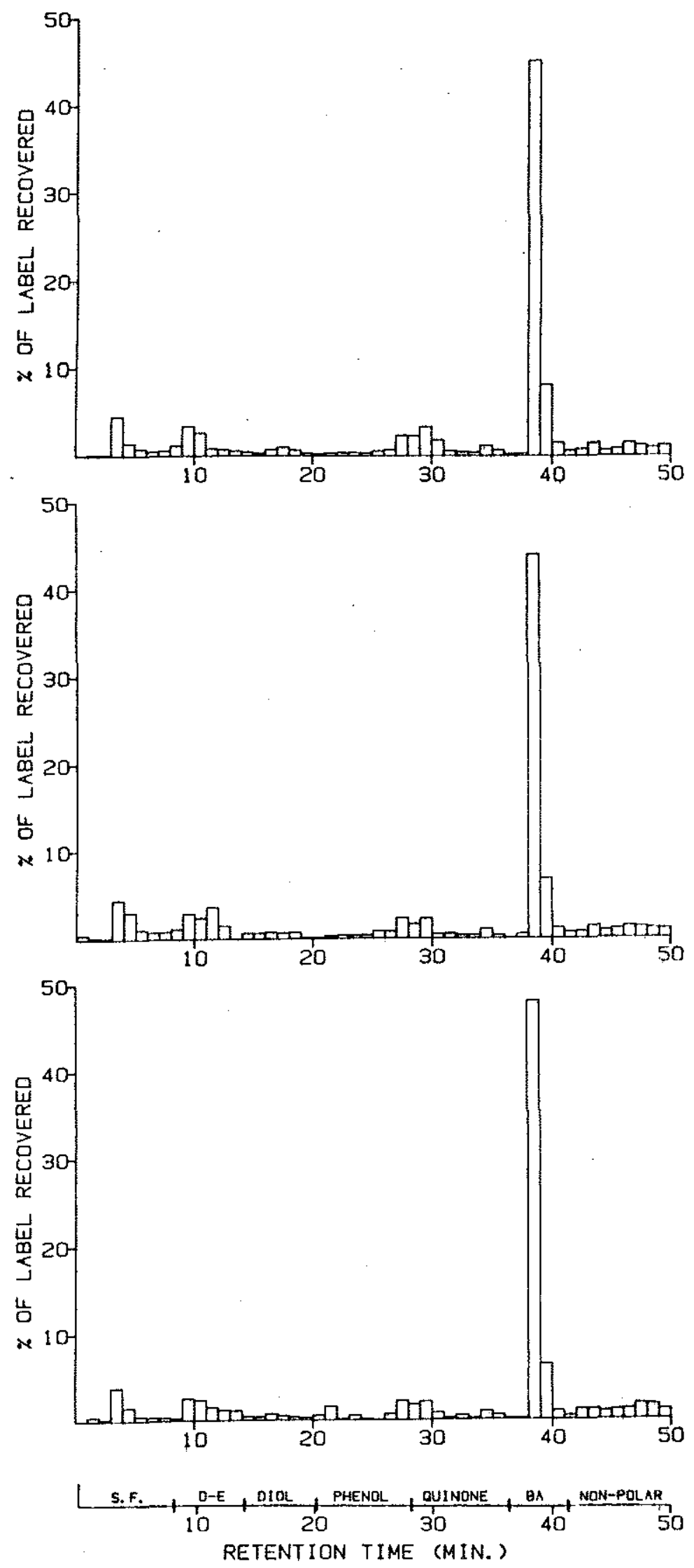
Figure 4.9: ${ }^{14} \mathrm{C}$ HPLC chromatograms of worm organic extracts from a 11 chambers in experiment 5. Overlay on $x$ axis refers to retention time windows corresponding to different classes of authentic BA metabolite standards. Abreviations: $S F=$ solvent front; $D-E=d i o l-e p o x i d e$. Non-polar refers to all activity eluting after BA. 

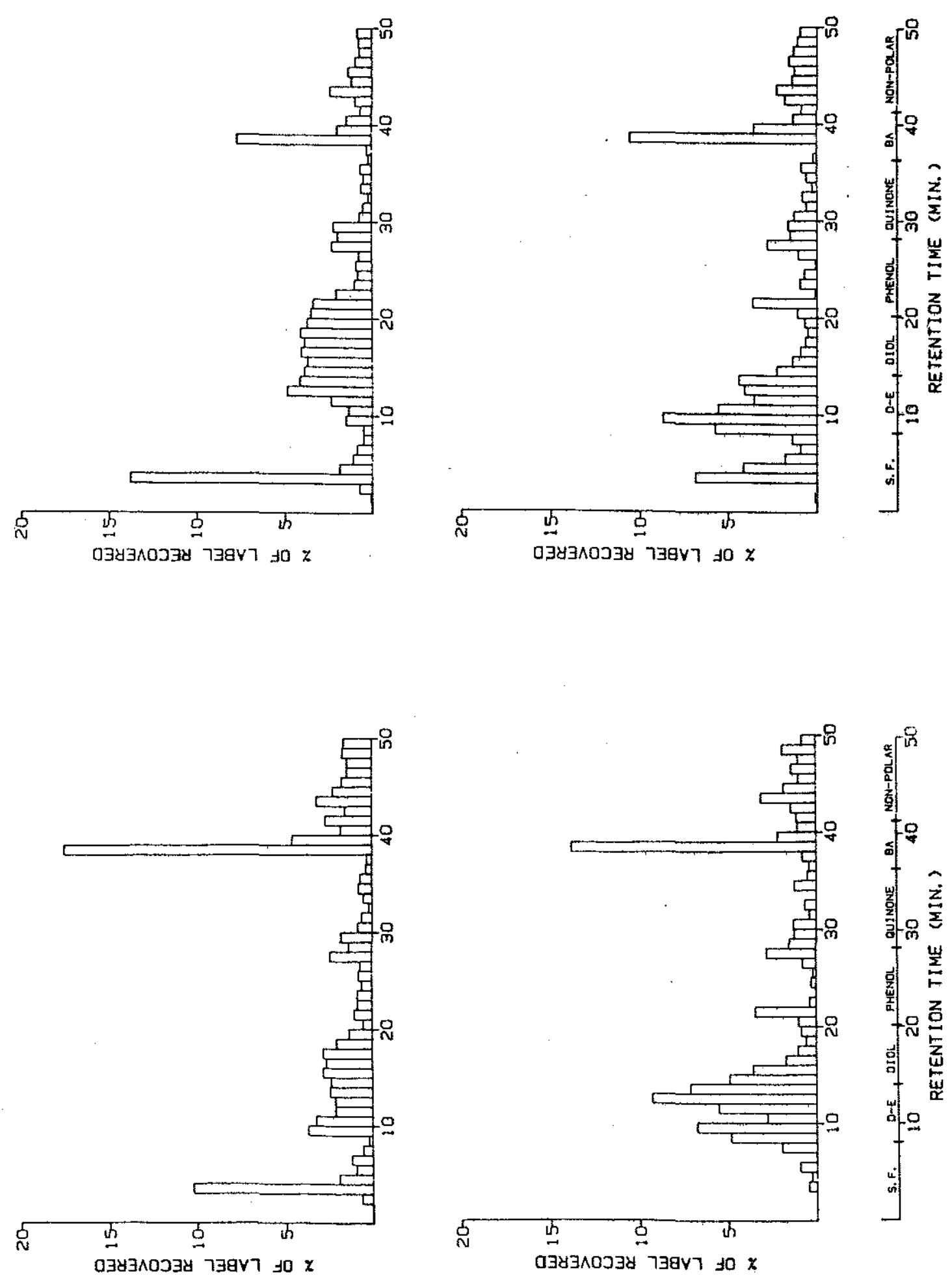
Radioactivity recovered in these intervals from each experiment is compiled in Table 4.3.

The patterns of polar metabolites separated by HPLC appear to be distinct $1 \mathrm{y}$ different between experiments. In all experiments the majority of radiolabel in the organic extract was present as unmetabolized BA. The short term experiments with sediment-sorbed BA had the highest proportions of activity chromatographing as unmetabolized $B A$, whereas the short-term experiments with BA labeled food had the lowest. A noticable peak in label eluting in the diol-epoxide/tetrol range was observed in the experiment with labeled food. Due to the imprecise nature of class identification, further dissection of these results would be presumptuous.

Bnzymatic analysis of glucuronide and sulfate conjugates:

The proportion of activity in the aqueous extract that was present as glucuronide or sulfate conjugates was measured in experiments 3,4 , and 5 , and is 1 isted in Table 4.4 . On 1 y $6 \%$ or less of total activity in the aqueous extract was found to be glucuronide or sulfate conjugates. Va1ues for this fraction were similar in the long-term experiment with sediment-sorbed $B A$ and the experiment with $B A$ added to the water column. Less than half that anount was found in the experiment with BA 1 abeled food. Organic extracts of the aqueous extract after enzymatic treatment, were analyzed by HPLC. Due to the low radioactivity in these extracts, it was necessary to pool fractions from replicate chambers within each experiment before chromatographic analysis. Chromatograms of organic extracts treated with conjugate cleaving enzymes and blanks which were incubated without enzymes are shown in Figures 4.9-4.12. It appears that 
Table 4.3

\section{DISTRIBUTION OF RADIOACTIVITY RECOVERED FROM WORHS: METABOLITE CIASSES II ORGAKIC BXTRACT SEPARATBD BY REVBRSE PHASE HIGH PRESSURE LIQUID CHROHATOGRAPHY}

\begin{tabular}{lrrrc} 
Metabolite Class & \multicolumn{4}{c}{ Experiment } \\
& $1 \& 2$ & 3 & 4 & 5 \\
Solvent front & 6.8 & 18.8 & 8.2 & 13.4 \\
& \pm 5.6 & \pm 13.0 & \pm 0.7 & \pm 3.4 \\
Tetrols \& & 5.3 & 2.4 & 10.1 & 24.1 \\
Diol-epoxides & \pm 2.1 & \pm 0.6 & \pm 1.2 & \pm 5.8 \\
Diols & 12.4 & 3.8 & 2.9 & 14.0 \\
& \pm 1.7 & \pm 1.7 & \pm 0.2 & \pm 3.4 \\
Phenols & 0.8 & 7.6 & 5.5 & 10.4 \\
& \pm 0.2 & \pm 1.3 & \pm 0.3 & \pm 1.5 \\
Quinones & 0.7 & 17.3 & 7.9 & 7.1 \\
& \pm 0.7 & \pm 4.3 & \pm 1.3 & \pm 0.2 \\
Parent BA & 74.7 & 38.5 & 55.1 & 18.8 \\
& \pm 4.7 & \pm 10.1 & \pm 0.8 & \pm 3.8 \\
Lipid & 0.8 & 11.6 & 10.5 & 12.1 \\
Nonpolar & \pm 0.8 & \pm 5.4 & \pm 1.3 & \pm 1.2
\end{tabular}

Experiment 1\&2: 6 day exposure to sediment-sorbed BA

Key 3: 25 day exposure to sediment-sorbed BA

4: 6 day exposure to $B A$ added to the water column

5: 4 day exposure to $B A$ in diet

Values expressed as means $\pm \mathrm{SE}$.

Metabolite class assignment based on comparisons to retention times of authentic standards.

Solvent front category refers to isotope eluting within the solvent front.

Lipid-nonpolar category refers to isotope eluting after BA 
Table 4.4

DBTERMINATION OF GLUCURONIDE AND SULFATE CONJUGATES

IN AQUBOUS EXTRACTS OF WORM TISSUE

\author{
\% Tota1 Radioactivity \\ in Aqueous Extract \\ Experiment 3 \\ 25 day exposure to \\ $6.03 \pm 1.53(3)$ \\ sediment-sorbed BA \\ Experiment 4 \\ 6 day exposure to \\ $5.66 \pm 0.25(3)$ \\ BA added to the water column \\ Experiment 5 \\ 4 day exposure to \\ $2.25 \pm 0.32(4)$ \\ BA. labeled diet \\ Values expressed as mean $\pm S E(n)$
}


nonenzymatic hydrolysis of conjugated metabolites in the blank extracts was substantia 1. Nonenzymatic hydrolysis probably resulted from the lengthy evaporation and incubation at elevated temperatures used in this procedure. Comparisons between chromatograms of extracts of analysis blanks with extracts of samples receiving enzymes, suggest that some phenolic, quinone, and diol metabolites were liberated by enzymatic treatment.

\section{Discussion:}

\section{Rapid in vivo metabolism of BA by Nereis virens}

The results of this investigation clearly demonstrate that Nereis virens is able to metabolize BA. In as little as 96 hours after ingesting food containing $\mathrm{BA}$, on $1 \mathrm{y} 2 \%$ of activity remaining in the worm was in the form of unmetabolized parent compound. These results are consistent with similar findings that $P A H$ can be rapidly netabolized in a few other invertebrates including the blue crab callinectes sapidus (Lee et al., 1976), the diptera larvae Chironomus (Leversee et a1., 1982), larva1 shrimp (Sanborn and Malins, 1977), and the sea urchin Strongelocentrotus. drobachiensis (Malins and Rouba1, 1982), and in many different marine and freshwater teleosts (See review by Maline and Hodgkins, 1981).

If only unmetabolized BA had been analyzed in the present study, measurements of total BA accumulated would have been underestimated by as much as $98 \%$. In organisms which are known to rapidly metabolize PAH such as fish, the discrepancy between accumulated parent PAH and total activity might be even higher. Lu et a1. (1977), clearly demonstrated the importance of including metabolite analysis in studies on accumulation of PAH. Accumulation of unmetabolized BP in fish could only be demonstrated 
Figure 4.10: ${ }^{14} \mathrm{C}$ HPLC chromatograms of organic extracts after enzymatic cleavage of glucuronide and sulfate conjugates in experiment 3 . (a) sample with enzyme (b) blank. Overlay on $x$ axis refers to retention time windows corresponding to different classes of authentic BA met abolite standards. Abreviations: $S F=$ solvent front; $D-E=$ dio1-epoxide. Non-polar refers to all activity eluting after $B A$. 

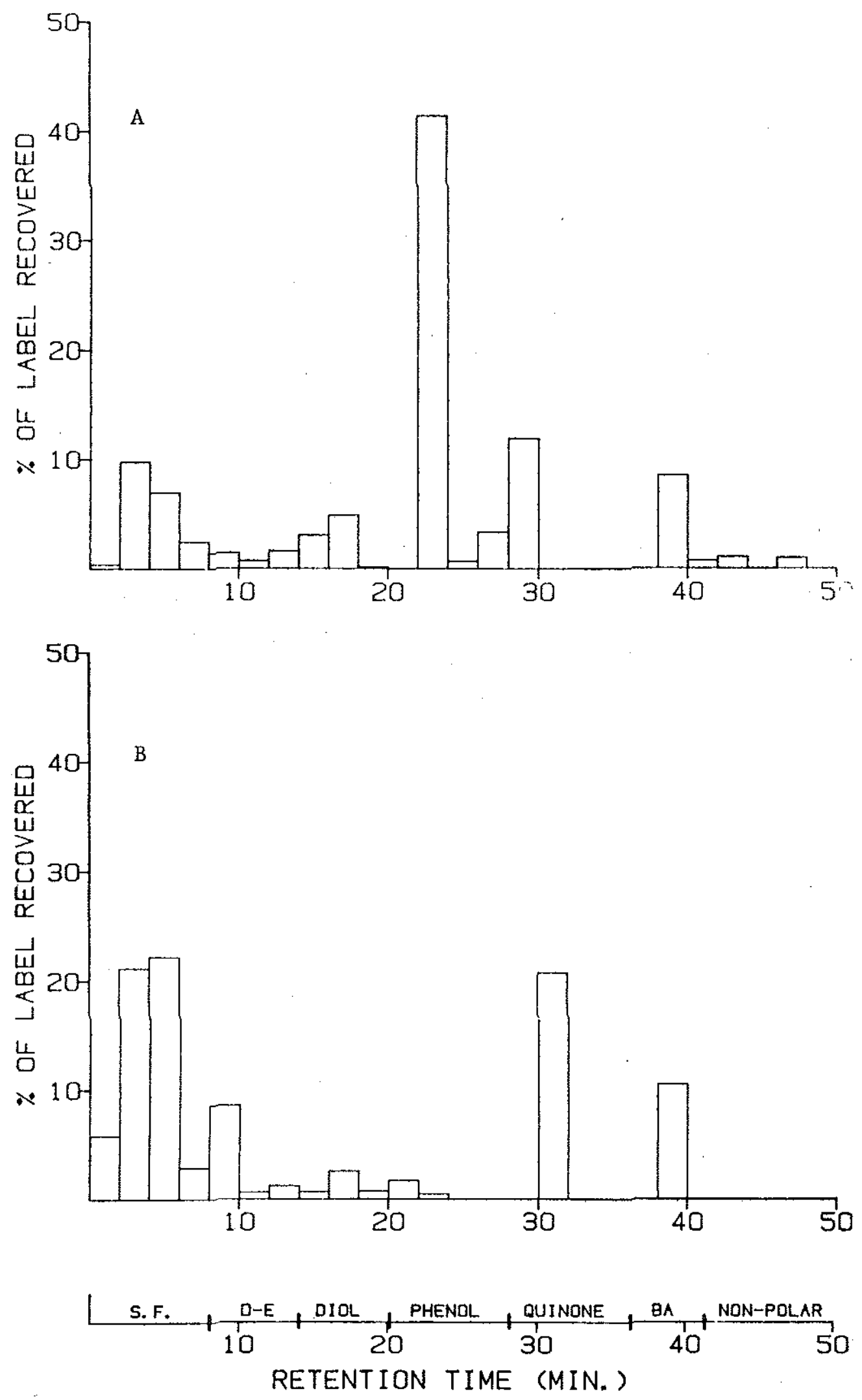
Figure 4.11: ${ }^{14} \mathrm{C}$ HPLC chromatograms of organic extracts after enzymatic cleavage of glucuronide and sulfate conjugates in experiment 4 . (a) sample with enzyme (b) blank. Overlay on $x$ axis refers to retention time windows corresponding to different classes of authentic BA metabolite standards. Abreviations: $S F=$ solvent front; $D-E=$ diol-epoxide. Non-polar refers to 11 activity eluting after $B A$. 

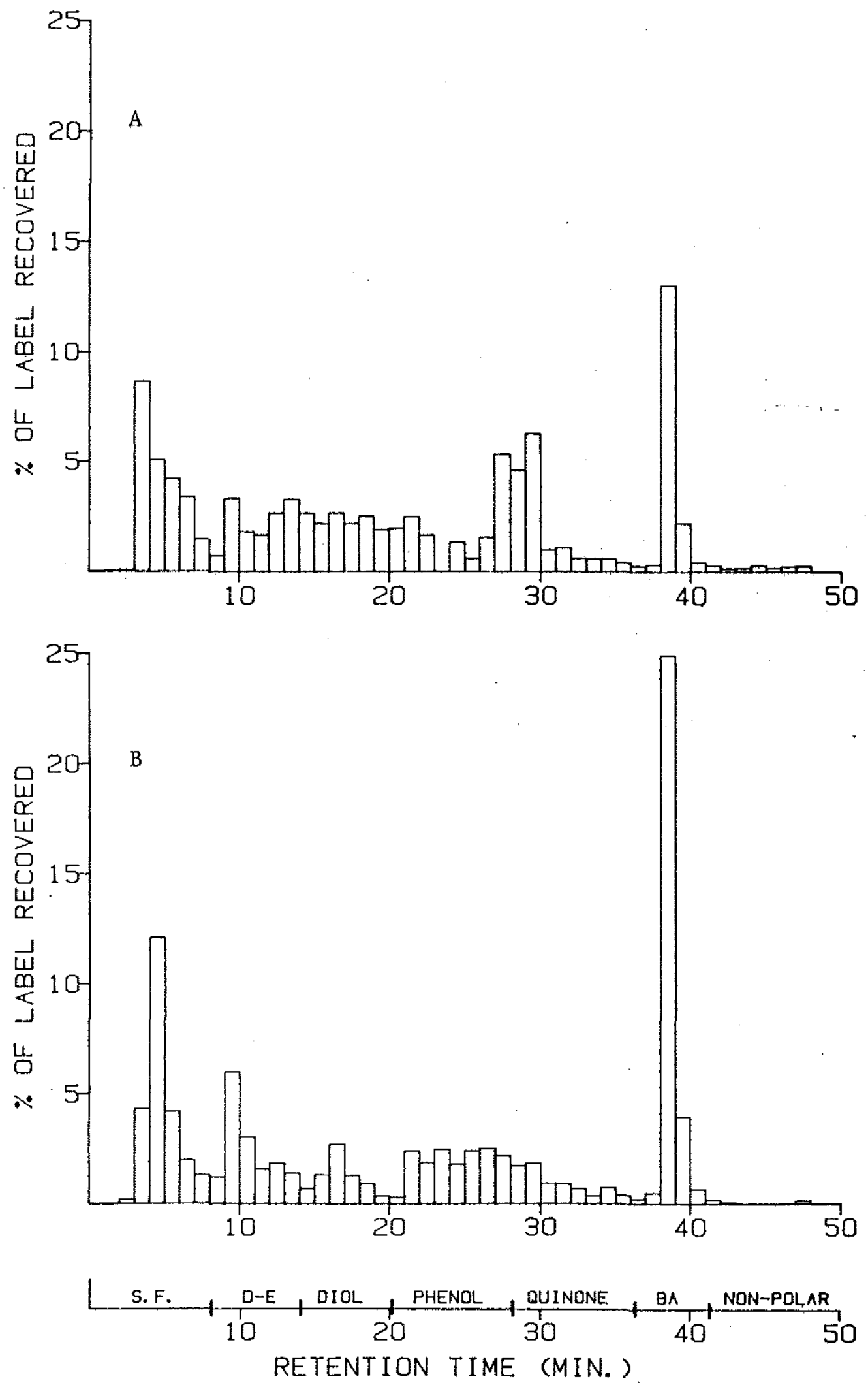
Figure 4.12: ${ }^{14} \mathrm{C}$ HPLC chromatograms of organic extracts after enzymatic cleavage of glucuronide and sulfate conjugates in experiment 5 . (a) sample with enzyme (b) blank. Overlay on $x$ axis refers to retention time windows corresponding to different classes of authentic BA metabolite standards. Abreviations: $S F=$ solvent front; $D-E=$ diol-epoxide. Non-polar refers to all activity eluting after $B A$. 

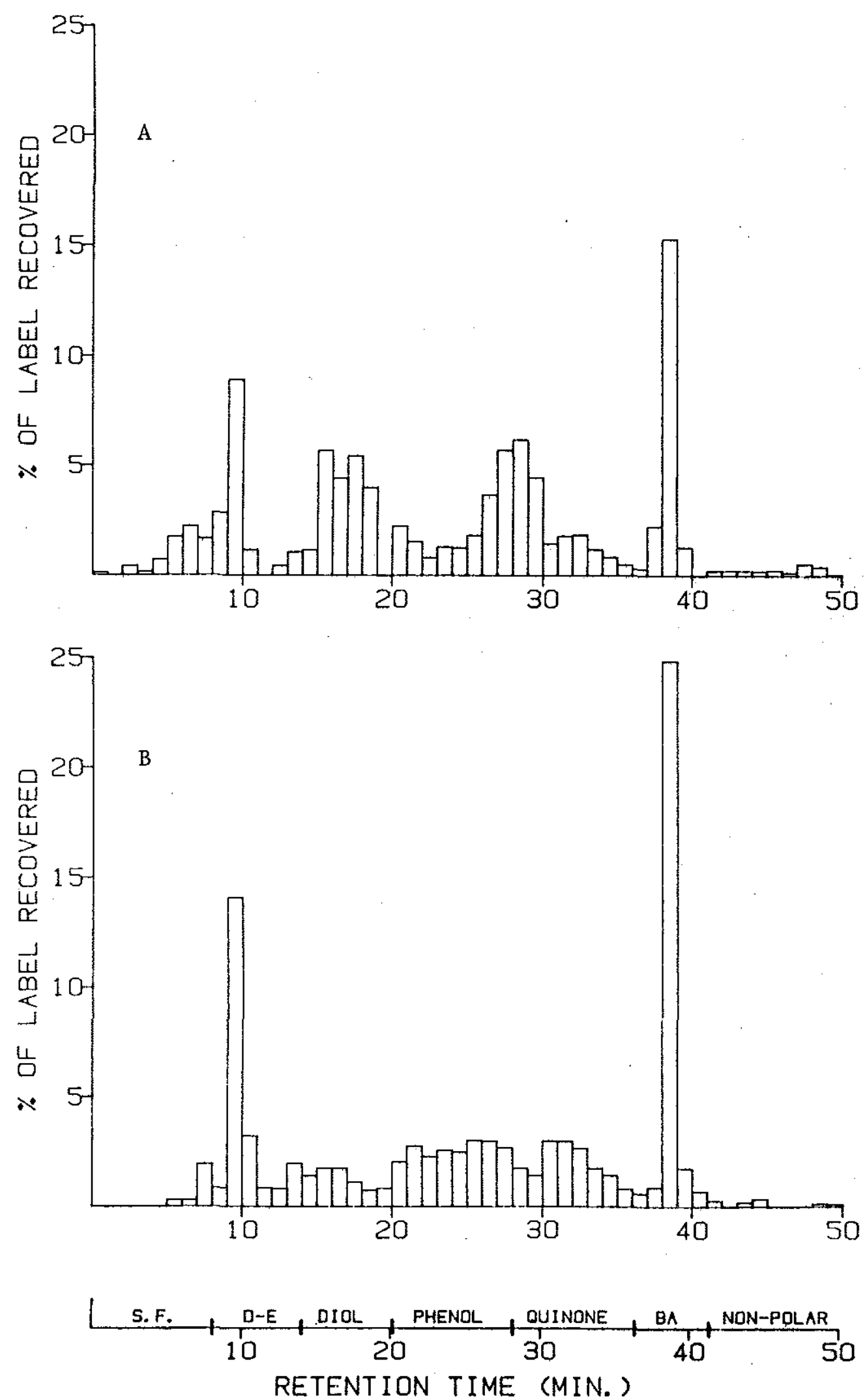
in the presence of the MFO inhibitor piperonyl butoxide. In multispecies mode 1 ecosystems, activity in all organisms capable of PAH metabolism was found primarily in an unextractable form after only one day of exposure. Addition of the MFO inhibitor increased activity in less metabolized fractions. Leversee et a1. (1982) found bioconcentration factors based on total activity to be more than three times those based on the parent compound alone in Chironomus riparius.

The present results are in apparent contrast with those of Augenfeld et a1. (1982), who reported no evidence of solvent extractable polar metabolites in tissues of the polychaete Neanthes arenaceodentata exposed for 60 days to sediment-sorbed radiolabeled BP, chrysene, or phenanthrene. They did observe that from 2 to $22 \%$ of isotope recovered from the worms was not solvent extractable, and acknowledged that this portion of recovered 1 abel was probably not due to parent compound. Unfortunate1y Augenfeld et a1. did not quantify isotope in the aqueous worm extract, which was found here to account for a major portion to accumulated activity. In addition, it is not clear from their report if the HPLC procedure they employed would have resolved polar metabolites from parent BA. Because of differences between techniques, it is difficult to say whether the results of the present study on in vivo PAH metabolism in Nereis virens are in conflict or agreement with the data reported by Augenfeld et al. for a closely related species Neanthes arenaceodentata.

Effect of time and mode of introduction on degree and type of wetabolites formed:

Length of exposure and mode of introduction significant ly affected both the extent to which BA was metabolized and the relative percentages of different metabolites formed. In experiments with sediment-sorbed BA 
absolute amounts of activity in the conjugate and unextractable pools increased with length of exposure. Comparing experiments with different methods of introduction, but similar lengths of exposure, parent BA was most extensively metabolized when presented in labeled food, and metabolized the least when accumulated from uniformly labeled sediments. The general trend, looking at al1 metabolic fractions, was for BA to be most extensively metabolized when accumulated from a protein based diet. BA added to the water column and secondarily adsorbed to surface sediments demonstrated intermediate availability for metabolism. BA sorbed to bulk sediments, prior to placement in the experimental chambers was least available for metabolism. The same trend was observed in the availability of BA for accumulation by worms (See Chapter 3).

These results support the premise that PAH from different sources, or accomodated in different matrices are not equally available for metabolism by marine organisms. Investigations with other species also support this conclusion. Lu et al. (1977) reported patterns of BP meta bolites in fish to be different when the parent compound was introduced to the water or when fish encountered BP through the food chain. Lu found higher biomagnification in fish from the food chain than from direct uptake from the water column. This is interesting, considering that the prey contained substantial amounts of BP metabolic products including those that were unextractable. Sanborn and Malins (1977) found that in vivo metabolism of naphthalene by larval spot shrimp was affected by complexation of the PAH with bovine serum albumin. Corner et al. (1976) reported differences in accumulation and metabolism of naphthalene from the water column or from dietary sources by the copepod calanus. 
Naphthalene was more available for accumulation and less rapidly depurated when introduced in the diet than when added to the water column. However, Corner found that only $10 \%$ of the activity accunulated from the diet was in the form of polar metabolites. This is in contrast to results of an earlier study by Lee (1975) who found several dissolved PAH to be accumulated and extensively metabolized by Calanus. Varanasi et a 1. (1979) found naphthalene to be more extensively metabolized when adsorbed through the diet than when injected intraperitoneally in two species of flat fish.

Although the results of these studies are consistent with the results of this present investigation, they are not directly comparable as type of PAH, method of dosing, and analytical methods were al1 different. In addition, the contribution of photo or microbial degradation to the production of PAH metabolites can be substantial, and were not assessed in these investigations. Nevertheless these studies do indicate that accumulation and metabolism of PAH encountered in the diet can be substantial in several marine organisms. The present study clearly demonstrates that PAH in the diet are also efficient $1 y$ accumulated and metabolized by the polychaete Nereis virens.

This investigation was not directed at the kinetics of BA metabolism by Nereis. However, the absolute proportions of activity in the different metabolite fractions in the short and long-term experiments with sediments-sorbed BA give some indication of the relative rates for the formation of these classes. The concentration of parent BA or of polar 1ipid soluble metabolites in the worms does not increase with time. However, the concentration of conjugated metabolites and of metabolites 
in the bound fraction increase dramatically with time. Similar differences are seen in the patterns between the short-term experiments with sediment-sorbed $B A$ and the experiments where BA was more available (exp. 4 \&5). These data show that neither unmetabolized BA nor polar metabolites produced via the MFO system accumulate relative to other metabolite fractions, suggesting that initial uptake and metabolism is rapid.

Transforwation into conjugated metabolites, and incorporation into cellular constituents as major fates of accumulated BA in Nereis virens

Thirty-two to forty-eight percent of accumulated activity was found as water soluble conjugated metabolites in these experiments. The rapid formation of conjugated metabolites observed in Nereis is consistent with reports of rapid conjugate formation in other aquatic organisms. Herbes and Rissi (1978) found $21 \%$ of the total 1 abe 1 in Daphnia in the aqueous extract after 168 hours of exposure to ${ }^{14} \mathrm{C}$-anthracene. Water soluble metabolites were found to account for up to $100 \%$ of the total accumulated activity in some organs of several marine animals also exposed to ${ }^{14} \mathrm{C}-$ anthracene by Solbakken and Palmork, (1981).

In contrast to work by other investigators, enzymatic analysis using B-glucuronidase and ary 1-sulfatase indicated that glucuronide and sulfate conjugates comprised on $1 y$ a maximum of $6 \%$ of total water soluble netabolites in Nereis. Malins and Roubal (1982) found sulfate conjugates of dimethy Inaphtha lene to comprise up to $90 \%$ of extractable activity in the gonads and digestive tract of the sea urchin strongelocentrotus drobachiensis. In the English sole Varanasi and Gmur found that a minimum of $30 \%$ of tota 1 metabolites of naphthalene or BP were present as glucuronide conjugates. The same trends are seen in mamals. In isolated rat hepa- 
tocytes typically 5 to $20 \%$ of BP conjugates were glucuronides (Jones et a 1., 1978).

Another major class of conjugated metabolites are those bound to glutathione which can lead to mercapturic acid formation. Reduced glutathione is present in all cells of higher organisms (Lehninger, 1.975), and glutathione s-transferases have been measured in a wide variety of marine organisms (James et a1., 1979a). The presence of glutathione conjugates is often inferred by difference (i.e. by the lack of other forms of conjugates). It is possible that water soluble metabolites in Nereis were conjugated to glutathione. Reactive electrophiles can also bind directly to glutathione s-transferase. This scavenging pathway provides an effective means of sequestering reactive electrophiles and lipophilic compounds (Jakoby and Habig, 1980). The large percentage of accumulated radioactivity present in an unextractable form is not inconsistent with this hypothesis, as both products (glutathione conjugates and macromolecular adducts) result from the same highly reactive epoxide intermediate (See Fig. 1.1).

In the first four experiments in this study, worms were in an environment containing unmetabolized BA throughout the experiment. Therefore, even though they were metabolizing BA, they were continuous $1 \mathrm{y}$ exposed to unmetabolized BA. Consequent $1 \mathrm{y}$ the patterns of accumulated radioactivity observed represent some sort of steady state between accunulation, metabolism, and excretion. In the last experiment worms were given a single dose of BA labeled food. The persistence of metabolic products of all types in tissue 4 days after feeding indicates that although some of these compounds were water soluble, they were not inmed- 
iately excreted from the worm's body. In addition, $83 \%$ of the entire dose added to the chambers was recovered from the worms. This indicates that at most $17 \%$ of the accumulated dose could have been excreted. The increase in conjugated metabolites over time in experiments where worms were exposed to a continuous supply of unmetabolized BA also supports the conclusion that water soluble BA metabolites have an appreciable residence time in Nereis.

The persistence of $\mathrm{PAH}$ metabolic products relative to parent compound has been reported for a number of marine organisms. In studies of BP accumulation by Chironomus, Leversee et al. (1982) reported that while tota 1 activity continued to increase for 8 hours, the percentage as unmetabolized BP leveled of after 1 hour. Rossi and Anderson (1978) reported depuration of metabolized naphthalene was slower than that of the parent compound in the worm Neanthes arenaceodentata. Similar findings have been reported for BP in the blue crab Callinectes (Lee et al., 1976) and in three species of $\mathrm{fish}$ (Lee et a 1., 1972b); for naphthalene in the rainbow trout (Varanasi et a 1., 1978); and for the chlorinated hydrocarbon lindane in Nereis virens (Goerke and Ernst, 1980).

Incorporation into cellular macromolecules appears to be the major fate of BA accumulated by Nereis virens. Varanasi et a1. (1981) reported binding to DNA and protein as the major fate of BP force fed to juvenile English sole. Lu et a1. (1977) in their studies on the fate of ${ }^{14} \mathrm{C}-\mathrm{BP}$ in model ecosysteris also found the majority of radioactivity recovered from organisms possessing MFO activity was unextractable. Incoroporation of accumulated radiolabeled $\mathrm{PAH}$ into invertebrate exoskeletons has been observed in several studies (Lee et a1., 1976; Leversee et a1., 1982; and 
Malins and Rouba1, 1982). In concert these studies indicate that incorporation of a major percentage of accumulated PAH into relatively stable cellular macromolecules may be a widespread phenomenon in marine organisms.

Sumary:

These results demonstrate that Nereis virens is capable of rapid in vivo metabolism of $\mathrm{BA}$ in the benthos. A possitive correlation was observed between the degree to which accumulated BA was metabolized and efficiency for accumulation of BA introduced in different ways. It appears that excretion of water soluble BA conjugates in Nereis is not as rapid as initial metabolism, and that incorporation into cellular macromolecules is a major fate of accumulated BA. 


\section{CHAPTBR 5: \\ PHYSTOLOGICAL EFFECTS OF BEXZ(a)ANTHRACENE EXPOSURB OH Hereis virens}

\section{Results:}

\section{Biochemical indices:}

Axy 1 hydrocarbon hydroxylase (AHH) activity was measured in vitro in microsomes prepared from homogenates of whole worms removed from the experimental chambers. This assay was done for two reasons: (1) to see if exposure to BA led to increased ability in the worms to metabolize PAH, and (2) as a check on the PAH metabolizing ability of the different groups of worms used throughout this study. Benzo(a)pyrene (BA) was used as a substrate for determining AHH activity.

Table 5.1 shows BP hydroxylase activity in microsomes prepared from whole worms used in these experiments. The rates were highly variable and quite low, ranging from 0.68 to 2.60 pmo $1 / \mathrm{mg}-\mathrm{min}$ with an average coefficient of variation of $34 \%$. No substantial or consistent differences were observed between control and exposed groups in any experiment or between worms used in different experiments. These results provide no evidence for induction of the MFO system by exposure to BA in these experiments. The similarity between rates observed in different experiments also indicates that all worms used in these experiments had approximately the same ability to metabolize PAH.

Concentrations and ratios of adenylate nucleotides extracted from worm tissue in each experiment are given in Table 5.2. In all experiments except No. 5 where the anima 1 s were fed, worms exposed to BA showed trends for lower ATP concentrations and higher ADP and AMP concentrations. The concentration of total adenylates showed no consistent trends 
Table 5.1

BEXZO(a)PYREHE HYDROXYLASE ACTIVITY IN HICROSOMES PREPARRD FROH Nereis virens HOMOGEMATES

Experiments wi.th

Sediment-sorbed BA

\author{
$\mathrm{pmo1} / \mathrm{mg}-\mathrm{min}$ \\ Contro1 Worms Exposed Worms
}

6 day

$0.89 \pm .25$

$2.19 \pm .18$

exposure

6 day

$0.68 \pm .27$

$0.78 \pm .17$

exposure

25 day

exposure

$1.04 \pm .05$

$1.24 \pm .37$

Experiment with

BA Added to the

Water Column

6 day

exposure

Experiment with

BA Labeled Food

4 day

exposure
$2.60 \pm .20$

$1.12 \pm .38$

$1.60 \pm .20$

$1.67 \pm .22$

Values expressed as mean \pm 1 SE $n=3$

Assays run in triplicate on microsomes pooled from 3 replicate chambers for each experiment. 
Table 5.2

ADEFrLATE NUChEOTIDE POOLS AND RATIOS IN WORHS TISSUZ Experiment

\begin{tabular}{|c|c|c|c|c|c|c|}
\hline \multicolumn{7}{|c|}{ Concentrations } \\
\hline \multirow[t]{2}{*}{ ATP } & Control & $\begin{array}{r}1.58 \\
\pm .09\end{array}$ & $\begin{array}{l}2.20 \\
\pm .13 \\
*\end{array}$ & $\begin{array}{r}2.40 \\
\pm .16\end{array}$ & $\begin{array}{l}2.45 \\
\pm .72 \\
*\end{array}$ & $\begin{array}{r}4.55 \\
\pm .45\end{array}$ \\
\hline & Exposed & $\begin{array}{r}1.49 \\
+.11\end{array}$ & $\begin{array}{l}1.77 \\
\pm .09\end{array}$ & $\begin{array}{r}2.30 \\
\pm .13\end{array}$ & $\begin{array}{r}1.79 \\
\pm .20\end{array}$ & $\begin{array}{r}4.75 \\
\pm .54\end{array}$ \\
\hline \multirow[t]{2}{*}{ ADP } & Contro 1 & $\begin{array}{l}.815 \\
\pm .062 \\
*\end{array}$ & $\begin{array}{l}1.02 \\
\pm .57\end{array}$ & $\begin{array}{c}1.13 \\
\pm .13\end{array}$ & $\begin{array}{l}.873 \\
\pm .072\end{array}$ & $\begin{array}{r}1.32 \\
\pm .13\end{array}$ \\
\hline & Exposed & $\begin{array}{l}1.04 \\
\pm .07\end{array}$ & $\begin{array}{r}1.02 \\
\pm .09\end{array}$ & $\begin{array}{r}1.34 \\
\pm .16\end{array}$ & $\begin{array}{r}1.08 \\
\pm .17\end{array}$ & $\begin{array}{r}1.02 \\
\pm .19\end{array}$ \\
\hline \multirow[t]{2}{*}{ AMP } & Control & $\begin{array}{l}.320 \\
\pm .034\end{array}$ & $\begin{array}{r}.225 \\
\pm .020\end{array}$ & $\begin{array}{r}.272 \\
\pm .030\end{array}$ & $\begin{array}{r}.224 \\
\pm .023\end{array}$ & $\begin{array}{l}.334 \\
\pm .057\end{array}$ \\
\hline & Exposed & $\begin{array}{r}.355 \\
+.064\end{array}$ & $\begin{array}{r}.282 \\
\pm .032\end{array}$ & $\begin{array}{r}.285 \\
\pm .037\end{array}$ & $\begin{array}{r}.247 \\
\pm .052\end{array}$ & $\begin{array}{l}.306 \\
\pm .057\end{array}$ \\
\hline \multirow[t]{2}{*}{$\mathbf{A}_{\mathbf{T}}$} & Control & $\begin{array}{l}2.72 \\
+.12\end{array}$ & $\begin{array}{c}3.50 \\
+.14 \\
*\end{array}$ & $\begin{array}{r}3.88 \\
+.13\end{array}$ & $\begin{array}{r}3.59 \\
\pm .22\end{array}$ & $\begin{array}{r}3.54 \\
\pm .38\end{array}$ \\
\hline & Exposed & $\begin{array}{l}2.86 \\
\pm .16\end{array}$ & $\begin{array}{r}3.04 \\
\pm .15\end{array}$ & $\begin{array}{r}4.93 \\
+.26\end{array}$ & $\begin{array}{r}3.12 \\
\pm .37\end{array}$ & $\begin{array}{r}5.19 \\
\pm .63\end{array}$ \\
\hline
\end{tabular}

\begin{tabular}{|c|c|c|c|c|c|c|}
\hline \multicolumn{7}{|l|}{ Ratios } \\
\hline EC & Control & $\begin{array}{l}.731 \\
\pm .016\end{array}$ & $\begin{array}{r}.784 \\
+.012 \\
*\end{array}$ & $\begin{array}{r}.784 \\
+.019\end{array}$ & $\begin{array}{c}.816 \\
\pm .009 \\
*\end{array}$ & $\begin{array}{l}.819 \\
\pm .014\end{array}$ \\
\hline & Exposed & $\begin{array}{l}.706 \\
\pm .013\end{array}$ & $\begin{array}{l}.746 \\
\pm .016\end{array}$ & $\begin{array}{l}.762 \\
\pm .014\end{array}$ & $\begin{array}{l}.754 \\
\pm .019\end{array}$ & $\begin{array}{l}.848 \\
+.014\end{array}$ \\
\hline \multirow[t]{2}{*}{ ADP/ATP } & Contro1 & $\begin{array}{l}.533 \\
\pm .045 \\
*\end{array}$ & $\begin{array}{l}.480 \\
\pm .037 \\
*\end{array}$ & $\begin{array}{l}.504 \\
\pm .095\end{array}$ & $\begin{array}{l}358 \\
\pm .026\end{array}$ & $\begin{array}{l}353 \\
\pm .036\end{array}$ \\
\hline & Exposed & $\begin{array}{l}.749 \\
\pm .086\end{array}$ & $\begin{array}{l}.598 \\
\pm .057\end{array}$ & $\begin{array}{l}.595 \\
\pm .077\end{array}$ & $\begin{array}{l}.604 \\
\pm .071\end{array}$ & $\begin{array}{l}.255 \\
\pm .029\end{array}$ \\
\hline \multirow[t]{2}{*}{ AMP / ATP } & Control & $\begin{array}{l}.215 \\
\pm .028\end{array}$ & $\begin{array}{r}.110 \\
\pm .014 \\
*\end{array}$ & $\begin{array}{r}.113 \\
\pm .016\end{array}$ & $\begin{array}{l}.090 \\
\pm .009 \\
*\end{array}$ & $\begin{array}{l}.092 \\
\pm .012\end{array}$ \\
\hline & Exposed & $\begin{array}{l}.230 \\
\pm .027\end{array}$ & $\begin{array}{l}.170 \\
\pm .054\end{array}$ & $\begin{array}{l}.125 \\
\pm .018\end{array}$ & $\begin{array}{l}.138 \\
\pm .023\end{array}$ & $\begin{array}{l}.081 \\
\pm .012\end{array}$ \\
\hline
\end{tabular}

Values expressed as mean $\pm S E$. Square root transformations of ratios were done prior to statistical analysis. Means compared using Student's t-test. * indicates significant difference $(p<.05)$. 
between experiments. Even though changes in the concentrations of individual nucleotides were consistent, these differences were not consistent ly statistically significant due to high variability between concentrations in different animals. AMP concentrations were never significantly different between exposed and control anima 1 s.

Energy charge (EC) was depressed in worms exposed to BA in a 11 experiments except No. 5 where the anima 1 s were fed. Again, these trends were only significant in two out of four cases. The ADP/ATP ratio was found to be significant ly higher in exposed animals in a11 of the shortterm experiments but No. 5. Although the ADP/ATP ratio was not significant $1 y$ different in the long-term exposure to sediment-sorbed $B A$, the magnitude of the difference between control and exposed groups was the same for this experiment as it was in two short-term experiments where the differences were found to be statistically significant. The AMP/ATP ratio was also higher in exposed animals in al1 experiments but No. 5, but this difference was only statistically significantly different in the second experiment with sediment-sorbed $B A$ and in the water column exposure experiment. In the experiment with BA labeled food, opposite trends were observed for al1 indices, with control animals having lower ATP and higher ADP and AMP concentrations, and lower EC and higher ADP/ATP and AMP/ATP ratios than exposed animals, These differences were never significant even though the sample size was larger in this experiment. The total dose of $B A$ to the chambers, or even the accumulated dose, in the experiment with labeled food was more than an order of magnitude less than observed in the other experiments. Therefore it is not surprising that no differences between control and exposed groups were observed. 
Concentration of ATP, ADP, total adenylates, and the ADP/ATP ratio in control animals used in experiment 5 were significant $1 \mathrm{y}$ different from values obtained from animals used in the other experiments (See Table 5.3). These differences indicate that the metabolic potential of recently fed animals was different from animals that had been starved for a period of days to weeks, which is not an unexpected result. Significant differences were also seen in total adenylate concentrations and $\mathrm{EC}$ and AMP/ATP ratios between control worms in the first experiment and a 1 others. These differences indicate that natural variability in all these indices, both concentrations of individual nucleotides and their ratios, is high. Analysis of variance indicated statistically significant differences between values for all indices between control worms used in each experiment. These differences may be due to dietary status, as mentioned above, seasonal or reproductive status, or just natural variability. Regardless of cause, variations in adenylate nucleotide concentrations and ratios of this magnitude make using absolute values of these indices as indicators of environmental stress equivocal.

Whole animal physiologic indices:

Whole chamber oxygen consumption and ammonia production were measured periodically during each experiment (Figures 5.1-5.5). Rates were highly variable between replicate chambers and with time. Analysis by two-way ANOVA comparing the effect of treatment and time (Tables $5.4 \&$ 5.5), showed that on $1 y$ in the 25 day sediment exposure experiment were significant differences due to treatment observed in oxygen consumption rate between control and exposed chambers. Both oxygen consumption rates and ammonia excretion rates were strongly affected by time, although no 
Table 5.3

\title{
SUIRARY OF MEWMAN-KRULS (SRK) ANALYSES FOR DIFFERBNCES \\ IN ADEFYIATE NUCLEOTIDE CONCEKTRATIONS AND RATIOS BETUEEN MEANS FROM CONTROL WORMS USED IN DIFTERENT EXPERIMENTS
}

\author{
Concentrations \\ ug/gww \\ Experiment \\ ATP \\ $1 \quad 2 \quad 3 \quad 4 \quad 5$ \\ $p<.001$ \\ ADP \\ $1 \longdiv { 2 } 3 4 ^ { 1 }$ \\ $\mathrm{p}<.01$ \\ AMP

\begin{tabular}{lllll}
1 & 2 & 3 & 4 & 5 \\
\hline
\end{tabular} \\ $\mathrm{A}_{\mathbf{T}}$ \\ $1 * \quad 2 \quad 3 \quad 4 \quad 5 *$ \\ $*_{\mathrm{p}}<.05$ \\ $* * \mathrm{p}<.001$ \\ Ratios \\ EC

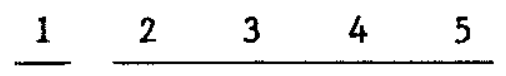 \\ $\mathrm{p}<.05$ \\ ADP / ATP \\ $\begin{array}{llll}1 & 2 & 3 & 4\end{array}$ \\ $\mathrm{p}<.05$ \\ AMP / ATP

\begin{tabular}{lllll}
1 & 2 & 3 & 4 & 5 \\
\hline
\end{tabular} \\ $\mathrm{p}<.001$ \\ Line joining groups indicates they are not statistically different \\ $A_{T}=A T P+A D P+A M P$ \\ $E C=\underline{1 / 2(A D P)+A T P}$ \\ $A_{T}$ \\ Experiment 1\&2: 6 day exposure to sediment-sorbed BA \\ $\mathrm{Ke}$ \\ 3: 25 day exposure to sediment-sorbed BA \\ 4: 6 day exposure to BA added to the water column \\ 5: 4 day exposure to $B A$ in diet
}


Figure 5.1: Whole chamber oxygen consumption, ammonia production, and the $0 / \mathrm{N}$ ratio in experiment 1 . Circles represnt contro 1 chambers.

Triangles represent exposed chambers. Values expressed as mean $\pm \mathrm{SE} n=3$. 

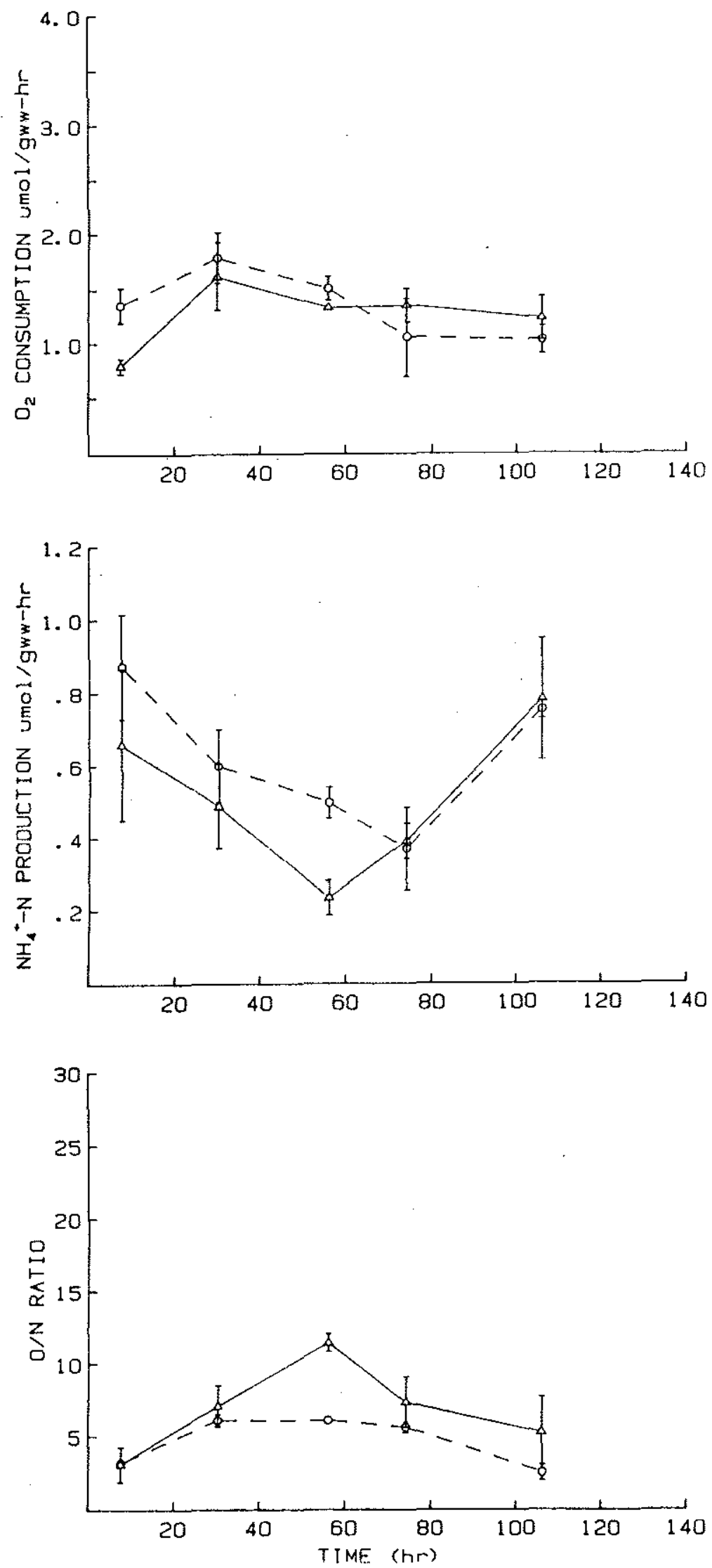
Figure 5.2: Whole chamber oxygen consumption, ammonia production, and the $0 / \mathrm{N}$ ratio in experiment 2 . Cixcles represnt control chambers.

Triangles represent exposed chambers. Values expressed as mean $\pm S E n=3$. 

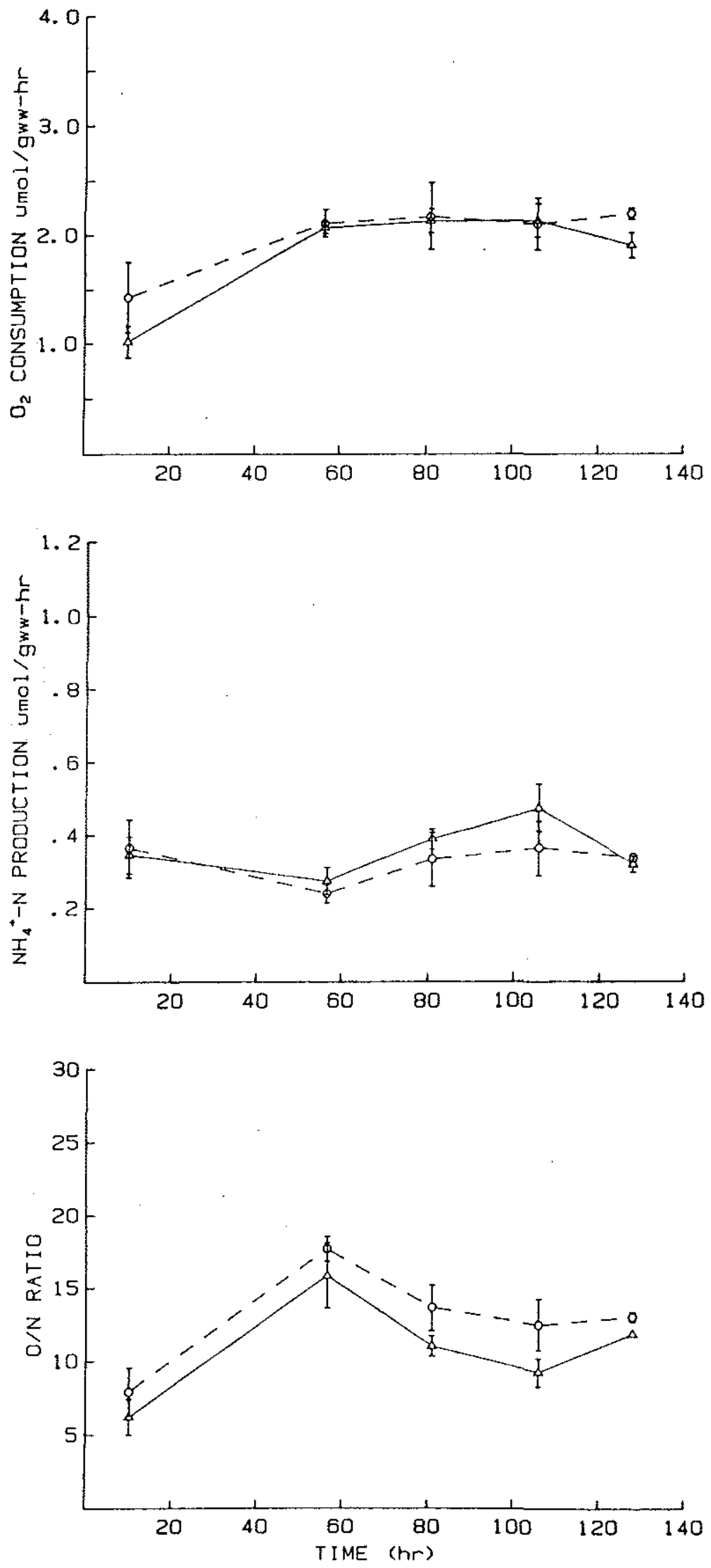
Figure 5.3: Whole chamber oxygen consumption, ammonia production, and the $0 / N$ ratio in experiment 3. Circles represnt contro 1 chambers. Triangles represent exposed chambers. Values expressed as mean $\pm S E n=3$. 

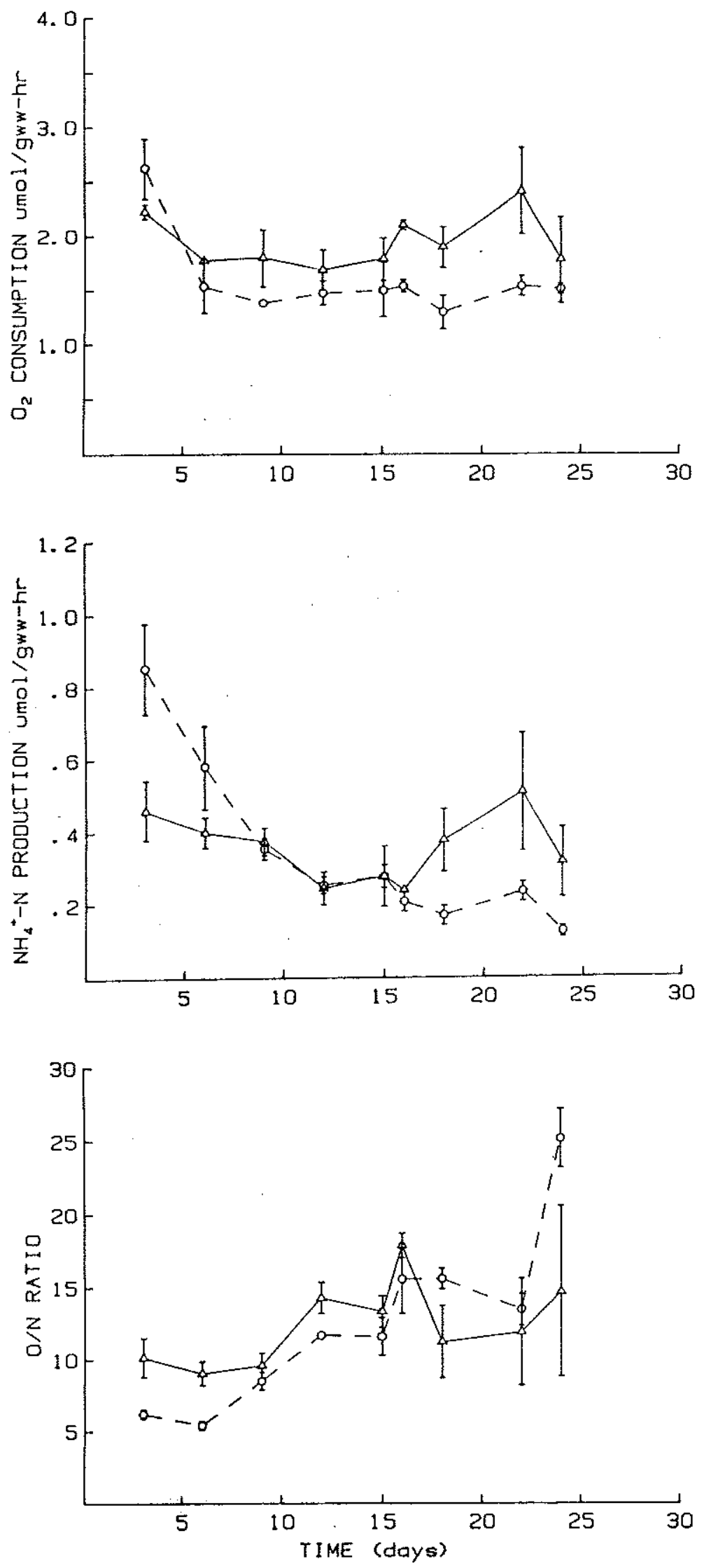
Figure 5.4: Whole chamber oxygen consumption, ammonia production, and the $0 / \mathrm{N}$ ratio in experiment 4. Circles represnt control chambers. Triangles represent exposed chambers. Values expressed as mean $\pm \mathrm{SE} n=3$. 

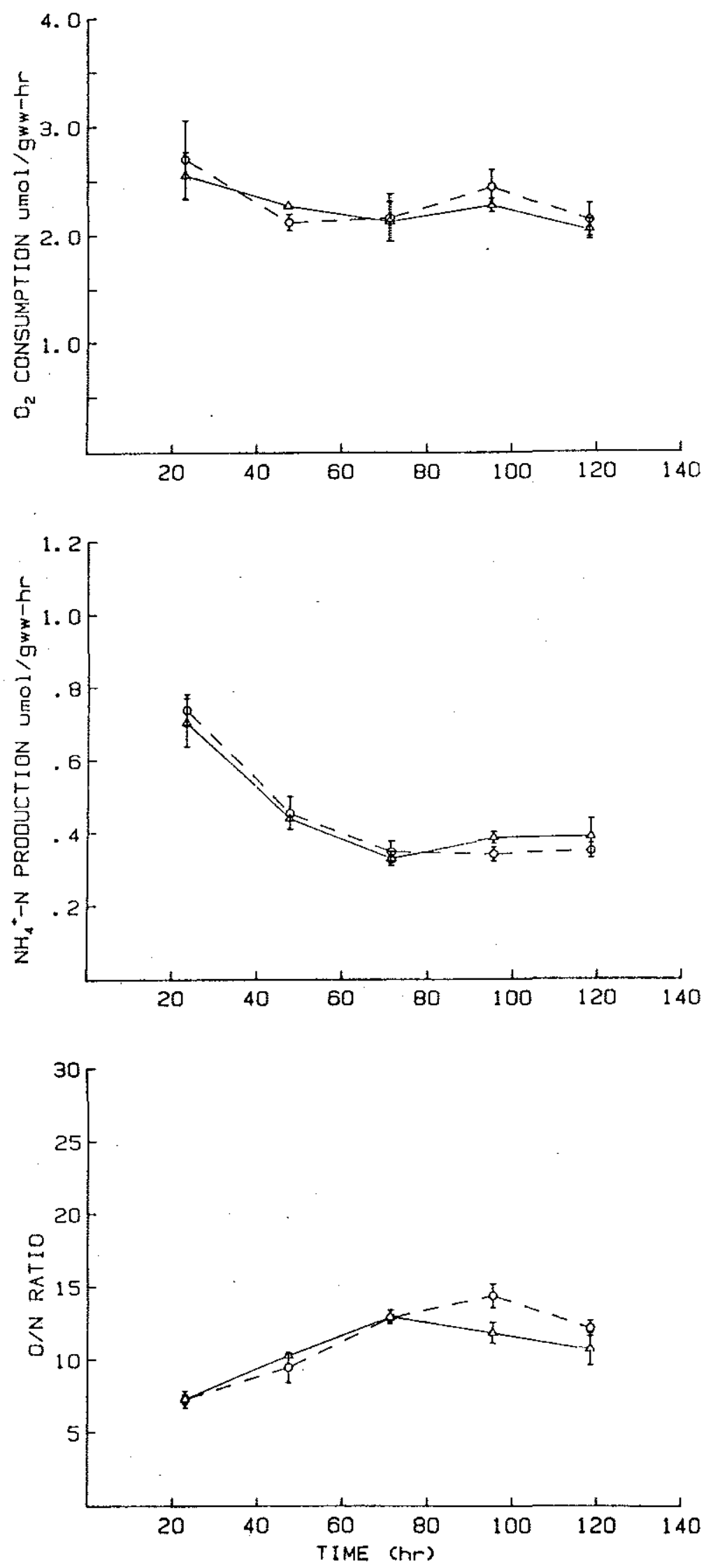
-183-

Figure 5.5: Whole chamber oxygen consumption, anmonia production, and the $0 / \mathrm{N}$ ratio in experiment 5. Circles represnt control chambers.

Triangles represent chambers with $B A$. Values expressed as mean $\pm S E n=4$. 

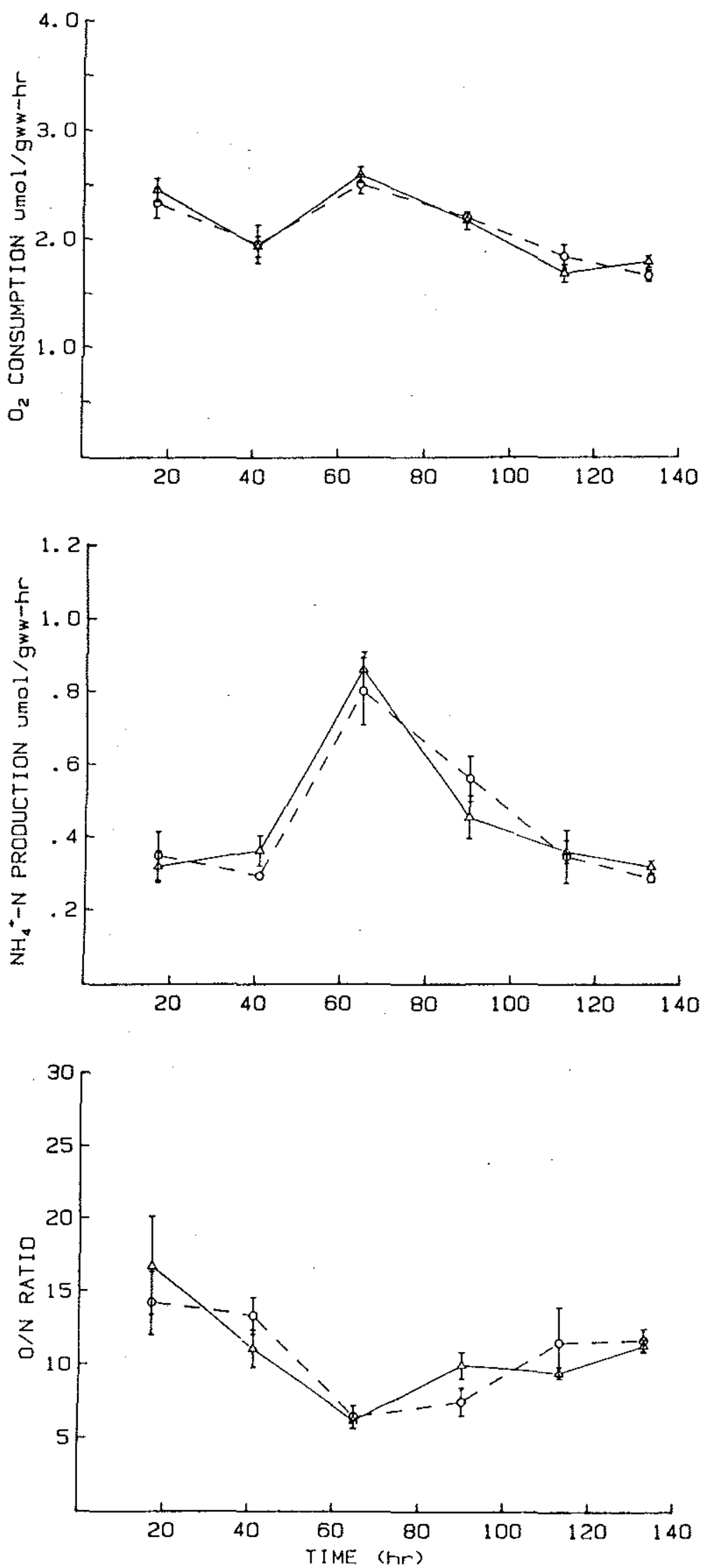
Table 5.4

\section{SUMMARY OF TWO-WAY AKALYSIS OF VARIANCE ON THE EFTECTS OF BEHZ(a)ANTHRACEIE BXPOSURB AID TINE OI \\ WHOLE CHAMBER OXYGEN CONSURPTION}

Exposure to

Exposure Time Interaction

Sediment-sorbed BA

6 days

6 days

25 days

Experiment with

BA Added to the

Water Column

$$
6 \text { days }
$$

Experiment with

BA Labeled Food

BA Labeled Food
ND

ND

*

ND

ND

ND
ND

ND

ND
4 days
ND
*
ND

* Control chambers significantly different from exposed chambers $(\mathrm{p}<.05)$

ND No difference 
Table 5.5

\section{SUHMARY OF TWO-WAY ANALYSIS OF VARIANCE ON THE EFTECTS OF BEAZ(a)ALTHRACEWE BXPOSURE AKD TIME ON \\ WHOLE CHAYBER AYMONIA PRODUCTION}

Exppsure to

Exposure Time Interaction

Sediment-8orbed BA

6 days

6 days

25 days

Experiment with

BA Added to the

Water Column

6 days

Experiment with

BA Labeled Food

4 days
ND

*

ND

ND

*

ND

* Control chambers significantly different from exposed chambers $(p<.05)$

ND No difference 
obvious trends with time were observed. In experiment 3 an interactive effect between time and treatment was observed.

0xygen consumption and ammonia production were also measured on chambers without worms in experiments 1-5. Rates were genera11y low and constant over time accounting for 29 and $20 \%$, respectively, of rates seen in chambers with worms. The physical and biological characteristics of chambers without worms did not represent realistic controls for microbial respiration in chambers with worms, thus worm chamber oxygen consumption and ammonia production rates were not corrected for microbial input. Respiration and ammonia production rates for chambers with worms include both worm and microbial contributions, and therefore should not be construed to be absolute values for worms alone, but comparative estimates between treated and control anima 1 s.

One caveat to the generally low and consistent ammonia production rates seen in chambers without worms was observed in the long-term experiment with sediment-sorbed BA. In this experiment a large increase in ammonia production was observed in chambers without worms beginning on day 6, where ammonia production was equal to or exceeded that seen in chambers with worms. This increase in ammonia production could have been due to several factors. Although none of the chambers appeared to be anoxic, either by visual inspection or analysis of redox potentia 1 , it is like ly that sediments in chambers with worms were more oxidized than unbioturbated sediment. Therefore, a lthough not measurable, there may have been patches of reducing environments were bacterial ammonia release might have occurred. The discrepancy between ammonia production in chambers with and without worms may also have been due to increased 
uptake of dissolved ammonia by microbes in chambers with worms. This possibility is supported by the elevated ${ }^{14} \mathrm{CO}_{2}$ flux seen in chambers with worms in this experiment (See Chapter 3).

The atomic ratio of oxygen consumed to nitrogen excreted, calculated here frow the oxygen consumption and ammonia excretion rates measured, gives an indication of the relative reliance on carbohydrate and lipid vs. protein reserves used for energy (Mayzaud, 1973). Considering the variability in oxygen consumption rates and ammonia excretion rates, it is not surprising that no large differences were seen between control and exposed chambers (See Figures 5.1-5.5). On 1y at the end of the 25 day experiment with sediment-sorbed BA (Fig. 5.3) did $0 / \mathrm{N}$ ratios for control chambers appear to diverge from those for exposed chambers. Analysis of variance indicated that there was a statistically significant effect of time and a significant time/treatment interactive effect in this experiment, although the effect of treatment alone was not significantly different. The relative decrease in $0 / N$ seen in exposed chambers indicates that worms exposed to BA were relying more heavily on protein reserves than contro1 worms.

No consistent significant changes in weight were observed between control and exposed worms (Table 5.6). In the long-term experiment with sediment-sorbed BA there was a trend for increased weight loss in exposed worms, but the significance leve 1 of the difference was on 1 y $94 \%$. The large variability in weights is primarily due to the necessity to pool worm weights from each chamber, there being no way to identify individual worms.

\section{Discussion:}


Table 5.6

\section{URIGHT CHANGE OF Hereis virens DURING EXPERIMIRMTS}

Experiments with

Sediment-sorbed BA

6 days
6 days
25 days
riment with
dded to the
Column

6 days

Contro1

Exposed

Experiment with BA Labeled Food

$$
4 \text { days }
$$

Experiment with BA Added to the Water Column

\author{
Weight Change Initial/Final \\ Initia1-Final Weights \\ gWw
}

$\begin{array}{llr}\text { Contro1 } & .938 \pm .263 & .910 \\ \text { Exposed } & -.167 \pm .280 & 1.01 \\ & & \\ \text { Contro1 } & -.216 \pm .082 & 1.01 \\ \text { Exposed } & -.869 \pm .444 & 1.05 \\ & & \\ \text { Control } & 2.032 \pm .132 & .874 \\ \text { Exposed } & 2.834 \pm .496 & .814\end{array}$


In general the physiological effects of BA on Nereis virens observed in these experiments were minima 1. The dose of this single PAH of less than $10 \mathrm{ppm}$ in the sediment is similar to concentrations seen in sediments receiving substantial petroleum input from urban run-off (Readman et a 1., 1982). However, on a total hydrocarbon basis, even with the added $B A$, toxicant levels were not significantly higher than those encountered in relatively clean coastal sediments (Youngblood and Blumer, 1975). Letha 1 concentrations for the WSF of fuel oil for polychaete worms have been estimated to be on the order of 1 to $20 \mathrm{ppm}$ in water (Carr and Reish, 1977), so it is not surprising that dramatic effects were not observed in this investigation. However, the subtle effects seen in adenylate nucleotide pools in as 1 ittle as 6 days with whole animal physiological effects beginning to becone apparent after a period of weeks, suggest that the multilevel approach used in this investigation has utility in ident ifying sublethal bioenergetic perturbations. Whether or not effects at this level. would lead to significant whole anima 1 or population level effects would require experimentation on a much longer time scale.

Activity of the mixed function oxygenase system measured using BP as a substrate in a microsomal preparation made from whole worm homogenates averaged on 1 y 1.38 pmo $1 / \mathrm{mg}-m$ in for control and exposed groups in a 11 experiments. Although this rate is low in comparison to rates reported for AHH activity in teleost fish (Stegeman, 1979), it is comparable to a value of $2.5 \pm 0.8 \mathrm{pmo} 1 / \mathrm{mg}-\mathrm{min}$ reported for crude Nereis virens homogenates by Lee et a1. (1981). Analysis of the whole worm results in a large dilution of intestinal tissue, where the majority of MFo activity in 
Nereis virens has been reported (Lee et a1., 1.979). AHH activity in microsomes prepared from intestinal tissues of Nereis virens taken from the same group of worms used form this study averaged $88.9 \pm 1.8 \mathrm{pmo} 1 \mathrm{e} / \mathrm{mg}-$ min $(n=7)$ (McElroy, unpublished data); a much more respectable rate. Unfortunately, using just intestinal tissue for the MFo assay was prohibited by the necessity of also using worm tissue for analysis of adenylate nucleotide pools and BA accumulation.

In investigations of MFO activity in intestinal microsomes, Lee has reported increases in BP hydroxylase activity 48 hours after feeding Nereis clams contaminated with BA (Lee et a1., 1979). The actual dose delivered to the worms was not determined, but potentially could have been much higher than exposures in this experiment. Subsequent experiments by Lee failed to detect significant increases in BP hydroxylase activity in Nereis given food contaminated with extremely high concentrations ( $1 \mathrm{mg} / \mathrm{g}$ ) of BP continuously for a period of four to eight weeks (Lee et a1., 1981). However, BP hydroxylase activity and P-450 concentrations in Nereis collected from an oiled environment were significant ly higher than in worms collected from a control site in Maine. These results suggest that the indication of induction observed in the field may have been due to factors other than PAH exposure, that induction of the MFO system in Nereis virens by PAH may require either exposure to very high leve1s, or that the induction process is extremely slow, requiring a period of months. Although the question of induction of the MFO system in Nereis virens remains equivocal, the absence of evidence for induction in these experiments can be used to support the similar abilities of worms used in different experiments to metabolize BA. 
Decreases in energy charge reported here after short-term exposure to BA are consistent with other studies showing decreases in energy with sublethal stress such as exposure to nickel in Mytilus edulis (Zaroogian et a 1., 1982), stress due to filtration of algal cultures (Jewson and Doku1i1, 1982), changes in metabolism during temperature acclimation in trout (Walesby and Johnston, 1980), anoxia in Spartina alterniflora roots (Mendelson, 1981), exposure in Fundulus grandis to low pH water (MacFarlane, 1981), anoxia in sea anemones (E1lington, 1981), tubificid worms (Schott ler, 1978), and Arenicola marina (Surho 1t, 1977). Adeny 1ate nucleotide ratios have also been implicated in regulation of glutamate dehydrogenase activity in brackish water clams (Matsushima and Kado, 1983). However, a similar number of studies have reported no consistent change in energy charge in response to temperature adaptation in sea anemones (Wa 1 sh and Somero, 1981), in response to zinc in lobster (Haya et a1., 1983), in isopods rendered moribund by exposure to toluene (skjoldal and Bakke, 1978), temperature stress on diatoms (Falkowski, 1977), and after starvation in crayfish (Dickson and Giesy, 1982). Since very different methods were used to analyze nucleotides in these experiments it is difficult to compare these results as various methods are better suited for different organisms (Karl and Holm-Hansen, 1978). Based on these results the general applicability of energy change is somewhat limited and probably very species and process dependent.

The results of this present study support the use of adenylate nucleotide ratios as a relative index of metabolic perturbation only when comparing groups in carefully controled laboratory exposures. The results also suggest that this measurement can be useful in signaling 
changes in the metabolic potential of an organism before effects are noticed at the whole animal level. Oxygen consunption and ammonia production rates measured here on Nereis virens exposed to BA were high 1 y variable, and were on $1 \mathrm{y}$ significant $1 \mathrm{y}$ different from controls in the longer-term experiment with sediment-sorbed BA where a significant increase in oxygen consumption, a tine dependent increase in ammonia production, and a decrease in the $0 / N$ ratio were observed. Similar observations have been reported for oxygen consumption and ammonia excretion in larval lobsters exposed to oil/water dispersions of crude oil (Capuzzo et a1., 1984). These results indicate that after prolonged exposure to BA, Nereis expended more energy maintaining basal metabolism, and showed an increased reliance on protein reserves than control worms.

Significant differences were not observed in growth rate in these experiments. However, it is likely that the trend observed for increased weight loss in exposed animals would have become significant with time. Carr and Neff (1984) reported significant differences between glycogen content of Nereis virens collected from petroleum contaminated and control environments in Maine. They found similar results in laboratory experiments in response to starvation or long term exposure to pentachloropheno1 (Carr and Neff, 1981).

The variability in oxygen consumption rates, and ammonia excretion rates observed here are probably largely due to intermittent burrow irrigation and respiratory activities in these worms, a phenomenon well documented in burrowing organisms in general (Mangum, 1964) and in Nereis virens in particular (Scott, 1976). Making these measurements on whole chambers containing 4 animals with a water column residence time of 2.3 
hours vould tend to produce a time-averaged rate which should have smoothed some of the individual and time related variability. However, microbial activity probably added variability to these measurements. Even with these caveats, oxygen consumption and ammonia production rates measured here compared wel1 with those reported for Nereis virens by Kay and Brayfield (1973) and Scott (1976). Additional1y, the increase in both oxygen consumption and particularly ammonia producton seen after feeding in experiment 5 was exact $1 \mathrm{y}$ what would be expected after consumption of a protein rich mea1 (Lied and Braten, 1984, Jobling and Davis, 1980), validating use of these microcosms as metabojic chambers.

It is possible that BA exposure caused changes in the worm irrigation or burrowing rate as has been observed in other polychaetes exposed to oiled sediments (Gordon et a1., 1978, Augenfeld et a1., 1980-81). Quantitative measurement of either irrigation rate or burrowing rate were not possible in this experiment, but visual observation of worm position in the sediment, fecal pellet production, and the number of burrow openings indicated no obvious differences between control and exposed groups. If exposed worms were irrigating their burrows at reduced rates, reduced oxygen consumption rates should have been observed. The enhancement of oxygen consumption in chambers with worms in the long-term experiment suggests that suppression of burrow irrigation due to BA exposure was not occurring.

\section{Sumary:}

In these experiments Nereis virens accumulated and metabolized up to ppm levels of BA, yet biochemical and physiologjcal measurments traditiona11y associated with stress were on $1 \mathrm{y}$ minimal1y affected. It appears 
that at least for the short term Nereis was capable of adapting to exposure to BA at these concentrations, or that BA is not particular ly detrimental to Nereis. The small increases in respiration and ammonia excretion observed in the 25 day exposure experiments suggests that with time exposure to $B A$ at this level may have deliterious effects. 


\section{CHAPTER 6:}

SUMARY

The benthos is a complex environment where biological, physical and chemical processes are continually interactive. In this study of the fates and effects of PAH in the benthos, an interdisciplinary approach was undertaken, focusing on interrelations between the source of $\mathrm{PAH}$ to the benthos, PAH metabolism, and anima1/chemical/sediment interactions. Although the results are separated into chapters dealing with the overall. fate of $B A$ in the system, in vivo BA metabolism by Nereis virens, and the physiological effects of BA exposure on Nereis virens, from an experimental standpoint, much information would have been been lost if any part of this investigation had been undertaken in isolation.

Many studies on the effects of pollutant compounds are weakened by the lack of detailed chemical characterization of the dose and its bioavailability. In many chemical studies on the fate of pollutant compounds, biological activity is evoked to take care of distributions that can not be explained purely by chemical or physical processes. In both cases, interpretations are limited by the absence of interdisciplinary data. Therefore, although the complexity of the experimental system made analysis and interpretation difficult, the results from this study provide biogeochemical and physiological information on both the fate and effects of a single $\mathrm{PAH}$ in an intact benthic system.

The results presented in Chapter 3 demonstrated that the mode of introduction had significant effects on the fate of $B A$ in the experimental chambers. BA sorbed onto particles in the entire sediment reservoix was relatively refractory, with concentrations remaining unchanged from the start to finish of experiments lasting from 6 to 25 days. On the 
other hand, BA added to the water column which became associated with the sediment-water interface, was much more labile. A significant portion of activity originally deposited at the sediment-water interface was removed via flux to the water column in 6 days. In addition, small but detectable rates of microbial mineralization were observed in this experiment as compared to undetectable rates observed in short-term experiments with sediments uniformly labeled with BA.

The presence of worms also had significant effects on the fate of BA in these chambers. In experiments with the sediment reservoir labeled with $B A$, the $f 1$ ux of $B A$ to the water column was significantly higher in chambers with worms. Increased $f l u x$ in chambers with worms was observed in both the short- and long-tern exposure experiments, and the effect intensified with time. The presence of worms also increased microbial mineralization of $\mathrm{BA}$. It was concluded that the effect of worms on flux rate was primarily due to thejr tubicolous lifestyle. In the experiment where BA was added to the water column, the presence of worms had no net effect on $f 1 u x$ of $B A$ sorbed to the sediment surface out into the water column. In this case the activity of worms resulted in mixing BA at the sediment-water interface down into the sediment reservoir.

Nereis was capable of accumulating BA, al though efficiency of uptake was strongly affected by how the chemical was introduced. Bioavailability is very difficult to assess. However, consistent trends became apparent when both relative accumulation as a percentage of total available, and concentration ratios between the worms and the source of $B A$ were considered. Under these experimental conditions, BA incorporated into a protein-based diet was most available, while BA sorbed to the bulk 
sediment reservoir was least available for accumulation by Nereis.

Analysis of BA metabolites produced in vivo, as discussed in Chapter 4, clearly shows that most BA accumulated was rapidly metabolized to more polar metabolic products. A minimum of $2 \%$ and a maximum of $23 \%$ of accumulated BA remained as unmetabolized parent compound. In a 11 but the short-term experiments with sediment-sorbed BA, most accumulated activity was present as either water soluble conjugated metabolites, or in an unextractable fraction that probably represented BA metabolites covalently bound to cellular macromolecules. PAH metabolite fractions are routinely missed by analytical procedures commonly utilized in hydrocarbon investigations. These results indicate that most of the literature on accumulated levels of $\mathrm{PAH}$ in marine organisms capable of PAH metabolism severely underestimate total accumulation and total exposure.

Mode of introduction also affected the degree to which accumulated BA was metabolized. The proportion of total BA-derived radioactivity accumulated and remaining as parent compound was inversely proportional to the efficiency of accumulation. In addition, the relative proportions of specific metabolite pools and the pattern of polar metabolites formed were different in experiments with different modes of exposure. Since different metabolic pools have widely different biological and chemical reactivity, these results indicate that not only are PAH from different sources disproportionately available for accumulation by benthic organisms, but in addition, longterm effects produced by the presence of these various metabolites may be quite different.

The high percentage of accumulated activity in the conjugate and unextractable pool relative to that retained as parent BA or polar meta- 
bolites implies some interesting conclusions about in vivo BA metabolism in Nereis. First $1 y$, these results suggest that primary metabolism to polar metabolites is a rapid process, and that polar metabolites are further transformed as rapidly as they are produced. Secondly, the build up of metabolic products in the later two pools suggests that excretion of water soluble metabolites is relatively slow, and that binding to cellular macromolecules is a major endproduct of BA accumulation. The high percentage of accumulated activity in these two pools, and the evidence suggesting minimal formation of sulfate and glucuronide conjugates, suggest that BA metabolism in Nereis is dominated by the highly reactivie epoxide intermediate leading to the formation of nacromolecular adducts and possibly glutathione conjugates preferentially over the formation of less reactive metabolites such as phenols, sulfate and glucuronide conjugates, metabolites that can be readily excreted. As binding to cellular macromolecules such as DNA, RNA, and protein is considered a toxification pathway, this finding suggests that PAH metabolism in Nereis may have delitereous consequences. Alternatively, binding to structural macronolecules such may provide a means to sequester xenobiotic substances in a manner analogous to metallothionein binding of metals.

Physiological effects of BA exposure to Nereis virens were minimal. Although the worms readily accumulated and metabolized up to ppm levels of $B A$, the single consigtent quant ifiable result was subt le perturbations in adenylate nucleotide pools. Only after a period of weeks of constant exposure to sediment-sorbed BA did changes in oxygen consumption and ammonia excretion begin to become evident. These results support the idea that Nereis virens as a relatively tolerant organism. These results 
are also not inconsistent with the conclusion that over the short term, BA or its metabolites are not particularly toxic. They also indicate that attempts to measure physiological responses to low level stress should be of longer duration. Additionally, the effects observed would have been more powerful if they had been generated in response to a wide enough range concentrations to demonstrate some sort of dose repsonse curve. A great deal of natural variability was observed between control groups of worms both within and between experiments in all indices neasured. These results also point out the fact that due to natural variability in physiological indices, particularly in invertebrates which are capable of tolerating wide fluctuations in their biochemical and physiological state, it is essential to use 1 arge numbers of organisms with closely matched controls when attempting to differentiate the effect of any kind of perturbation from normal variability.

The conclusions of the experiments discussed above describe the fate and metabolism of $\mathrm{BA}$ in controlled nicrocosms containing fine sediments and high densities of Nereis virens. Nevertheless, some of the conclusions of this study can be extrapolated to describe factors important to the fate and metabolism of PAH in the benthos. This study demonstrated that not a 11 PAH reaching the benthos are equally available for bioaccumulation and metabolism, or removal by purely physical forces. Although PAH in a form similar to those generated by fossil fuel combustion cauld not be investigated in this study, the data and relative bioavailability of sediment-sorbed vs. initial1y dissolved PAH suggests that PAh released by combustion would be even less available for accumulation and metaboljsm. PAH in the water column which becomes associated with particulates 
at the sediment water interface is likely to have a much shorter residence $t$ ime than $\mathrm{PAH}$ buried in the sediment, even though buried PAH may stil 1 be in the bioturbated zone. The presence of infaunal organisms in environments with buried PAH are likely to enhance their removal, primarily due to bioturbation and irrigation activities, rather than metabolism. Although microbial mineralization of the larger ( $>3 \mathrm{ring}$ ) PAH occurs, this process will probably be insignificant relative to other processes acting to remove $\mathrm{PAH}$.

PAH accumulated by marine organisms are likely to be metabolized quickly by any organism with a functional MFO system. Even though PAH metabolites are more polar than the unmetabolized parent compound, they have an appreciable residence time in the organism. Retention of BA metabolic products in Nereis and the efficiency of uptake and metabolism of BA introduced as food, as observed here, indicates that dietary transfer of PAH in the benthos is an important process. Dietary accumulation of PAH would provide a rapid vector for the transfer of PAH in benthic reserves to highly mobile fish and human consumers.

Results from the physiological effects portion of this work do not bear directly on the fate of PAH in the benthos. However, the absence of dramatic effects due to exposure to PAH or from the production and accumulation of metabolic products in Nereis virens suggests that, at least for the relative1y short duration of these experiments, the physiological adaptive capacity of this worm was not exceeded by exposure to a single PAH, BA. The natural variability observed between control groups both within and between experiments in the absolute values of indices measured also points out the problems inherent with making these measurments on 
field populations and using absolute values as indices of environmental stress.

These results suggest several avenues of further research. More specific information on in vivo metabolism of PAH by Nereis and other organisms is warrented. To assess to importance of the bound fraction of accumulated activity in organisms, it will be necessary to first determine what type of cellular macromolecules are involved. Secondly, kinetic experiments are needed to determine the speed of formation and persistence of these adducts. An attempt should be made to determine if Nereis realiy does preferential1y form conjugates with glutathione. Also it would be interesting to know what other benthic organisms are capable of rapid in vivo metabolism of PAH. This information would be of interest to regulatory agencies which are increasingly looking at residues of toxic substances in benthic organisms as an index of bioavailability and exposure of marine communities to contaminated sediments. Further work on routes of uptake for substances like PAH by inauna 1 organisms would be interesting, particularly addressing dietary vs. body surface pathways. Additiona $11 y$, the question of bioavailability of PAH liberated by combustion vs petroleum source PAH stil] reeds to be addressed. 


\section{CORCLUSTORS}

1. The majority of BA accumulated by Nereis was metabolized, regardless of how $B A$ was introduced.

2. The primary fate of accumulated BA in Nereis is incorporation into macroriolecular components.

3. Nereis accumulated and metabolized BA most efficient ly from labeled food in comparisicn to BA previously sorbed to sediment particles.

4. BA loosely associated with particles at the sediment-water interface was much more labile than $B A$ sorbed to the entire sediment reservoir. It was accumulated and metabolized more rapidly by Nereis, was removed more rapidly via diffusion, and was mineralized more readily by microbes.

5. The presence of worms had significant effects on the distribution and removal of PAH from the benthos.

6. Under the conditions of these experiments, Nereis virens was only minimaly affected by accumulation and metabolism of up to ppm concentrations of BA. 


\section{APPENIDX 1 \\ BIOGEOCHEMISTRY OF BENZ(a)ANTHRACENE IN RECIRCOLATING \\ BENTHIC MICROCOSYS}

\section{Introduction:}

This study was the final portion of a larger investigation on the biogeochemistry of petroleum components at the sediment-water interface under the direction of J.W. Farrington and J.M. Tea1. Two recirculating benthic microcosms were used to $100 \mathrm{k}$ at the metabolism of ${ }^{14} \mathrm{C}-1$ abe 1 ed benz(a)anthracene (BA) at the sediment-water interface. This experiment was a collaborative effort between J.W. Farrington, J.M. Tea1, B.W. Tripp, and myself. Appendix 1 provides a brief description of the experiment and results obtained.

\section{Methods:}

Methods used in this investigation were esscentially the same as those described in Chapter 2 with the following exceptions. Two 2301 recirculating benthic chambers (Winget, 1978) each containing a $0.25 \mathrm{~m}^{2}$ sediment box were used in this experiment. Sediments were collect from Buzzards Bay (See Chapter 2 for location and method), frozen, and then placed in the sediment trays of the chambers. Seawater was recirculated over the sediment reservoir for approximately two weeks prior to addition of the spike. ${ }^{14} \mathrm{C}-\mathrm{BA}$ was added in a carrier mixture of aromatic hydrocarbons the total dose calculated to be the same as that used by Hinga et a . (1981) in their investigation of BA metabolism in the MERL microcosms at URI. After spike addition, sediment cores, and water samples were collected periodically over 42 days for analys is of extractab $1 e^{14} \mathrm{C}-$ labeled compounds in the water column and sediment cores, and for ${ }^{14} \mathrm{CO}_{2}$ in the water column. The sediment reservoir was divided into two com- 
partments by a metal partition placed parallel to the direction of flow. On day 17 approximately 40 Nephtys incisa were placed in one portion of each chamber. The worms were retrieved at the end of the experiment. Extraction of sediment and worm tissue was done using tetrahydrofuran, ethylacetate, and methanol following methods described in Hinga et al. (1981).

\section{Results and Discussion:}

BA added to the water column quickly became associated with suspended particulates. Over the coarse of the experiment, concentration of BA in suspended particulate decreaed steadily (Figure A-1). Due to the smal1 amount of radioactivity in the water column, it was not possible to analyze water samples for polar BA metabolites. Microbial mineralization of $\mathrm{BA}$ to carbon dioxide was observed with concentrations of ${ }^{14} \mathrm{CO}_{2}$ increasing logarithmically over the first 18 days, then remaining relatively constant for the remainder of the experiment (Figure A-2). The kinetics of $\mathrm{BA}$ mineralization to $\mathrm{CO}_{2}$ were very similar to those observed by Hinga et a 1.(1981) in the much larger MERL microcosms.

Most of the isotope added to the chambers quickly became associated with the sediment reservoir. After 42 days, $98 \%$ of radioisotope recovered from the chambers was found in the sediment, with more than $97 \%$ located in the top $2 \mathrm{~cm}(T a b 1 e \mathrm{~A}-1)$. Figures A-4, A-5, and A-6 show radio- and UV chromatograms of HPLC analysis of organic extracts of representative sediment samples taken throughout the experiment. For comparison, figure A-3 shows the UV chromatogram of representative authentic BA metabolite standards. Unfortunately the specific activity of isotope in these samples was too low to say much about production of 


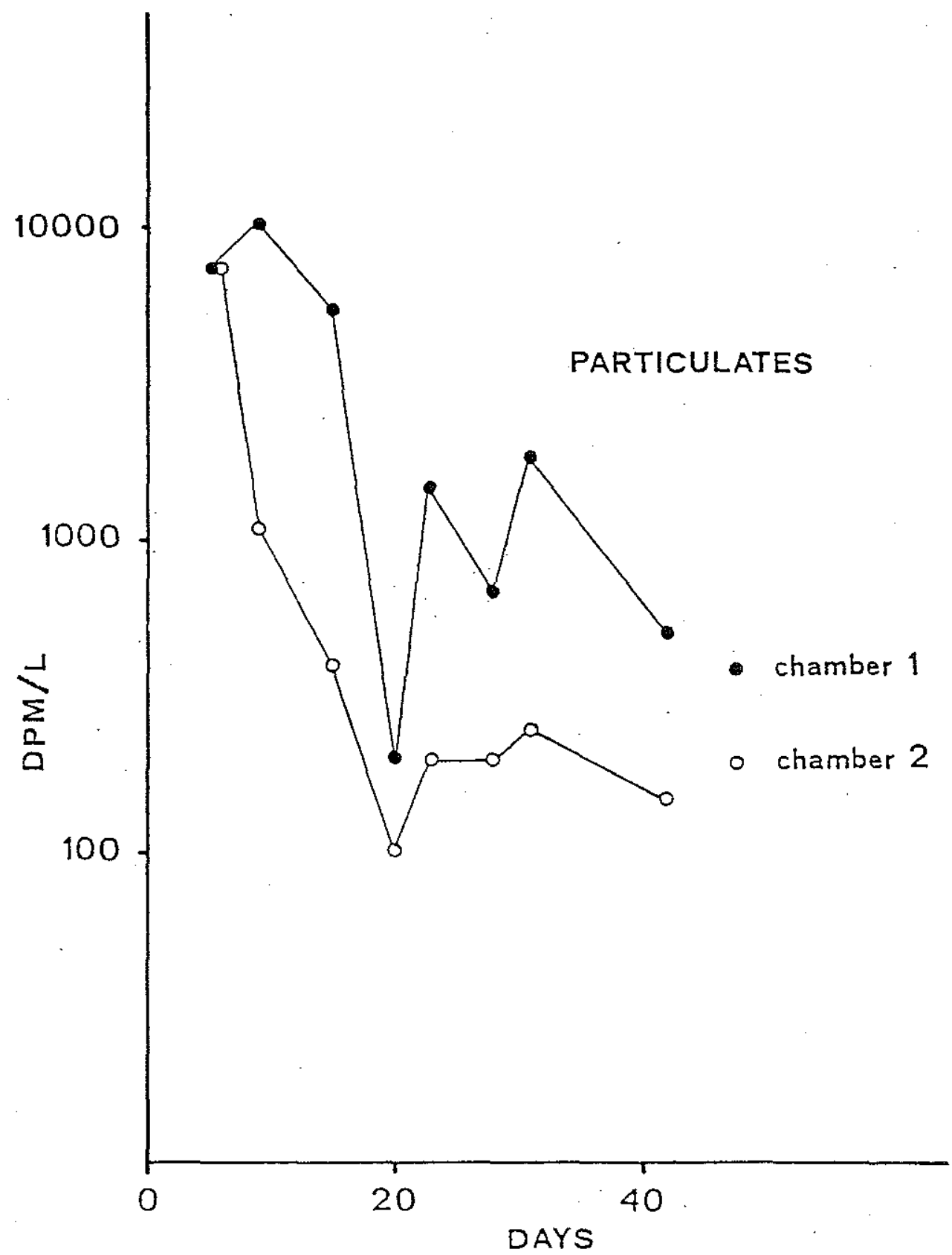

Figure A-1: Radioactivity recovered on suspended particulates. 


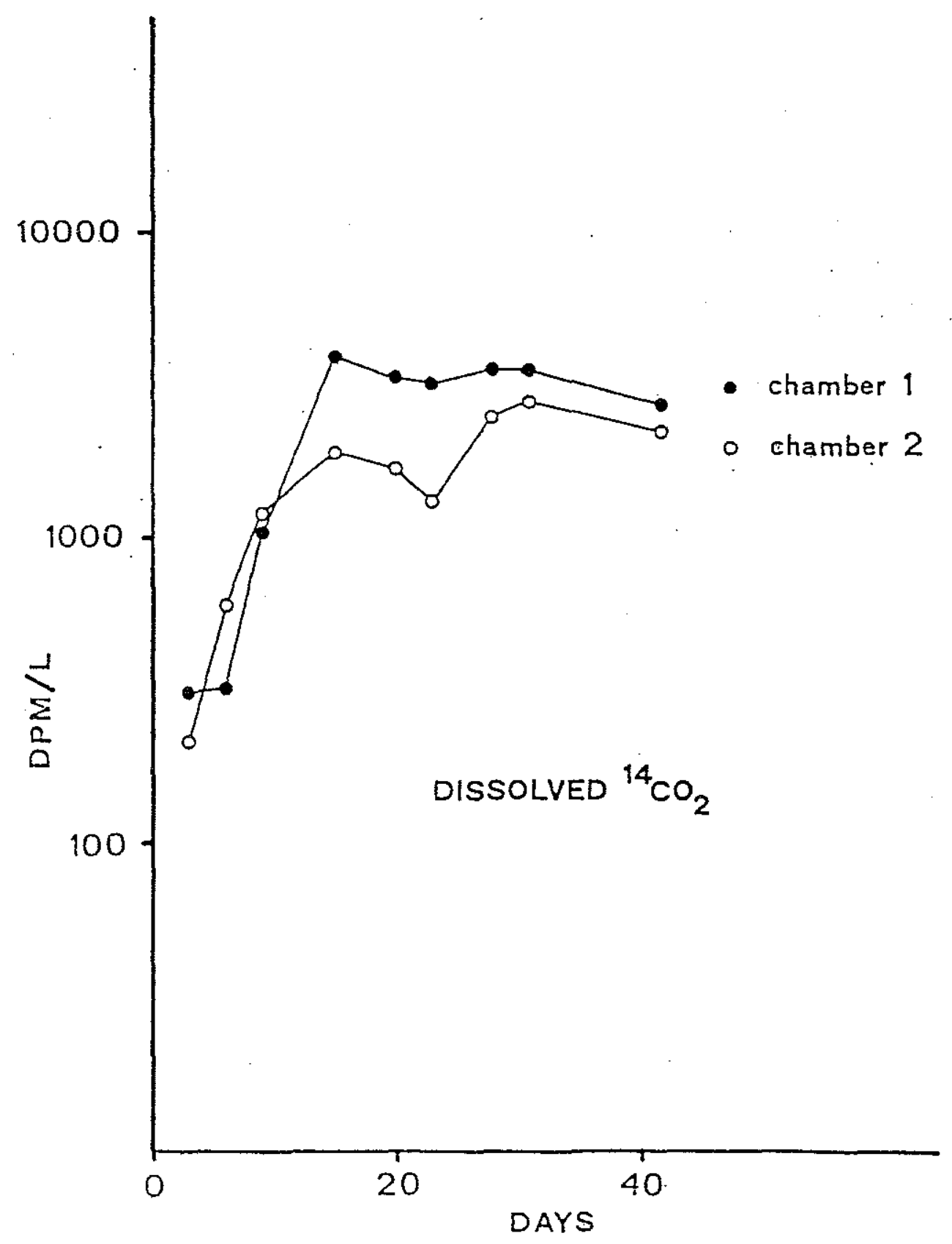

Figure A-2: Concentration of ${ }^{14} \mathrm{CO}_{2}$ in the water column. 
Table A-1:

DISTRIBUTION OF ${ }^{14} \mathrm{C}$ AT END OF 42 DAY EXPERIMENT

\begin{tabular}{|c|c|c|c|c|c|c|c|}
\hline \multirow{3}{*}{ SEDIMENT } & & \multicolumn{6}{|c|}{ PERCENT OF ${ }^{14} \mathrm{C}$-BENZANTHRACENE RECOVERED } \\
\hline & & \multicolumn{3}{|c|}{ CHAMBER 1} & \multicolumn{3}{|c|}{ CliAMBER 2} \\
\hline & & A & B & $A+B$ & A & B & $A+B$ \\
\hline & $0-1 \mathrm{~cm}$ & 37.29 & 48.82 & 86.12 & 56.14 & 24.40 & 80.73 \\
\hline & $1-2 \mathrm{~cm}$ & 4.96 & 5.20 & 10.19 & 1.I0 & 15.50 & 16.62 \\
\hline & $2-4 \mathrm{~cm}$ & 1.14 & 0.34 & 1.48 & 0.17 & 0.54 & 0.71 \\
\hline & TOTAL & & & 97.79 & & & 98.06 \\
\hline WORMS & & & & 0.01 & & & 0.02 \\
\hline SUSPENDED & PARTICULATES & & & 0.28 & & & 0.09 \\
\hline DISSOLVED & $\mathrm{CO}_{2}$ & & & 1.48 & & & 1.52 \\
\hline DISSOLVED & & & & 0.47 & & & 0.30 \\
\hline TOTAL DPM & RECOVERED & & & $4.25 \times 10^{7}$ & & & $3.42 \times 10^{7}$ \\
\hline PERCENT OF & ${ }^{14} \mathrm{C}-\mathrm{BEN} Z A N T H R A C E N E$ & & & & & & \\
\hline ORIGINALLY & Y ADDED TO CHAMBER & & & 54.1 & & & 43.4 \\
\hline
\end{tabular}

$A=$ WORMS ABSENT

$B=$ WORMS PRESENT 


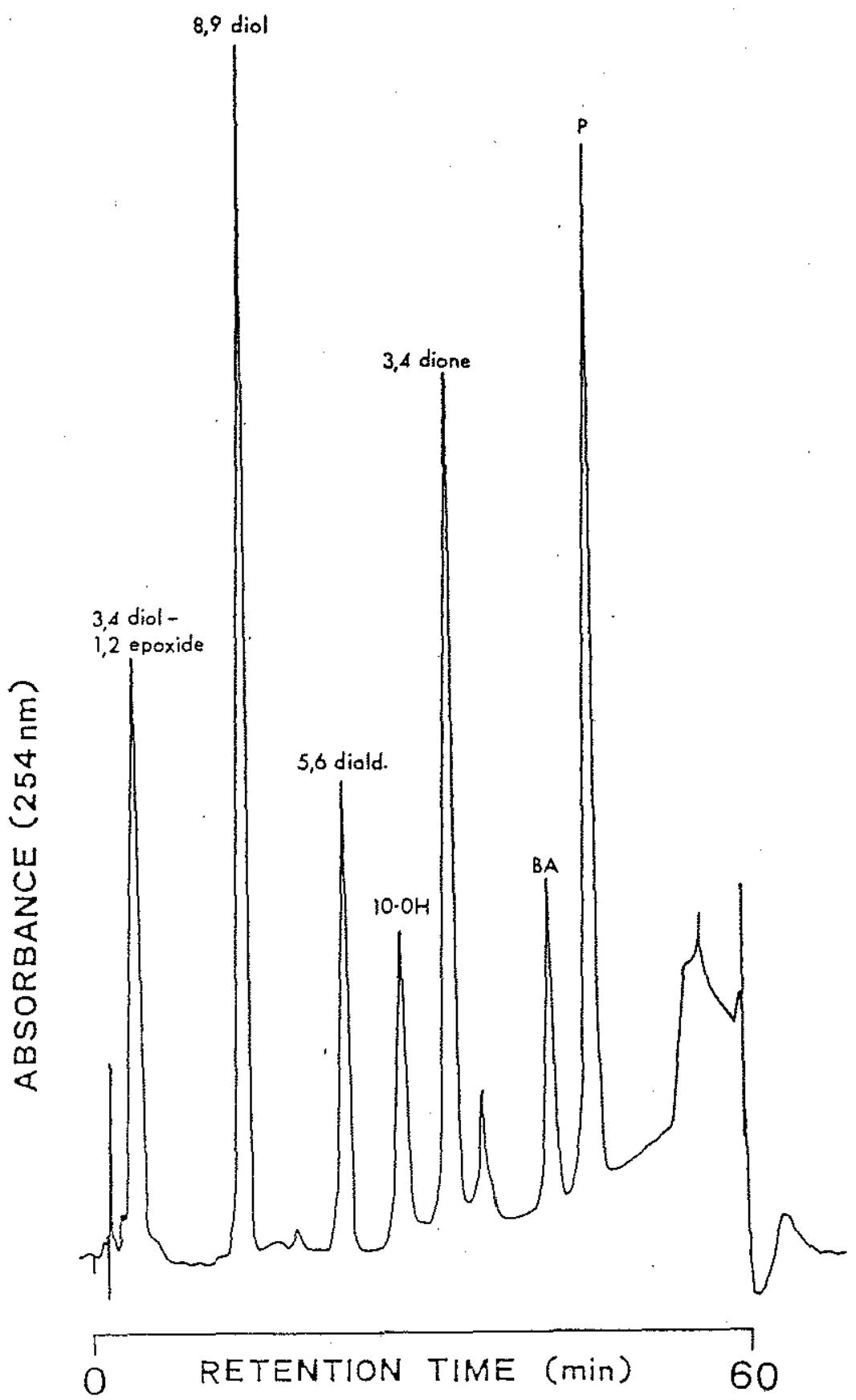

Figure A-3:

UV chromatogram of metabolite standards.

$\mathrm{P}=$ perylene, $\mathrm{BA}=$ benz $(\mathrm{a})$ anthracene. 


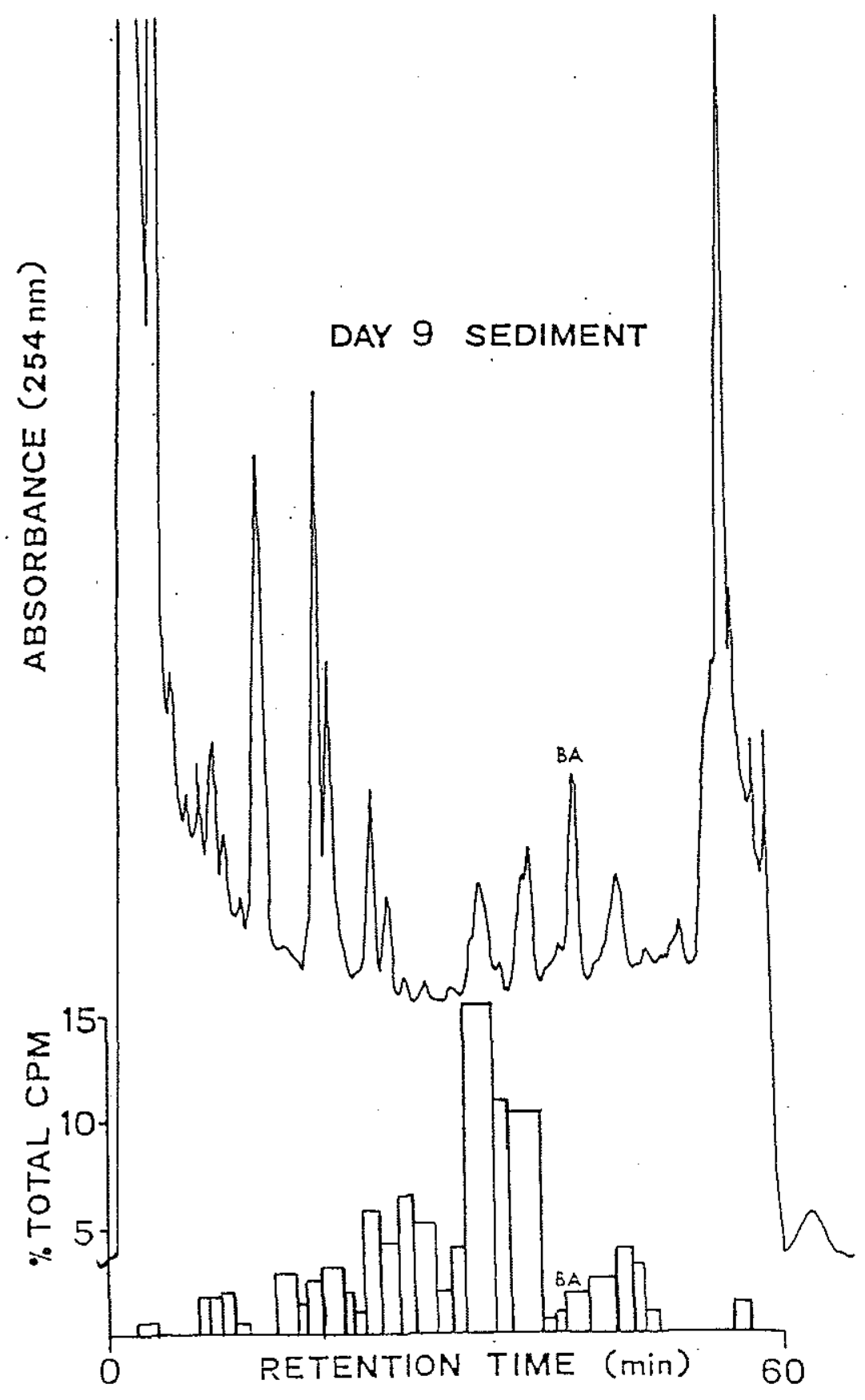

Figure A-4: HPLC chromatogram of organic extract of sediment collected on day 9 . 


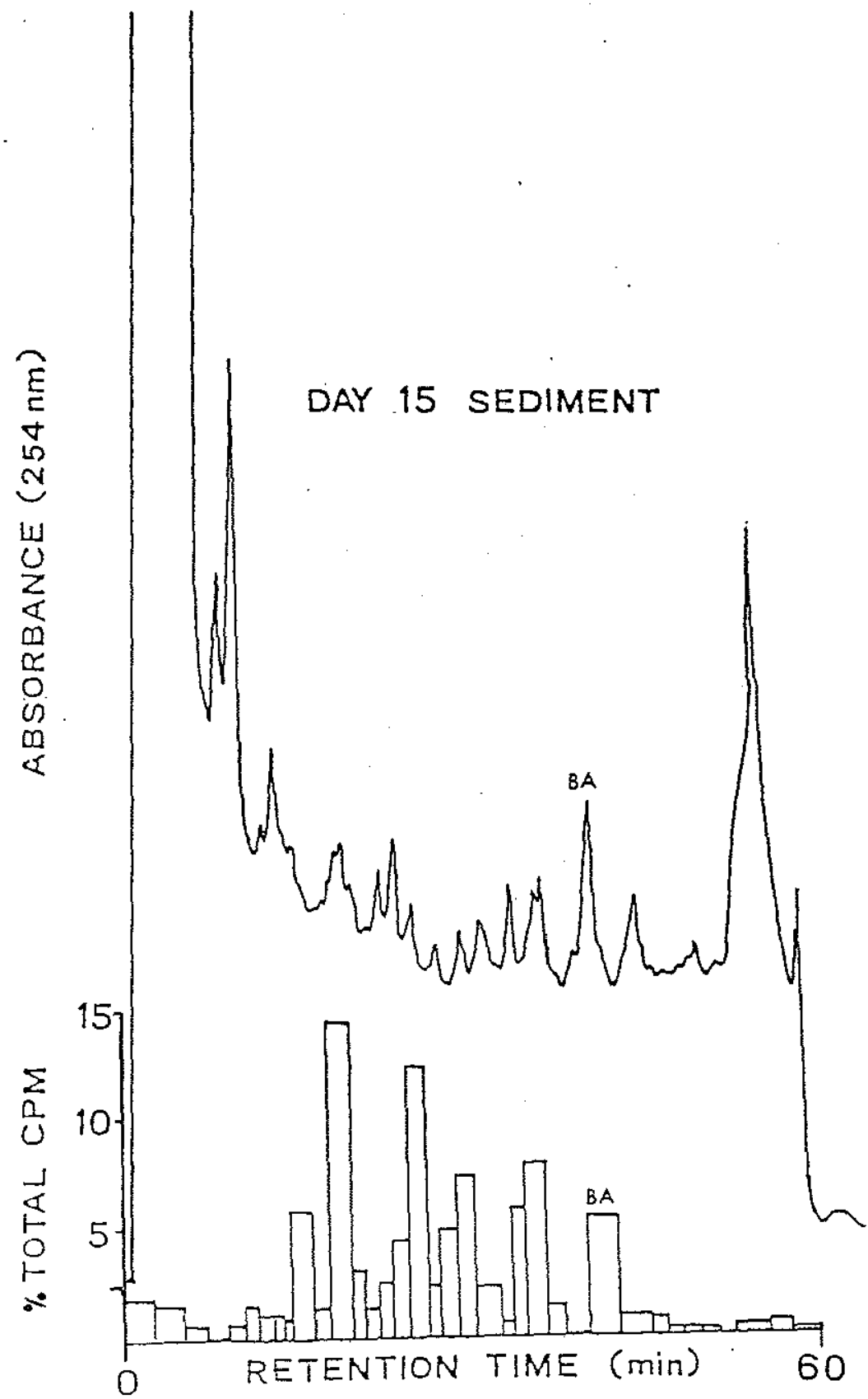

Figure A-5: HPLC chromatogram of organic extract of sediment collected on day 15 . 


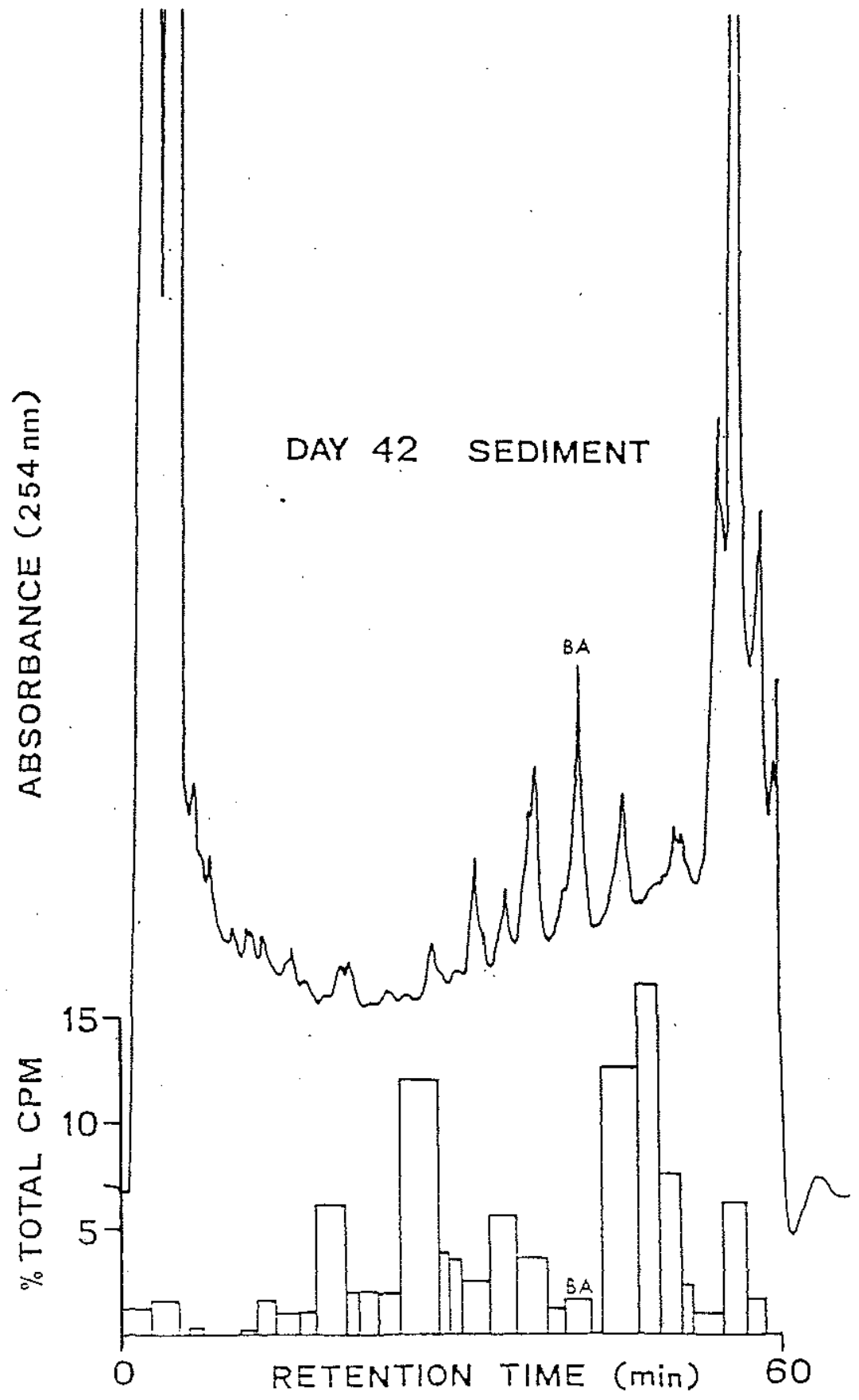

Figure A-6: HPLC chromatogram of organic extract of sediment collected on day 42 . 
specific metabolites. As early as nine days after spiking the isotope to the chambers, most of the BA in sediments had been metabolized. Analysis of a group of polychaetes Nephtys incisa exposed to BA in the chambers revealed patterns of metabolite formation similar to those seen in the sediment (Figures $A-7 \& A-8$ ).

Table A-2 summarizes the distribution of radioactivity separated using reverse phase HPLC summed into three general classes. In all samples analyzed, most radioactivity recovered was in the form of polar metabolites. At the end of the experiment, on $1 y$ a few percent of radioactivity in both worm and sediment samples was unmetabolized parent compound. In a lmost a 11 extracts analyzed, a significant portion of radiolabel eluted after $B A$ using reverse phase HPLC. The proportion of total activity recovered in this class seemed to increase with time. Preliminary data using ge 1 filtration chromatography suggested that this activity was associated with compounds of a higher molecular weight than BA (McElroy, unpub. data). The reverse phase and gel filtration data collectively suggest that this activity represents BA or BA metabolites that have been incorporated into larger molecules with non-polar characteristics.

Only $50 \%$ of the isotope spiked to these chambers was recovered in by our sampling procedure (Table A-1). A large portion of the surface area of these microcosms was involved in the water recirculation system, and could not be sampled. It is possible that particulate matter and microorganisms associated with these surfaces sequestered a significant portion of the unrecovered radioactivity.

The presense of worms had no measurable effect on the distribution 


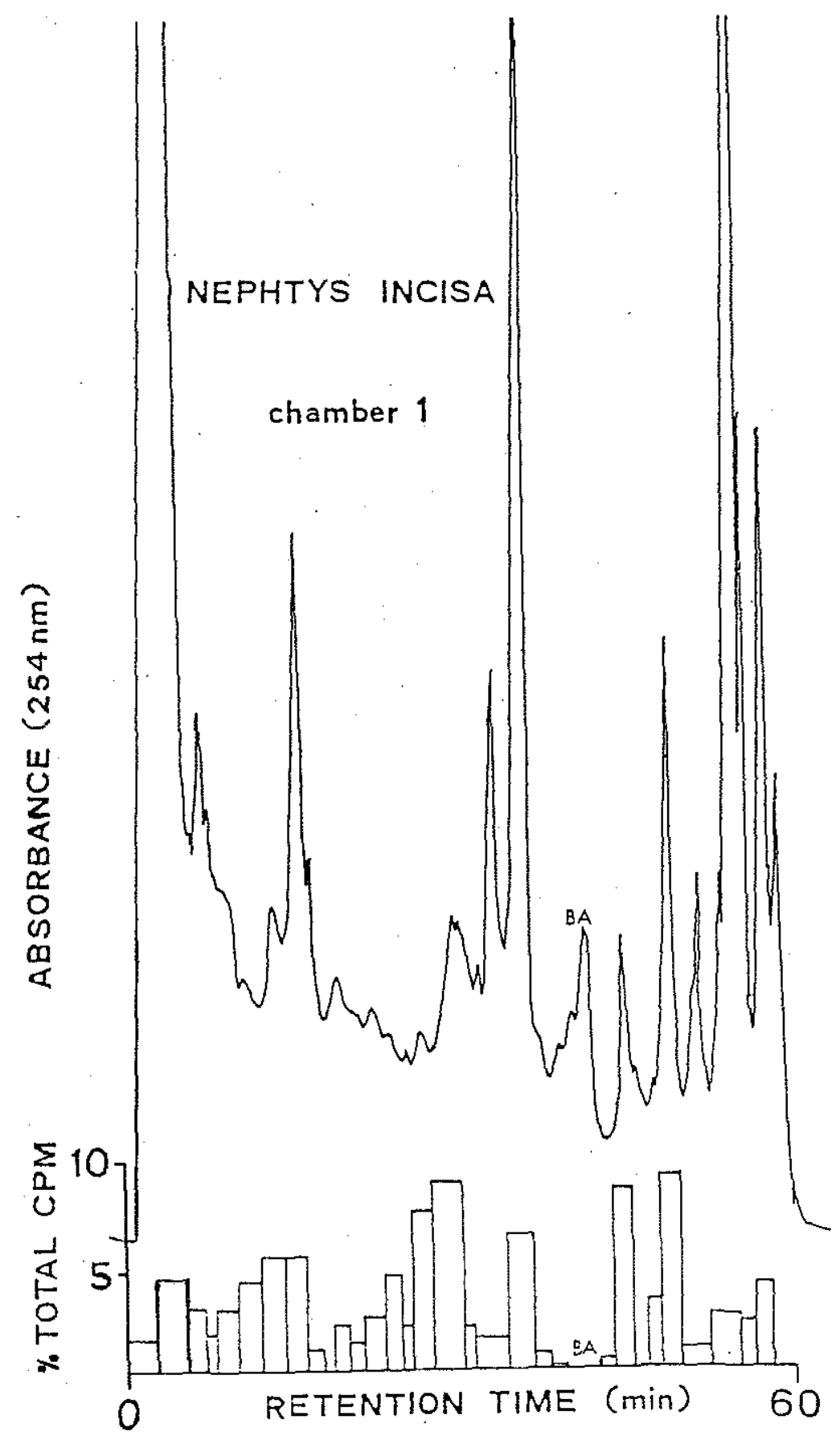

Figure A-7: HPLC of organic extract of Nephtys incisa from chamber 1 . 


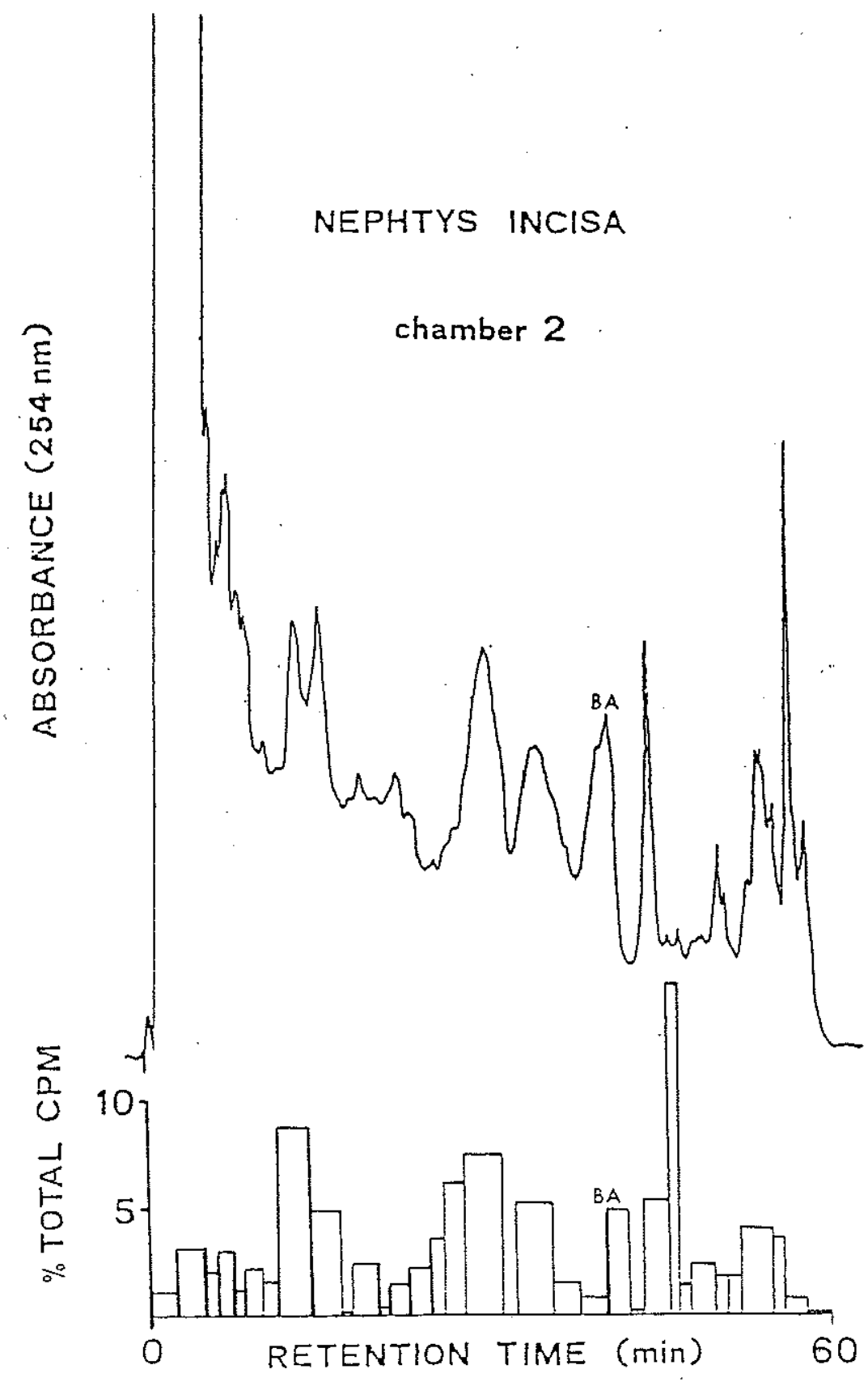

Figure A-8: HPLC of organic extract of Nephtys incisa from chamber 2 . 
Table A-2:

DISTRIBUTION OF ${ }^{14} \mathrm{C}$-LABELED FRACTIONS FROM SURFACE SEDIMENT AND WORM TISSUE SEPARATED USING REVERSE PHASE HPLC

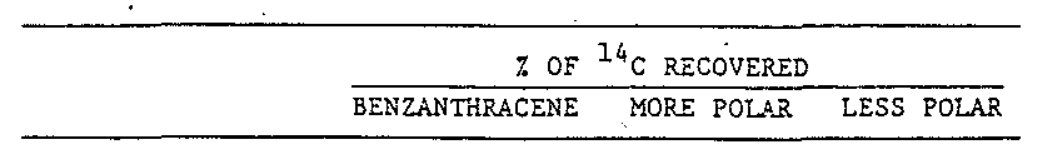

\section{DAY 42}

$\begin{array}{lccc}\begin{array}{l}\text { SEDIMENT } \\ \text { CHAMBER LA. }\end{array} & 2 & 70 & 28 \\ \begin{array}{l}\text { SEDIMENT } \\ \text { CHAMBER 1B }\end{array} & 3 & 50 & 48 \\ \begin{array}{l}\text { SEDIMENT } \\ \text { CHAMBER 2A }\end{array} & 3 & 65 & 32 \\ \begin{array}{l}\text { WORMS } \\ \text { CHAMBER 2 }\end{array} & \text { ND } & 69 & 31 \\ \begin{array}{l}\text { WORMS } \\ \text { CHAMBER 2 }\end{array} & 6 & 57 & 37\end{array}$

DAY 23

SEDIMENT

CHAMBER $2 A$

11

69

20

DAY 15

SEDIMENT

CEAMBER 1

6

904

SEDIMEN I CHAMBER 2

31

618

DAY 9

SEDIMENT CHAMBER 1

4

84

$A=$ WORMS ABSENT

$B=$ WORWS ERESENT 
or degree of metabolism of $B A$ in the sediments (See Table A-1 \& A-2).

Summary:

This experiment was a preliminary attempt to investigate the metabolic fate of $B A$ in a relatively controled benthic system containing a large burrowing polychaete. The results clearly show that substantial metabolism of BA occurred rapidly, in a matter of days. Although metabolites were recovered from the worm Nephtys incisa it was not possible to to determine if the metabolites were produced in the worms, or if the worms accumulated them directly from the sediment. Microbial mineralization of BA was observed. It was not possible to determine from these data whether mineralization occurred in the water column or at the sediment surface. 


\section{RRPRREMCES}

Aller, R.C. 1978. Experimental studies of changes produced by deposit feeders on pore water, sediment, and overlying water chemistry. Am. J. Sci. 278:1185-1234.

Aller, R.C., and J.Y. Yingst. 1978. Biogeochemistry of tube-dwe11ings: a study of the sedentary polychaete Amphitrite ornata (Leidy). J. Mar. Res. $36: 201-254$.

Ames, B.N., P. Sims, and P.L. Glover. 1972. Epoxides of carcinogenic polycyclic hydrocarbons are frameshift mutagens. Science. 176:47-49.

Anderson, J.W., J.M. Neff, B.A. Cox, H.E. Tatem, and G.M. Hightower. 1974. The effects of oil on estuarine animals: toxicity, uptake, and depuration, respiration. In: Pollution and Physiology of Marine

Organisms. F.J. Vernberg and W.B. Vernberg, eds. Academic Press, NY. pp. 285-310.

At 1as, R.M. 1981. Microbial degradation of petroleum hydrocarbons: an environmenta1 perspective. Microb. Rev. 45:180-209.

Augenfe1d, J.M., J.W. Anderson, S.L. Kiesser, G.W. Fe 1 lingham, R.G. Riley, and B.L. Thomas. 1983. Exposure of Abarenicola pacifica to oiled sediment: effects on $g$ lycogen content and alterations in sediment-bound hydrocarbons. In: Proceedings 1983 oil Spil1 Conference (Prevention, Behavior, Contro1, Cleanup. American Petroleum Institute. Washington, D.c. pp. 443-450.

Augenfeld, J.M., J.W. Anderson, R.G. Riley, and B.L. Thomas. 1982. The fate of polyaromatic hydrocarbons in and intertidal sediment exposure system: bioavailability to Macoma inquinata (Mollusca:Pelecypoda) and Abarenicola pacifica (Annelida:Polychaeta). Mar. Environ. Res. 7:31-50.

Augenfe Id, J.M., J.W. Anderson, D.L. Woodruff, and J.I. Webster. 1980-81. Effects of Prudhoe Bay crude oil-contaninated sediments on Protothaca staminea (Mollusca:Pelecypoda): hydrocarbon content, condition index, free amino acid leve 1. Mar. Environ. Res. 4:135-143.

Augenfe1d, J.M. 1980. Effects of Prudhoe Bay crude oil contamination on sediment working rates of Abarenicola pacifica. Mar. Environ. Res. 3:307313.

Baird, W.M., C.J. Chern, and L. Diamond. 1977. Formation of benzo(a)pyrene-glucuronic acid conjugates in hamster embryo ce 11 cultures. Can. Res. 37:3190-3197.

Balk, L., J. Meijer, J. Seidegard, R. Morgenstein, and J.W. Depierre. 1980. Initial characterization of drug-metabolizing systems in the liver of the northern pike, Esox 1ucius. Drug. Met. \& Disp. 8:98-103.

Bayne, B.I., P.A. Gabbott, and J. Widdows. 1975. Some effects of stress 
in the adult on the eggs and larvae of Mytilus edulis. L. J. Mar. Bio1. Ass. U.K. 55:675-689.

Bayne, B.L.s J. Anderson, D. Enge 1, E. Gilfillan, D. Hoss, R. Lloyd, and F.P. Thurberg. 1980. Physiological techniques for measuring the biological effects of pollution in the sea. (Physiology panel report) Rapp. P-v. Reun Cons. Inter. Exp. Mer. 179:88-9.

Beis, I. and E.A. Newsholme. 1975. The contents of adenine nucleotides, phosphagens and some glycolytic intermediates in resting muscles for vertebrates and invertebrates. Biochem. J. 152:23-32.

Binder, R.L. and J.J. Stegeman. 1980. Induction of ary 1 hydrocarbon hydroxylase activity in embryos of an estuarine fish. Biochem. Pharm. $29: 949-951$.

Blackstock, J. 1980. Estimation of activities of some enzymes associated with energy-yielding metabolism in the polychaete, Glycera alba (Muller), and applications of the methods to the study of the effect of organic pollution. J. Exp. Mar. Bio1. Eco1. 46:197-217.

B1igh, E.G. and W.J. Dyer. 1959. A rapid method of total 1ipid extraction and purification. Can. J. Biochem. Physio1. 37:911-917.

Blummer, M. and J. Sass. 1972. The West Falmouth oil spil1. Data available in November, 1971. II. Chemistry. Technical Report. Woods Hole Oceanographic Inst. Ref. No. 72-19.

Boehm, P.D. and J.G. Quinn. 1973. Solubalization of hydrocarbons by dissolved organic matter in seawater. Geochim. Cosmochim. Acta. 37:24592477 .

Boehm, P.D. and J.G. Quinn. 1976. The effect of dissolved organic matter in seawater in the uptake of mixed individual hydrocarbons and number 2

fue 1 oil by a marine filter-feeding bivalve. Mercenaria mercenaria. Est. Cosst. Mar. Sci. 4:93-105.

Brown, D.A., R.W. Gossett, and K.D. Jenkins. 1982. Contaminants in white crokers genyonemus 1ineatus (Ayres, 1855) from the Southern California Bight: II. chlorinated hydrocarbon detoxification/toxification. In: Physiological Mechanisms of Marine Pollutant Toxicity. W.B. Vernberg. A. Calabrese. F.P. Thurberg, and F.J. Verngerg eds. Academic Press. N.Y. pp. 197-213.

Burns, K.A. and J.M. Tea1. 1979. The West Falmouth oil spil1: hydrocarbons in the salt marsh ecosystem. Est. Coast. Mar. Scj. 8:439360 .

Capuzzo, J.M. 1985. Biological effects of petroleum hydrocarbons. Assesments from experimental results. NAS. In Press.

Capuzzo, J.M. and B.A. Lancaster. 1981. Physiological effects of South 
Louisiana crude oil on larvae of the American lobster (Homarus americanus). In: Biological Monitoring of Marine Pollutants. Vernberg et a1 eds. Academic Press. pp. 405-423.

Capuzzo, J.M., B.A. Lancaster, G. Sasaki. 1984. The effect of petroleum hydrcarbons on 1 ipid metabolism and energetics of larva 1 development and metamorphosis in the American lobster (Homarus americanus Milne Edwards). Mar. Environ. Res.14:201-228.

Carr, R.s. and J.M. Neff. 1981. Biochemical indices of stress in the sandworm Neanthes virens (Sars). I. Responses to pentachloropheno1. Aquat. Toxico 1. 1:313-327.

Carr, R.S. and J.M. Neff. 1984. Field assessment of biochemical stress indices for the sandworm Neanthes virens (Sars). Mar. Environ. Res. $14: 267-279$.

Carr, R.S. and D.J. Reish. 1977. The effects of petroleum hydrocarbons on the survival and life history of polychaetous annelids. In: Fate and Effects of Petroleum Hydrocarbons in Marine Ecosystems and Organisms. D.A. Wolf ed. Pergamon Press. N.Y. Pp. 168-173.

Clement, L.E., and M.S. Steko 1, and D.G. Shaw. 1980. Accumulation, fractionation and release of oil by the intertidal clam Mercenaria ba1thica Mar. Bio1. 37:41-50.

Conne 11, E.W., and G.J. Miller. 1980. Petroleum hydrocarbons in aquatic ecosystems-behavior and effect of sublethal contamination: Part 1. Crit. Rev. Environ. Contro1 11:37-104.

Conne 1, E.W. and G.J. Miller. 1981. Petroleum hydrocarbons in aquatic ecosystems-behavior and effect of sublethal contamination: Part 2. Crit. Rev. Environ. Control 11:106-162.

Corner, E.D.S., R.P. Harris, C.C. Kilvington, and S.C.M. O'Hara. 1976. Petroleum compounds in the marine food web: short-term experiments on the fate of naphthalene in Ga1anus. J. Mar. Biol. Ass. U.K. 56:121-133.

Corner, E.D.S., C.C. Kilvington, and S.C.M. O'Hara. 1973. Qual itative sutdies on the metabolism of naphthalene in Maia squinado (Herbst). J. Mar. Bio 1. As8. U.K. 53:819-832.

Courtney, W.A.M., and W.J. Langston. 1978. Uptake of polychlorinated bipheny1 (Arochlor 1254) from sediment and from seawater in two intertidal polychaetes. Environ. Poll. 15:303-309.

Crider, J.Y., J. Wi $1 \mathrm{hm}$, and H.J. Harmon. 1982. Effects of naphthalene on the hemoglobin concentration and oxygen uptake of Daphnia magma. Bu11. Environ. Contam. Toxico1. 28:52-57.

Davis, W.R. 1979. The burrowing, feeding and respiratory activities of Nephtys incisa Ma lmgren, 1965 (polychaeta:Annelida). Ph.D. Thesis. Marine 
Sciences. University of South Carolina.

DeWilde, P.A.W. Jr. 1973. A continuous flow apparatus for long-term recording of oxygen uptake in burrowing invertebrates, with some remarks on the uptake in Macoma balthica. Neth. J. Sea Res. 6:157-162.

Dickson, G.W., and J.P. Giesy. 1982. The effects of starvation on muscle phophoadenylate concentration and adenylate energy charge of surface and cave crayfish. Comp. Biochem. Physio1. 71A:357-361.

Dixit, D. and J.W. Anderson. 1977. Distribution of naphthalenes within exposed Fundulus similis and correlations with stress behavior. In: Proceedings of 1977 0i1 spil1 Conference (Prevention, Behavior, Contro1, Cleanup). American Petroleum Institute, Washington, D.c. pp. 633-636.

Dobroski, C.J. Jr. and C.E. Epifanio. 1980. Accumulation of benzo(a)pyrene in a larval bivalve via trophic transfer. Can J. Fish. Aquat. Sci. 12:2318-2322.

Eckman, J.E. 1979. Sma11-scale patterns and processes in a softsubstratum, intertida1 community. J. Mar. Res. 37:437-457.

Edward8, R.R.C. 1978. Effects of water-soluble oil fractions on metabolism, growth, and carbon budget of the shrimp Crangon crangon. Mar. Bio 1. $46: 259-265$.

Elder, D.L., S.W. Fowler, and G.G. Polikarpov. 1979. Remobilization of sediment-associated. PCB's by the worm Nereis diversicolor. Bu11. Environ. Contam. Toxico1. 21:448-452.

El1ington, W.R. 1981. Effect of anoxia on the adenylates and the energy charge in the sea anemone, Bunodosoma cavernata (Bosc). Physio1. Zoo1. $54: 415-422$.

Elmgren, R., G.A. Vargo, J.F. Grassle, J.P. Grassle, D.R. Heinle, G. Langlois, and S.I. Vargo. 1980. Trophic interactions in experimental marine ecosystems perturbed by oil. In: Microcosms in Ecological

Research. J.P. Giesy, ed. U.S. Dept. Energy. Washington, D.C.

Falkowski, P.G. 1977. The adenylate energy charge in marine phytoplankton: the effect of temperture on the physiological state of Skeletonema costatum (Cure.) Cleve. J. Exp. Mar. Bio 1. Eco1. 27:37-45.

Farrington, J.W. 1980. An overview of the biogeochemistry of fossil fue 1 hydrocarbons in the marine environment. In: Advances in Chemistry: \#185 Petroleum in the Marine Environment. L. Petrakis and F.T. Weiss eds. Am. Chem. Soc. pp. 1-22.

Farrington, J.W., N.M. Frew, P.M. Gschwend, and B.W. Tripp. 1977. Hydrocarbons in cores of northwestern At lantic coastal and continental margin sediments. Est. Coast. Mar. Sci. 5:793-808. 
Farrington, J.W. and B.W. Tripp. 1977. Hydrocarbons in western North At lantic surface sediments. Geochim. Cosmochim. Acta 41:1627-1641.

Farrington, J.W., B.W. Tripp, J.M. Tea1, G. Mil1e, K. T jessum, A.C. Davis, J. Livramento, N. Hayward, and N.M. Frew. 1982. Biogeochemistry of aromatic hydrocarbons in the benthos of microcosms. Toxico1. Environ. Chem. 5:331-346.

Farrington, J.W., S.G. Wakeham, J.B. Livramento, B.W. Tripp, and J.M. Tea 1. (Submitted) Aromatic hydrocarbons in New York Bight Polychaetes: UV-flourescence analysis and GC/GCMS analysis. Envrion. Sci. Tech.

Fingerman, S.W. and E.C. Short Jr. 1983. Changes in neurotransmitter levels in channel catfish after exposure to benzo(a)pyrene, naphthalene, and arochlor 1254. Bu11. Environ. Contam. Toxico1. 30:147-151.

Fisher, J.B., W.J. Lick, P.L. McCa11, and J.A. Robbins, 1980. Vertica 1 mixing of lake sediment by tubificid oligochaetes. J. Geophys. Res. $85: 3997-4006$.

Fletcher, G.L., M.J. King, J.W. Kicenink, and R.F. Addison. 1982. Liver hypertrophy in winter flounder following exposure to experimentally oiled sediments. Comp. Biochem. Physio1. 73C:457-462.

Fowler, S.W., G.G. Polikarpov, D.L. Elder, P Parsi, and J-P. Villeneuve. 1978. Polychlorinated bipheny $1 \mathrm{~s}$ : accumulation from contaminated sediment and water by the polychaete Nereis diversicolor. Mar. Bio 1. 448:303-309.

Fries, C.R. and R.F. Lee, 1984. Pollutant effects on the mixed function oxygenase (MFO) and reproductive systems of the marine polychaete Nereis virens. Mar. Bio 1. 79:187-193.

Gardner, W.S., R.F. Lee, K.R. Tenore, L.W. Smith. 1979. Degradation of selected polycyclic aromatic hydrocarbons in coastal sediments: importance of microbes and polychaete worms. Wat. Air Soi1 Po11. 11:339347.

Gearing, J.N., P.J. Gearing, T. Wade, J.G. Quinn, M.B. McCarthy, J.W. Farrington, and R.F. Lee. In: Proceedings 1979 0i1 Spil1 Conference. (Prevention, Behavior, Contro1, Cleanup). American Petroleum Institute. Washington, DC.

Gearing, P.J., J.N. Gearing, R.J. Prue 11, T.L. Wade, and J.G. Quinn. 1980. Partitioning of no. 2 fue 1 oil in controlled estuarine ecosystems, sediments and suspended particulate matter. Environ. Sci. Tech. 14:11291136.

George, J.D. 1971. The effects of pollution by oil and oil-dispersants on the common intertidal polychaetes, Dirriformia tentaculata and Cirratulus cirxatus. J. App 1. Eco1. 8:411-420. 
Gibson, D.T. 1976. Microbial degradation of carcinogenic hydrocarbons and related compounds. In: Sources Effects and sinks of Hydrocarbons in the Aquatic Environment. American Institute of Biological Sciences, Washington, DC. pp. 224-238.

Giger, W. and M. Bluumer, 1974. Polycyclic aromatic hydrocarbons in the environment: isolation and characterization by chromatography, visible, ultraviolet, and mass spectrometry. Ana 1. Chem. 36:1663-1671.

Gilfillan, E.S. and J.H. Vandermeulen. 1978. Alteration in growth and physiology of soft-she $11 \mathrm{clams,} \mathrm{Mya} \mathrm{arenaria} \mathrm{chronically} \mathrm{oiled} \mathrm{with}$ Bunker C from Chedabucto Bay, Nova Scotia, 1970-76. J. Fish. Res. Bd. can. 35:630-636.

Goerke, H. 1979. Nereis virens (Polychaeta) in marine pollution research: culture methods and oral administration of a polychlorinated biphenyl. Veroff. Inst. Meeresforsch. Brenerh. 17:151-161.

Goerke, H. 1984. Temperature-dependent elimination of $2,4,6,2^{\circ}, 4^{\prime}-$ pentachloro[U14C] biphenyl in Nereis virens (Polychaeta). Arch. Environ. Contam. Toxico1. 13:347-355.

Goerke, H. and W. Ernst. 1980. Accumulation and elimination of 14C- $-\mathrm{HCH}$ (1indane) in Nereis virens (Polychaeta) with consideration of metabolites. Helgolander. Meers. 33:313-326.

Gorden, D.C., J. Dale, Jr., and P.D. Keizer. 1978. Importance of sediment working by the deposit-feeding polychaete Arenicola marina on the weathering rate of sediment-bound oil.

Grassholff, K. 1976. Methods for Sea Water Analysis. Verlag Chimie Weinheim, NY. p. 11.

Grimmer, G. and H. Bohnke. 1975. Profile analysis of polycyclic aromatic hydrocarbons and metal content in sediment layers of a lake. Can. Let. $1: 75-84$.

Hauschildt-Li11ge, Do 1982. Long-term effects of petroleum hydrocarbons on the life cycle and productivity of the littoral oligochaete Lumbrinereis 1ineatus. Neth. J. Sea Res. 16:502-510.

Haya, K, D.W. Mcleese, B.A. Wiawood, and L.E. Burridge. 1984. Organochlorine pesticides and the metabolic energy state of Nereis virens. Mar. Envrion. Res. 14:481-482.

Haya, K. B.A. Waiwood, and D.W. Johnston. 1983. Adenylate energy charge and ATPase activity of lobster (Homarus americanus) during subletha 1 exposure to zinc. Aquat. Toxico 1. 3:114-126.

Herbes, S.E. and 1.R. Schwa11. 1978. Microbia1 transformation of polycyclic aromatic hydrocarbons in pristine and petroleum-contaminated sediments. App 1. Environ. Micro. 35:306-316. 
Herbes, S.E. and G.F. Risi. 1978. Metabolic alteration and excretion of anthracene by Daphnia pulex. Bul1. Environ. Contam. Toxico1. 19:147-155.

Hinga, K.R., R.F. Lee, J.W. Farrington, M.E.Q. Pilson, K. Tjessum, and A.C. Davis. 1980. Biogeochemistry of benzanthracene in an enclosed marine ecosystem. Environ. Sci. Tech. 14:1136-1143.

Hites, R.A. R.E. Laflamme, and J.W. Farrington, 1977. Polycyclic aromatic hydrocarbons in recent sediments: the historical record. Science 198:829831.

Hites, R.A., R.E. Lafl amme, and J.G. Eindsor Jr. 1980. Polycyclic aromatic hydrocarbons in an anoxic sediment core from the Pettaquamscutt River (Rhode Is 1and, U.S.A.). Geochim. Cosmochim. Acta 44:873-878.

Hoffman, E.J., G.L. Mil1s, J.S. Latimer, and J.G. Quinn. 1984. Urban runoff as a source of polycyclic aromatic hydrocarbons to coastal waters. Environ. Sci. Tech. 18:580-587.

Hooftman, R.N. and G.J. Vink. 1981. Cytogenetic effects on the eastern mud-minnow, Umbra pygmaea, exposed to ethy 1 methane-sulphonate, benzola]pyrene and river water. Ecotoxicol. Environ. Safety 5:261-269.

Hose, J.E., J.B. Hannah, D. DiJulio, M.I. Landolt, B.S. Miller, W.T. Inaoka, and S.P. Felton. 1982. Effects of benzo(a)pyrene on early devolopment of flatfish. Arch. Environ. Contram. Toxicol. 11:167-171.

Hu1t, J.E. 1969. Nitrogenous waste products and excretory enzymes in the marine polychaete Cirriformia spirabranchia (Moore, 1904). Comp. Biochem. Physio 1. 31:15-24.

Ivanovici, A.M. 1980. Application of adenylate energy charge to problems of environmental impact assessment in aquatic organisms. Helgolander. Meeres. 33:556-565.

Jakoby, W.B. and W.H. Habig. 1980. Glutathione transfereases. In:

Enzymatic Basis of Detoxification Vol II. W.B. Jakoby ed. Academic Press. NY. Pp. 63-94.

James, M.0., E.R. Bown, P.M. Dansette, and J.R. Bend. 1979a. Fpoxide hydrase and glutathion S-transferase activity with selected alkene and arene oxides in several marine species. Chem.-Biol. Interact. 25:321-344.

James, M.O., M.A.Q.Khan, and J.R. Bend. 1979b. Hepatic microsomal mixed function oxidase activities in several marine species common to coastal Florida. Comp. Biochem. Physio1. 62C:155-164.

Jerina, D.M. and J.W. Daly 1974. Arene oxides: a new aspect of drug metabolism. Science 185: 573-582.

Jewston, D.H. and M Doku1i1. 1982. Adenylate energy charge measurements 
in freshwater microbioal studies. J. Eco1. 70:595-606.

Jobling, M. and P.S. Davis. 1980. Effects of feeding on metabolic rate, and the specific dynamic action in plaice. Pleuronectes platessa $\mathrm{L}$. J. Fish. Biol. 16:629-638.

Jones, C.A., B.P. Moon, G.M. Cohen, J.R. Frey, and J.W. Bridges. 1978. Studies on the metabolism and excretion of benzo(a)pyrene in isolated rate hepatocytes. Biochem. Pharm. 27:693-702.

Karickhoff, S.W., D.S. Brown, and T.A. Scott. 1979. Sorption of hydrophobic pollutants on natural sediments. Wat. Res. 13:241-248.

Karickhoff, S.W. and R.R. Morris. 1985. Impact of tubificid oligochaetes on pollutant transport in bottom sediments. Environ. Sci. Tech. 19:51-56.

Kar1, D.M. and 0. Ho $1 \mathrm{~m}$-Hansen. 1978. Methodology and measurement of adenylate energy charge ratios in environmental samples. Mar. Biol. $48: 185-197$.

Kay, D.G. and A.E. Brafield. 1973. The energy relations of the polychaete Neanthes (=Nereis) virens (Sars). J. An. Eco1. 42:673-692.

LaFlamme, R.E. and R.A. Hites. 1978. The global distribution of polycyclic aromatic hydrocarbons in recent sediment. Geochem. Cosmochim. Act a $42: 289-303$.

Laughlin, R.B. Jr. and J.M. Neff. 1980. Influence of temperature, salinity, and phenanthrene (a petroleum derived polycyclic aromatic hydrocarbons) on the respiration of larval mud crabs. Rhithropanopeus harrisii. Est. Coast. Mar. Sci. 10:655-669.

Leavitt, D.F. 1985. An evaluation of techniques to measure digestibility in the American lobster. Aquaculture (In press).

Lech, J.J. and J.R. Bend. 1980. Relationship between biotransformation and the toxicity and fate of xenobiotic chemicals in fish. Environ. Hea 1th Perspec. 34:115-131.

Lee, R.F. 1975. Fate of petroleum hydrocarbons in marine zooplankton. In: Proceddings 1975 0i1 Spil1 Conference (Prevention, Behavior, Contro1. Cleanup). American Pertroleum Institute. Washington, DC. pp. 549-553.

Lee, R.F. 1981. Mixed function oxygenses (MFO) in marine invertebrates. Mar. Biol. Lett. 2:87-105.

Lee, R.F., W.S. Gardner, J.W. Anderson, J.W. B laylock, and J. Barwe 11Clarke. 1978. Fate of polycyclic aromatic hydrocarbons in controled ecosystem enclosures. Environ. Sci. Tech. 12:832-838.

Lee, R.F. and C. Ryan. 1983. Microbial and photochemical degradation of polycyclic aromatic hydrocarbons in estuarine waters and sediments. Can. 
J. Fish. Aquat. Sci. 40:86-94

Lee, R.F., C. Ryan, and M.L. Neuhauser. 1976. Fate of petroleum hydrocarbons taken up from food and water by the blue crab Callinectes sadpidus. Mar. Bio1. 37:363-370.

Lee, R.F., R. Sauerheber, and A.A. Benson. 1972a. Petroleum hydrocarbons: uptake and discharge by the marine musse 1 Mytilus edulis. Science $177: 344-346$.

Lee, R.E., H. Sauerheber, and G.H, Dobbs. 1972b. Uptake, metabolism and discharge of polycylic aromatic hydrocarbons by marine fish. Mar. Biol. $17: 201-208$.

Lee, R.F., S.C. Singer, K.R. Tenore, W.S. Gardner, and R.M. Philpot. 1979. Detoxification system in polychaete worms: importance in the degradation of sediment hydrocarbons. In: Marine Pollution: Functional Responses. W.B.Vernberg, F.P. Thurberg, A. Calabrese, and F.J. Vernberg eds.

Lee, R.F. and S.C. Singer. 1980. Detoxifying enzyme system in marine polychaetes: increases in activity after exposure to aromatic hydrocarbons. Rapp. P-v. Reun. Cons. Int. Exp Lor. Mer 179:29-32.

Lee, R.F., S.C. Singer, and D.S. Page. $1981 \mathrm{a}$. Responses of cytochrome P450 systems in marine crab and polychaetes to organic pollutants. Aquat. Toxico 1. 1:355-365.

Lee, R.F., J. Stolzenbach, S.Singer, and K.R. Tenore. $1981 \mathrm{~b}$. Effects of crude oil on growth and mixed function oxygenase activity in polychaetes, Nereis sp. In: Biological Monitoring of Marine Pollution. F.s. Vernberg, A. Calabrese, R.P. Thurberg, and W.B. Vernberg eds. pp. 323-334.

Lee, R.F. and M. Takahashi. 1977. The fate and effects of petroleum in control led ecosystem enclosures. Rapp. P-v. Reun. Cons. Int. Explor. Mer $171: 150-156$.

Lehninger, A.L. 1975. Biochemistry. Second edit. Worth Pub. NY. p. 96.

Leversee, G.J., J.P. Giesy Jr., P.F. Landrum, S. Barte11, S. Gerou 1d, M. Bruno, A. Spacie, J. Bow Iing, J. Haddock, and T. Fannin. 1981. Disposition of benzo(a)pyrene in aquatic systems components: periphyton, chironomids, daphnia, fish. In: Chemical Analysis and Biological Fate: Polynuclear Aromatic Hydrocarbons. M. Cooke and A.J. Dennis eds. Batte1le Press. Columbus, Ohio. pp 357-366.

Leversee, G.J., J.P. Giesy, P.F. Landrum, S. Gerould, J.W. Bow 1 ing, T.E. Fanwin, J.D. Haddock, and S.M. Barte11. 1982. Kinetics and biotransformation of benzo(a)pyrene in Chironomus riparius. Arch. Environ. Contam. Toxico1. 11:25-31.

Lied, E. and B. Braaten. 1984. The effects of feeding and starving, and 
difference ratios of protein energy to total energy in the feed on the excretion of ammonia in At lantic cod (Gadus morhua). Comp. Biochem. Physio 1 . 78A:49-52.

Lowry, 0.H., N.J. Rosebrough, A. I. Farr, and R.J. Randa11. 1951. Protein measurement with the folin phenol reagent. J. Biol. Chem. 193:265-275.

Lu, Po-Yung, R.L. Metcalf, N. P lummer, and D. Mande 1. 1977. The environmental fate of three carcinogens: benzo(a)pyrene, benzidine, and vivyl chloride evaluated in laboratory model ecosystems. Arch. Environ. Contam. Toxico1. 6:129-142.

Lyes, M.C. 1979. Bioavailability of a hydrocarbon from water and sediment to the marine worm Arenicola marina. Mar. Bio1. 55:121-127.

MacFarlane, R.B. 1981. Alterations in adenine nucleotide meatbolism in the Gulf killifish (Fundulus grandis) induced by low pH water. Comp. Biochem. Physiol. 68B:193-202.

Malins, D.C. M.M. Krah, D.W. Brown, L.D. Rhodes, M.s. Myers, B.B. McCain, S.-L. Chan. 1985. Toxic chemicals in marine sediments and biota from Mukilteo, Washington: relationship with hepatic neoplasms and other hepatic lessions in English sole (Parophrys vetulus). J. Nat. Can. Inst. (In press).

Malins, D.C. and H.O. Hodgins. 1981. Petroleum and marine fishes: a review of uptake, disposition, and effects. Environ. Sci. Tech. 15:12721280.

Malins, D.C., B.B. McCain, D.W. Brown, S-L. Chan, M.A. Myers. J.T. Landah 1, P.C. Prohaska, A.J. Friedman, L.D. Rhodes, D.G. Burrows, W.D. Gronhard, and H.0. Hodgins. 1984. Chemical pollutants in sediments and diseases in bottom-dwe11ing fish. Environ. Sci. Tech. 18:705-713.

Malins, D.C. and W.T. Rouba1. 1982. Ary 1 sulfate formation in sea urchins (Stronglocentrotus drobachiensis) ingesting marine algae (Fucus distichilus) containing 2,6-dimethy 1 naphthalene. Environ. Res. 27:290297.

Mangum, C.P. 1964. Activity patterns in metabolism and ecology of polychaetes. Comp. Biochem. Physio1. 11:239-256.

Matsushima 0 . and Kado. Y. 1983. Effect of adenine nucleotides on glutamate dehydrogenase activities of the brackish and freshwater clams, Corbicula japonica and C. leana. Annot. Zoo1. Japon. 56:3-9.

Mazzaud, P. 1973. Respiration and nitrogen excretion of zoop lankton. II. Studies on the metabolic characteristics of staved anima1s. Mar. Biol. $21: 19-28$.

McE 1 roy, A.E., B.W. Tripp, J.M. Tea1, and J.W. Farrington. 1982. The biogeochemical fate of benzanthracene and its oxygenated metabolites in 
recirculating benthic microcosms. E0S 63:957-958.

Mclusky, D.S., M Teare, and P Phizacklea. 1980. Effects of domestic and industrial pollution on distribution and abundance of aquatic oligochaetes in the Forth estuary. Helgolander. Meeresunters. 33:384-392.

Means, J.C., J.J. Hassett, S.G. Wood, and W.L. Bannert. 1979. Sorption properties of energy-related pollutants and sediments. In: Polynuclear Aromatic Hydrocarbons. P.W. Jones, and P. Leber, eds. Ann Arbor Sci. Pub. Inc. Ann Arbor, MI pp. 327-340.

Means, J.C. and R. Wijayaratne. 1982. Role of natural colloids in the transport of hydrophobic pollutants. Science. 215:968-970.

Mendelssohn, I.A. and K.L. McKee. 1981. Determination of adenine nucleotide levels and adenylate energy charge ratio in two Spartina species. Aquat. Bot. 11:37-55.

Mohammad, M-B.M. 1974. Effect of chronic oil pollution on a polychaete. Mar. Po11. Bu11. 5:21-24.

Moore, M.N., D.M. Lowe, and P.E.M. Fieth. 1978. Lysosoma 1 responses to experimentally injected anthracene in the digestive cells of Mytilus edulis. Mar. Biol. $48: 297-302$.

National Academy of Sciences. 1971. Marine Environmenta1 Quality. Suggesed Research Programs for Understanding Man's Effects on the Oceans. Washington, DC. 107 pp.

National Academy of Sciences. 1975. Petroleum in the Marine Environment. Washington, DC.

Nee 1y, W.B., D.R. Bronson, and G.E. B lau, 1974. Partition coefficient to measure bioconcentration potential of organic chemicals in fish. Environ. Sci. Tech. 8:1113-1115.

Neff, J.M. 1979. Polycyclic Aromatic Hydrocarbons in the Aquatic Environment. Source, Fates, and Biological Effects. App 1. Sci. Pub. London. 262 pp.

Neff, J.M., B.A. Cox, D. Dixit, and J.W. Anderson. 1976. Accumu 1 ation and release of petroleum-derived aromatic hydrocarbons by four species of marine anima 1s. Mar. Bio1. 38:279-289.

O'Malley, and R.C. Terwilliger. 1975. Aspects of nitrogen metabolism in the terebe11id polychaete Pista pacifica. Comp Biochem. Physio1. 52A:367369.

Palmork, K.H. and J.E. Solbakken, 1980. Accumulation and elimination of radioactivity in the Norway lobster (Nephrops norvegicus) following intragastric administration of [9-14C]phenanthrene. Bu11. Environ. Contam. Toxico 1. 25:668-671. 
Pamatmat, M.M. 1982. Metabolism of a burrowing polychaete: precaution needed when measuring toxic effects. Mar. Po11. Bu11. 13:364-367.

Perry, J.J. 1979. Microbial cooxidations involving hydrocarbons. Microbiol. Rev. 43:59-72.

Pesch, G.E. and D. Morgan. 1978. Influence of sediment in copper toxicity tests with the polychaete Neanthes arenaceodentata. Wat. Res. 12:747-751.

Pesch, G.G. and C.E. Pesch. 1981. Neanthes arenaceodentata (Polychaeta: Annelida) a proposed cytogenetic model for marine genetic toxicology. Can. J. Fish. Aquat. Sci. 37:1225-1228,, worms, toxico1., genetic, effects

Prah1, F.G., E. Creclius, and R. Carpenter. 1984. Polycyclic aromatic hydrocarbons in Washington coastal sediments: and evaluation of atmospheric and riverine routes of introduction.

Prosser, C.L. Comparative Animal Physiologcy. W.B. Saunders Co. Philadephia.p. 23.

Readman, J.W., R.F.C. Mantouro, M.M. Rhead, and L. Brown. 1982. Aquatic distribution and heterotrophic degradation of polycyclic aromatic hydrocarbons (PAH) in the Tamar estuary. Est. Coast. She if Sci. 14:369389.

Reichert, W.I. and U. Varanasi. 1982. Metabolism of orally administered naphthalene on spawning English sole (Paxophrys vetulus). Environ. Res. $27: 316-324$.

Riley, R.G., B.L. Thomas, J.W. Anderson, adn R.M. Bean. 1980-81. Changes in the volatile hydrocarbons content of Prudhoe Bay crude oil treated under different simulated weathering conditions. Mar. Environ. Res. 4:109-119.

Riley, R.T., M.C. Mix, R.I. Schaffer, and D.I. Bunting. 1981. Uptake and accumulation of napthalene by the oyster Ostrea edulis in a flow-through system. Mar. Bio1. 61:267-276.

Roesijadi, G., J.W. Anderson, and J.W. B laylock. 1978. Uptake of hydrocarbons from marine sediments contaminated with Prudhoe Bay Crude 0i1: Inlfuence of feeding type of test species and availability of polycyclic aromatic hydrocarbons. J. Fish. Res. Bd. Can. 35:608-614.

Rossi, S.S. 1977. Bioavailability of petroleum hydrocarbons from water, sediment, adn detritus, to the marine annelid Neanthes areanceodentata. In: Preceedings of 1977 0i1 Spi11 Conference (Prevention, Behavior, Control, Cleanup). American Petroleum Institute. Wahington, DC. Pp. 621625 .

Rossi, S.S., J.W. Anderson, and G.S. Ward. 1976. Toxicity of watersoluble fractions from test oils for the polychaetous annelid Neanthes 
areanceodentata and Capite11a capitata. Environ. Pollut. 10:9-18.

Rossi, S.S. and J.W. Anderson. 1977. Accumulation and release of fue 1oil-derived diaromatic hydrocarbons by the polychaete Neanthes areanaceodentata. Mar. Bio 1. 39:51-55.

Rossi, S.S. and J.W. Anderson. 1978. Petroleum hydrocarbon resistance in the marine worm Neanthes arenaceodentata (Polychaeta: Annedlida) induced by chronic exposure to No 2 fuel oil. Bul1. Environ. Contam. Toxicol. $20: 513-521$.

Roubal, W.T., T.K. Collier, and D.C. Malins. 1977. Accumulation and metabo 1 ism of carbon-14 labelled benzene, naphthalene, and anthracene by yound coho salmon (Oncorhynchus kisutch). Archiv. Environ. Contam. Toxico 1. 5:513-519.

Royal Society. 1980. Polycyclic Aromatic Hydrocarbons in the aquatic envrionment. App 1ied Sciences Publ. London.

Rubinstein, N.I., W.T. Gill iam, and N.R. Gregory. 1984. Dietary accumulation of PCBs from a contaminated sediment source by a demersal fish (Leiostomus xanthurus). Aquat. Toxico 1. 5:331-342.

Sabo, D.J. and J.J. Stegeman. 1977. Some metabolic effects of petroleum hydrocarbons in marine fish. In: Physiological Responses of Marine Biota to Pollutants. F.J. Vernberg, A. Calabrese, F.P. Thurberg, and W.B. Vernberg eds. Academic Press, N.Y. pp. 279-288.

Sabourin, T.D. 1982. Respiratory and circulatory response of the blue crab to naphthalene and the effect of acclimation salinity. Aquat. Toxico 1. 2:301-318.

Saltzman, H.A. 1982. Biodegradation of aromatic hydrocarbons in marine sediments of the North Sea oil field. Mar. Biol. 72:17-26.

Sanborn, H.R. and D.C. Malins. 1977. Toxicity and metabolism of naphthalene: a study with marine larval invertebrates. Proc. Soc. Exp. Bio 1. Med. 154:151-155.

Schottler, U. 1978. The influence of anaerobiosis on the levels of adenine nucleotides and some glycolytic intermediates in Tublifex sp. (Annelida, 01igochaetea). Comp. Biochen. Physiol. 61B:29-32.

Scott, D.M. 1876. Circadian rhythm of anaerobiosis in a polychaete annelid. Nature 262:811-813.

Shaw, D.G. and J.N. Wiggs, 1980. Hydrocarbons in the intertidal environment of Kachemak Bay, Alaska. Mar. Po11. Bu11. 11:297-300.

Sims, P. and P.L. Grover. 1974. Epoxides in polycyclic aromatic hydrocarbons metabolism and carcinogenesis. Adv. Can. Res, 20:165-274.

Sims, P., G.P. Grover, A. Swais 1 and, T. Pa1, and A. Hewer. 1974. 
Metabolic activation of benzo(a)pyrene proceeds by a diol-epoxide. Nature $252: 326-327$.

Singer, S.C. and R.F. Lee. 1977. Mixed function oxygenase activity in blue crab Callinectes sapidus: tissue distribution and correlation with changes during molting and development. Biol. Bu11.153:377-386.

Skjolda1, H.R. and T. Bakke. 1978. Relationship between ATP and energy charge during lethal metabolic stress of the marine isopod Cirolana borealis. J. Bio1. Chem. 253:3355-3356.

Smith, R.L. and B.R. Hargreaves, 1984. Oxygen consumption in Neomysis americana (Crustacea:Mysidacea), and the effect of naphthalene exposure. Mar. Bio 1. 79:109-116.

Solorzano, L. 1969. Determiantion of ammonia in natural water by the phenolhypoch1orite methods. Limno1. Oceanog. 14:799-801.

Solbakken, 1980. Urinary and biliary metabolites of phenanthrene in the coa 1 fish (Po1lachium virens). Acta. Pharm. et Toxico1. 46:127-132.

Solbakken, J.E. and K.H. Palmork. 1980. Distribution of radioactivity in the Chondrichthys Squalus acanthia and the 0steichthys Salmo gaidneri following intragastic administration of (9-14C)phenanthrene. Bu11. Envion. Contam. Toxico 1. 25:902-908.

Solbakken, J.E. and K.H. Palmork. 1981. Metabolism of phenanthrene in various marine animals. Comp. Biochem. Physiol. 70C:21-26.

Statham, D.N., C.R. E 1 comb, S.P. Szyjka, and J.J. Lech. 1978. Effect of polycyclic aromatic hydrocarbons on hepatic microsomal enzymes and disposition of metyl-naphthalene in rainbow trout in vivo. Xenobiotica $8: 65-71$.

Steen, W.C., D.F. Davis, and G.L. Baughman. 1978. Partitioning of selected polychlorinated bipheny 1 s to natural sediments. Mar. Res. $12: 655-657$.

Stegeman, J.J. 1981. Polynuclear aromatic hydrocarbons and their metabolism in the marine environment. In: Polycyclic Hydrocarbons and Cancer. Vo1. 3. H.V. Gelboin, and P.0.P. Ts;0 eds. E1sevier Press. N.Y. pp.1-60.

Stegeman, J.J. and D.J. Sabo. 1977. Aspects of the effects of petroleum hydrocarbons on intermediary metabolism and xenobiotic metabolism in marine fish. In: Sources, Effects, and Sinks of Hydrocarbons. American Institute for Biological Science. pp. 424-436.

Stegeman. J.J. and J.M. Tea1. 1973. Accumulation, release and retention of petroleum hydrocarbons by the oyster Crassostrea virginica. Mar. Biol. $22: 37-44$. 
Surholt, B. 1977. The influence of oxygen deficiency and electrical stimulation on the concentrations of ATP, ADP, AMP and phosphotaurocyamine in the body-wal1 musculature of Arenicola marina. Hoppe-Seyler's Z. Physio 1. Chem. 358:1455-1461.

Taghon, G.L. 1982. Optima1 foraging by deposit-feeding invertebrates: roles of particle size and organic coating. Oceologia 52:295-304. Taghon, G.L. and P.A. Jumars. 1984. Variable ingestion rate and its role in optimal foraging behavior of marine deposit feeders. 65:549-558.

Tea 1, J.M., K. Burns, and J.Farrington. 1978. Analysis of aromatic hydrocarbons in intertidal sediments resulting from two spilis of 2 fue 1 oil in Buzzards Bay, Mass. J. Fish. Res. Bd. Can. 35:510-520.

Tripp, B.W., J.W. Farrington, and J.M. Tea 1. 1981. Unburned coa1 as a source of hydrocarbons in surface sediments. Mar. Po11. Bu11. 12:122-126.

Van Cantfort, J. J. DeGraeveand J.E. Gielen. 1977. Radioactivity assay for ary 1 hydrocarbon hydroxylase; improved method and biologica 1 importance. Biochem. Biophys. Res. Comm. 79:503-512.

Varanasi, U., D.J. Gmur, and P.A. Treseler. 1979. Influence of time and mode of exposure on biotransformation of naphthalene by juvenile starry founder (platichthys stellatus) and rock sole (Lepidopsetta bilineata) Arch. Environ. Contam. Toxico1. 8:673-692.

Varanasi, U. and D.J. Gmur. 1980. Metaboic activation and covalent binding of benzo(a)pyrene to deoxyribonucleic acid catalyzed by 1 iver enzymes of marine fish. Biochem. Pharm. 29:753-761.

Varanasi, U. and D.J. Gmur. 1981. Hydrocarbons and metabolites in English sole (Parophrys vetulus) exposed simultaneous ly to [3H] benzo(a)pyrene and [14C] napthalene in oil-cont aminated sediment. Aquat. Toxico1. 1:4967.

Varanasi, U. and D.C. Malins, 1977. Metabolism of petroleum hydrocarbons: accumulation and biotransformation in marine organisms. In: Effects of Petroleum on Arctic and Subarctic Marine Environments and Organisms Vol. II. Biologica 1 Effects. D.C. Malins ed. Academic Press. N.Y. pp. 176-269.

Varanasi, U., J.E. Stein, and T. Hom. 1981. Covalent binding of benzo(a)pyrene to DNA in fish liver. Biochem. Biophys. Res. Comm. 103780-787.

Varanasi, U., M. Uhler, and S.I. Stranahan. 1978. Uptake and release of naphthalene and its metabolites in skin and epidermal mucus of salmonids. Toxico 1. App 1. Pharm. 44:277-289.

Vargo, S.I. 1981. The effects of chronic low concentrations of No 2 fue 1 oil on the physiology of a temperature estuarine zooplankton community in the Mer 1 Microcosms. In: Biological Monitoring of Marine Pollution. F.J. Vernberg, A. Calabrese, F.P. Thurberg, and W.B. Vernberg eds. Academic 
Press. NY. pp. 295-322.

Vernberg, W.B., B.C. Cou 11, and D.D. Jorgensen. 1977. Reliability of laboratory metabolic measurements of meiofauna. J. Fish. Res. Bd. Can. $34: 164-167$.

Viarengo, A. and M.N. Moore. 1982. Effects of aromatic hydrocarbons on the metabolism of the digestive gland of the mussel Mytilus edulis $L$. Comp. Biochem. Physio1. 71C:21-25.

Vieth, D.G., D.I. Defoe, and B.V. Bergstedt. 1979. Measuring and estimating the bioconcentration factor of chemicals in fish. J. Fish. Res. Bd. Can. 36:1040-1048.

Wakeham, S.G. and J.W. Farrington. 1980. Hydrocarbons in contemporary aquatic sediment. In: Contaminants and Sediments Yol. I. R.A. Baker ed. Ann Arbor Sci. Pub. Inc. Ann Arbor, MI. Pp. 3-32.

Walesby, N.J. and I.A. Johnson. 1980. Temperature acclimation in brook trout muscle: adenine nucleotides concentrations, phosphoadenylate state and adenylate energy charge. J. Comp. Physio 1. 139:127-133.

Walsh, P.J. and G.N. Somero. 1981. Temperature adaptation in sea anemones: physiological and biochemical variability in geographical1y separate popultaions of Metridium senile. Mar. Bio1. 62:25-34.

Winget, C.L. 1978. A recirculating seawater benthic chamber for the study of the biogeochemistry of petroleum components at the sediment-water interface. WHOI Tech. Rep. 78-94.

Wood, A.W., W. Levin, R.L. Chang, R.E. Iehr, M.Schaefer-Ridder, J.M. Karle, D.M. Jerina, and A.H. Conney. 1977. Tumorigenicity of five dihyrodiols of benz(a)anthracene on mouse skin: exceptional activity of benz(a)anthracene 3,4-dihydrodio1. Proc. Nat. Acad. Sci. 74:3176-3179.

Wood, A.W., P.G. Wislocki, R.L. Chang, W. Levin, A.Y.H. Lu, H. Yagi, O. Hernandez, D.M. Jerina, and A.H. Conney. 1976. Mutagenicity and cytotoxicity of benzo(a)pyrene benzo-ring epoxides. Can. Res. 36:33583366 .

Young, D.K. and D.C. Rhodes. 1971. Animal-sediment relations in Cape Cod Bay, Massachusetts. I. A transect study. Mar. Biol. 11:242-254.

Youngblood, W.W. and M. Blumer. 1975. Polycyclic Aromatic Hydrocarbons in the environment: homologous series in soils and recent marine sediments. Geochim. Cosmochim. Acta 39:1303-1314.

Zaroogian, G.E., J.H. Gentile, J.F. He 1 tshe, M. Johnson, and A.M. Ivanovici. 1982. Application of adenine nucleotide measurments for the evaluation of stress in Mytilus edulis and Crassostrea virginica. Comp. Biochem. Physio1. 71B:643-649. 
Zarr, J.H. 1984. Biostatistical Analysis 2nd Edition. Prentice-Ha11 Pub. Co. Englewood C1 iffs, N.J. 718 pp.

Zepp, R.G. and P.F. Schlotzhauer. 1979. Photoreactivity of selected aromatic hydrocarbons in water. In: Polynuclear Aromat ic Hydrocarbons. Ann Arbor Sci. Pub. Ann Arobor MI. pp. 141-158. 